University of San Diego

Digital USD

1989

\title{
Think Globally, Act Locally: A Delphi Study of Educational Leadership through the Development of International Resources in the Local Community
}

Stuart R. Grauer EdD

University of San Diego

Follow this and additional works at: https://digital.sandiego.edu/dissertations

Part of the Leadership Studies Commons

\section{Digital USD Citation}

Grauer, Stuart R. EdD, "Think Globally, Act Locally: A Delphi Study of Educational Leadership through the Development of International Resources in the Local Community" (1989). Dissertations. 523.

https://digital.sandiego.edu/dissertations/523

This Dissertation: Open Access is brought to you for free and open access by the Theses and Dissertations at Digital USD. It has been accepted for inclusion in Dissertations by an authorized administrator of Digital USD. For more information, please contact digital@sandiego.edu. 
THINK GLOBALLY, ACT LOCALLY:

\title{
A DELPHI STUDY OF EDUCATIONAL LEADERSHIP THROUGH THE DEVELOPMENT OF INTERNATIONAL RESOURCES IN THE LOCAL. \\ COMMUNITY
}

by

Stuart R. Grauer

\begin{abstract}
A dissertation submitted in partial fulfillment
of the requirements for the degree of
\end{abstract}

\author{
Doctor of Education \\ University of San Diego
}

1989

Dissertation Committee

Joseph C. Rost, Ph.D., Director

Susan M. Zgliczynski, Ph.D.

Edward Kujawa, Ph.D. 
(C) Stuart Robert Grauer 1988

All Rights Reserved

Reproduced with permission of the copyright owner. Further reproduction prohibited without permission. 
THINK GLOBALLY, ACT LOCALLY: A DELPHI STUDY OF ECUCATIONAL LEADERSHIP THROUGH THE DEVELOPMENT OF INTERNATIONAL RESOURCES IN THE LOCAL COMMUNITY

GRAUER, STUART ROBERT, ED.D. University of San Diego, 1989. 347 pp.

Director: Joseph C. Rost

The probable future of international resource development in the local school community for the years leading up to 2000 was researched using the Delphi method--the best available tool for building consensus in emerging fields. A panel of 28 identified experts in elementary and secondary schools and districts from Southern California in the field of school-community relations with demonstrable experience in international education completed three rounds of surveys. The surveys served to identify (1) educational resource people who could bring constructive change communitywide, (2) program developments and school-community partnerships, (3) practical and philosophical goals for fusing international, national, community and academic educational values, and (4) competing demands and pressures.

Results show specific, readily apparent trends in each area. Trends from all areas fell into one of four models, each reflecting a distinct perspective of international education. The perspectives are Model I, involving curriculum and instruction values, iviodel II, involving local multicultural and political values, Model III, involving national economic security values and, Model IV, involving more universal, globally shared values. Model IV unites the fundamental values of all four models and complements the findings in the literature on leadership. The strongest trend was towards Model IV, although there was no single, unified consensus among the respondents. Model II concerns formed the second 
strongest trend and provided the basic diversion towards the achiever ent of Model IV. The author concludes that the emergence of Model IV will have a unifying influence on the traditionally fragmented field of global education. 
For Eileen, Bill, Lana, David, Florencia, and Mom, my family

For my teacher, advisor, editor, inspiration and friend, Dr. Joseph Rost 


\section{ACKNOWLEDGEMENTS}

This work would not have been possible without the enthusiastic support of a good many people. I express my deep gratitude to Christine and Judson Cornish of Fairbanks Country Day for their constant encouragement, patience and friendship, and for the long hours they spent teaching me Macintosh computing and behaviorism. Long hours and endless encouragement, criticism and confidence also were also provided by my doctoral committee members at the University of San Diego, Dr. Susan Zgliczynski and Dr. Edward Kujawa. I express my appreciation to Dr. William Foster of the University of San Diego for his outstanding teaching. Many thanks also go to my companions at the University of San Diego, Jennifer Jeffries, P.A. Moore, Frank Osgood, Dallas Boggs and many others, with whom I formed so many of the ideas expressed herein. 


\section{TABLE OF CONTENTS}

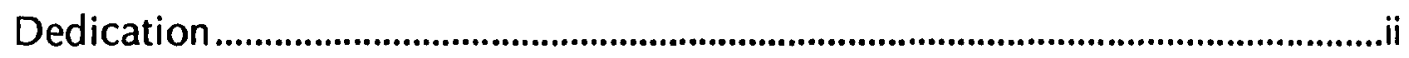

Acknowledgements.........................................................................................ii

List of Tables ..........................................................................................................

List of Appendices .......................................................................................................ii

CHAPTER I: STATEMENT OF THE ISSUE.................................................................

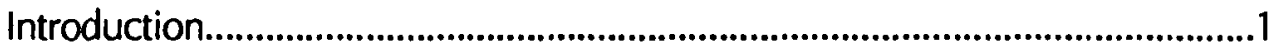

Theoretical Basis of the Research:

Leadership and the Shaping of Values.....................................3

The Issue ......................................................................................................

Purpose of the Study ................................................................................

Research Questions...............................................................................................

Relevance to the Issue of Leadership ..........................................................9

Definition of Terms................................................................................................10

Limitations and Assumptions of the Study...................................................15

CHAPTER II: REVIEW OF THE LITERATURE..........................................................17

Leadership and the Challenge of Cultural Change........................................17

Opening Up the System .......................................................................17

Cultural Leadership in Action .............................................................23

From Local Issues to Global Values...................................................29

Leadership: Concluding Statements................................................35

The Legacy of $U s$ and Them............................................................................

The Local Arena .........................................................................................37 


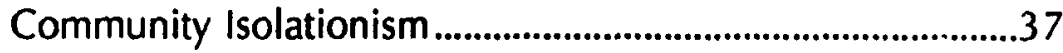

A New Community of Education...............................................41

Curricular Change Versus Social Change..................................47

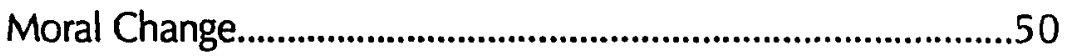

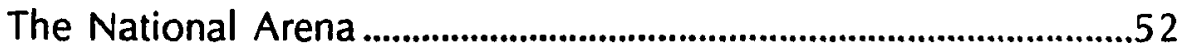

The Tradition of Isolationism.......................................................53

The History of Decentralized Educational System.................57

Federal Education Policy in the 1980s ..................................61

Decentralization and the Reorganization of Local School Funding..........................................63

Education for Economic Security .................................66

The Global Arena ...............................................................................

International Initiatives in International Education................70

Thinking Globally, Acting Locally ......................................................75

The Four Faces of Internationalism in Education ..........................................77

Global Perspectives in Curriculum .........................................................79

Multicultural Education .......................................................................8

International Education for Economic Security ....................................84

Federal, Nationwide and State Initiatives................................84

Business Initiatives..........................................................................

Cultural Leadership ...............................................................................92

Synthesis: Community Education, Leadership, and International

Education ...............................................................................................97

CHAPTER III: RESEARCH DESIGN AND METHODOLOGY ..................................99

Introduction...........................................................................................................99

The Delphi Technique ......................................................................................101

Historical Development of the Delphi Technique............................101 
The Rounds of the Delphi Survey .....................................................104

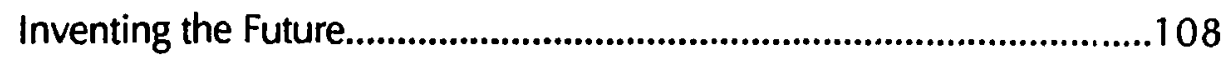

Survey Development and Implementation..................................................111

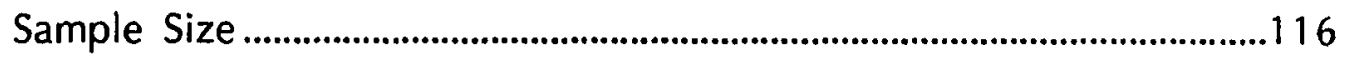

Site and Sample Selection:

Round Zero of the Delphi Process......................................................117

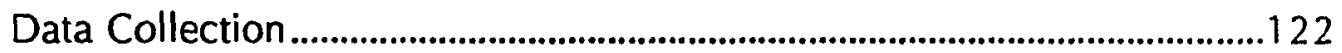

Round One Delphi Process.................................................................123

Round Two Delphi Process...............................................................125

Round Three Delphi Process ...............................................................130

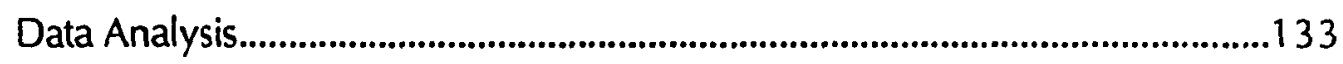

Weaknesses in the Technique .........................................................................135

CHAPTER IV: FINDINGS OF THE STUDY .........................................................140

Demographic Analysis.................................................................................140

Panelist Data............................................................................................141

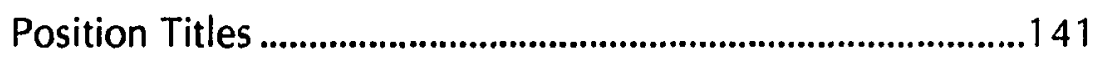

Years in Job and Years at Current Site...................................142

Age .............................................................................................. 142

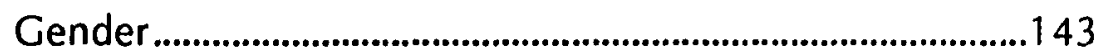

Academic Degrees........................................................................143

Formative experiences...............................................................144

Institutional Data.................................................................................145

The Institutions...............................................................................145

Student Enrollment................................................................146

International Make-up in the Schools/Districts,

Present and Future...........................................................147

Typical Respondent Profile .................................................................152 


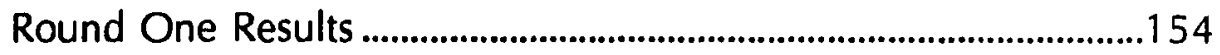

International Resource People in the Community ...............156

Agenda for the Town Meeting..................................................157

The Needs and Goals for Developing International

Resources.

Philosophy of International Education ......................................161

Competing Needs and Goals...................................................162

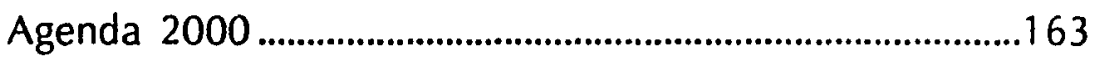

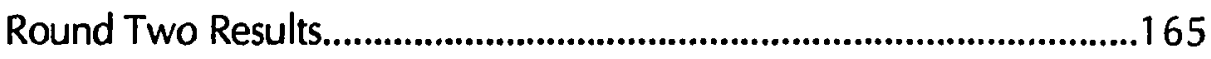

International Resource People...................................................166

International Resource Development Programs ....................168

Agenda Items--Salient Issues in Developing International Linkages.......................................................171

Statement of Philosophy ........................................................172

Competing Needs and Pressures ................................................173

Round Three Results:

Data Analysis Through the Town Meetings .............................175

International Resource People:

Consensus Items

International Resource Development Programs:

Consensus Items.

Agenda Items--Salient Issues in Developing

International Linkages: Consensus Items.....................180

Statement of Philosophy:

Consensus Items.

Competing Needs and Pressures:

vii 
Importance of the Town Meeting.

Analysis of the Town Meeting Format................................................192

CHAPTER V: ANALYSIS AND SYNTHESIS OF THE FINDINCS ..........................195

Second Cut: Toward a Categorized Approach.............................................195

Four Models of Global Education ........................................................195

Model I: Global Curriculum Development............................199

Model II: Multicultural Education..............................................201

Model III: Education for Economic Security...........................204

Model IV: Cultural Leadership............................................209

Summary: Descriptors of the Four Models........................................212

Consensus on Perspectives ....................................................................214

International Resource People:

Priority Perspectives........................................................216

International Resource Development Programs:

Priority Perspectives.

Agenda Items--Salient Issues in Developing

International Linkages: Priority Perspectives..............224

Philosophy of International Education:

Priority Perspectives........................................................228

A Third Cut: Toward an Integrative Model.......................................232

Delphi Summary: Composite Profile.......................................235

CHAPTER VI. SUMMARY AND RECOMMENDATIONS.......................................246

Summary of the Study ..............................................................................246

Background Issues.................................................................................246

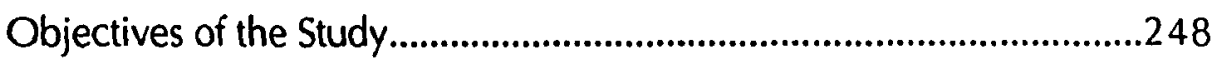

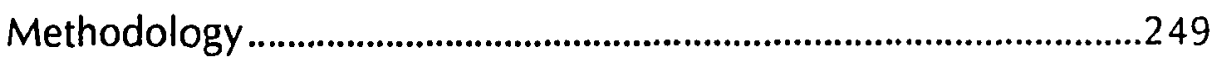

viii 
Results . .252

Conclusions: Getting to Model IV ..........................................................256

Developments in Curriculum and Instruction.................................256

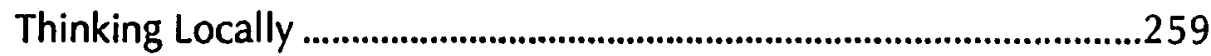

Views From the Corporate Boardroom and Capitol Hill.................266

Coming Together of Concerns ......................................................273

Recommendations for Global Educators ...............................................2276

Recommendations for Further Research.................................................279

Model IV and the Process of Change .........................................................281

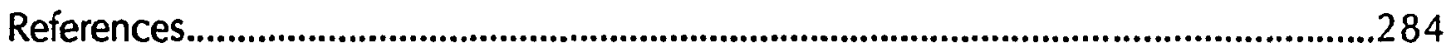

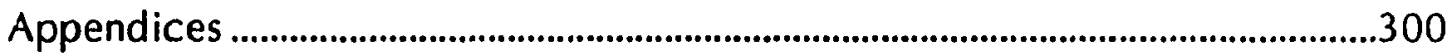




\section{List of Tables}

Table

Page

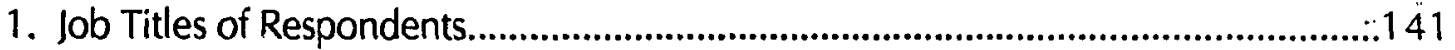

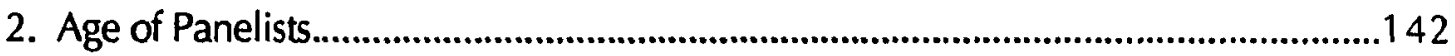

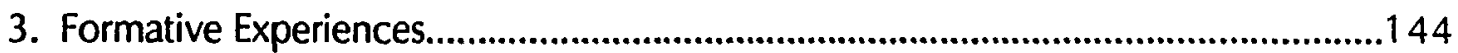

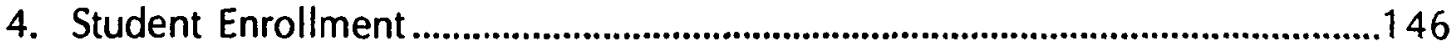

5. International Make-up of Schools/Districts....................................................150

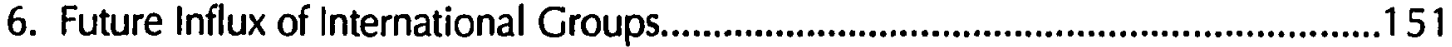

7. International Resource People: Consensus Items ........................................176

8. The Functions of International Resource People: Consensus Items .................178

9. Agenda items--Salient Issues in Developing International Linkages:

Consensus Items.

10. Which Pressures Compete Most for Administrative Time:

Priority Items? .186

11. Competing External Pressures: Priority Items

12. International Resource People: Global Curriculum Development.

Perspective

13. International Resource People: Multicultural Education Perspective

14. International Resource People: Education for Economic Security

Perspective

15. International Resource People: Cultural Leadership Perspective

16. International Resource Development Programs: Global Curriculum

Development Perspective 
17. International Resource Development Programs: Multicultural Education Perspective.

18. International Resource Development Programs: Education for Economic Security Perspective.

19. International Resource Development Programs: Cultural

Leadership Perspective

20. Agenda Items: Global Curriculum Development Perspective 225

21. Agenda Items: Multicultural Education Perspective. 225

22. Agenda Items: Education for Economic Security Perspective. .226

23. Agenda Items: Cultural Leadership Perspective 226

24. Statement of Philosoph: Multicultural Education Perspective. 229

25. Statement of Philosophy: Education for Economic Security Perspective 229

26. Statement of Philosophy: Cultural Leadership Perspective 230

27. Comparison of the Four Models of International Resource Development. 


\section{LIST OF APPENDIXES}

Appendix Page

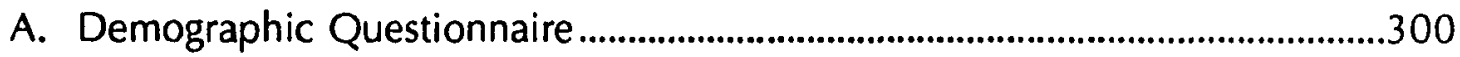

B. Round One: Letter of Transmittal and Delphi Instrument ..............................302

C. Round Two: Letter of Transmittal and Delphi Instrument...............................310

D. Round Three: Letter of Transmittal and Delphi Instrument ............................321

E. Researcher Correspondence with the Respondents .....................................336

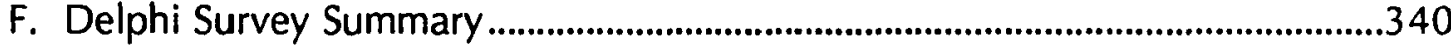

G. Demographic Questionnaire Summary..........................................................346 
THINK GLOBALLY, ACT LOCALLY:

A DELPHI STUDY OF EDUCATIONAL LEADERSHIP THROUGH THE DEVELOPMENT OF INTERNATIONAL RESOURCES

IN THE LOCAL COMMUNITY

CHAPTER I

THE ISSUE: DEVELOPING INTERNATIONAL RESOURCES IN THE LOCAL COMMUNITY

Introduction

Modern schools are in constant contact with the outside world. Through time, this interaction has been demanding, sometimes positive, sometimes negative, and all too often cacophonous. By the sixties and the seventies, as Hill described, "school reform had come to mean social reform" (Hill, 1987, p. 1). Today there is vast confusion over the basic mission of providing students "with the learning and skills they will need for a successful, self-sufficient life" (p. 1). Rapid changes in the United States and its citizenry have mired the task of passing along a clear cultural heritage (Read \& Louhran, 1984). Communications interconnections and the need for both global and local planning have effectively eluded our centralized educational bureaucracy (Mitropoulos \& Psomopoulos, 1983). 
The road to a new paradigm has been blocked by the deeply held assumptions embedded in this bureaucracy and its accompanying, often outmoded traditions. Movements in community education and in global perspectives in education of the 1970 s did much to respond proactively to this repressed condition by coming to terms with developing forces from outside the school. Similarly, school-business partnerships characterizing the 1980 s are evidence of a step in a new direction. Learning specialists and consultants have become excellent, guiding partners with schools, too. Despite these efforts, the sound of an isolated school beneath the rising, discordant noise of the outside environment has grown faint.

The school exists not in a stagnant environment, but an ever expanding one, representing interests from around the community and around the globe (Boyer, 1984; National Advisory Board on International Education Programs, 1983). In fulfilling their fundamental role of cultural transmission, leading schools represent not only traditional values, but emerging ones filled with potentials and guiding ideals. Leading educators are futurists.

Among the most salient forces impacting school, governmental and corporate environments alike are the forces of internationalism. The drumming is getting louder. With global interdependence accelerating, internationalism is struggling to find its rightful place in the community of the school (United States Senate Committee on Labor and Human Resources, 1986). Left out, this inevitable force is liable to exacerbate the problems schools have. On the other hand, leadership in this area can open up a world of resources to education and to tomorrow's educated citizens.

What outside support does a school need? How can it get this support without simply submitting to the external demands surrounding it and forsaking its mission? Can it set the agenda rather than be the victim of it? A wealth of 
resources exist in the community of every scheol which, when woven into the vision of leaders, can be tools used in gaining support for schools and in converging internal and external organizational demands. These tools and how they are used by leaders need identification.

\section{Theoretical Basis of the Research: Leadership and the Shaping of Values}

Communities in the United States are changing rapidly along with social values. International constituencies are raising their voices in the school community. An increasing amount of resources to be found in every local school community are international, and research in identifying their uses and potentials can have powerful applications for educators. Left unattended, these resources will represent an unmet challenge to educators, a gap filled in by foreign and taxing demands upon the school. There has been constant research into understanding how cultural values shape our schools. Current research in educational leadership dictates that serious inquiry is needed into understanding how school leaders can shape cultural values, including, in particular, the value of global interconnectedness (Anderson, 1979; Bowman, Kierstead, \& Dede, 1980; California State Department of Education, 1985; Winfield, 1986; Woyach and Love, 1983).

Reform advocates, theorists, parents and teachers agree that there is a crisis in education, and that this crisis is largely owing to the plethora of external demands being made upon today's schools (Boyd, 1976; Hill, 1987). Breakthrough research in organizational change and leadership will be crucial in charting the way out of this crisis and into the next century. Much of this research is particularly crucial to the development of resource networks throughout the community and globally. 
Can refining our understanding of leadership serve also to help to clarify the educational mission of the schools? Burns stated: "For institutions are encapsulated within social structures that are themselves responses to earlier needs, values and goals. In seeking to change social structures in order to realize new values and purposes, leaders go far beyond the politicians who merely cater to surface attitudes" (1978, p. 421). Schools are encapsulated in their surrounding cultures; they are reflections of values developed primarily outside of them. Educators in these schools have characteristically perceived their external environments in one of two ways. The first way is the perception of the external environment as foreign, if not hostile. In the middle is the victimized school, trapped in the crossfire of political and moral conflicts. But in a second way, the same energy of hostility can be reconstructed and newly perceived as it is channeled into constructive, generative conflict. Those with the ability to manage generative conflict find the school in the center of a global network of opportunities and resources.

Fundamental values underlie school goal formation, management, and curriculum development, and these values have been transmitted from prevalent cultures within which the school exists. As values are shaped and new cultural paradigms replace old, fundamental values of the schools, in theory, change. But are they changing?

Burns (1978) and, later, school reformers of the early 1980s, searched for fundamentals of culture. In their searches, the reformers and Burns found an emerging global perspective penetrating the core. Reformers believed that students were entitled to a "richer core" reflecting the "ideas, experiences, and traditions common to all of us by virtue of our membership in the human family" (Boyer, 1983, p. 95). Reformers felt that fragmented values and lack of common purpose had caused an educational crisis demanding "widespread action" 
(National Commission on Excellence in Education, 1983, p. 10). They too addressed an imperative. An international educational arena, wherein "America's place in the world will be either secured or forfeited" (p. 10), would have to be entered, or United States schools of the nineties would go the way of United States cars of the seventies. Steadily, international competence has become established as a primary objective in the search for fundamental cultural values (United States Senate Committee on Labor and Human Resources, 1986).

Burns believed that the spearhead of the search was leadership, stating, "Leaders and followers can mutually shape their purposes" (p. 431). Through this process there lay the "profoundly important hope . . . that principles can be identified that to a marked degree transcend national and cultural borders" ( $p$. 431). Educators involved in the search for cultural universals may find vast, untapped resources in their own communities. Thinking globally and acting locally, they may place their schools in positions of community leadership, on the pulse of global rhythms. The following pages are dedicated to this search.

The Issue

The contemporary literature on organizational leadership and schoolcommunity relationships has suggested a dialog. The first question: How can anyone expect the school to be effective if its cultural interconnections are shorted? As Smith framed it, every entity belongs to an ecosystem and "cannot be understood separate from this relationship" (1984, p. 366). The networks formed by most educational organizations spin out into surrounding cultures as intricately as a spider's web. The ongoing synthesizing of all of those interactions takes form in the school's educational mission. Among these networks, as research demonstrates (Alger, 1980a; Alger, 1987, Hamilton, 1986), international 
constituencies are proliferating across the United States perhaps faster than any other and competing for the attention of educational leaders. Likewise, there is a considerable momentum building among theorists and practitioners of educational leadership on the importance of integrating international education into classrooms, and many roads are being travelled to do just this (Kirkwood, 1985; Lonzetta, 1988; McKiddy, 1986/87). One need not travel far. International resources are everywhere, in every community. Typical examples are foreign language groups, import/export firms, cultural and ethnic organizations, exchange visitors, international banks, restaurants and universities.

Still, in the field of educational research, the study of international resources being used to exert leadership in the local community is in the embryonic stage. Given the powerful significance of the growing body of work supporting that of Burns and the accelerating impact of internationalism on education, such research is conspicuously scarce in the literature on organizational change and leadership. My own experiences and those of a widening front of social and political observers have shown that international resources in the community provide today's school officials with new opportunities to exert community leadership (Gilman \& Theobald, 1985; Prigogine \& Stengers, 1984). This is the issue to be explored.

Local community leadership and international resource development would at first appear to be strange bedfellows. Yet, given the increasingly international nature of United States communities, the growing need for resourcefulness in the community by school leaders, and the critical importance of international education to possible United States futures, a study of their interrelatedness seems at once logical and neglected. Precious little work has been done to isolate the unique interactions of schools and the international 
constituencies within their local communities, or to explore what resourceful educators can do to mobilize these resources.

\section{Purpose of the Study}

No one would deny that education needs a philosophy. Effective schools convey clear philosophies. And yet, if this philosophy is gleaned from community interest groups on the outside, or from teaciners and people strictly on the inside, the philosophy can hardly be expected to embrace broadly held values.

Educators have a role as community leaders, enabling their schools to become centers wherein the interests of many people and groups crystallize. These interests are not to be confused with the fundamental role of basic academic education, yet they eventually filter into it as deeply held cultural values evolve and change the meaning of education (Mitchell, 1986). When they have not filtered in, the characteristic results can be resistance to change, racial prejudice, ignorance, reliance upon force before reason, and feelings of isolation (Alderfer, 1984; Argyris, 1982; Burns, 1978). Until the world stops changing, continuous examining will be required, first, of the perceptions of the schoolcommunity interface and, second, of how these perceptions are articulated by educational leaders and woven into the fabric of shared school, local, national and global cultures.

The objectives of this research are to examine the current state of international resource development as it germinates in the local elementary and secondary school community, and to discover how it can grow as envisioned and practiced by school administrators. The aim is to discover more about the true community of interest of today's schools and to identify dynamic international partnerships being created through community resource development. The 
ultimate goal is to identify the leadership values contained in the development of international resources found within the school community. In time, local initiatives similar to this may serve the purpose of making schools more responsive to the changing global needs and values.

As Schoen described, "In the course of inquiry, we often discover new purposes at stake in our action" (1985, p. 249). Educational, or more generally, organizational planning is dialectical; products, processes and symbols are there all along, and the leader's role is to call them into play, interact with them, and identify those that should ripen to the benefit of the environment, internal and external. In locating opportunities and "discovering new purposes" for schoolcommunity resource sharing, traditional surveys would assume that the researcher's one interaction with each respondent was representative of all these opportunities. Interviewing would also limit the range of findings due to the smaller sample on which it would have to rely. The Delphi technique applied in this research, since it circulates responses back to the respondents for additional rounds of surveys, has facilitated the discovery of new purposes for resource sharing. Respondents were given the opportunity to consider new perspectives, ideas and available resources which they admittedly may never have considered, and they have reached some telling new consensuses. By using the Delphi technique to create a dialectical process among leading school officials, this investigation has aimed to enrich and advance the dialog in the areas of international education and community resource development.

\section{Research Questions}

The research was designed to achieve its objectives, first, through a review of related literature and second, through continuing consultation with recognized 
experts (researchers, evaluators and practitioners). A third component of the research design was the development and implementation of the Delphi survey. Seven research questions, listed below and reflected in the Delphi instruments and the Demographic Questionnaire, represent the basic objectives of this investigation.

1. Who are the educators responsible for developing local international resources?

2. What is the personal background of these individuals?

3. What resource people in the school community are most valuable to school leaders in their efforts to bring fundamental change?

4. What plans are school community leaders making in order to fuse the international perspectives existing in the community with the fundamental purpose of the school by the year 2000?

5. What philosophical goals are sought by school leaders who are active in fusing the international perspectives and universal cultural values existing in the community with the fundamental purpose of the school?

6. What resources and practical program developments are sought by school leaders who are active in fusing the international perspectives existing in the community with the fundamental purpose of the school?

7. What demands and pressures compete most directly with internationalism for the attentions of school leaders? This includes (a) educational demands and (b) community demands.

\section{Relevance of the Issue to Leadership}

The promise of leadership is contained, for one thing, in the ability to articulate dominant and emerging cultural values. Communication is the basic 
tool relied upon in the mobilization of resources. Thus, the achievement of leadership hinges upon the creation of a high level of dialog, one which enables followers to transcend their past assumptions and limitations, and to envision the community of interest--perhaps the world--in new ways. This will be a dynamic dialog about the meanings of cultural diversity, at the often unstable nexus of independence and interdependence. The Delphi survey, at its outset, proposes the creation of a new consensus, a consensus of broad, global values which leaders can use in synthesizing and articulating an enduring vision of educational mission.

If leaders are to take us anywhere, the new consensus which they are building must reflect a culture shared not only by traditional constituencies, but emerging ones. The changing demographics and increasing global interconnectedness of United States communities demands a futures oriented leadership aimed at the mobilization of our increasingly international community resources. Does such a leadership exist? What this research has questioned is how and whether school oficials can be community leaders; that is, whether local educational leaders, like leaders in competing and cooperating community institutions, can be on the shaping end of intercultural and community values rather than on the receiving end.

\section{Definition of Terms}

The following terms have been referred to and used in the body of this research.

Community: A community is the locus of intellectual, social, moral and ethical, and emotional values, shared, transferred and mutually cultivated. 
Broad "communities of interest" share information which is networked all over the world. The growth and prominence of telecommunications technologies have blurred this distinction though, which has complicated the definition. As this study is limited to local communities, a working definition will be used: A community is the geographical area wherein schools can readily and physically access resources for their students and teachers. A community includes shops, homes, streets, local organizations, recreational areas, media, public names, symbols, history, shared fears and prides, myths and legends, and so on. It also may include foreign exchange scholars and students, foreign expatriates, ethnically homogeneous interest groups, linguists, world travellers, refugees, international centers, and a cultural heritage and identity.

Community Education: Community education consists of those efforts to bring local resources into the school and to use those resources to add to the educational opportunities available to teachers and/or students. It also includes efforts to involve students and teachers in activities that take place outside of the school in order to develop community resources and educational opportunities.

During the 1970s, literature and action in community education took on a new emphasis. This resulted in programs such as student volunteer work and school/university sharing. School leaders can create a shared culture throughout their communities and centered in the school.

In this study, resources sought out will be those useful to the school in order to increase the educational opportunities available to educators and students in ways that contribute to the mission of the school. Ideally, such development also contributes to the goals of the organization with which the school shares resources, enables the school to further develop its mission, and furthers the sense of shared culture in the community at large. Once this has 
occurred, we can say that school and community leadership has been in evidence.

Community Resource Development: This term refers to the location and utilization of resources within the community for the purpose of interorganizational and intercultural sharing.

Cutlure: A culture represents a set of values that are held in common.

Traditionally, these values have been seen as predetermined or intrinsic among local, ethnic, language, national, religious and racial groups. This concept may have changed little in existing traditional societies; however, in today's complex, pluralistic societies, individuals tend to be members of more cultures than individuals have been historically. Thus, formerly diverse groups can come to share culture. Recent research has extended the definition to include any group where values, created or inherited, are shared (Bolman \& Deal, 1984; Mitchell, 1986). Examples of today's concept of cultures include ethnic cultures, but also include the cultures which form in organizations and coalitions. In fact, culture is central to today's concept of leadership in that theorists view the creation of culture as fundamental to leadership.

Delphi Study: A Delphi study is an anonymous debate. "This frequently employed forecasting procedure is used to obtain a consensus of opinion from a panel of experts through a series of questionnaires. Between question rounds, the panel members are informed of the group's previous distribution of opinions" (Linstone, 1978, p. 807).

A more general definition reflects the naturalistic aspects of Delphi research: "Delphi may be characterized as a method for structuring a group communication process so that the process is effective in allowing a group of individuals, as a whole, to deal with a complex process" (Linstone, 1978, p. 295). 
The Delphi study engages experts in an anonymous debate in an effort to consider all factors involved in an issue. Often the issue regards perceptions of future conditions. In gaining consensus on that issue, the successful Delphi contributes to the development of a richer conception of the field and a heightened vision of the future.

Global Education: "Essentially, it is developing an ecological image of international affairs. [An ecological image reveals] an interrelated and interdependent chain of life: neither the ocean, the air, the land nor the animal life ... can be independent. The global system metaphor calls for transnational behavior--behavior which is beyond ... the definition and boundaries of security policy or foreign policy" (Remy, 1985, p. 2).

Global education is not always distinguished from international education. When it is, the difference is that global education is less concerned with educating for diversity than international education often is, and more concerned with educating for commonalities, such as the "spaceship earth" and "global village" metaphors convey. Global education is about concerns that are basic to all humanity including human rights, intergroup relations, peace studies (irenics), ecology, and community development.

International Education: This movement involves programs which, first, heighten awareness of global interdependence and/or, second, impart skills and competencies which will enable students to eventually function in foreign and international settings.

International education uses education as an instrument of international understanding. In many cases, national efforts in international education are made for the purposes of spreading national influence in foreign countries. In the United States, systematic initiatives in this area began after the second world war. The major impetus of United States international education, as it has existed 
since the 1970s, stresses the increasing international nature of United States communities, locally and in business.

Leadership: Leadership is the achievement of a synthesis of diverse values. It is an achievement because it must be manifest in effective action. It is a synthesis of diverse values because it must engage groups and/or individuals to transcend the limitations of parochial values and to promote higher, mutually held values acceptable by both. Rost noted that leadership often arises "in a competitive situation" (1987, p. 4).

As applied to this research, the competitive situation is represented by community resource groups as they vie for influence in a given community of interest. Once these groups support the more universally acceptable vision articulated by the leader, they can overcome their conflicts and contribute towards a sense of shared cultural values in the community. With all of the above factors in mind, this working definition was used in the Delphi survey: Leadership is the ability to bring real, constructive change and to unite coalitions in new understandings.

Multicultural Education: The movement here focuses on cultural pluralism. It involves programs which help schools adapt to changing ethnic populations.

The purpose of multicultural education is generally to provide equal opportunity for all children in their education. Politically charged programs such as bilingual instruction, busing, equal opportunity in hiring, and civics curriculum development are common multicultural education objectives. 


\section{Limitations and Assumptions of the Study}

This study required the assumption that subjects were truthful and cooperative, and that my own interpretation of respondents' answers on the surveys would be objective. The interpretive nature of the data analysis is a limitation.

Although the topic is global, efficient communication with the respondents demanded that the population used was only that of a small selection of urban and suburban school officials in Southern California. This is limiting since the research was not guaranteed to discover important instances of and opportunities for a more widespread practice of leadership in and among educational institutions. For example, many teachers could be leading global educators, as could involved persons from professional organizations, universities and foundations which cooperate with the schools. Also, the literature points to important international education movements elsewhere in the country which would have been salient to the findings of this survey. More specifically, Southern California has been internationalizing in its own, distinct way. Few school leaders have totally escaped the special impact of the influx of southeast Asians and Mexicans. It is always possible that such an influx could create a special condition, not easily transferrable to other populations. On the other hand, it is possible that this influx has presented Southern Californians with the unique opportunity to develop model programs, useable across the nation and beyond. Furthermore, developments across the country have been represented in the second chapter based upon findings in the literature and personal contact with a wide spectrum of involved educators nationwide. In any case, a search for global values should not be regionally limited in its implications. 
As Delphi researchers have documented, sample selection and representativeness in Delphi surveys are fraught with unknowns. There can be no claim to including the most representative uses of community resources, particularly future uses, nor the most expert ones. Nevertheless, this work adds productively to the literature with the discoveries that have been made.

And finally, there are limitations in perspective. A centralized, increasingly homogeneous world is a world of less quality and endurance; history and science alike demonstrate that diversity breeds strength. The role of international education is to cultivate the appreciation of diversity, not to eliminate it. If we are identical, we have little to offer one another. Thus, the survey assumed that international resource development would be necessary of effective school leaders. This assumption can be viewed as a bias and it limits the study. Some readers lacking in the global perspective described could view the whole endeavor as based upon circular reasoning, a case of defining a social condition and then gathering incidental evidence of it from those who agree with that definition. As Linstone stated, "The Delphi questionnaire, like the typical written test or the conference, assumes a certain cultural background. Those with significantly different backgrounds find it exceedingly difficult to respond as requested" (Linstone, 1978, p. 299). The cultural orientation of educational leaders is assumed to be somewhat different from that of widget manufacturers, whose leadership might understandably be confined to a far narrower moral periphery. The review of the literature also led to the assumption that, in an educational culture, change is a constant goal. This research does have a frame of reference. Through another frame the view will seem oblique. 
CHAPTER I|

\title{
REVIEW OF THE LITERATURE
}

\author{
Leadership and the Challenge of Cultural Change
}

\section{Opening Up the System}

"How can I talk to the frog of the sea, if he has never left his pond" (Anonymous, Chinese Proverb).

Whatever level of academic excellence they may oversee, it is not enough for school officials to be instructional leaders or site level managers. Today's school communities include clashing cultures, global interconnections and political agendas; these must be faced if educators and students are to function in an harmonious environment which reflects cultural realities. Education today is in need of cultural leadership so that a new sense of community can be achieved. In addressing this need, appropriate models in organizational theory and leadership need to be found and applied.

Community building, the shaping of value systems which are shared across group boundaries, is fundamental to leadership. Research in leadership and related findings in organizational behavior and change, political science, futurism, politics of education, community education, internationalism, evaluation and school administration all have much to tell us about the needed leadership behaviors and attitudes as we plan for the next century. 
Traditionally, many authors have stressed either external or internal models for organizational change: respectively, how does the outside environment impact the organization, or how can changes in internal organizational structure promote change? For example, systems theorists of the 1960s and 70s evaluated organizations based upon the inputs they received from the environment and the outputs they produced in response. On the other hand, both the rational managers of earlier in the century and the human resource oriented managers of the late 1960 s and the 1970 s emphasized in-house efficiency. They sought ways to channel human capabilities within the organization (Bolman \& Deal, 1984; Schein, 1985a).

Current change theory transcends prevalent systems, rational management and human resources theories. "Your inside is out and your outside is in," sang the Beatles. It has taken years, but many organizational theorists now agree. As John Dewey observed, any ends can be confounded with means in a larger system. Escaping this dilemma would require that the dialog for change be opened, and that the remedies be found through a dialectical process with the outside environment.

Integrating the internal and external environments may not be an easy process, but organizational theorists have gone far in describing it. Grabow and Heskin (1985) theorized that managers need to open the dialog of change with the outside environment. In this sense, if we are to lead a change effort we need to restructure past change theories. We exist not against our outside environment or as a response to it, but within it. Ultimately, there is no outside environment. This notion has led to searches for the constants shared by cultural universals and leadership, morality and leadership, and democracy and leadership (Burns, 1978), discussed below. 
Smith (1982) affirmed a consensus of views by leading change theorists over the past thirty years that every entity belongs to an ecosystem and "cannot be understood separate from this relationship" (p. 366). Real, long term change occurs when it includes both the internal environment of organizations and the larger ecosystem.

Grabow and Heskin viewed this fragile interrelatedness with an eye toward "paradigm shift" (1985, p. 262). To them, the future is open and negotiated, beyond the control of single actors: "The major theme of radical planning is every individual's organic desire to merge with the unity of the world" (p. 262). Enduring change in this new paradigm means not control, but harmony and spontaneity, and the facilitation of social experimentation through which new realities emerge. This they called the "ecologic ethic" (p. 264). Schoen has elaborated on this: "When planners become participants in a reflective conversation with the planned for, they become more vulnerable to learning from the previously counterintuitive consequences of their own (and their predecessors') interventions. They are more likely to become aware of the need to restructure the theories underlying their earlier moves" (1985, p. 253). As Maslow viewed it, ideas help us stretch our limits, and then grow to new, larger possibilities (Hamachek, 1971).

There are problems, risks and potential costs to breaking down barriers in the way of sharing. An organization may misread its cultural context and cause serious harm to itself. Managers may feel they are giving something of their organizations away. The organization also may not be ready to receive feedback about its culture; it may have constructed the barrier, subconsciously or consciously, as a defense mechanism to help avoid anxiety, such as an individual who avoids therapy or self-encounter (Schein, 1985a). Managers may feel that the organizational relationships are too fragile to shake up through scrutinizing. 
They may feel complacent or that they are "getting by," and that a restructuring of relationships would be too much of a set-back or too much work (Bolman \& Deal, 1984). Or the effect may be the cause: feelings of lack of control may promote continued inaction.

Forced, top down change is tempting. No one in power wishes to surrender control over his/her environment. Status may suffer. Frustration may have to be endured. The temptation to pull all the strings is traditionally strong among managers. But by cutting off dialog with the external environment, the result is resistance to "an open-ended creative process" (Grabow \& Heskin, p. 260). Change may still occur, but forced change can not endure.

Motamedi (1985) has described a social system as either attempting to attain control over the external environment or "modifying its internal structures to meet the requirements of the changing external environment" (p. 188). Traditionally, four types of actions have been used for adaptation: conforming, controlling, resisting or opposing. These adaptive actions inhibit proactive decision making and leadership initiatives. Alternatively, "dynamic homeostasis [is a condition of maintaining a system's stability by establishing a constant set of interactions with the external environment" (p. 188). In this environment, leaders would be those who find opportunities to facilitate a continuous, creative, dynamic dialect. They aspire to more than coping or responding; they engage. American schools are in the process of finding this out and the leaders among them are out there collaborating towards the redefinition of their environments and the synthesis of the diverse ideas in those environments.

There are difficult questions to answer once an organization has committed to collaborative change. How far beyond the organization's walls does a felicitous and relevant external environment extend? Striking the balance between day to day issues and global values is one of the biggest challenges for 
cultural leadership. Inside the organization, values may be coalesced and needs may be fulfilled, but still we are left with the problem of the frog, the problem of limited vision. Refinement of internal systems may be good management, but it is too limiting and short-sighted to call leadership. On the other hand, universals, if we can find them, may not apply to a good many management decisions. No system can be completely open and leaders attempting to apply only universal principles would probably die before they were understood anyway. As Burns explained, "However transcendent their theories and values, intellectual leaders are not detached from their social milieus; typically they seek to change it" (1978, p. 143). The easiest way to avoid detachment is to stick to temporal, local political issues and day to day management decisions. This is an understandable reaction to the vexing problem of how to find limits in a totally open system.

Nevertheless, traditionally, educational systems have been too closed, as evidenced by continual school-community conflicts (Hill, 1987; Peck, 1987; Waterlow, 1980; Winfield, 1986). Schein attempted to realistically describe an opening system in his statement that "once culture is present in the sense of shared assumptions, those assumptions, in turn, influence what will be perceived and defined as the environment" (p. 51). Burns' model of transformational leadership also emphasizes the sharing of cultural values, and is compatible with theories of leading change theorists (Alderfer, 1982; Argyris, 1982; Goodman \& Kurke, 1982; Rost, 1981; Schein, 1985; Schoen, 1985; Weick, 1982) in its emphasis that "planning leaders, more than other leaders, must respond not simply to popular attitudes and beliefs, but to the fundamental wants and needs, aspirations and expectations, values and goals of their existing and potential followers" (1978, p. 420). Thus, leadership stretches the periphery of social expectations but, as Burns described, "all in a context of specificity and immediacy, and with an eye to actual consequences rather than lofty intent" ( $p$. 
45). Leadership would be the successful articulation of a paradigm come of age as a result of the overall evolution of culture. Analogous is Michelangelo's perception that it was not he who created the statue; he was only engaged in the constant process of uncovering the forms that had evolved in nature.

One way in which leaders determine the periphery of external organizational relationships is through dialog, both symbolic and actual. Culture and leadership provide vehicles for communication of widely held social perceptions. Like art, organizational form is the manifestation of an unconscious, adaptive process. If everyone has the same dream, then the dream is enculturated. It becomes a guide for action, a social reality. Goodman (1982) has cited Weick's work on enactment and subsequent work by leading phenomenologists, including Meyer and Rowan in 1978, Zucker in 1977, Ranson, Hinings, and Greenwook in 1980, and Pfeffer in 1981 in documenting how "social actors construct their life-worlds and come to share them as if they were real" ( $p$. 29). Similarly, Schoen described a of process "conversational planning" (1985, p. 247): "We understand ourselves as inquirers within a larger system of entities which are both parts of our environment and agents in the environment of which we are parts" (p. 253). Burns integrated theorizing by Lewis Coses, Theodore Radcliffe-Brown, Ted Gurr, Karl Mannheim, and others in describing leadership as requiring a consciousness "of the web of interrelated means and ends" (p. 404): the coordination of social and cultural relationships which are constantly evolving. There can be no doubt: real change intertwines the internal environment of organizations and the larger ecosystem. If we can understand ourselves as living within a wider social context, then we are living in a more open system. Groups which were once heterogeneous become homogeneous once they adopt more common values. The promotion of such values is the function of cultural leaders. 
Much current thinking on the planning of organizational change in the cultural view has resulted in the description of planning not just for the desired products, but for the human and organizational processes and symbols that will have to adjust along with them. Educational (and, in general) organizational planning is dialectical: products, processes and symbols are there all along, and the leader's role is to call them into play, interact with them, and identify and project those that should ripen to the benefit of the environment, internal and external. As Grabow and Heskin described it: "The dialectic acknowledges an unbearable tension, an incongruity in the context of presently perceived reality, and gives rise to forces which are wholly at odds with existence as we know it to be" (p. 261). A new paradigm is achieved.

\section{Cultural Leadership in Action}

With their paper, "Foundations for a Radical Concept of Planning" (1985, pp. 259-269), Grabow and Heskin could offer little more than philosophical "foundations." Realistically, the only prescription they gave was "to facilitate social experimentation" (p. 266). This theory is global, esoteric, idealistic, and not very down to earth In fact, Grabow and Heskin themselves raised the issue of an "action component" (p. 266) to their theory. Can we assume it has one? Can we discover what leaders really do?

Schoen has written of the "reflexive ... conversation concerning the meanings [the planners and the planned for] have formed for their own and the others' moves" (1985b, p. 250-252), where policies and values are "restructured as the conversation unfolds" (p. 253). As can be true of Delphi research, which models reflexive conversation, the process is the plan. Many of these restructurings will yield objectives which appear impractical and irrational at first, 
but the planner would only be cutting oneself off from the values and needs of his/her environment to suppress them.

An action component of Grabow and Heskin's very idealistic model can be constructed by applying a concept which is quickly gaining a profile in many organizations worldwide--decentralization. The organizational environment is defined as broadly as possible, which accommodates the unification of a multiplicity of components or coordinated parts. This models an open system or a force field: the field is in flux. Players come and go, exert influence, then seem not to, and their needs and values are subject to manifestation based upon their strength, immediacy, and the level of articulation of the organizational leadership. Stated Buchen, "The need for a new multiplicity will characterize the future not only of ... . education, but also of business and industry" (1987, p. 25). Practically speaking, what this new multiplicity describes is a community of shared values.

Scully, head of Apple, described the creation of a shared environment, symbolized by the Apple job title of "evangelist" (Goodman, 1987, p. 59). In his view, the role of the organization is to develop leading technological concepts. These concepts are built into a "platform" (p. 59). The evangelist articulates; he takes the platform technologies and helps other organizations "get excited about developing their products to fit on top of ours" (p. 59). New concepts and their manifestations, in the form of communications and program development, breed more new concepts which parallel or complement them. The conversation with the organization's external environment is on-going. It relates to the outside in terms of shared potentials, motivations and goals, not parochial concerns. In merges the internal and external in common pursuit.

Our cultural and technological future is often limited by the vision of could-be leaders. This aspect of leadership--its consensual and evolutionary way of using interrelationships to create the future, its isolation of the process of 
discovery, its mutual crafting of new visions of cultural organizations--is crucial to the process of generative change in organizations and cultural values.

Similar and related leadership developments are underway in business and industry today, "linking firms, areas and states into a common effort [providing] an important method for legitimation, diffusion, and [maintenance of] change" (Goodman \& Kurke, 1982, p. 11).

It is true that the United States educational system is among the most decentralized in the world. Yet decentralization on a national level has historically provided local insiders with autonomy and, consequently, many local systems are insulated from their communities of interest (Althen, 1988). School leaders achieve local decentralization through the utilization of community resources, which "plug into" the school platform (Goodman, p. 59). Resources are located which can mutually benefit the school, the organization's external interface and, in the end, the whole community. Such resources open the conduits of interconnectedness on local, national and global levels.

From this frame of reference, we can perceive academic or cultural education of students as one subsystem in an open, evolutionary system. Other community interests may and should come into play: community experts can form specialty clubs or training programs; near-by colleges can offer high school students advanced or vocational courses; students can be introduced to community service organizations; pessimists and critics can be put to work; school-business partnerships can bring about resource sharing; continuing education opportunities can help make the school a community focal point; cooperating psychologists can cultivate the dialog on behaviors; and international partnerships can cultivate the school's global networks. Sharing arrangements benefit students and raise the level of cultural dialectic. In a school-business partnership, for example, a talk to students about careers by a businessman is 
paralleled by increasing public perception of the values shared between business and educational organizations. A school is a product of its surrounding culture and so to do the fundamental job of cultural transmission, schools need to be centers of community culture.

Beyond its physical boundaries a school, like a nation, exists in a diplomatic community. It needs an external cultural policy. Stated Coombs,

Clearly, external cultural policy cannot be practiced in abstraction: its validity will depend on the vitality of the domestic scene, on internal cultural policy. The two should ideally interlock. . . . There is also a connection between internal and external cultural policies in domestic matters such as the treatment of minorities: it would hardly make sense to present an image of tolerance abroad while maintaining a stance . . at home that is contrary to this. $(1964, p . x)$

Education is inseparable from culture, and that makes it international. As Combs added,

Education ... contains elements, such as the teaching of languages, which constitute a link with other countries, at least potentially. One of the services rendered by cultural relations is to facilitate the opening-up of international dimensions in national education systems. (1964, p. x)

Applying theory on leadership and organizational change to today's school communities means viewing them as a plurality of competing and cooperating groups with an ongoing set of interactions. Social, personal and political forces will continue to conflict and converge on the school until, through some form of persuasion, school constituencies are induced into seeing some higher principles upon which their needs and demands can be united.

The properties of such a unified field are far better than those of school systems which become caught in social tug-of-wars, something which systems 
analysts for the most part fail to see. No one wants the internal organization to change as rapidly as the outside social environment, especially in times of turbulence. A school-community interface could absorb the shock of change while, as Weick would have it, the internal academic systems remain relatively "tight" (1982). The external system remains "loosely coupled from the vantage point of the suprastructure" (Smith, 1984, p. 321).

Schools are interpenetrated and controlled by their environments and are heavily dependent on local communities for a large portion of their support. School heads have a role as community leaders and spokesmen, enabling their schools to become community centers or platforms "by establishing a constant set of interactions with the external environment" (Motamedi, 1985, p. 188). All of these functions are synthesized into a unified, fundamental purpose of education. Burns described the process of leaders and followers becoming "locked into relationships," explaining, "In the progression of both leaders and followers through stages of needs, values, and morality, leaders find a broadening and deepening base from which they can reach out to widening social collectivities to establish and embrace 'higher' values and principles" (1978, p. 429).

The questions of how and when the values of subsystems move into the core are crucial here, and require much research, but some theorists believe that conflict plays a part. Research demonstrates that leaders enjoy conflict (Burns, 1978; Cleveland, 1986). Alderfer explained this ironic relationship between conflict and leadership. He found that "power differences exist across groups," creating dynamic relationships (1984, p. 142). So when popular issues are hammering at the community, leaders recognize the opportunity to uplift the dialog so that higher principles can emerge.

If an organization wishes to internationalize, it must embed its values across diverse, often conflictual groups. If relations among these groups are congruent, 
"affective patterns, cognitive formations and leadership behavior" (Alderfer, 1984, p. 142) will be consistent, and interactions will serve to maximize the advantages and power gained by all groups as they interact. Incongruent relationships will produce threatening and short sighted win-lose interaction. Historically, it has taken leaders with vision to recognize generative conflict and to penetrate and articulate values in a way that arouses followers. The dynamic dialog of leadership enables values of diverse stakeholders to emerge more clearly. "It is leadership that draws the crowd into the incident, that changes the number of participants, that closely affects the manner of the spread of the conflict, and constitutes the main prosthesis of relating the wide public to the conflict" (Rost, 1981, pp. 17-18).

A wide range of educational and community interests have been served by contemporary schools, but an uneasy line between them has been drawn and the line has always been blurred. From the outside, the perception of the school has remained confused or erratic. Much more work needs to be done on examining the perceptions of the school-community interface. Research could never be completed until the world stops changing; yet this much is clear from the application of organizational and leadership theory: schools lose their identity if they cannot broadly communicate, much less inspire, a clear cultural mission both within and across cultural lines. Without that, anything might be expected of them. They are left to cope with or fend off the infinite demands of an infinitely complex, ever demanding society. Once engaged in making the distinction required of decentralization at the organizational level, for the purpose of the divestiture of distracting functions, fundamental educational values and goals will be able to evolve more constructively and clearly.

Community service, independent physical education, clubs formed by community interest and athletic groups, speakers bureaus, and exchange programs, insofar as they make the community care about the school and share in its 
mission, add to the list of exemplary programs. These programs, embraced and integrated by the school, can all be creative responses to the multiplicity of community needs, helping to place the school in a leadership rather than a reactive position. The existence of such programs in many schools points to potentials and opportunities for communitywide leadership on the part of schools. Once plugged into the values of our internationalizing communities, the school is committed to broadening its own organizational values. Many more such programs pertaining specifically to international resources in the community will be discovered, organized, and placed into the context of the literature on leadership and organizational change in the pages to come. The development of these programs is only at its beginning and so each is more powerful in its potential than in its current existence.

\section{From Local Issues to Global Values}

Of what application is Burns' leadership model to educators who would be cultural leaders? Does leadership imply a global perspective? To answer these key questions we need to agree upon the crisis in educational leadership. Reform advocates, parents and teachers agree that there is a crisis, and that it has been exacerbated by the plethora of demands being made, largely externally, upon today's schools. This is only logical. Although arithmetic tables and spelling change little over generations, their cultural functions do change. Students receive facts differently because they come from different worlds than past generations did. Curriculum, like students, constantly changes in response to cultural change. Historically, responsible educators have been cultural followers.

I have on my desk a newspaper clipping describing a California State Assembly debate on a bill which would force all public schools to show teenagers 
an AIDS-prevention video or film ("Assembly rejects," 1987). Other clippings review the banning of books at the insistence of community interest groups. A by-line is "Teachers and Public Found Split on Issues" (1984). Other articles call the schools "dumping grounds," "a football game without a scorecard," and "a national disgrace" (Grauer, 1986). They hardly represent an harmonic synthesis of views. Closer to the belt is an article reminding us, as we are often reminded, of the disintegration of federal and community support for education (Smith, 1988). Problems such as substance abuse, rapidly changing ethnic make-up, gang violence and teen pregnancy are colliding in the schools and have threatened the integrity of academic education. These are situational, temporal, anything-butglobal, and sometimes knee jerk problems. Often enough they are the results of earlier solutions to variations of the same problems. And as legislators, school boards and community interest groups continue to thrust upon schools political solutions for every surface attitude arising of social issues, one wonders where they would stop. What issues are not the schools' problems? Is any current event beyond the scope of the school curriculum or outside the expectations we thrust upon our teachers and school officials? Does anyone know what a school is any more, or who should run one? Perhaps it is not enough for educators to be cultural followers.

Isolated and encapsulated, schools understandably risk clashing with their external environments. As early as 1965, Gardner tied the problem of conflict and fragmenting goals to the promise of leadership.

Leaders have a significant role in creating the state of mind that is the society. They can conceive and articulate goals that lift people out of their petty preoccupations, carry them above the conflicts that tear a society apart, and unite them in the pursuit of objectives worthy of their best efforts. (p. 12) 
Being more kind about our petty preoccupations, Burns called leaders those who "lift a people out of their everyday selves" $(1978$, p. 461). Followers come to hold the same aspirations for their children as school leaders do. Yet, a great mariy school administrators, deluged in work and demands, end up viewing the school as "us" and their external systems as "them." "Watch out for the towering giant with feet of clay, especially if we are the giant," warned Burns (p. 461). Authentic leadership," he reiterated, "is a collective process" (p. 460).

Political and curricular agendas can become litanies of every imaginable surface issue, "garbage cans wherein streams of problems, solutions, participants, and choice opportunities intermingle" (Goodman \& Kurke, 1984, p. 34). Culturally, the goal of the school leader is not to cope with external demands, but to mobilize broad social needs and values which ultimately focus the interior system on responsible academic change. Development of outside resources, international or not, is no substitute for a basic organizational mission. However, it is the outside environment which harmonizes with internal goals, as they change each other gradually over time. Harmony makes surface change distinct from fundamental, lasting and global change.

Leaders among educators, especially those with enough vision, facilitate social experimentation rather than fend it off by synchronizing their own work with ongoing cultural activities and felt social futures. These activities often reflect the values not only of parents, but of psychologists, mass media, athletes, businesses (as partners), vocational training centers, colleges and universities, community leaders and experts, cultural and political leaders and others. Each of these constituencies has its own extensive network, linking the school globally and limitlessly.

In a globally linked school community, leadership requires a global perspective. Scattered efforts to integrate a global perspective into the United States 
national educational mission have sprung up over the past decade. In concert with the the work of some of the school reformers, Burns' Leadership conveys a global perspective through its search of principles that would "transcend national and cultural borders" (1978, p. 431). Cleveland has tried his hand in isolating leadership attitudes reflecting a global perspective. They are as follows.

First, a lively intellectual curiosity, and interest in everything that happens--because everything really is related to everything else, and anything that happens may be relevant to what Americans are trying to accomplish in the world.

Second, a genuine interest in what other peoples think, how they think, and (especially) why they think that way. And that requires us to be at peace with ourselves for a start.

Third, an attitude that risks are there not to be avoided but to be taken. "Risk averse" is not in the vocabulary of a people who bring other peoples together in organizations to make something different happen.

Fourth, the feeling that crises are normal, tensions can be promising, and complexity is fun.

Fifth, the realization that paranoia and self-pity are reserved for the citizens of nations that don't want to be leaders.

Sixth, the quality I have called unwarranted optimism: the conviction that there must be some more upbeat outcome than would result from adding up the available expert advice.

Seventh, each individual's sense of personal responsibility for the general outcome. This translates, in world affairs, into each person's sense of personal responsibility for the workability and fairness of international systems. (Cleveland, 1986, p. 12)

Cleveland added, 
For the world's leading nations, like generalist leaders in every domain, the steepest part of the learning curve is not skills but attitudes. If we all can learn--and our school children can learn early in life--what it takes to be effective in situations where persuasion and bargaining and compromise are the stuff of leadership, we will also have learned a basic clue to what it takes to promote freer institutions, fairer economic growth and more peaceful political change worldwide. (1986, p. 12)

Psychologists and theologians have long searched for global values and cultural universals, often looking to common symbols, myths and life transitions experienced by all humankind (Arrien, 1988).

The search for cultural universals has spread across the field of cross-cultural counseling. In 1986, the American School Counselor Association's Human Rights Committee began a program to commit counselors to explore their own bias systems and read professional literature on multicultural issues. The purpose was the "development of school and individual goals toward cultural diversity" ("ASCA Program," 1987, p. 12). "Instead of focusing on the cultural distinctiveness and uniqueness of American racial-ethnic groups," the new conceptual models emphasize "universal counseling processes and principles" (Ponterotto, \& Benesch, 1988, p. 237). A 1988 Delphi survey of cross-cultural counseling experts forecast "a $25 \%$ increase in the development of general theories applicable across cultures" (Heath, Neimeyer, \& Pedersen, 1988, p. 29).

According to the framers of the "Universal Declaration of Human Rights" (Basic Facts About the United Nations, 1977), democracy is one globally pertinent principle. As Gagnon stated, "Democracy is not narrowly prescriptive or culture-bound" ("Response by Paul," 1988).

Local educational officials have attempted to lead in a globally interconnected school community, but often become preoccupied by the short 
term needs for in-district ethnic integration and the satisficing of the political demands of a growing diversity of constituencies and interest groups. They know there are broader issues, but they can't get their communities to see the forest for the trees. Sometimes they don't think this is their job. Often, they say, there isn't the time or the money.

The passport to global values is leadership. These values seem hard to come by. Internationally recognized human rights including integrity of the individual and civil rights are goals almost everywhere, but even these are relative to the culture. Some human rights seem both universal and obvious at home, yet are contested on foreign turf. "As an extreme example, a representative of Iran at the United Nations took the unprecedented step in 1984 of declaring that the Universal Declaration of Human Rights does not apply to Iran" (Bureau of Public Affairs, 1984). In bridging over these battle lines, leadership is tested. The right to education, freedom of movement and the right to speak out need bridging today (Bureau of Public Affairs, 1985). Often ignored amidst the zeal for human achievement are the global values incarnate in the physical world. Human culture exists at the mercy of a delicately balanced physical world, and so leadership with a global perspective must require a feeling for ecology (Martin, 1988; Pirsig, 1974). Unfortunately, the environment too is a bitterly contested battle field where leaders are not always easily distinguishable from zealots and opportunists. Transcending petty or selfish preoccupations and moving cultural universals into the core of community and educational values would indeed be leadership. 


\section{Leadership: Concluding Statements}

Are school leaders and their followers, and their followers' followers, mutually shaping their purposes, as Burns hoped (1978)?

Burns (1978) demonstrated that congruence between groups is achievable; not at the insistence of popular attitudes and issues, but when issues become fundamental social, moral and intellectual values. . Thus, the popularly documented crisis in the classroom will have to remain until schools emerge from closed systems--until the crisis is understood as one in the surrounding, ultimately global culture. Coping--the lack, or failure, of leadership--forces the school into a closed system, in a demanding, degenerative environment. On the opposite pole, leadership promotes a pluralistic, cooperative environment.

As Cleveland wrote, fundamental to leadership is a positive view towards conflict. Added Burns, "Much depends on the alignment of conflict--that is, on whether conflict cuts through these entities and arrays human beings by purpose and principle rather than by geography or enthnocentricity" (1978, p. 431). Conflict may isolate schools, or it can stir up compelling, dynamic forces for ultimate alignment. Any problem might be viewed as a rational, clear one upon which a patch of a certain size can be fit, and this is the model most organizations follow. The second, leadership model, however, is not intended to solve problems but to restructure the off balance systems which have caused these problems.

Despite intellectual breakthroughs in the study of leadership and organizational theory, the crisis will remain until leaders can take Burns' model and turn perception into form. In the long run, visions that lead are the bridges linking the internal and external, personal and cultural, instinctive and intuitive, and local and global. Such visions are uncommon. For the most part, the 
realization of change of a transformational nature remains trapped within separate left brain and right brain metaphors. The parallel lines of metaphor and reality have been set into a dynamic tension by Burns and others, and they struggle to merge. "The ultimate test of practical leadership is the realization of intended, real change that meets peoples' enduring needs" (Burns, 1978, p. 461).

It is always the diversified organisms which flourish. The outside environment changes, experiments, and evolves as always, and works within and without the school to the mutual benefit of all. Schools need internal integrity, and yet "they must be free to form their own unity with the world" (Grabow \& Heskin, 1985, p. 262).

Schools could spearhead democratic and pluralistic values and school leaders, like wise mayors, would have the opportunity to articulate those values, cog-wheeling with academic, community and global needs and values to a higher level of social dialog and creativity.

The Legacy of Us and Them

"None of us can be completely freed from the shackles of our environment ..." (Borg \& Gall, 1983, p.74). The result can be cognitive dissonance, tension that we know exists but can't always define: we believe our actions and philosophies are sound, but somehow, should we dig deeper, we feel that we are out of synchrony with our surroundings, or perhaps even that we must live in an adverse environment. On the opposite pole is the challenge of leadership: to actively articulate salient issues, tap resources, and shape the environment in concert with followers. Educators in every community face this challenge.

The relationship between schools and the world outside the classroom emerges from a long and slow mating dance, a long resisted dance, continually 
interpreted, invented and re-invented, negotiated in words, money and symbolic interaction. Out of this relationship--and not out of some pure, academic pursuit of intelligence, for intelligence means a different thing in every culture--comes the school into the world. From complacent youth to rebellious adolescent struggling to leave home and find a place in the world, the United States school has stumbled its way through history towards the embrace of its wider communities of interest. Today, a fundamental failure of the United States efforts in education nationwide is in finding a unified, coordinated approach to internationalizing the system. School sites, communities, businesses, states, the federal government, and international organizations, all to some degree concerned about meeting the needs for an interconnected world, plan separately and often at cross purposes. Global values are denied in favor of special interests. Local needs are typically found not meeting broader needs, and local officials, at the eye of the storm, now have the responsibility for finding more universal, less divisive models. There is a crisis in community educational leadership.

The Local Arena

\section{Community Isolationism}

The long legacy of United States national isolationism has been paralleled in the local school community. United States schools were born into closed systems and bred on myths where, to some degree, they are still trapped. Eighteenth and nineteenth centuries schools were rooms where schoolmasters provided functional literacy and the educational precursors for a little technical 
work. This was not a pluralist education, but an education reflecting our manifesting international isolationism.

Much of the stumbling of the United States school was over what Rost called the politics of education myth (1986). This recurring theme in United States education tells a tale of a politics free education. In such a system, the local educational professionals are free to remain aloof from whatever social tribulations federal, state and local politicians squabble about (Campbell). They are viewed as intellectually superior to groups of outsiders: groups of nonacademics; groups of "self-appointed guardians of the public morality who want smut, anti-Christ, or communist literature removed from the bookshelves" (Wiles, Wiles \& Bondi, 1981, p. 179). Guardians of the myth historically came to feel degraded having to do battle over a wide range of political issues like "the theory of evolution, the communist menace, sex education, use of teaching machines, black studies, and competency testing" (p. 182), all of which they felt uniquely qualified to handle. The myth has held that board and administrators must be autonomous, privatized and protected from community control (Rost, 1986). "Let's get back in our office and write up a good curriculum, and we'll give it to our teachers and they'll go into the classroom and use it," they say, or so Scriven typecast the syndrome in its contemporary form (Wiles, Wiles \& Bondi, p. 181). Rost has demonstrated how "the politics of education myth has been used consistently throughout our history," and that it persists across America today (1981, p. 423). So it came to pass: there was "us" and there was "them."

By the turn of the twentieth century, muckraking journalists had already inscribed the little red schoolhouse into myth. Myths and folk tales served to soften the squabbling of a changing, invaded, and potentially turbulent community and to preserve the comforting privileges of the majority. But the American Grimms had their harsh side. Incensed by corrupt school board politics 
and frustrated by the changing ethnicity on Main Street, Progressives saw politics as the greatest threat to education (Schattschneider, 1960). Politics, the allocation of diverse group values, had not been mentioned much in the earlier, more homogeneous days of United States education. Now, as the nation changed its ethnic and demographic composition and cultural values diversified, the reality of the new school community and the remembrance of simpler days clashed. It was in this fashion that Progressives found themselves thrust, ironically, into the one place they sought to avoid, the one place where all their anxieties turned to fear: the political arena. The influential Cubberly demonstrated well Edelman's lampoon that "Political history is largely an account . . . of the expenditure of vast resources to cope with mythical fears and hopes" $(1971$, p. 1).

Through the first half of the twentieth century, immigration radically altered the face of the local community. Meanwhile, the view of education's role in the community changed little. When change engulves a system and that system doesn't change internally, the product is conflict. In response, state and federal governments began to step in, both with their own mandates and with incentives for local citizen involvement (Campbell, 1959).

Nationwide, by the 1960s schools were being drafted to "fight the war on poverty, the war on racial discrimination, the war on sexism, the war on bad driving, the war on malnutrition and the war on unemployment" (Hill, 1987, p. 1). In the 1960s and 1970s parent advisory councils and other community groups began monitoring school expenditures and policies with vigilance, and asserting their own inputs. Governors across the nation lauded these efforts and called for more (Governor's Citizens', 1973; Governor's Study, 1975; Massachusetts State Board, 1974; New York State, 1972; Riles, 1970; Zusman, 1974). Inside the districts, particularly in the inner city, school boards had developed into powerful political pulpits to ward off the multicultural clash of agendas. To many, the 
politics of education myth formed in more homogeneous days seemed more than an appealing bit of nostalgia.

Internationalization of the local community was not the only source of confusion and clash during the 1960s and 1970s. A variety of forces, mostly in the local school community, fragmented the mission and prevented educators from approaching internationalism in a serious and cohesive way. During this period the school continued to be a prominent target for social reform movements and the mission of the school became contested in federal, state and community arenas. School boards grew more heterogeneous and more volatile than ever. In his classic discussion of the politics of the educational arena, Boyd copyrighted the empathy for many a beleaguered school superintendent: "He must adjust to, and become a part of, a social system he did not help create. He is compelled by the pressures around him to organize his thoughts and activities in accordance with the demands made upon him by the people who wield the power in the community" (1976, p. 540). By 1976, the educational administrator came to be viewed as "engulfed in a pressure-packed set of constraints" (p. 540).

Looking back from the mid and late 1980s, educators began to see how the school had become the monkey in the middle of politicians and intellectuals, of protectionists and globalists, of realists and dreamers, and of preservationists and futurists. In 1986, the Carnegie Forum on Education and the Economy stated "resources are scattered and so is school leadership" (p. 1). Today, the windowless schools built in the early 1970s still stand as haunting metaphors: the myth persists. The schools and their officials have inbred isolation and, still, a sense of powerlessness pervades the spirits of educators who would never be leaders.

[There is] an increasing sense that "others" are running the show. Those members of society who have power to affect educational policy (i.e., legislators, parents, the media, business interests, and the federal 
government) are seen by many educators as "externals." This we/they dichotomy must be resolved if any concerted action is to take place. (Bowman, Kierstead, \& Dede, 1980, p. 324)

The culture bound relationship between schools and communities is now widely confused, ignored or misunderstood (Mitchell, 1986). This is due to failures in leadership and in our ability to adapt to the rapidly changing compositions and interests developing in the United States communities (Alger, 1987; Bowman, J., Kierstead, \& Dede, 1980; Boyd, 1976; Boyer, 1984; Burns; 1978; Cetron, 1985; D'Amour \& Rittenberg, 1980; Gardner, 1965; Hill, 1987; Scott-Blair, 1985; Winfield, 1986; Woyach \& Love, 1983; Wynne, 1985/86). A community has an identity, a sense of place, of "us" and "them" and this is "the collective significance" of its name (Husen and Postlethwaite, 1985, p. 658). Problems occur whenever community institutions, such as the schools, make slow or unrepresentative adaptations to changing community make-up. Continual research is required in examining the roles and promises of relationships, particularly intercultural relationships, of competing interest groups and values as they struggle to coexist within the school community.

\section{A New Community of Education}

Before a unified approach to international education can occur, schools will have to emerge from their isolation. Doing this will mean making connections with business, cultural, political and other organizations. It will require schools to be on the leading edge of social and moral change.

An educator could be viewed as someone ... who helps others shape values within the cultural context. Educators, therefore, would be news reporters, media experts, community leaders, politicians, business 
executives, parents, the clergy, engineers, and teachers. Linking these groups together . . . would be a major step in educating the public. (Bowman, Kierstead, \& Dede, 1980, p. 325)

Stated the National Advisory Board on International Education Programs, We have the resources. We enjoy rich ethnic diversity, with linguistic and cultural ties to every part of the globe. We have advanced communication, a vigorous free press, highly diversified broadcasting media, expertise in area studies in a network of national resource centers, a tradition of internationally-minded community, professional, and civic organizations, and the world's strongest commitment to universal access to public education at all levels.

We must make better use of all these resources. (National Advisory Board on International Education Programs, 1983, p. 4)

Modern telecommunications and transportation have placed international constituencies in every community. Yet despite these new communications channels, today's schools are in conflict with a greater diversity of external forces than ever. Calls for global perspectives compete with cries for new sources of funding and needs for university training; social problems such as racial discrimination or unwanted pregnancy are invading or even germinating in the schools, hacking away at fundamental educational goals. As of this writing the cries are for suicide prevention and AIDS education and, as pressing as such cries always seem, there is always something else next year. The demands keep coming, and from a greater diversity of interest groups: parents, powerful elites, community organizations, growing state and national political forces, unions, minorities, ethnocentric citizenry, and many others. In answering the call, and in an admirable show of futility, educators have attempted to exert what they call leadership. They have assumed responsibility for nutrition, psychological referrals 
and services, vocational training, recreation, child care, busing, medical care, training of the profoundly handicapped, fund-raising, job retraining and the diverse charges proffered by theorists. This kaleidoscope of issues does not reflect a broad or systematic vision on behalf of educational planners; nor does it reflect a community of shared values. Rather, it reflects tunnel vision and crisis management, the failure to twist the lens, to adapt vision to a new and ever changing environmental field. In short, educational planners at the local level have tried to be all things to all people. The environment pressurizes, the schools try to cope, and the result is over complexity and diffuse goals.

The needs and potentials for a global perspective and universally shared values have never been more evident. Yet through crisis and rebuke, schools in the United States are amazingly resistant to fundamental change. Why?

Haas (1986) cautioned that "when comparing proposed or probable social and economic futures with education futures, one is struck by the lack of bold, imaginative, exciting futures for education." He explained that "the forces for change and those for little or no change can be found both within and without the educational establishment. These internal and external pressures seldom coincide. Usually, a precarious balance of power prevails between competing conceptions of what schooling should be, ensuring the status quo or a few incremental but insubstantial changes" (Haas, 1986, p. 15). Thus, Haas concluded, barring major shifts in the structure of schools, far reaching technological innovations, alternative funding schemes or all out "cultural revolution," schools may continue to resist change (p. 30). Walter and Choate (1984) have demonstrated that the consequences of limiting vision to the internal workings of the organization are disordered management, domination of public spending by interest group politics, favoring of short-term payoffs over long-term goals, and imposition of limits on joint public-private action. Yet all we can conclude from 
Haas, Walter and Choate, and a spate of social and technological theorists and practitioners, is this: the cause of limited vision is limited vision.

Schools failing to find a shared vision of the educational mission attract conflict and resist change. This indicates that a basic role of schools is in collaborating in the building of community.

Peck explained that "Community is integrative. It includes people of different sexes, ages, religions, cultures, viewpoints, life styles, and stages of development by integrating them into a whole that is greater--better--than the sum of its parts. . . Community does not solve the problem of pluralism by obliterating diversity. Instead it seeks out diversity, welcomes other points of view, embraces opposites, desires to see the other side of every issue" $(1987$, p. 234). Yet, as a trend, children in our public school systems are not provided with a socially integrated environment. In fact, they have been increasingly "segregated from the general population" and increasingly educated by a special class of adults, i.e., trained teachers and school officials (Winfield, 1986, p. 59). Schools have isolated children and their teachers alike, and in this way have contributed to the growth of youth cultures and an impoverished sense of efficacy among students and teachers. These, in turn, further isolate students from the family, the work place and the values of the local community: a mocking outcome of the myth of politics-free education which, perhaps unknowingly, holds elitism and isolation as the asylum of community.

There is considerable evidence that the United States culture as a whole has suffered from a loss of community. This makes it still harder to adopt global values in the educational systems which are charged with passing along the culture. Peck stated that many geographical areas which formerly could be called communities are now "nothing more than a geographical aggregate of people that have a certain tax base and use services in common but have precious little 
else, if anything, that relates them together as human beings" ("Peck Stresses Community," 1987, p. 1). The church is "sadly, often no more of a real community--a place of sharing, intimacy and connectedness--than are today's American towns" (p. 3). Likewise, the the concept of the local community school lost most of its relevance in the 1970s and 1980s. Schools have invested few resources in the process of community building. Like all closed systems, they have inbred their very own cultures, turning principals into lords of the flies.

The perception of the school as a closed system was the inspiration for a small, community education movement which began in the early 1970s in response to the loss of community. New approaches to community building were suggested. The Progressive pointed out that "The transmission of values-and in many instances, even of basic skills--may be a task that can be better accomplished ... in various community settings that are not called schools" ("What We Want," 1985, p. 10). Trends isolating children from community life "can be mitigated by requirements (and incentives) for youth work and service in the adult community, by integrating adults of diverse experiences (as both teachers and students) into schools, and by restructuring the time that youth spend in school" (Husen \& Postlethwaite, 1985, p. 848). This can be done through community-based learning experiences where schools become involved, for example, with local voluntary, church, and business groups (Cetron, 1985; Schine \& Harrington, 1982). As admirable as these ideas were, they can be used to demonstrate how the community education movement was treated as ancillary; it has never really been integrated into the fundamental educational mission; nor was the movement ever focussed on what may have been its most far reaching, promising arena, global education.

Like the community education movement, the local movements in international education have concerned themselves more with internal change 
(mostly curriculum development) than with the creation of interorganizational and communitywide connections. Understandably, this has not amounted to anything like community leadership. Nevertheless, through the late seventies and the eighties, research began developing which specifically considered opportunities for resource sharing with international organizations in the community (Alger, 1980a; Alger, 1987; Bowman, Kierstead, \& Dede, 1980; Husen \& Postlethwaite, 1985). This research indicates that the days of curriculum development in international education may be superseded by larger scale organizational change with a global perspective.

"A major challenge for community education in either modern or traditional settings is to respond to the considerable evidence that communal forms of life contribute significantly to human dignity" (Husen \& Postlethwaite, 1985, p. 849). In 1983, Woyach and Love stated that "a community-based approach to global education attempts to use the personal resources and information which result from local involvement in world affairs to teach about the political, economic, social and cultural systems which make up the international community" (p. 37).

Woyach and Love's research attempted to demonstrate that "by introducing students to the local community's involvement in international systems and problem solving, educators can encourage attitudes found to be prerequisites to citizen participation" (1983, p. 36). Anderson felt that through citizen participation, students might "link themselves . . . to the public affairs of the groups of which they are members" $(1979$, p. 335). While Woyach and Love's research could not demonstrate more than an implied effect of student participation programs, the concept is still very young and there is much to learn about targeting and timing these efforts. Woyach and Love explored studentcommunity interactions, but they did not consider the interorganizational 
relationships or the school-community interface which would have to exist for the programs to bring lasting change. School community leadership will require more than the encouragement of student participation. The engagement in school participation would reflect a deeper commitment and a longer term plan.

The goal of citizen participation is to help educators and their pupils collectively engender the perception that they have a personal stake in cultural and world affairs, to gather their culture beyond the school walls, and to develop their sense of efficacy in community development. School culture building has been a pillar of the 1980 s school reform movement. Unless that culture is an accurate reflection of community culture and, ultimately, a reflection of world culture, it is isolated. The work is new, and initiatives are scattered and few, but a developing mass of research and social experimentation is powerfully challenging the old assumptions.

\section{Curricular Change Versus Social Change}

There are a few principles which can guide the development of the building of international culture in the local community.

The literature on leadership and organizational change indicates that community education can consist of either short lived, surface experiences, or it can become fundamental to the school mission. Adding an extracurricular option of volunteer work can be educational, but alone this innovation is superficial. Is this option a scheduling change or a broadening of the overall educational mission? Are the people at the organization where students volunteer really involved in the shaping of community education goals? Are the school and the outside organization taking steps to share other resources in a truly sharing community? Do people from the outside organization come to the 
school or understand the educational context of the students' experiences? Do they conceive of the student and staff experiences as a free resource for their own organization (What's in it for us) or as a means of unifying community culture (What's in it for all of us?) (Cleveland, 1988)? With a fuller interaction among people in the school and its surrounding community, a mutual exchange of resources, a common set of organizational, educational and community goals--a common culture--is created. Community educators envision schools as community centers, part of the network of many organizations, bearers of community values and aspirations.

The call for citizen participation in an internationalizing United States points to the same new direction for community education. Community-based global educational experiences must be conceived and designed not primarily in an effort to affect the learning of students, preposterous as this might sound. The higher purpose of these experiences is to weave goals of local international (and other) groups into the goals of schools: to merge goals. It is at this interorganizational level where community leadership occurs. It is among groups more than within groups where cultural conflict is transcended and fundamental cultural values are developed, enhanced and transmitted. And it is among groups where fundamental social values which are to be integrated into school curricular goals are shaped. Adding another section of international relations to an already over-stuffed curriculum is not the answer. It might make an excellent addition to the curriculum, but it can't bring the needed involvement in the community and it is not leadership. On the other hand, for example, using paraprofessionals of rich cultural experience as teacher aides or tutors can "give way to the political purpose of providing useful linkages between school and community and the subsidiary purpose of providing jobs for some community members" (Guba \& Lincoln, 1985, p. 295). There are many such potentials across the community. 
Interorganizational leadership is a precursor of curricular change. In 1988, the Association of California School Administrators developed a quarterly newsletter, TRACES, to broadly focus on this issue. "The goal of TRACES is to get readers thinking beyond today's busy schedule and immediate problems, to encourage leaders to brainstorm and anticipate ways that what's going on in our society now may bring a whole new function into our existing realm of responsibility" ("ACSA Expands," 1988, pp. 1-2).

Given this perspective, studies of curricular change based upon internal school programs are all putting the horse before the cart. No valid, planned social change can occur in an isolated organization. And so, curricular change alone has failed in crisis proportions. Follow-up studies of the 1983 and 1984 reform reports are already finding this out ("AACD Helps," 1987). "If the purpose of education is to prepare students for effective and responsible citizenship," stated Lamy, "the content of what we teach must reflect the transformations which have created a complex, interconnected world in which cultures collide every minute and dependencies limit the flexibility of individuals and nationstates" $(1987$, p. 37). Schools do not change because curricula change. Curricula change because cultures change, firstly, and secondly because schools and societies change in their interrelationships. New relationships result in new, broader values, and these are eventually reflected in curricula. Reaching these values often requires the "confrontation and attempted reconciliation of conflicting value orientations" (Benne, 1984, p. 471). Norms in a democratic society, stated Benne, are shaped through "a moral process [between] all the publics affected by [a] resolution" (p. 478). Partnerships between schools and their communities are a tool in sewing up the lag in time and effort between social change and the subsequent curricular change. 
Local school communities are not at the opposite side of a spectrum from the global community, they are the substance of it. As the school subscribes to increasingly universal, global values its conflicts must approach resolution.

\section{Moral Change}

Wynne has looked at the change issue as a question of morals. Considering the "diverse cultural systems" (1985/86, p. 5) we live in, he questioned whether curricular change or internal school management "are adequate remedies for our current school problems" (p. 4). It is "common 'moral values,' he stated, that "are the vital common beliefs that shape human relations on the larger, cultural level" (p. 5). Burns linked cultural and moral change to leadership, stating:

Leaders and followers are "locked into relationships" that are closely influenced by particular local, parochial, regional, and cultural forces. In the progression of both leaders and followers through stages of needs, values, and morality, leaders find a broadening and deepening base from which they can reach out to widening social collectivities to establish and embrace "higher" values and principles. (1978, p. 429)

He added, "Leaders must offer moral leadership. Both leaders and followers are drawn into the shaping of purpose" (p. 452). "In the enmeshing of goals and values both leaders and followers are raised to more principled levels of judgment" (p. 455).

Neither morals nor intellect are created or developed primarily by schools, and this truth represents a fundamental, wasteful mistake made by educational theorists and administrators through the sixties and much of the seventies. This has been the crisis implied but not identified by many of the more than thirty 
nationwide reform reports in the early eighties. Moral and intellectual values are created by society, and the effective schools can only increase their integration in the surrounding culture in order to transmit and, perhaps, lead in the shaping of these values.

Universals are difficult to find. The search for a moral periphery has no end. All the same, two goals are compatible with this search: system transformation wherein values are sought in an ever widening environment and, beyond this, acceptance of ambiguity. As soon as one surrounds his/her moral system by the values of a closed environment, a barrier has been created, beyond which moral dilemmas cannot be resolved (Alderfer, 1984; Burns, 1978). The unconscious barrier, which often takes form in racism, is the moral equivalent of war, is the most formidable requirement of change, and is the most difficult barrier to see (Alderfer). To visualize this barrier and what lies beyond it, to confront value conflicts and from them synthesize higher, shared values, is to approach the universals of culture.

To produce fundamental curricular change, school leaders become active participants in the shaping of far reaching, relevant values. The school is a reflection of its surrounding culture and until schools offer cultural leadership, they risk being surrounded by conflict. Curricular change is not the answer unless the process of curriculum development integrates the shared values of a multicultural community and world.

Optimists and a handful of innovative schools leaders are attempting to demonstrate that the creation of new partnerships will not pose another demand upon our already overburdened schools. The National Council on Foreign Language and International Studies stated: "[a few] innovative schools around the country have managed to integrate international studies and the teaching of 
foreign languages into their curricula at little cost and without sacrificing the transfer of traditional skills" ("Want to Internationalize," 1987, p. 1).

The Constitutional Rights Foundation's Youth Community Service (YCS) and Youth Leadership for Action projects are exemplary projects designed to put the school in the lead in building community awareness (Annual Report, 1987). The National Association for Foreign Student Affairs' Community Strengthening Grant program could also help do this, while focussing on the international dimensions of the community (Sharareh Durabmia, personal communication, April, 1988).

Technology and advances in efficient use of community resources will free site level educators up from some time consuming tasks (Cetron, 1985; Uhl, 1983). This freedom will enable teachers to focus on accelerating student progress in skill work, give schools and their diverse communities a common bond and, ultimately, place schools on the leading edge, not the mercy, of social change.

\section{The National Arena}

The United States local educational systems have failed to internationalize. Local educators often become preoccupied with local political issues such as busing or mainstreaming. Parallel problems also exist at the national level. First, persistent isolationist traditions have interfered with opportunities to participate in multilateral educational advances. Second, the result of an equally long standing tradition of decentralization of educational systems is that federal and local interests in internationalism have little in common. These traditions have led local and federal concepts of international education and culture to clash. 


\section{The Tradition of Isolationism}

As hard as the road to sharing in the local school community has been to travel, the road to sharing in a world system has been harder. The United States Department of Education and the business community have grown increasingly dissatisfied with the level of knowledge of foreign languages and foreign cultures exhibited by our people. The 1983 National Advisory Board on International Education Programs stated: "This should be a source of national embarrassment," calling it an area "critically in need of attention" (p. 3). These critical needs are the outcome of a long history.

In the early days of United States public education, the federal government and the education system had no clear, formal relationship. The United States Constitution does not even mention education. The "implied powers" doctrine left educational authority in the hands of the states; states in turn transferred educational responsibility to local districts which, they reasoned, could best serve the interests of their own communities. Local educators interpreted this transference as a sanction to their own, expert autonomy. Education was viewed as a specialized, local concern.

The first overseas educational involvement was created by an Act of Congress in 1866, which established Department of Defense schools. However, these schools were set up to "insure English language education whenever troops are serving at any post," and they were carefully dissociated from foreign cultures (Johns \& Morphet, 1983, p. 336). As of 1867 the Office of Education was established for the purposes of maintaining an "efficient school system and to promote the cause of education throughout the country" (Johns \& Morphet, 1983). It provided for a Commissioner of Education to report to Congress 
annually. The Office was downgraded the following year to a Bureau of Education (Johns \& Morphet, 1983). In the international arena, the Bureau provided for army, navy and marine schools.

For the next half century, until after World War I, there was very little activity by the federal government in the area of education, and certainly none in the area of international education. However, in the aftermath of World War I, domestic education became more open to foreign influence.

In 1920 the United States Congress rejected Woodrow Wilson's efforts to join in a League of Nations. Despite this rejection, telecommunications, rapid transportation, and the ever more pressing need for global cooperation were connecting the world. The doctrine of isolationism was adapting to the twentieth century. Wilson's commitment to global cooperation made him perhaps the first inspiration to the cause of international education in the United States.

It would take a second war to convince the United States that it was being woven into an international community. During the war, the need of the United States government to "obtain and absorb complex geopolitical information" was immediate (Cline, 1981, pp. 23-25). United States policymakers acknowledged that national interests could only be protected by involvement in the international arena. Educational policy making kept in step. It followed that international education was considered a matter of foreign affairs, to be controlled by the Departments of State and Defense and not local districts or a centralized education authority. During the war, a separate United States Department of Education was still about 40 years away.

In 1946 PL 584 of the 79th Congress created the United States National Commission for United Nations Educational, Scientific and Cultural Organization (UNESCO) (United States Advisory Commission on Public Diplomacy, 1985 Report, 1985). Soon after, widespread educational exchanges were begun, 
always under the auspices of our foreign policy apparatus. This marked the beginning of the United States' involvement in worldwide international education movements.

Two years later, in 1948, the "United States Information and Educational Exchange Act" (1948) became law, creating the USIA. Its objectives were "to enable the government of the United States to promote a better understanding of the United States in other countries and to insure mutual understanding between the people of the United States and the people of other countries." It provided for information services, exchanges of students, teachers, scholars, technicians, and interchange in the fields of art, education, and science. It also emphasized participation in the United Nations (1948). Significantly, the USIA is a branch of the State Department, not the Department of Education.

Although this Act did not supersede any other laws or policies, it still was a clear step forward. But the fact that this was coded as "Foreign Relations and Intercourse" law, not education law, suggests that as of 1948 the United States viewed international education as a matter of national security and diplomatic strategy. The United Nations' conceptualization of a world community was not relevant. Indeed, this law had the same Constitutional justification as all federal educational acts. Article I, Section 8 of the United States Constitution reads simply that the Congress shall have the power "to provide for the common defense and general welfare of the United States" (La Morte, 1982, p. 381). The Act was a bargaining chip, whereby educational and cultural exchanges would only be permitted when there was a reciprocal action taken in other countries. Reciprocal actions mostly meant trade agreements. Into the Cold War years, through the 1950s and early 1960s, internationalism remained a matter for State Department officials to pursue. 
The Information and Educational Exchange Act, at least those aspects pertaining to education, was repealed in 1961 and superseded by the "Mutual Educational and Cultural Exchange Act." The new law read as though it were written more for the promotion of global education and international culture, and less as a reflection of the United States defense interests abroad. Understandably the law was, and still is, limited to exchange and interchange with friendly governments, again mostly trading partners. The Congressional Statement of Purpose of this chapter demonstrates this view:

The purpose of this chapter is to enable the Government of the United States to increase mutual understanding between the people of the United States and the people of other countries by means of educational and cultural exchange; to strengthen the ties which unite us with other nations by demonstrating the educational and cultural interests, developments, and achievements of the people of the United States and other nations, and the contributions being made toward a peaceful and more fruitful life for people throughout the world; to promote international cooperation for educational and cultural advancement; and thus to assist in the development of friendly, sympathetic, and peaceful relations between the United States and the other countries of the world. (United States Mutual Educational and Cultural Exchange Act, 1961, p. 1) More than in the past, federal lawmakers attempted to express universally acceptable educational principles. But with the Cuban missile crisis and the Cold War in the backdrop, this wording seems idealistic. In fact, this statement of purpose veiled practical objectives such as the development of military bases and trade relationships, which emerged later in the statute.

In 1968 the United States Congress amended the United States Education Code to include an "International Center for Scholars" as a part of the Nation's 
memorial to Woodrow Wilson (United States Advisory Commission on Public Diplomacy, 1985 Report, 1985). In this way, United States federal policy on international education sought to balance national security and defense needs on the right and the needs for global, intercultural cooperation on the left. We leaned well to the right.

\section{The History of Decentralized Educational System}

During the 1960s, this balance became increasingly precarious, altering the traditional federal policy of decentralization. Local districts were struggling to cope with increasing cultural and ethnic diversity and, for the first time, federal policy making focussed hard on the local district.

Starting in the 1920s, eastern Europeans and Asians had begun entering United States communities in significant numbers. By the 1960s, their demands began to resonate in local school board rooms and national political arenas. The myth of the politically aloof, white, Anglo-Saxon school board was becoming anachronistic. A new form of international education was developing, and it all took place inside the national borders.

Meanwhile, overseas, by the 1960s, the Soviet Union was showing the world how education could be used as an instrument of national power. A group of educators for survival saw the Russian educational system and its national multiyear plans as a threat to United States national security. Hence, after its reluctant but ambitious beginnings, the tide went out on the international education developments of the post-World War Two era. Coping with internal diversity superseded seeking out commonalities as the fundamental goal of international education. The United States needed to get its little red 
schoolhouse in order. The Russians were coming, and this was no time for cooperative world education.

Tradition dictated a centralized policy on international education at the federal level and decentralized, unrelated district policies on the local level. Now these two levels had to deal with the common problem of multicultural discord and, unfortunately, they were not coordinated. Indeed, the two were often at odds. The federal government mandated integration and the local districts, sometimes forcibly, had to comply. For example, the 1954 Supreme Court case of Brown v. Board of Education, 347 U.S. 483, had attempted to eliminate the doctrine of "separate but equal" education (La Morte, 1982). This began a series of judicial branch mandates which, through the 1960s, undercut traditional local autonomy. Neither the federal government nor the local community undersiood the conflicts of the 1960s as an opportunity to seek cooperative, broadly shared values. Neither the federal government nor the school board could transcend their parallel legacies of self-interest.

Immigrants arriving earlier in the century had changed America's ethnic make-up, and accommodating this change became a progressively difficult and sometimes painful process for the schools. As a part of the "Great Society" program of President Lyndon Johnson, a drive to educate those groups in society most often passed over by the educational system was inaugurated in the mid 1960s. Johnson voiced the goal to "bring better education to millions of disadvantaged youth who need it most" (Husen, \& Postlethwaite, p. 1434).

Despite a heightened commitment to the education of diverse and unequal ethnicities, the Elementary and Secondary Education Act of 1965 contained no reference to internationalism; nor do any of its subsequent amendments. School districts were attempting to blend and to integrate cultures, not diversify or internationalize them. The Higher Education Act of 
1965 included titles on community service, library assistance, assistance for developing colleges, student assistance, teacher programs, financial aide, but nothing related to internationalism. By 1967-68 the funding for international education began to dwindle because the Congress was interested in something else (Hansen, 1988). The ensuing period brought legislation on a brand of international education which seemed confined to educating groups such as migratory farm worker children and children in American territories such as Puerto Rico and the South Pacific. Likewise, eastern European and Asian immigrants tended to form pockets of poverty in urban and rural areas, and their schools obtained federal assistance. By 1976, The Indochina Refugee Children Assistance Act had been passed, providing educational assistance to these children. A substantial amount of legislation was also enacted to provide native American Indians with various school facilities and educational opportunities. All of these statutes reflect how the United States began to deal with internationalism from within. Multicultural education came of age, and began to compete for the name international education.

By the late 1970s, following a flurry of over twelve years of federal activity in multicultural education, public laws amending the Elementary and Secondary Act of 1965, the Higher Education Act of 1965 and the International Education Act of 1966 (which was concerned with higher education only) were great in number and in need of consolidation and updating. In 1978, sixty one organizations and governmental bodies were invited to submit recommendations for the organization of new educational codes (National Advisory Board on International Education, 1983). By 1980, an extensive reorganization effort was under way in Congress to formulate a new set of statutes dealing with international education. After 35 hearings the Congressional Committee found that: 
1. Knowledge of other countries is important in promoting mutual understanding and cooperation between nations.

2. Strong American educational resources are a necessary base for strengthening our relations with other countries.

3. Present and future generations of Americans should be given the opportunity to develop to the fullest extent possible their intellectual capacities in all areas of knowledge pertaining to other counties, peoples and cultures; and

4. The economy of the United States and the long range security of the Nation are dependent upon acquiring such knowledge (National Advisory Board on International Education, 1983).

Based upon the Committee's findings, a new higher education policy was forged. This Act was called the Educational Amendments of 1980, and it included a new International Education Act. The 1980 amendments included three parts regarding international education:

A. International and foreign language studies (Title VI of the Education Code),

B. Business and international education programs, and

C. Creation of an Advisory Board.

The first part dealt primarily with foreign language study. The second and third parts are called "Subchapter VI, International Education Programs" and are coded collectively as the International Education Act of 1980 (1980a; 1980b). This was the heart of federal policy on international education in the 1980s (Grauer, 1986).

The Advisory Board on International Education Programs would consist of two subcommittees, one for each of the first two objectives. It would meet four times yearly in order to review existing programs and to recommend critical areas for legislation and innovation. 
Unfortunately, this Act left two important areas of confusion. First, the four findings of the Congressional committee set forth above did not remain equal partners at law making time. It became clear that the first three would serve largely to lead up to the priority item, the fourth. Second, the model was distinct from multicultural education, which many local districts had arduously and sometimes reluctantly learned was the whole point of international education.

In summary, after over a century of stagnation, massive legislative efforts in the 1960 s and 70 s radically altered the federal government's relationship with local schools. Through this process, local districts began developing a conception of multicultural education. Federal programs changed from mandates to financial incentives as districts embraced the new conception.

In addition, the federal government at the start of the eighties renewed its conception of international education as a matter of national security interests, a conception that was now around 15 years stagnant. No federal incentives for local districts existed in this area, and local districts could not change emphasis so readily. There existed no local parallel to the federal policy of international selfinterest, with the possible exception of the myth of the isolated, politics free school board. By the 1980s school-community relationships were marred by the confusion of multicultural education with international education.

\section{Federal Education Policy in the 1980s}

The three education acts of the 1960s had been amended frequently over the years; yet the Educational Amendments of 1980 were the clearest international initiatives to date. Predating the landmark A Nation at Risk report (National Commission on Excellence in Education, 1983), the Congressional Committee which authored the amendments stated: 
The economic welfare and long range security of the United States are dependent upon acquiring knowledge of foreign areas and languages. The Committee wishes to emphasize the interdependent nature of the world's economy and the vulnerability of the United States if it does not become more aware of the cultures and languages of other countries. (International Education Act, 1980b)

Despite the fashionable emphasis on interdependence, this Act was hardly prototypical and not much more than a new wording of the twenty year old Mutual Educational and Cultural Exchange Act of 1961. The Act portrayed international education almost strictly as a matter of economics and national security and there was no place for it in the local community. It was not really global interdependence that the International Education Act addressed, despite the fact that the term was used. A review of this Act bears this out.

A total of $\$ 100$ million was given for the implementation of the International Education Act for the year 1981, increasing by $\$ 5$ million per year until the October, 1985 expiration. (By comparison, the pursuit of equal opportunity in United States education, which is a wholly internal national goal, generally had been receiving about fifty times the funding of international education). A small but innovative part of the International Education Act appropriated $\$ 7.5$ million per year, from 1981 to 1985 , for what was termed internationalization of the curriculum. This phrase sounds open-ended and discretionary but it is not. Its purpose was to upgrade international skills, training programs and "export education" for the business community, and also to increase public awareness of the internationalization of our economy.

Federal programs continued to emphasize national goals and not globally shared goals. In 1981, as export education was getting funded, the United States Department of Education's International Understanding Program was eliminated 
from the federal budget, and other federal sources reduced their financial support for precollegiate international education projects. "There were over 100 elementary and secondary projects in 1981. Only a handful survived until the end of 1982, and most were dramatically reduced in size" (Smith, 1988, p. 9).

Decentralization and the Reorganization of Local School Funding. The tradition of decentralization of federal educational policy, after its haitus in the 1960s and 1970s, was revitalized in the 1980s. In 1983 the National Advisory Board on International Education Programs (which had been created by the 1980 International Education Act) reported: "There are in this country hundreds of thousands of people with overseas experience and competence in foreign languages: former Peace Corps volunteers, business executives, diplomats and military personnel" (1983, p. 4). The board asserted that our "internationallyminded" communities had never taken notice of these experts (p. 4).

Despite such espoused interest, by the mid 1980s the federal retreat from the local community was well underway. A fundamental principal of the new, Reagan view of education was to deemphasize the federal role in the schools in favor of the roles of businesses, states and communities. After their foray into community ethnic conflicts of the 1960s and 1970s, the federal government remembered decentralization. In 1984, the United States Congress proposed recognizing "the necessity of enhancing the level of citizen interest ... through provision of Federal aid to carry out flexible programs to meet local needs" (House of Representatives, 1984, pp. 1-2). These flexible programs are nowhere to be found in education code and are known as the American Defense Education Act, an act updated from its original 1958, post-Sputnik form (Hansen, 1988). In 1986 the United States Senate addressed "critical national education concerns, as delineated in a number of recent reports on educational quality" and concluded that "no single national solution will resolve the problems confronting education. 
Rather, they can only be resolved when there is a commitment to address and resolve them where they exist--at the local level" (United States Senate Committee on Labor and Human Resources, 1986). Thus, despite the ambitious beginnings made by the International Education Act of 1980, the tradition of decentralization was strong again. Local education, even in its international dimensions, would have to be left up to local experts. Through the 1980s, assisting them became a business of America. The federal government saw its role as encouraging these partnerships to develop.

The [Senate] Committee believes that the growth of foreign language and international studies at the elementary and secondary level is clearly in the national interest. The Committee wishes these nascent programs to be developed and encourages the development of a strong partnership for outreach. (United States Senate Committee on Labor and Human Resources, 1980, p. 65)

This "good-bye and good luck" statement represented the transference of the fundamental responsibility for international education held by the federal government to the nation's businesses and, in some cases, universities. This move towards business and private support for local education has spawned considerable academic research in professional organizations and universities. Deemphasis of federal initiatives in international education, expressed in reduced funding, was a clear message by the Reagan administration that businesses, states and communities were the stakeholders, and that they would have to pick up the slack.

Non-federal, national organizations responded. For example, in January of 1988 the National Association of Secondary School Principals announced the creation of "School Partnerships, International," a project to develop long-term relationships between secondary schools in the United States and more than ten 
other nations. "As our world is shrinking it becomes increasingly important that high school students learn about all nations' people, cultures, economies and political systems," said Dunn, director of School Partnerships International ("NAASP Develops," 1988, p. 1).

Through the 1980s, school officials began pointing to the need for partnerships with the business community (National Association of Secondary School Principals, 1987). Public and elected officials began calling upon schools and local businesses "to work together to define expectations for graduates and define opportunities for students to learn in community settings" ("Outstanding Recommendations," 1984, p. 2). In his newsletter, Senator Alan Cranston of California wrote:

We need to encourage schools to form partnerships with businesses, private community organizations, institutions of higher education, museums, libraries and state and local governments. Students need to know first-hand about the opportunities that await them. And businesses and other employers need to know about the talent in their local schools. (Cranston, 1987, p. 1)

The courts played a role in further decentralizing education. The bellwether Serrano v. Priest decision in California, 1971 had altered conceptions of school funding. By virtually eliminating property taxes as a funding source for local education, the Serrano decision sent many districts scurrying for new sources of funds. Since the federal government was decreasing funding at the same time, pressure grew for an increase of supposedly more democratic state funding (La Morte, 1982). But state funding was not enough, and a new movement began. Nationwide, as a result of Serrano and a series of subsequent court decisions nationwide, the trend has been towards the decrease local school funding. Schools now seek funding through a bountiful array of private 
foundations. Examples are very easy to come by, and a typical one is the San Francisco Education Fund (SFEF), "started in 1976 to raise money and provide grants to teachers and principals for specific projects. This particular foundation is an independent entity that disperses funds directly to educators, apart from school boards."

By the late 1980s, a great many of the international education endeavors in the United States were being sponsored by corporations, notably the Danforth, Ford, Rockefeller, Hewlett and Exxon Education foundations, along with many smaller foundations (Smith, 1988).

Education for Economic Security. The most significant follow-up to the International Education Act came in the form of a 1984 law, which captured the traditional spirit of federal policy on international education. It was called the Education for Economic Security Act. Its premise was that learning is critical to national security, economic security, and scientific needs.

Congress appropriated $\$ 100$ million to the Department of Education to carry out the act. It was perhaps the clearest confirmation that education would be viewed as a separate international policy arena for bargaining and negotiation, in the same way that commerce and foreign aid had historically been. The act called over 100 languages "critical in importance" after considering:

- The national security interest in diplomatic and military situations, or strategic geographic locations;

- The economic security interest of the United States in our economic ties with other nations; and

- Scientific inquiry and research which have significant world-wide or regional importance. (United States Department of Education, 1985a)

This was one of the first pieces of legislation introduced by the then new Secretary of Education, William J. Bennett, who had some interest in 
demonstrating that the Department of Education was unnecessary. It was not a humanities grant. For the link it formed with other United States international interests such as economic security, intelligence gathering, and controlled scientific research, this act ranked as one of the most significant, archetypical international educational developments in United States history.

The priority languages specified in the act were: Arabic, Bahasa Indonesian, Chinese, Czech, Hausa, Hindi, Japanese, Korean, Polish, Portuguese, Russian, Swahili, and Urdu (United States Department of Education, 1985a). The federal government determined that these were the languages of our most promising outposts of trade and military defense. International competitiveness became the buzz word around the Pentagon and Capitol Hill. In step, the Department of Education created the International Research and Studies Program, which gave its first grants in 1982 . In 1985 the program gave away $\$ 1.5$ million. The objective of the program was to develop area and language studies and the purpose was, again, international competitiveness (Department of Education, 1985b).

To nobody's surprise, from 1980 on the number of bills and amendments dealing with languages and international competitiveness increased each year for seven years running (Edwards, 1987, p. 40-43). Reorganization of Title II of the Education for Economic Security Act took place in 1987, a year when over fifty pieces of legislation in the area of international education were considered by Congress. The funding was extended through 1993. A singular addition to this legislation was the establishment of the Star Schools Program, which authorized $\$ 100$ million for the creation of an educational telecommunication network which could be used by teachers everywhere (Draper, 1987-88, p. 3). Telecommunications was viewed as an area essential to future business needs. 
A variety of other United States organizations, federal, local and private were reoriented according to the economic security paradigm. The largest such agency playing in the international education arena has been the United States Information Agency. The USIA maintained 205 posts in 176 countries in 1986. This was up from 133 posts only eleven years earlier. Although it was founded in the post-World War II period, it was expanded, reorganized and put into its present form in 1982 in order to consolidate a variety of diplomatic, cultural and educational functions. Today it advises the President, the National Security Council, the departments of Defense, Commerce, and State, and other related agencies. It develops materials, many of them educational, and plans cultural and educational exchanges, grants and media events (U.S. Government Manual, 1984).

The USIA, using a variety of educational satellites, has taken American cultural values and security interests and attempted to implant them in countries all over the world. In 1986, Mitchell stated, "Education is in reality one of the basic factors in international relations, quite as important as diplomacy and military power in its implications for war and peace" (p. 190). 1 Unfortunately this has also meant that, like diplomatic relations, educational exchanges, fellowships, grants, and specialized graduate and postgraduate educational initiatives have

\footnotetext{
'An example of this is the USIA's Fulbright program of international scholarly exchange. This program was stepped up in the 1980 s since, according to the USIA, international training represented a valuable resource for bilateral relations in students' later careers. In 1985, the USIA concluded that the United States educational system was in critical condition in this sense. Under their auspices, the United States Commission on Public Diplomacy claimed that a huge increase in funding for student and scholarly exchanges was occurring (United States Advisory Commission on Public Diplomacy, 1985 Report, 1985, p. 39). In fact, public communications of these opportunities increased far more than the actual number of exchanges (President's International Youth Exchange Initiative, 1984).
} 
traditionally been either short term or specialized, and remote from the American population (Husen \& Postlethwaite, 1985).

To summarize, although observers have been critical of the politicization of education in the United States at least since the 1940s (Husen \& Postlethwaite, 1985), never has United States education so clearly and intentionally been placed in the arena of international politics as it has by the Reagan administration. Today, a review of grants and current agency activities bears out this point easily, and the word is out: if you want federal money, ask for it in the name of national security. Education has become global business. Beyond arms and monetary aid, today's world leaders perceive that one of the key ways to protect and promote security interests is through worldwide control of information and learning.

The integration of education with economic development has almost always been a fundamental federal educational goal (Scanlon, 1960, pp. 178182); however, global perspectives and proactive leadership in a small, interdependent world would mean that the goal of economic development would extend beyond national borders, beyond national self-interest. Perhaps the spirit of competition will inadvertently lead to the pursuit of cooperation. The Star Program and school partnerships with multinational corporations would exemplify this pursuit. But self-interest, not cooperation, has been the goal.

Perhaps also if the Department of Education was more than a subservient follower of Department of Defense and Department of State programming in international education, international education policy could reflect a more shared vision. Today, federal isolationism, decentralized schools, and politically and culturally conflictual school communities have prevented the United States' educational effort from being unified and globally responsive on the national and local levels. 


\section{The Global Arena}

There are serious cultural barriers in the way of understanding the educational needs of other cultures, but global educators seek cross-cultural commonalities.

Last year I asked a visiting Ghanaian school administrator what we should do to acquaint our children with the outside world. She laughed out loud. "In America you have a unique problem," she said. "Our problem is the opposite of yours: Ghanaian children spend too much time watching old American movies and television shows, and it's hard to get them to focus on the future of Africa." I thought for a moment. "Then we do have the same problems after all," I replied. "Our children also spend too much time watching old American movies and television shows, and it's equally hard to get them to focus on the future of Africa." (Cleveland, 1980, p. 7)

The perception of cultural barriers exists in every school community. Often these are small scale reflections of worldwide barriers. In finding common international education goals at the organizational, community, federal and business levels, it is useful to examine the international education movement in the global organizational arena. This can help in locating cultural universals and communalities which can be applied at all levels, starting at the community level where United States education is most directly shaped.

\section{International Initiatives in International Education}

As in the community and national arenas, conceptions of international education vary widely in the global arena. 
After the Second World War, the combined effect of increased international trade, travel and the independence of colonies resulted in an increasing need for internationalism in local educational systems worldwide. Systematic efforts were begun in order to make education an instrument of international understanding and "to devise curricula and programs that would enable young people to study and work in other countries," as many would need to do (Husen \& Postlethwaite, 1985, p. 2,660). Likewise, international organizations such as UNESCO began creating wide-ranging initiatives towards strengthening the networks of international education. As was demonstrated in their Associated Schools Project in Education for International Understanding, UNESCO exemplifies an organization which has produced resources of powerful moral and political influence. Muller, Secretary for the United States Economic and Social Council, wrote:

There is an urgent need for global education. This is very important for the future of mankind. How can our children go to school and learn so much detail about the past, the geography and the administration of their country and so little about the world, its global problems, its interdependencies, its future, and its international institutions? . . Global education must prepare our children for the coming of an interdependent, safe, prosperous, friendly, and happy world. . . . The great period of human fulfillment on planet Earth is beginning only now. (McKiddy, 1986/87, p. 3-4)

There have developed a variety of international sources providing information in this area, through both periodical publications and computerbased information systems. These organizations include the Centre for Educational Research and Innovation (CERI), the International Bureau of Education, the European Documentation and Information System for Education (EUDISED), and 
many more (Husen and Postlethwaite, 1985, p. 2,669). Although there is no research on this, it appears doubtful that these networks have ever been seen as useful by local educators in the United States.

However well intentioned efforts at global networking have been, intergovernmental organizations on international education have had shamefully little direct interface with local educational institutions. Faced with integrating enormous amounts of information, global education researchers typically resort to the analysis of large scale world systems. But comparisons of national text book distributions, teacher training programs and professional organization memberships reveal little about local community needs and values which exist across cultures. A smattering of global goals have been integrated into the curricula of some local districts in the United States, but these efforts are still new. Early efforts at goal setting have placed the global education movement into the realm of philosophy, not action. These efforts have, however, been instrumental and inspirational in forging understandings as to the fundamental, universal objectives of international education: (1) to heighten awareness of global interdependence in order to create attitudes towards intercultural harmony and understanding and an orientation towards the future and, (2) to impart skills and competencies which will enable youths to function in international settings.

Despite their continuing remoteness to many United States school districts, global networks are tightening and philosophies on global education are being refined. This refinement should move the United States towards the development of a global community (Waterlow, 1980, p. 157). For many, the global community represents the future of education: "We can hope to form multi-dimensional people who, because they will think through the broader implications of the particular actions they advocate, will be able to tackle the increasingly complex world where each area is inextricably connected to others" 
(Small, 1980, p. 350). Philosophical movements in global perspectives are far sighted in reminding us that the future is always now, however much time we need to confront it.

Clobal education is in need of a great deal more analysis before it can have broadly shared and understood meaning. For example, many would agree that what is meant by global perspectives in education is "that at every level of schooling, every subject taught--science and history and geography and art and music and English and economics and sociology and citizenship, and most emphatically the 'basics' of reading, communication and computation--is an occasion for introducing young people to concepts that help them understand that the world is round and fragile and fully packed" (Cleveland, 1988, p. 8). At first glance this statement seems be hard to refute; however, such statements apply basically to the development of global curricula in United States education. Global education means more.

Some conceptions of global education go farther: "The . . . lesson is to value the differences among people--not just 'all men are brothers,' but the higher wisdom that all brothers are different" (Cleveland, 1988, p. 8). This concept is global, and it can be useful locally. For example, international cultural exchange and partnership with multinational corporations can be acted out locally.

Arthur C. Clarke envisioned a communications device that would transcend culture, class, religion and race. Eventually national boundaries would blur and isolationism would become extinct. Here is a global conception of education, although many would disagree with its goals. Through Rupert Murdock's "Sky Channel" or the United States "Armed Forces Radio and Satellite Network," organizations can be linked worldwide (Williams, 1988). American students and teachers mastering ham radio operation could share perspectives 
with Soviet Young Pioneers (P. DeCosse, personal communication, May, 1988). Technology has become closely associated with global education.

Ironically, the technological conceptions of global education are often those which are farthest from being useful. Here is another conception of global education: Walking three miles from home, no buses, to no more than two classrooms. The classroom is not overcrowded since only half the children can attend. Living in a largely illiterate community. Two thirds of these illiterates are women (UNICEF News, 1982, p. 14).

These global norms are hard to locate in the United States. A world cross section of education reveals a group of poorly dressed children of mixed ages learning two or three R's from tattered books. Their parents, at home working a small field, often resent the occasional literacy programs that come to their communities; they view them as foreign, externally imposed and unnecessary training. Real training starts as a small child, sealing the ends of bangles over a small kerosene flame, or scavenging in the streets. The lucky work over a rudimentary windmill and irrigation system. Then home, fingering dried seaweed or a piece of maize bread. In a world community, this would be a more accurate setting for global education. There would be no satellite dishes. As the world shrinks from tightening interconnectedness, developed nations with dramatic, hitech capabilities for the advancement of world education will increasingly share in the blame for these conditions.

In 1970, 269 million children were out of school compared with the 212 million attending. By 1985 the first figure rose to around 375 million, the second to 350 million (UNICEF News, 1982). Any truly global scenario of global education will have to be able to include these truths in one way or another, and it would be hard to conclude that even the most well meaning of United States children who collect change in orange UNICEF cartons every Halloween are 
experiencing much of a confrontation. The problem with locating a moral periphery is that there isn't one. It makes defining moral leadership difficult.

Some conceptions are truly global, but apply only to curriculum development. Guidance on leadership in the school community, where common intercultural interactions are taking place, is harder to come by.

All the philosophical progress in global education will not amount to action or leadership, though. Given the structure of today's thought, global education in a global arena presents many more opportunities than either curriculum developers or global idealists suggest. Thinking. on opportunities for actually practicing global education locally is only in its infant stages.

Thus, whatever resources a school official has in his/her efforts to link global values, they must serve radically varying cultural and economic conditions from one culture to another.

\section{Thinking Globally, Acting Locally}

Alger began his pioneering efforts in 1975 to obtain detailed views of the international contacts of local communities. He stressed that in our rapidly changing nation, research would need continual updating. Alger's work was a reaction to world systems analysis. The world systems metaphor, Alger found, reflected the "tendency for international relations research in the United States to be preoccupied with conflicts among a few powerful governments" $(1985, p$. 198) and with transnational production systems, as if they were all independent actors. This same phenomenon plagues local schools which historically have preferred to operate as separate from their surrounding, demanding communities. Though there has been little progress in linking world communities, there is promise. Alger, citing Kothari, noted "'grass-roots 
movements and not-party formations' springing 'from a deep stirring of consciousness and an intuitive awareness of a crisis that could conceivably be turned into a catalyst of new opportunities"' (1987, p. 18).

Alger described his research this way:

We collected information on international connections through business, agriculture, religion, travel, ethnic groups, the arts, students, research, voluntary organizations, the military, [banks, multinational corporations and insurance companies, science,] etc. So, I increasingly became aware how virtually all human settlements, even some very small, have extensive connections to humanity on all continents. (1982, p. 191)

"Most people in the world now live their lives in a sea of worldwide transactions," Alger contemplated. "At the same time, those who study local politics have for the most part failed to take note of the distant involvements of people and institutions who inhabit towns and cities" (1987, p. 1). And yet, Alger found, "The role of local communities in alternative future worlds has largely been ignored by futurists" (1985, p. 24). We do not say, "We must bring prominent international experts to our community who can help us overcome provincialism." Instead we say, "It is vital to identify and use the abundance of international expertise that already exists in our community" (1980b, p. 4).

This has been done through development of international events calendars, international visitors' handbooks, handbooks of international services and opportunities in the community, speakers' and consultants' services, curriculum development projects, and symposia. Conducting such projects in local elementary and secondary schools could mean not only a changed schoolcommunity relationship, but a changed school community.

In assessing local relations with the world, Alger suggested three questions to guide citizens: "(1) What do we [the school] get from the world?, (2) What do 
we give to the world? and (3) Are the two in balance?" (1982, p. 197). Despite his research from 1973 to 1987 , Alger concurred with other internationalists in noting "an absence of theory, and even penetrating descriptions, of how local communities are linked to the world" (1987, p. 21). Stated Sheth, this absence "can be satisfied only by a growing partnership between activists and intellectuals [in small communities] in the process of social transformation" (Alger, 1987, p. 22). If this is true, adding Alger's three questions to local needs assessments would be the greatest challenge for school officials and the first step towards transformational leadership in the school community.

"No nation has a separate future anymore" (Bell, 1984, p. 64). Leadership across cultural boundaries is rare today, but, as Bell's quote illustrates, there is a growing awareness of the need for it. Indeed, research on leadership and organizational change implies that there is no leadership unless cultural boundaries are crossed and wider communities of interest are created. Searching for patterns, a culturally universal movement in global education can be distilled from its traces in international, national and local arenas. The movement among international organizations towards defining a philosophy for global education can provide guidance in the search. By looking at all of these traces as parts of a common system and synthesizing them, it is possible to formulate a distinct model of cultural leadership applicable to all school communities.

The Four Faces of Internationalism in Education

"I know the answer is Woodrow Wilson, but that is just an empty fact in my mind ..." (Wilson, 1988, p. 4 ). Wilson was the first truly international President of the United States, the first President to emphasize the need for global, cooperative efforts. 
Seventy years after Wilson's death, this need is still unmet. As the above quote demonstrates, the needs of a society very often surface most clearly as problems with its educational systems. Problems and promises of American society, as well as shared global problems and promises, have led to various, distinct needs for internationalism in education. Global perspectives curriculum change has been used in an effort to prepare tomorrow's citizenry for a new world. Traditionally, inside the schools teachers and curriculum developers develop foreign language and social studies curricula. Multicultural education has attempted to integrate the continual influx of newcomers into American culture. Out in the local communities varied constituencies juggle the school boards and gerrymander the districts, while school officials attempt to answer the demands of these constituencies. All the while, the federal government sees education as just one more facet of national economic strength. International education for national economic security is the perspective applied by the Federal government and adhered to by the business world, and its intent is to help tomorrow's Americans compete better in the global marketplace. Many still adhere to one of these models; but, while globally shared problems accelerate, the global education movement often seems listless and without momentum these days. A more unified vision of global education is needed.

The application of these three well intentioned movements and their failure to complement one another has caused continued conflict in the schools. Through cultural leadership in the local community all three models could be eclipsed. The identification and continuance of the emergence of this new paradigm offer prospects for more leadership in global education. The new paradigm can be conceptualized as a synthesis of the three currently prevalent models. 
The following sections review typical initiatives made by proponents of each of the perspectives, and suggest ways in which each of these perspectives can be integrated with the principles of cultural leadership. These sections also review some of the most promising recent developments which have taken place towards integration.

\section{Global Perspectives in Curriculum}

To respond to the perceived needs of an increasingly pluralistic polity and an increasingly interconnected world, global perspectives have been integrated into school curricula. This need was perceived strongly in the late 1970s. Eastern studies became a popular secondary school curriculum addition. International relations courses multiplied on United States campuses. Global perspectives lessons supplied facts and developed awareness of world hunger, the law of the seas, the interdependence of global environmental systems, the Third World and shared global problems and promises.

By the early 1980s, a menu of complementary thinking skills needed for responsible participation in a global community were integrated into the scope and sequences of curricula in many states and districts. Separate courses featured the latest findings in mind and brain research, futuristics, moral decision making, conflict resolution, systems thinking, integrative thinking, lateral thinking, and guided imagery. Many curriculum specialists thought that left brain/right brain thinking skills were requisite for the coming, global age and the successors to the three R's as the basic skills (Grauer, 1983).

A basic assumption behind this model is that organizations need not work on the global or national levels to develop international resources. The job of the schools, this model has emphasized, is classroom education and this is where the 
school's role in cultural transmission is cast. American organizations such as Global Perspectives in Education and the University of Denver's Center for Teaching International Relations have been instrumental in establishing communications networks for teachers and curriculum developers working at the local level. Citizens Network for Foreign Affairs is a useful example of global perspectives curriculum development efforts, since it was inspired by federal initiatives in international education ("News and Notices," 1987, p. 13). The Alliance for Education in Global and International Studies (AEGIS) was formed in 1987 of 125 global and international studies organizations for the purpose of "working to improve the international dimensions of elementary and secondary education in this country" ("International Studies Organizations," 1987, p. 3).

Global perspectives curricula can have an impact outside of the classroom. Some elements of interorganizational sharing are drawn upon for integrating global perspectives into curricula. School districts across the country have begun contracting with community specialists such as private teaching partnerships, businesses, cable TV networks, libraries, museums, and colleges to obtain supplementary instructional activities ("Global Privatization," 1987, p. 39), as well as organizational resources. Stated Buchen, "Increasingly, educators are acknowledging the value of learning that takes place outside of the classroom" (1987, p. 23).

Locally, some school districts tap international curricular resources to integrate foreign culture into the school. Integrating global perspectives in the curriculum provides needed change, but it doesn't provide the communitywide leadership that schools need or the cultural leadership that the field of international education, as a field, needs. Futures oriented organizations can take the lead in developing internationalism beyond the classroom curriculum. These resources include speakers bureaus, school-universities partnerships, teacher 
education programs, cultural exchange organizations, intercultural counseling programs, and instructors from international businesses.

\section{Multicultural Education}

In one of the most unexpected findings of the 1970s, Grove (1982), demonstrated that the extreme difficulty many exchange students and scholars of the United States had was not in arriving in new countries, but upon returning home. If a global perspective existed in many countries, the United States was evidently not one of them. This failure was reflected, if not originated, in school communities across the United States.

Since the late 1970s, the United States has been in the midst of the largest influx of immigrants in its history. In 1980 alone, more people immigrated to the United States, legally and illegally, than in any previous single year (Brigs, 1984). Local communities became increasingly internationalized. In light of this, the need for a multicultural, international education moved steadily into the mainstream of community values, community education and subsequently, fundamental school goals. The assumption underlying these goals was that the school's job of cultural transmission could not be met in the classroom alone, and that the school, as a center of community culture, needed to respond to surrounding demands for social change.

These demands accelerated in the 1980s. By 1984, Southern California schools were serving 56 different language groups (Corcoran, 1984). Black, Hispanic and Asian segments of the population grew faster than any others in the 1980s, and by the year 2000 Caucasians will lose their majority status in California (Apker, 1984). Social changes in the United States have brought educational upheavals, expected and unexpected, and educators of the 1970s and 1980s 
have been pressed with the challenge of preparing the citizenry for a more pluralistic life outside of the school fence. As educators address this challenge with programs reflecting global values and integrating international resources, the possibilities for lasting change increase.

The Institute of International Education (IIE) reported that "the enrollment of foreign students in U.S. colleges and universities during 1986/87 academic year reached a new high" ("Record Enrollment," 1988, p. 4). Boyer detailed how, by the mid-1980s, minorities made up close to $30 \%$ of the nation's high school students, and the figures were rising steadily (1984, p.63). And while 79 percent of all white nineteen-year-olds in the nation finished high school in 1981, the figure was less than 60 percent for minority students (National Commission on Excellence in Education, 1983). Schools were being integrated more through busses than through ideas. University heads and trustees were widely urged to team up with school district officials in "seek[ing] qualified students of diverse racial and ethnic backgrounds" (Rhoads, 1984, p. 1). School-university partnerships may increase the likelihood of schools producing programs which reflect more widely shared values and making better use of available local resources.

In the 1980s the United States came of age as a global nation in numbers, but not in spirit. Schools responded to their wildly changing demographics through a variety of tools of the trade learned in the 1960s and 1970s: forced busing, gerrymandering, bilingual programs, drop-out prevention programs, multiethnic school site councils and advisory boards, mainstreaming, tracking, vocational education, adult education, public relations, prescriptive evaluation, and multiethnic counselling. These are the tools of multiethnic education, and despite the frequency with which they are used, still, the nation's population increasingly diversifies along racial, ethnic and cultural lines (Study Commission 
on Global Education, 1987, p. 1). To adequately address these demographic and cultural changes, education will need to continue to progress from operating within its traditional closed system, its mythical community, and to begin accepting the reality of the worldwide network within which it exists. In raising intergroup awareness, an enhanced global perspective will enable Americans to preserve rather than shed the layers and generations of their valuable ethnic heritage (Henderson, 1980).

Integrating global and multicultural perspectives in education is not easy in research or practice. Mallea and Shea (1979) attempted to define the scope of multiculturalism and Hoopes (1984) attempted to define the scope of international education. The definitions had in common cultural relations, bilingualism, English as a second language, minority education, ethnic relations and immigration. The definition of the field of multicultural education does not include conflict resolution studies and global perspectives, as definitions of international education do; but in practice, as in the above definition, this shortcoming is normal. By applying the basic tenets of community education in which the community takes an active role in the shaping of the educational mission, multicultural education would begin to look a great deal like international education (Davies \& Zerchykov, 1978).

There has been sporadic progress in integrating multiethnic and global educational goals. In an exemplary program, Santa Maria Elementary School District in California sent 26 district employees to Spanish language classes. The district.assistant superintendent stated, "We have the responsibility to be able io communicate in a pluralistic society" (Buchman, 1988, pp. 36). This adaptation reflects changing school goals. Santa Maria's superintendent, perhaps unwittingly, reworked this statement into one with a more practical but short sighted perspective: "Even if we don't come out of this class in May bilingual, at least we 
will be able to start and close a meeting in Spanish and that should go a long way" (p. 37). They may go a long way, yet these statements reflect a fundamental difference often found between local international education goals, and state and federal goals. Exemplary as Santa Maria's program was, its purposes were after all neither as global in nature nor as long term as those espoused by state and federal governments. They were, for the most part, local goals for strictly local and fairly short term needs. But multicultural education has at least brought progress towards linking the school more closely with its surrounding environment.

This multicultural face of global perspectives in education has spread into state goals and curricula. In response to its rapidly changing ethnic make-up and subsequent local action, the California State Board of Education announced its policy on multicultural education in 1978. It directed that, "The people of the community should be viewed as a resource for helping students to understand similarities and differences among individuals and groups" (Riles, 1978, p. A). Although multicultural education knits the school more closely with the community, and it is has been a powerful force in responding to nationwide needs for equality of opportunity, it is hardly involved with the development of global culture. Multiethnic education is a step towards global education, but it is still not global education.

\section{International Education for Economic Security}

Federal, Nationwide and State Initiatives. Federal and state initiatives in international education most characteristically emphasize (1) foreign language instruction, (2) foreign exchange and (3) business partnership as the primary objectives towards meeting national security needs for international education. The assumption behind this model is that the fundamental purpose of 
international education is to make the nation's economy stronger. Cultural transmission and community building are possible outcomes of the applications of this model, but they are normally viewed as incidental or dependent goals.

Foreign language study is an area receiving increasing attention as an avenue for change. Yet children in only one percent of elementary schools in the United States are taught a foreign language (Buchen, 1987, p. 2B). Wrote Oriven (1984), "The fact that we are embarrassingly behind every other country in our linguistic capabilities must be more widely publicized" (p. 54). Oriven reported that in Russia of the early 1980s there were more teachers of English than there were students of Russian in the United States. As a result of such findings, foreign language came to figure prominently in efforts for international educational goals of the 1980s, as espoused in Washington and by national educational organizations. The National Association of Elementary School Principals (NAESP) resolved in 1987 to support the teaching of foreign languages in the elementary school.

NAESP recognizes that today's students live in a nation characterized by ethnic and linguistic diversity--a diversity that is likely to continue and, perhaps, even increase in coming years. The growing economic interdependence of the United States and its trading partners requires that tomorrow's citizens be competitive in the world marketplace. The ability to express oneself in and to understand languages other than English contribute to success in that competition. (Rosenbusch \& Ames, p. 5)

The NAESP's statement is promising in that it wears the global perspectives in curriculum, the multicultural and the economic security faces of international education.

The federal government and United States multinational corporations are the foremost advocates of education for the promotion of United States 
economic security. "The theme of economic competitiveness will certainly govern decisions made by national policymakers through the rest of this decade and probably into the next century" (Edwards, 1987, p. 40). The federal Advisory Council on International Education announced, "Each day, we pay a political and economic price for our inability to understand and communicate with our global neighbors" (1986, p. 1).

Meanwhile, in concert with dominant federal decentralization policies of the 1980s, federal cuts in the budget for scholarly exchange have placed this change more into the hands of independent, private sector exchange organizations.

During the 1980s, more and more state governments acknowledged the economic security model of international education. In 1987, the Alliance for Education Act was introduced in California to establish partnership programs involving schools and the businesses and non-profit groups in their communities for the purpose of maintaining and improving "our ability to compete in world markets" (Cranston, 1987, p. 1). A report from the state governors at the National Governors' Association annual meeting in the summer of 1987 reads:

We must create a new national consensus that acknowledges today's economic realities and our global interdependence. Governors and other national leaders must begin thinking internationally--from the way we educate our children to the nature of the research we undertake, the type of products we develop, and the kind of public programs we enact. ("Nation's Governors," 1987, p. 2)

This is one of the few major national reports emphasizing the need for integration of national and local school goals in global education.

The 1985 California Model Curriculum Standards argued on its opening page, "First, if we are to stay competitive internationally, our economy requires a 
more sophisticated education for all students" (California State Department of Education, 1985, p. 1). Similarly, there have been scattered but remarkable changes in the policies of states across the United States (Edwards, 1987, p. 41). Thirty one states have instituted some form of language requirement. Sixteen states have reinstituted courses in world geography and world history (Edwards). In 1987 and 1988 alone, international divisions were established in the departments of education of Tennessee, Florida, Utah, and California ("State Delegations," 1987, p. 1).

Business Initiatives. American multinational corporations are aware of the stakes existing in a multinational nation within an interconnected world. The Study Commission on Global Education, funded by the Rockefeller, Ford and Exxon education foundations, found that America's next generation was woefully unprepared to understand or face global political, economic or military problems and it urged the adoption of a wide variety of new educational goals and programs. Unlike the recommendations typical of most earlier studies, this report emphasized curricular areas specific to elementary and secondary schools and not to higher education (Study Commission on Global Education, 1987, p. 1). This change in emphasis was only the beginning of the long term efforts that will be required to overcome a long history of emphasis on higher education and lack of emphasis on elementary and secondary education. Urging is not enough.

One of the single greatest educational outcomes of the federal focus on economic security has been the school-business partnership movement. Cetron has been a well spoken advocate of educational involvement with business.

In the crises of this century, we have allowed schools to be acted upon rather than to be one of the main actors. It is in the hands of our communities and our schools to answer the question of whether we will 
shape our own social and economic future or allow technology to lead us to new crises in 1990, 1995, and 2000. (Cetron, 1985, p. 126)

This urgent call for schools to be main actors highlights the existing dearth of leadership and collaboration. Schools of the future will be guided by continually changing forces. Isolation brought on the crisis that prompted the reform movement of the early 1980s ("AACD Helps Revive," 1987, p. 10). Schools cannot act alone. Opportunities for partnership, such as adopt-a-school plans, student apprenticeships in businesses, and resource sharing exist throughout the school community. School-business partnerships, for example, include:

1. Business representatives serving in school-community action groups

2. Adopt-a-school (or class) programs

3. Scholarships programs for students and teachers

4. Training programs for teachers and administrators

5. Materials and equipment sharing

6. Student apprenticeships

7. Local school administrator/business administrator planning sessions and task forces

8. Business use of school facilities for retraining employees for new jobs (e.g., operators of high-tech equipment)

9. Business experts going into the classroom, and

10. Planning for utilizing retirees in the educational process (adapted from Cetron, 1985).

Given the emerging pattern of school-community interaction, the first challenge for educational leaders is to intensify the interests of community groups in order to strengthen their competitiveness for funds and resources. A key dimension to this challenge will be to gain and sustain the power backing of organizations such as multinational corporations operating in the community. 
These organizations have a common interest in the welfare of specific minorities or international groups, as well as an interest in making international connections (Cetron, 1985; United States Senate Committee on Labor and Human Resources, 1980). Through school-business partnerships international education can be pursued for the purposes of national security, multiethnic education, and curriculum resource development.

Incentives for intracommunity and intercultural partnerships may spawn networks around the community and across the globe (Warner, 1987). Funding patterns will need examination to discover new ways of handling problems in resource acquisition. Creating community partnerships may generate income for schools as schools offer services to businesses in return. Cooperative ventures, diverse opportunities for school leaders to mobilize scarce resources, will also raise the stature of school leaders in government at the community level and challenge their financial creativity. Schools are finding that they have desirable resources to offer. Joint administrative planning, use of school language and computer labs, public communications, and community education programs offering human resources to the cooperating businesses are a few possibilities of resources that schools can offer. Given their potentials, these ventures call for relatively little school funding and require very little staff time outside of the classroom (Wurr, 1986/87). In the future community of education, communities and their businesses will favor school leaders who can provide high school graduates with the international skills they need.

There are a variety of areas where school-business sharing can have a large scale impact on curriculum. Training in future studies and global perspectives will be needed. The development of flexibility, goal setting techniques, and higher order thinking skills will reach a premium for students and school officials alike (Cetron, 1985). Public diplomacy skills will emerge, as they will be increasingly in 
demand by business firms and governmental agencies of the future (Graver, 1987; United States Advisory Commission on Public Diplomacy, 1985). Futuristics will increasingly be integrated into the curriculum and the budget alike, as communities change more rapidly both in their internal pluralism and their interrelatedness with the outside. The sculpting of change will challenge futurist educators and and business leaders to unite their roles (Amara, 1980; Grauer, 1986).

The chairman of the California Business Roundtable's education task force stated that the business community "can provide the incentives and guidance to assist students in meeting the increased demands" of an increasingly competitive, more technically oriented business community ("Business-School," 1988, p. 1). Agreements such as the California Compact, the Boston Compact, the California Peninsula Academies, and the Cleveland Initiative for Quality Education are viewed by their sponsoring agencies as tools for achieving long term school reform ("Business-School"). As the fate of businesses gradually becomes vested in international competence, school-business partnerships will take on an increasingly global perspective.

School business partnerships have their risks as well as their promises. In creating shared culture, schools will need to reciprocate and not simply be the fawning recipients of corporate good will. In order for these partnerships to work over the long term, businesses must receive their fair share from school-business partnerships.

Another potential problem is that private foundation funding can be structured as a contemporary adaptation to the politics of education myth, designed to obtain local community support for the schools which can "bypass the political process" (Thompson, 1983, pp. 394-395). As a Laguna Beach foundation director explained, "We give our fund's directly to the director's general fund and 
never specify what it should be used for. We purposely work [around] the elected officials" (Thompson, p. 394). Thus, the process of localization is often not as democratic as it sounds.

In an effort to cope with needs for privatized educational funding, many wealthy districts have gained the financial backing of their communities' resources such as libraries, youth foundations, chambers of commerce, and private patrons, creating veritable country clubs out of at least a handful of small, wealthy suburban school districts. Aside from the inequity of such situations, another problem here emerges when businesses view school-business partnership as a matter of public relations. Teachers are approached with promotional materials unknown to school officials. Curricular and economic security models of education are promoted, without integration into a shared cultural vision. Thus, the increasing pattern of school-community resource sharing alone is not enough to bring lasting, positive change which transcends public relations.

Some school, community, state, federal and business initiatives in global education do seem to address the need for integration of shared values and goals. But these visions really only began forming in the mid-1980s and they are heavily laden with deep traditions of isolationism and self-interest. They are still much more widely espoused than practiced. Historically, espoused theory has only suggested the possibility that change might come with continued emphasis and the refinement of practical application.

Local support of private education has always been necessary and, like private educators, public school officials may ultimately find that building new sources of support is the only realistic take charge approach (Finn \& Doyle, 198485; Fiske, 1985).

As the United States internationalizes, the consensus on school boards, in school governance, and in state and national policy arenas will change, requiring a 
global perspective of school, community and political leaders and the development of citizenship in a globally interconnected America (Bowman, Kierstead, \& Dede, 1980). As communities change faces, educational leaders will be required to unite new coalitions in understanding and provide the power and funding needed for sculpting community efforts and goals. And as local educators wish increasingly to network abroad, business may increasingly find it advantageous to pay their fares.

\section{Cultural Leadership}

Toffler (1980) warned of the need to synthesize the various social, technological and informational changes for a vision of the future. Given the three historically prevalent faces of international education, the challenge is to unify them. This requires the creation of a new, more encompassing model.

Although the first three faces of international education conflict in many ways, their elements of similarity can be integrated into the fourth, unified model. By structuring initiatives from any of the first three models so that they address broader, global education needs, the field can be unified. Change agents will have to check each program development against all four models. For example, foreign language expertise in the schools is a resource falling into all four categories, as is conflict resolution.

The new, global education model, cultural leadership, could operate inside the system as well as locally, nationally and globally. This open system is needed to help create a systemwide, cooperative and moral future in an increasingly interconnected world, where the problems of one will more directly affect the problems of all. Through cultural leadership, global educators could demonstrate that, although leadership has been believed possible from any of the 
first three perspectives, it is possible in the long run only insofar as any one perspective is conceived to encompass all of them.

The fundamental prerequisite for cultural leadership is a global perspective. This global challenge does not simply reflect a struggle for power and wealth, either within the community or within the global system. Separatism, driven by political sanctions, import and exchange controls and the special interests, is not consistent with the extensive international cooperation that will be needed to deal with impending, globally shared problems such as climatic disturbances, depleted ocean resources, pollution and star wars (Stewart, 1984). Thus, as American educational communities have internationalized, the nation's communities have just barely begun gearing up to meet the needs of an increasingly interdependent world.

A few proponents of international education have managed to integrate some of its myriad needs into single concepts. Sprosty challenged educators to generate an integrated concept in his statement, "We have to stop thinking that Western ideas are the only valid ideas" (Brooks, 1984, p. 14). Emerson combined multicultural education and national security education perspectives with his contention that deeply rooted parochialism undermines the nation's performance in international trade and impairs foreign policy strategies, adding, "the Americans of the next generation are going to be seriously disadvantaged if we don't take steps to address that gap in our education system" (Brooks, p. 16). A report released by the National Endowment for the Humanities emphasized that:

Self-knowledge requires that we understand other cultures. Daily life increasingly demands it. The world our children live and work in will seem even smaller than the one we know now. Its parts will be even more tightly linked by technology; its citizens, more interdependent. Due to the 
changing nature of our population, it is important that students understand not only their own heritage but also that of other Americans. ("NEH Releases Report," 1988, p. 3)

Despite being somewhat of an Irish stew, this statement manages to gather together all of the first three perspectives; at the same time, it glaringly omits the entire world outside of the United States. If the world is really growing smaller, how can we limit our understandings to only the heritage of other Americans?

There are intellectual problems preventing integrative thinking on global education. A common one is the indiscriminate use of the term international education for any number of uncomplementary agendas. Earlier, various arenas of educational change were introduced, concluding with the cultural leadership arena. Given the field of international education, all of these models are operating. This has led to confusion in both defining the field and developing programs to meet all of the four basic needs described above. As reviewed, each of the first three needs seems rooted in its own set of problems, assumptions and dreams. Various actors define their arenas differently, and only occasionally do they play in the same ball park. For this reason, in any school and at any governmental level, there may be people running in any of at least three different directions, all in the name of international education. Some of their work may be the same and some may be so different that their efforts can be mutually exclusive.

Lack of funding is another large obstacle in the way of global education. Local community groups and populations, federal and state governments and, increasingly, businesses fund schools, not the Third World or the United Nations. Yet Third World problems are rapidly spilling across national boundaries. The long term pay off of global education will have to increasingly be made attractive in the short term. 
There are sufficient resources within many local communities so that educational institutions need not rely solely upon textbooks and the chalk and talk of teachers to integrate international perspectives into their institutional goals (Amara, 1980). Examples of model programs are:

- Offering community service credit for students,

- Arranging classroom visitations by representatives of cultural organizations,

- Offering career programs and forming school-business partnerships which highlight the international dimensions of various careers,

- Promoting international administrator, teacher and student exchanges,

- Applying leading-edge technology to expand contacts with schools and organizations in other countries,

- Restructuring the school's scheduling or organization so that it encompasses a wider view of its role in the intercultural community,

- Working with locally branched global organizations such as Amnesty International, and

- Hosting international events (Alger, 1980a; Alger, 1980b; John J. Cogan, personal communication, September, 1987; Steven L. Lamy, personal communication, September, 1987; Paul Mulloy, personal communication, September 18, 1988; Robert B. Woyach, personal communication, February 25, 1988).

These activities may help schools stop studying international education and start doing it. Alger cited the work of many local groups, those which: (1) have declared themselves nuclear-free zones, (2) organized group visits to foreign points to meet officials and ordinary citizens, (3) campaigned for anti-apartheid legislation, (4) convinced banks, universities and corporations to change their foreign investment strategies, (5) provided homes for refugees, (6) served the poor 
through international charitable organizations, and (7) developed export and import markets. He noted that although each community is different, educators have a wide variety of ways to involve themselves and their students in "increasing local/global linkages" (1980b, p. 23). In the future, the potential advantages of creating global linkages could challenge the resourcefulness of local school officials.

Alderfer's work on group identities demonstrates that so long as shared resources are not integrated into organizational and social goals, individuals will fail to accept them into their own value systems. Change in thought requires this type of fundamental change in the organization of the school, its resources and its relationship patterns. By integrating international resources, patterns of teacher and student perception and behavior can be changed in concert with social changes (Alderfer, 1982).

Today, efforts to develop global education locally are applied sporadically to the curriculum, the structure of the school organization, the community or the international networks in which today's schools exist, and so each of these efforts risks being perceived as just another in the continual series of educational movements which come and go. Global education initiatives in literature and practice lack integration into a shared vision. If local educators agree on the tactics for enduring cultural leadership in global education, it is rarely documented.

Each response to educational needs, no matter how global in its perspective, can germinate at the local level. Past efforts to meet each of the four categories of need have been designed around change strategies which have met mostly short term needs. Attempts to integrate all of the needs into the emerging paradigm of global education represent the ultimate goal: a broadly unified field of needs and a clear strategy for enduring change. Cultural 
leadership can be the achievement of the synthesis that globally interconnected educational systems and more universal educational program goals promises.

The prospects of cultural leadership in global education fade rapidly if these needs are addressed as "a grab bag of unrelated and unconnected special projects and programs" (Smith, 1988, p. 9). Understanding of each is necessary in finding common threads and charting a common future. Schools can cultivate "an enriched sense of ... ethnicity" (Alderfer, 1982, p. 160). Enriching the whole field in unified theory and in practice will be the the greatest challenge to global educators as they plan for the next century (Smith, 1988).

Synthesis: Community Education, Leadership, and International Education

International education and community education are subject to substantial research today; however, the world in today's school community is clearly a world needing further research (Alger, 1980b). A search through the related literature through the 1980 s revealed only a few studies. Local educators share the need for international linkages with communities, businesses, government organizations, and other communities worldwide. What is needed in the literature and in practice is an understanding of the ways in which local educators can escape their confinement to curriculum development or multicultural education. Although the documentation about these ways is light and the efforts have been sporadic, an overture can be heard. A synthesis of international education and community education is at hand. This synthesis is perhaps at the heart of a new paradigm in the understanding of educational leadership. Whether it be Benne's "collective responsibility" (1985, p. 478), Schoen's "reflexive conversation" (1985b, p. 252), Burns's "encapsulated institutions" (1978, p. 421), Schein's "shared assumptions" (1985b, p. 51), Smith's "ecosystem" (1982, 
p. 366), Grabow and Heskin's "ecological ethic" (1982, p. 264), or Scully's "platform" (Goodman, 1987, p. 59), clearly there exists the opportunity for a new understanding of the role of leadership in the process of cultural transmission and evolution, interorganizational sharing and international linkages.

A consensus is needed to describe a new community of education which is tailored to a global perspective. The environment is undergoing a redefinition, synthesizing an emerging set of "fundamental wants and needs, aspirations and expectations, values and goals," and future leaders, as we are coming to envision them, may be both charged with and defined by the achievement of this synthesis (Burns, 1978, p. 420). 


\title{
CHAPTER III
}

\section{RESEARCH DESIGN AND METHODOLOGY}

\author{
Introduction
}

This research was designed to discover ways in which school officials demonstrate community leadership through the development of local international resources. Although this was the highest purpose, the researcher did not know whether leadership could be discovered, and a variety of underlying aims and objectives were also valued. The basic aims of the research were to identify the dynamic partnerships which school leaders create by using local international resources and to discover the emerging communities of interest in today's schools. The literature demonstrates that internationally oriented groups and individuals in the local school community representing business, culture and arts, media, nonprofit agencies, technology, psychology, in addition to traditional school constituencies (parents and other stakeholders) have current, emerging or potential roles as school resources.

"Researchers must match research methods with research questions," stated Marshall, and she added, "researchers who apply organization theory to schooling must expend energy searching and exploring and generating hypotheses" (1985, p. 353). The Delphi technique is not wholly qualitative or quantitative methodology, and it applies elements of both types of research. This technique has been successful in generating a consensus of ideas in a wide variety 
of contexts. For this reason, for its ability to reach more people than more qualitative research would have, and for its application in engaging experts in a process of restructuring perceptions of school community leadership and generating rich descriptions, the Delphi technique was used as the research method in this study. An effective Delphi study can enable the researcher and respondents to shape emergent beliefs based upon sharing of values.

In researching emergent social issues and synthesizing them into paradigms, wholly quantitative methodologies are confining. First, preformulated questions cannot apply in a trustworthy way in measuring innovative programs, where such questions could hardly avoid leading the respondents. Nor would quantitative research apply well where the research explores several theoretical perspectives. Thirdly, research seeking subjective, sometimes hidden understandings of respondents is best left to more qualitative research (Marshall, 1985).

Wholly qualitative data would also be burdensome in these conditions. Fewer respondents could be used, reducing the collective expertise. Odd perceptions which might be a part of underlying patterns would be considered random, and they could not have the benefit of the broader consideration of an expert panel.

Through the Delphi process new linkages can be explored and competing, cross-cultural perspectives can be extracted and then systematically coded. Through the process of continuing rounds, qualitative responses can be shaped into increasingly quantifiable data. The Delphi process can offer the best of both worlds. 
The Delphi Technique: Review of the Literature

\section{Historical Development of the Delphi Technique}

"Project Delphi" is the name for a research technique first invented in 1953 by Dalkey and Helmer for the Rand Corporation and aimed at developing consensus. The method is "characterized by the use of group processing of individual experts' opinions to arrive at potentially better predictions" (Loye, 1978, p. 46). The Delphi veritably exploded in popularity following Dalkey and Helmer's publication of the original Rand study in 1963 (Helmer, 1983). Originally, it was used as a method of surveying expert opinions regarding the prediction of future United States defense needs. The Delphi technique was thus rooted firmly in technological forecasting, and it was fairly confined to this through the 1960 s and early 1970 s (Linstone \& Turoff, 1975).

By the mid 1970s, however, the term Delphi had gained substantially in breadth and was applied to various forms of surveys which used successive rounds towards the reaching of consensus. The Delphi became recognized for its obvious advantages for social (non-technological) research. To start, its anonymity reduced traditional, single round surveying drawbacks such as the bandwagon effect, dominance, specious persuasion, and poorly considered alternatives (Amara, 1978; Cetron, 1969; Uhl, 1983). These drawbacks were common in committee decision making or face to face interviewing. The Delphi came to be viewed as a committee of experts, but free of the group dynamics problems committces usually face. Martino pointed out that anonymity prevented vocal members of committees from swaying the group, which in turn prevented the group from considering all factors of an issue. "Members feel fewer inhibitions about changing their minds," he found (1978, p. 391). 
The Delphi technique can be used whenever a consensus is desired among persons knowledgeable in a particular area. The purpose of the Delphi "is to make the best use of a group of experts in obtaining answers to questions requiring reliance, at least in part, on the informed intuitive opinions of specialists in the area of inquiry" (Helmer, 1983, p. 134). "It can be used to identify problems, define needs, establish priorities, and identify and evaluate solutions" (Borg \& Gall, 1983, p. 413). In this way, the Delphi began to grow from a specific tool of technology to a "family of methods" (Amara, 1978, p. 50). The family now contains a range of surveys from simple Likert-type scale instruments to openended, consensus building surveys which border on lengthy, written panel discussions.

Education is an area where "agreement is usually hindered by great divergences of opinion," calling for a planning technique "that can be used not only to help overcome such difficulties but also assist in arriving at collective decisions" (Uhl, 1983, p. 81). This makes the Delphi technique well tailored to educational surveying and planning. "Unfortunately," noted Uhl, "the better-known bibliographies on the Delphi method include very few applications to education" (p. 83). He found that most of these studies were located in the areas of curriculum planning and school goal formation. For example, in 1973, the New Jersey State Department of Education conducted a Delphi study to "explore cultural lag [and] demographic change" in order to design appropriate grades 9 through 12 curricular programs (Shane \& Weaver, 1978, pp. 711-712).

Through the 1970s, futures research spread as schools, often drawing upon scholars and consultants from local universities, used futures planning studies to connect changing social conditions with elementary and secondary curricula (Shane \& Weaver). In 1978, Helmer pointed out the particular suitability and importance of the Delphi technique to international developments and 
interactions as well as to education, generally due to the exploratory nature of this type of surveying. An interesting parallel trend was that during the 1970s future studies curricula infiltrated many elementary and secondary schools. Their mutual concerns with long term and global trends have always given future studies and global education a common bond. In contrast to this fact, short or medium term, local demographic changes have always been associated with educational programming in bilingualism and civics.

Uhl and other researchers have distinguished between Delphi studies used to reach final decisions, sometimes referred to as normative research, and those which use respondents "to generate and screen ideas and to bring significant ideas to the attention of the coordinator," sometimes called exploratory research $(1983$, p. 7). Although it can be used both ways, the Delphi technique has become one of the most common methods of exploratory forecasting (Martino, 1985). Delphi survey respondents, as well as those in their spheres of influence, may be engaged in generating ideas, making decisions and taking actions as a result of the process of participating.

An effort to test the validity of the Delphi technique was made by Dalkey. He assembled eight groups of about twenty each and gave short-range prediction questions. His finding was that "where answers can be checked against reality, it is found that the median response tends to move in the direction of the true answer" (Loye, 1978, p. 47). Dalkey's groups satisfactorily made 32 of 40 correct predictions where only one half of the predictions could be made by individuals. In another of Dalkey's experiments, a group with an average IQ of 120 was found to function in a Delphi survey at a 150 IQ (Loye, p. 47). By engaging respondents in a reflexive dialog, a Delphi survey can draw upon their foresight, persuasiveness and leadership in identifying and developing possible futures. 
Helmer criticized Delphi surveying for two basic reasons. 'First, he found that some respondents were not as motivated given the anonymity of the surveys, since there was no chance for public recognition. Second, he found that some of the Delphi surveys which he had run had posed questions which were too general, and that they "produced literary outpourings" which were not valuable enough in analysis (1983, p. 145). This second criticism is pertinent to the forecasting of technological futures. Richer description is useful, however, when dealing with societal issues and attitudes since these issues are not as quantifiable. It is also useful when the survey involves a relatively small sample population. For example, this study aimed to measure developments in what people do in their communities, but these activities are dependent upon developments in the ways they perceive those communities. If a Delphi survey is used as a model of committee decision making, as it often is, then the use of exposition seems more appropriate in identifying, if not facilitating, the emergence of a new way of seeing the school community.

\section{The Rounds of the Delphi Survey: The Pooling of Vision}

The Delphi technique can begin with the preparation and presentation of a scenario for evaluation. For example, respondents may be given the background and introduction of a scenario about opportunities for community resource development and asked to generate examples of how this scenario would unfold in real life. This scenario and the questions it raises are the results of a literature review and, sometimes, consultation with experts in the field.

Theorists have disagreed as to the extent of preformulation of the initial range of options given to respondents. Some researchers favor the use of closed form questions from the start. Others begin the Delphi process with wholly open- 
ended questions in the hope that respondents will generate ideas without the bias inherent in the researcher's choices (Billingsley, 1984; Uhl, 1983). In the open-ended process, closed form questions may be created in later rounds based upon responses from the first round. In either case, however, respondents may normally make additional, open-ended statements of their own which they believe are important considerations for the survey. Thus, a bank of examples is developed, reflecting expert responses to a given scenario or set of questions. This comprises the first of, customarily, three rounds of questionnaires.

An objective of the second and succeeding rounds is to provide feedback to respondents. Preceding rounds are analyzed. In the case of analyzing responses of closed form, more structured Delphi surveys, this process is quite straightforward. Descriptive statistics are developed and inserted in the second round survey for the respondents to see. In the case of analyzing open form surveys, closed form items are constructed from the first round responses and used in the second and subsequent round surveys. Respondents then react to an item pool which they themselves have generated.

There is little difference between the format of open-ended and closed form Delphi surveys after the first round. Once the researcher has received the round one responses, the overall group statistics for each item or question are calculated and then fed back to the respondents (Uhl, 1983). Key examples and comments made by respondents are also fed back. These key ideas are presented in the form of either a Delphi round summary or new survey items, so that the experts may increasingly respond to one another's opinions and stated actions. Respondents are asked to revise their answers after considering the newly emerged information that they receive with each new round. This enables them to be influenced by prevalent expert opinion based upon their pooled intuition and expertise. Through the rounds they may be asked to provide 
rationales for extreme or novel statements (relative to modal or median responses) deemed salient by the researcher. Needless to say, exploratory research must be particularly open minded to unexpected ideas. Some Delphi surveys include Likert-type rating scales, since they are considered accurate, reliable reflections of mutual attitudes held and developed through the rounds (Borg \& Gall, 1983). The bank of items may be added to and refined. Some researchers also indicate each individual's previous responses to items as a measure of reliability (presumably so they may resist being swayed by group opinions), although many researchers consider this extra work unnecessary since the survey's anonymity is believed to facilitate the honest changing of minds.

The result can be likened to an "anonymous debate," which improves upon traditional surveys in that respondents react to statements which the researcher could not have provided a priori (Borg \& Gall, 1983, p. 414).

A researcher's method of accurately summarizing and reflecting strong and prevalent expert opinions and of selecting exemplary comments are tested here. A consensus must emerge on its own, that is, without researcher bias. As implied above, when we compare today with tomorrow, or whenever we attempt to capture leadership in action, the accuracy of our results are only knowable in the future as the actions shape culture. Thus, Delphi studies of future or emergent trends are, like all perceptions, reality only insofar as they are agreed upon. In this way, the second and subsequent rounds are the key to a unique element of the Delphi technique: consensus building.

Consensus in a Delphi survey is considered to be stability of responses. This relates well to Guba's concept of "thick description" $(1985$, p. 119). Description is said to be thick where it can be shown that the intuition and knowledge of experts is held in common. Thick description is used as a method of achieving external reliability and validity. Similarly, reliability in Delphi surveying is achieved 
through consistency and stability of responses which emerges by the final round (Linstone, 1978). Stability of responses is achieved when there are "less than 15 percent marginal changes" from one round to the next on any item (Linstone, 1978, p. 296). It may also be practical to declare a final consensus on any item with the emergence of a majority (Tiedeman, 1985).

The results of the early Delphi surveys were normally expressed as a series of dates forecasting the emergence of specific trends. Delphi results have been presented in an increasing variety of forms to suit the growing uses of the technique. An interesting variation from the early way of summarizing Delphi results was applied in a study undertaken by the Smith, Kline \& French Laboratories. The study was conducted for the purpose of providing educators with a more vivid explanation of medical school education trends. Here, the consensus statements were combined into a scenario or profile. This scenario was a composite of the experiences which experts envisioned future medical students going through (Linstone, 1978, p. 273-300). This type of analysis emphasizes the researcher's ability to accurately synthesize diverse information into prose form, which is of course essential to the validity of the research findings. Eisner has called this process "structural corroboration," which is "a process of gathering data or information and using it to establish links that eventually create a whole that is supported by the bits of evidence that constitute it. Evidence is structurally corroborative when pieces of evidence validate each other, the story holds up, the pieces fit, it makes sense, the facts are consistent" $(1979$, p. 215). Delphi has become a tool for "group communication" (Linstone, p. 299), wherein the method may be "suited to the problem, not the problem to the method" ( $p$. 275). 


\section{Inventing the Future}

As Linstone has stated, our perception "is anchored in today's values and institutional settings. We 'see' them in terms of present (or recent) categories, organizations and cultures" $(1977$, p. 29). Thus, identification of future developments is a problem, one which Delphi researchers sometimes address.

The function of Delphi studies is the building of consensus. Opinions are mobilized through interactions in the rounds of surveying. D'Amour and Rittenberg referred to this process as "participation momentum" (1980, p. 414) or, an attempt "to generate participation in a spirit of respect, mutual trust, adaptation, and open cooperation" (p. 413). The Delphi technique places participants in a forum where changes may be planned in the later rounds as responses get recycled and consensus is closer at hand. As the group's perceptions as a whole gravitate towards the positions of single members, and as respondents make new discoveries motivated by transcendent or persuasive comments and viewpoints, ideas and plans emerge which would not have emerged outside of the Delphi study.

Delphi studies can result in changes in action as well as perceptions. This perspective was taken by D'Amour and Rittenberg in their studies of social planning. In attempting to involve various social groups in the planning process, they relied upon the Delphi technique, stating:

Each of these publics has a right and indeed the responsibility to participate in the research that is being done as part of a social change process. The objective of the project was not simply the accumulation of data, facts, and information for the eventual preparation of a report; but rather the initiation of action by the involvement of people from all segments of the 
community in what can best be described as an action research process. (1980, p. 413)

The success of professional exercises such as cooperation with research projects brings about mutual expectations for quality from researchers and research participants. At this point practice, research and learning begin to converge. "Survey feedback discussion may contribute to understanding by eliciting new information" (Alderfer \& Brown, 1975, p. 113). By identifying actual behaviors and reflections of respondents, and not just attitudes expressed, change just may occur as a result of the survey process (Argyris in Alderfer \& Brown, 1975). Further, "Even when the feedback is ineffective in changing behavior, that ineffectiveness in itself may elaborate or confirm the diagnosis" (Alderfer \& Brown, p. 114).

Today, many theorists believe that futures research is a change agent. It may create a self fulfilling prophesy. B. F. Skinner's prediction that teaching machines would enhance the effectiveness of teachers stimulated much research in this area, which in turn brought action: A 1964 Delphi study by Helmer and Gordon not only confirmed Skinner's prediction, it disseminated the information widely. It stimulated the involvement of a number of scientists and other experts (Cornish, 1977), and in this sense helped fulfill Skinner's prophesy. Today, the power of the classroom computer, although it is still largely untapped, is widely understood and increasingly spreading. Uhl also measured the effects of the Delphi process. After a one year follow-up study, Uhl reported that when the results of Delphi surveys are widely disseminated at the institutions of participants, these participants effectively maintain opinions close to the consensus reached through the rounds (1983).

In traditional thinking, the causes of present conditions lie in the past. Theory on organizational change and leadership asserts that enduring change 
requires a restructuring of the perceptions of the world as we know it and the embracing of new visions. Research in these areas has demonstrated that the most powerfully articulated visions become the future (Bolman \& Deal, 1984; Burns, 1978). Thus, as Cornish incisively phrased it, "the causes of the present may lie in the future" $(1977$, p. 214). The Delphi technique gives experts and stakeholders the opportunity to develop and articulate potentials, which in turn raises their profiles. "Futuristics changes our ordinary functioning from being reactive to being proactive. Instead of simply responding to pressures from the environment as we encounter them, we begin to develop goals that we are willing to work to attain" (Cornish, p. 228).

It is interesting to compare the effects of the Delphi technique with the effects of leadership. Walter and Choate (1984) sought to isolate replicable principles required of leadership in public and private organizations and found that what motivated followers was systematic foresight and the creation of clear, long-term goals and strategic plans. Bennis and Nanus said this about leadership: "It pools collective energies in pursuit of a common goal" (Bennis \& Nanus, 1985, p. 33). Motivation and the pooling of energies are also effects of participation in Delphi research. Leaders are the "masters at selecting, synthesizing and articulating an appropriate vision of the future" (Bennis \& Nanus, 1985, p. 235). Scholars in the fields of organizational change, leadership, futurism, and psychology all agree that effective change is born of a clear vision of the future. Like current leadership and futurist research, Delphi studies often aim to go beyond the simple gauging of change. They can contribute to the process of change. Leaders invent the future, and a unique panel of experts was assembled for this research to see if they might do this. 


\section{Survey Development and Implementation}

The "Think Globally, Act Locally" survey consists of two parts: the demographic questionnaire and the Delphi instrument. The survey was developed and implemented in ten steps common to Delphi studies.

1. The first step was the review of the literature, conducted in the spring, summer and fall of 1987. The literature was located through a broad reviewing process including a search of relevant sources listed in the E.R.I.C. computer data base, Educational Abstracts, Future Survey Annual, Review of Education Research and Dissertation Abstracts International. Additionally, a collection of nontechnical articles, conference attendance, and fourteen years of work in global education were all very useful in designing the survey. During the same time period, the researcher also consulted personally with recognized experts on international resources in the school community and on leadership. Recognized experts were identified in the literature and also located in organizations dedicated to international education. The organizations included Global Perspectives in Education, Inc., The Ohio State University Mershon Center, the SPICE Center at Stanford and the ISTEP Center at San Diego State University. The content and categories to be used in the Delphi survey emerged out of these ventures.

2. Next, a demographic questionnaire was developed (see Appendix A, research questions 1-2, and "Site and Sample Selection," below) to measure background information about respondents. This instrument was designed to gather information on the backgrounds of the respondents in an effort to isolate the attributes of school officials who were recognized as being active in developing international resources in the community. 
Standard demographic information such as job, site and education was collected on a two page instrument using objective or one line fill-in questions. A unique addition to the demographic questionnaire was an open form question which queryied the "formative experiences" of the experts as they developed interests in international relations.

3. The first round form of the Delphi instrument (see the second part of Appendix B and research questions 3-7) was then developed along with the demographic questionnaire. This instrument was designed to test the problems and promises of the development of international resources as resources for school-community leadership.

The procedure for this step of the study, as prescribed by Helmer, was to initiate the development of categorized hypotheses about community international education which are likely "to make a decisive difference in the future" of educational leadership in the community $(1983$, p. 119).

The Delphi instrument measured five specific areas. First, which community members do the experts view as the best resources for internationalizing education in the local schools. Second, what purposes do these community resource people serve for the school community? These purposes were categorized, spanning various educational values identified in the literature. They included leadership and organizational change values (adapted from Alderfer, 1982; Burns, 1978; Mitcheil, 1986a; Smith, 1986/87; Weick, 1982) and global education values (Alger, 1980a; Lamy, 1986/87; Torney-Purta, 1986/87). Third, as leaders, how do the experts go about bringing real, intended change (adapted from Alderfer, 1982) and, more specifically, what programs and goals are considered most purposeful and effective? Fourth, what are the philosophies of the experts in the field? Fifth, what pressures and demands compete for the valuable time of the experts as they attempt to develop 
international partnerships in their communities? Questions in each area emphasized not past practices, but the areas that the respondents believed would change most as a result of efforts to prepare for the coming century. All questions were open form and each answer space was followed by another space in which respondents could make comments of a general nature. The first round Delphi survey represented a skeletal scenario upon which respondents were to fill in the details of a community rich in opportunities.

4. At this point, the Delphi instrument and the demographic survey were formatted for face validity based upon the guidelines provided by Borg and Gall (1983, pp. 418-435). These guidelines generally include conciseness and precision of language; nonthreatening, nonbiased, positively stated and (where possible) closed form questions; and simple, logical and attractive format.

5. Pretesting is the next requirement. In December of 1987, I conducted a pretest validation of the survey. Recognized experts, all of whom represented international education centers and had developed survey instruments in the area of international education, were sent the survey and asked for comments and recommendations before it was sent out to respondents. Pretesters were asked to screen for ambiguity, salience, lack of bias, completeness of response choices and other points. This pretesting included a mailing to the 41 test developers listed in Torney-Purta ("the most extensive set of Iglobal education evaluation] materials which has been made available to educators") (1986-87, p. 3). With the addition of several noted international educators identified in the literature, the final list included elementary, secondary and university level program developers, all of whom had worked with or were closely involved with the development of international resources in elementary and secondary schools. Pretesters included prominent international educators from across the United States. Among them were: 
James Becker, Director, Midwest International Studies Project, Indiana University;

John J. Cogan, University of Minnesota;

Marlyn Crofts, Madison, Wisconsin;

Anita Dekock, Project Coordinator, The Stanley Foundation;

Doni Kwolek Kobus, Coordinator, Multiple Subject Credential Program, California State University;

Steven L. Lamy, Director of Public Education, University of Southern California;

Paul Mulloy, Director, Massachusetts Global Education Program;

Robert Pickus, President, World Without War Council, Inc.;

George Remick;

Mary Hill Rojas, Virginia Institute of Technology;

Jan L. Tucker, Director, Global Awareness Programs, Florida International University;

Ken Tye, Education Department, Chapman College; and

Robert B. Woyach, The Ohio State University.

Chatwick Alger of The Ohio State University, whose coined the phrase "thinking globally, acting locally," contributed to the survey design through his input over the telephone.

Several prominent, local educators were also selected and asked to pretest the survey for face validity.

Pretester suggestions concerned clarity of the questions, clarity of the purposes of the survey, wording, narrowing of the focus, quality of the print, objectivity of the approach, increased use of closed form questions, attractiveness of the package, and elimination of repetition. All of these suggestions are in conformance with Borg and Gall's "mistakes sometimes made in survey research" 
(1983, pp. 455-456), and they led to useful changes in the instrument. Of perhaps more importance were the insightful content-oriented comments made by the pretesters. These comments broadened the researcher's perspective.

6. The sixth step in this process was to form a sample (see "Site and Sample Selection," below). A potential Delphi sample population of 50 leading elementary and secondary school officials throughout Southern California was formed. Of these 50 officials, 29 would eventually agree to serve as respondents.

7. After the sample was formed, the survey was mailed. In April of 1988, I composed a letter of transmittal (Appendix B), emphasizing to the respondents why they had been selected. This mainly served to clarify the purposes of the survey, but it was also intended to serve as an additional screening tool beyond the process of forming the sample group. The letter provided potential respondents with reasons for completing the survey, assured of them of confidentiality (although this was not viewed as a particularly sensitive issue), and offered evidence of the value of their personal participation. The demographic survey and the first round of the Delphi instrument accompanied the letter of transmittal.

8. Upon receiving completed first round surveys, the results were compiled (see Chapter 4), yielding the data for the second round Delphi. Subsequently, round two was created and mailed out (see Appendix C).

9. Next, the second round results were compiled, and the third and final Delphi instrument mailed out (see Appendix D).

10. Completion of the third round paved the way for the data analysis. 


\section{Sample Size}

To allow for a liberal dropout rate after the first round, as Delphi surveyors expect, the original first round sample pool included 50 experts of whom 29 chose to participate. Of the 29,28 completed all three rounds of the study. Based upon response rates of typical Delphi surveys reviewed, the final round was expected to include approximately 12 to 15 respondents, typical of smaller Delphi surveys.

The number and representativeness of respondents are normally important concerns when using any surveying technique. Regarding the Delphi, Murray (1968) stated that "in this kind of survey of expert opinion and estimates, since it is not a statistical survey of the Gallup type, it is immaterial whether the experts be a representational sample" (p. 30). A search for a representative sample would have been stifling, since the degree of expertise in any sample of individuals making future projections is not controllable; it is knowable only in the future. For example, the most radical ideas are often those which are transcendent enough to lead to real change. What was important here was only to include a large enough sample size for the identification of patterns among experts to emerge (Guba \& Lincoln, 1985).

The Delphi studies conducted over the past twenty years since they have been used in research have typically included fewer than 50 respondents (Cyphert \& Gant, 1970, p. 421; Murray, 1968, p. iii), but recommendations on sample size vary widely. Some of the Delphi studies conducted by the Rand Corporation have had sample populations as small as 12 (Rosenbaum, 1983, p. 3). Helmer questioned whether or not a panel of a dozen reasonably good exerts is really preferable to a panel of "two or three top-notch experts" $(1983$, p. 118). The implication is that with increasingly focused (narrowed) scope of the research 
questions and with increasing expertise of the respondents, a rich and full scenario can be developed with the input of fewer individuals. Delbecq, Van de Vans and Gustavson (1975) stated, "Our experience indicated that few new ideas are generated in a homogeneous group once the size exceeds thirty well-chosen panelists" (p. 89).

Questions regarding sampling still call for extensive experimentation. Martino left Delphi sample size wide open. He applied a committee metaphor, indicating the need for only several experts corresponding with the researcher (1978, p. 391).

Site and Sample Selection: Round Zero of the Delphi Process

The conception and formation of the Delphi panel were guided by. Alderfer's proposal for establishing a "microcosm group" (1982, p. 141). This group, given a valid task, functions as a quasi-organization by focusing upon a specialized problem. The quasi-organization is valuable since group members may not have the opportunity to isolate this issue in such depth in their own organizations or to consider it along with a group of specialists. The Delphi technique is well tailored to the facilitation of a productive microcosm group since it simulates a committee meeting or discussion group format, herein called a Town Meeting, where concrete examples are generated. It is not, however, wholly a simulation or contrivance, as respondents were asked to base their responses upon actual examples from their own experiences or the experiences of others of whom they were aware. This requirement, that the examples be workable, is the key to the worth of the survey.

Borg and Gall (1983) cited the two basic considerations in selecting the actual sample: first, the selection of subjects who have a thorough knowledge of 
the situation and, second, salience of the questionnaire content to the respondents. These considerations guided the location of sample sites. Southern California provides an extraordinarily rich, multinational environment, providing many opportunities for leaders to synthesize diverse, international perspectives and mobilize of diverse resources (Stephenson, 1980).

By focusing on Southern Californian sites near where the research was conducted, telephoning was convenient and mailing times short. The result was that closer personal contacts with the survey participants were established, which helped insure a high return rate. Additionally, the sample selection helped tailor the research to the specific, unique international population of Southern California. This focus helped keep the sample small and specialized. Considerable time was spent on the telephone during round zero of the Delphi survey (the nominating process) and in following up the surveys in order to achieve a high response rate.

The sample selection process began with a random selection of 50 school districts from Santa Barbara, southward and generally along the Californian coastline to the Mexican border. The goal was to gather nominations for the sample. The data collection sites, as well as the potential respondents, were screened by a telephone nominating process. A site was considered potential once a school official at that site justified that he/she was active and interested in the area being researched and he/she agreed either to complete or consider completing the round one survey.

All initial contacts were made by telephone. In general, telephone discussions were guided by information provided by a review of the literature indicating the leadership objectives which closely pertained to the purposes of the study. In contacting each district, I asked for the superintendent and, when he/she was not available, I asked for "a deputy superintendent who was especially 
active in the community." Using a very general, preformulated telephone guide, I described the research to these individuals. According to the guide, I explained that school officials who were active in developing school-community partnerships and international resources would make the best nominees, especially since they would be asked to give evidence of such activities during the survey. If a school official had a standing interest in the research and was familiar with specific work in the field, I asked him/her to consider his/her personal participation. If that official did not have the required, active interest in the research, 1 asked for the nomination of a top district official considered to be expert in the area being researched.

This process led to self-nominations or nominations of colleagues, county administrators, and site administrators which, in turn, often led to further nominations. Approximately one-half of all such contacts resulted in either an agreement to participate or a nomination of a district official who was considered an expert.

Efforts to elicit nominations of private school officials were futile. Six Southern California private school heads were asked to recommend the most prominent private schools. The heads of the recommended schools were contacted and the research was described. They were asked for further nominations. After nine of these discussions, it was determined that private school officials would not make suitable respondents, primarily because the community interactions they described were in every case apparently governed by supply and demand in terms of student applications, rather than by broader cultural trends and social needs. Thus, the research was confined to public schools.

The final sample population generally included high ranking public school officials who were deemed by nominators to have considerable influence on the 
process of change in the schools. I elicited clear evidence of this influence from each participant, such as programs he/she had developed, before accepting him/her into the sample population. These precautions were taken to satisfy salience and expertise requirements. Several individuals were nominated by more than one school official, which added weight to those nominations. Fifty potential sites were finally selected based upon nominations of school officials throughout Southern California and subsequent telephone discussions with those officials.

Thus, conforming to the recommendations of Borg and Gall (1983) for increasing response rate, the researcher made personal contact with all respondents and clarified the purposes of the research prior to the sending of the first round of the survey. The written guide used during phone contact with nominators and nominees helped control the uniformity of the researcher's presentation of the issues and purposes of the the study and therefore boosted the validity of the survey. No effort was made to persuade individuals to participate in the survey. Any individual who was not clearly and actively involved in the process of adaptation of school goals to suit needs for international education was screened out. Surprisingly, several nominees were drawn into the sample who were from communities experiencing little demographic change. Generally, these nominees had found less opportunity for developing international education, but they expressed considerable interest, knowledge and background in the subject.

In the end, the nomination process yielded useful information, as well as serving to isolate committed, if not expert or leading individuals.

Round zero presented dilemmas which are common to formative and responsive program evaluation. The nominating process was designed to produce expert participants. The first criterion used to locate experts was 
organizational position. During the nomination process, I was able to consider specific work nominees had accomplished in the field of international schoolcommunity partnerships, as well as expressed interest in the research. Yet when one who is presumed to be expert in international education and community resource development expresses that international relationships are not organizational concerns (as was occasionally the case in round zero)--that they are not distinguishable from any other community interactions--what can be concluded? Were these experts justified in such assessments, or were they after all not really experts? Are there experts whose views are so transcendent that outside researchers can't see them until they and the experts take the time to "learn each other's languages?" Is the field being researched so new that those individuals who are most qualified as experts are not really familiar with the particular perspective of the research? Are the research questions irrelevant to educational practitioners? Perhaps even expertise is not enough; there may be experts in any field of research who do not attempt leadership because the do not believe the time or the conditions are right.

No nominees were liable to be perfect candidates. As Cleveland explained in his conception of "unwarranted optimism, . . . there must be some more upbeat outcome than would result from adding up the available expert advice." (1986, p. 12). Or, perhaps leaders characteristically have perspectives that defy commonly held beliefs; and what other alternative is there if new ground is to be broken? Perhaps, paradoxically, we know so little about experts that we can't identify them until we already know them. Things may seem simpler to leaders, or not as tied to conventional or objective standards. To recognize the experts could require clairvoyance on the part of the researcher.

"Practice is usually ahead of research when a profession is new and developing" (Alderfer \& Brown, 1975). The respondents being sought were 
partnership agents who were working in a new profession and involved in the shaping of trends which were not yet clear. Given an apparently successful professional, a researcher cannot agree or disagree that the ideas and practices of that professional are right or wrong, relevant or irrelevant, on track or off track, expert or not expert, and so by the end of round zero, after all the nominations were in, it was simply the concern and enthusiasm of the nominees towards the area of inquiry which bore the most weight as a criterion for expertise. Perhaps one of the best indicators of expertise, then, given the prominent stature of the individuals contacted for participation in this research, was dedication, sometimes indicated by not a lot more than the willingness to participate in a rigorous research exercise.

Given these uncertainties, round zero resulted in 50 potential respondents, clearing the way for round one. Of the 28 respondents who completed all rounds, 23 consented to release their names, and these names are listed Appendix E. If there was a profession known as school official involved in creating global linkages through community resource development, these 29 participants would be the experts. Whether they were leaders in this field (something which requires more than expertise) is a more complex question.

\section{Data Collection: The Delphi Process}

Most Delphi studies include three rounds (Brockhoff, 1975, p. 320; Cyphert \& Gant, 1970, p. 423; Linstone \& Turoff, 1975, p. 229; Uhl, 1983, p. 82), and this study was designed according to this norm. Now that the sample group was formed, the rounds of the Delphi could begin.

The data were collected by mail between April and June of 1988 using one demographic questionnaire (see Appendix $A$ ) and three rounds of Delphi 
instruments (see Appendices B, C, and D). Of the $\mathbf{5 0}$ potential participantnominees, $29(58 \%)$ returned the first round survey, and 28 respondents $(96.6 \%$ of those who completed round one and $56 \%$ of the potential participants) remained in the study through the conclusion of the third round. The high response rate indicates first, that the sample population was concerned with the topic, that is, strategies for making international linkages in local school communities and, second, that these educators were interested in exploring new perspectives for leadership.

Although all three rounds drove towards the reaching of consensus, the three rounds each served different purposes. The first round generated item banks so that response patterns could be identified and, subsequently, responses could be categorized into different clusters for analysis. These item banks were the heart of the survey. They contained all the data to be analyzed. By finding consensus on a select few items, the most valued examples of and objectives for international resource development in the local community could be identifiable.

\section{Round One Delphi Process}

Review of the literature, pre-testing and round zero all contributed to the development of the round one Delphi instrument. The round one package included the six page survey instrument (including a cover page designed as a flier to promote the research) accompanied by a letter of transmittal (see Appendix B), a stamped, pre-addressed return envelope and a pen with the survey theme ("Think Globally, Act Locally: A Delphi Study of the Leaders") and the researcher's telephone number printed on it. Notes had been kept of each telephone conversation during the nomination process. To encourage responses from the 
round one participants, specific references were made in customized letters of transmittal to certain nominees regarding their comments in the telephone interviews. An eye-catching flier welcomed each participant upon his/her receipt of the first round survey.

The questions in the first round Delphi instrument were open form. Nine categories of questions were presented. The purpose of each question category was to gather statements for an item pool which related to one of the research questions. Attached to it was a two page demographic survey. This package was mailed to the 50 potential respondents on April 6, 1988. The requested date of return was no later than April 22. On April 13 one respondent requested that he be able to send the package to a colleague whom he felt was better suited to the task. After a telephone interview with this colleague, I agreed to include him in the Delphi process and eliminate the original nominee. On April 19 follow-up letters were sent to encourage all respondents whose surveys had not been received to complete them (see Appendix E). On April 21 phone calls were made to twenty of the potential participants whose surveys had not been received, each of whom had been considered particularly willing and promising survey participants, to confirm their participation. Some who had seemed tenuous in their commitment during round zero were not contacted by phone. 1 felt that using persuasion in an effort to tip the scales against tenuous participation would have injected researcher bias into the sample formation process.

Four of the 50 potential participants responded to round one by excusing themselves from participating. These four were deleted from the mailing list. There were 16 potential participants who did not respond at all and their names were removed from the mailing list. One completed survey came in the mail after the second round survey instrument had been prepared, and so these responses were added in the round two summary where possible. This 
participant had requested during round zero to return the first round survey late. Including her, the second round survey included 29 participants.

After a total of three and one-half weeks from the first mailing, 1 completed the compilation of surveys and the second round could begin.

\section{Round Two Delphi Process}

The shaping of the content and format of the survey instrument were changed after the round one Delphi process. Basically, I felt that the survey needed shortening. Round two collapsed some of the questions in order to shorten and focus the survey. Aside from the survey being lengthy, some respondents found the round one questions to be unnecessarily overlapping. The process of collapsing categories led me to some useful conclusions about the research which are detailed in the Delphi analysis section in the next chapter.

The end result of collapsing round one responses was that five categories of items were generated. These categories represented the five questions of the survey and the items underneath each question were possible answers, some of which the respondents would eventually reach consensus on. The purpose of the second round was to feed back all the responses given to the each of the open ended questions included in the first round. The presentation of this information to respondents enabled them to review the responses of their peers and to pick those responses that they thought were best. The feedback of a great deal of round one data had to be kept to a manageable length. One first round question, for instance, had asked for respondents to list agenda items they would include at a meeting to promote international education in the community. The 29 respondents produced 80 responses to this question, and these 80 were collapsed to 40 items listed in round two. 
Still, even with collapsing, the lists seemed long and unwieldy; the lists for the first three questions seemed especially so. In the first round a listing of 40 items for question 1 (specific resource people), 26 items for question 2 (specific functions for these people), and 31 items for question 3 (salient issues for an agenda) were generated. These lengthy listings were possible answers to the first three questions which respondents had to choose from in the second round instrument. Likert-type scales for each item, commonly used in Delphi surveying, would clearly have made the survey too lengthy; another method of filling out the instrument was needed for these three questions. Likewise, asking respondents to select several of their priority items out of the lists was deemed too complicated a task. For example, selecting 10 priority items out of a list of 40 items is not a task which can be done with high reliability; selecting 5 of 20 items is much more manageable. Therefore, to improve upon reliability, two separate lists were created for each of the first three questions. Understanding this process of division requires a basic understanding of the exploratory nature of this research and of the Delphi analysis which would eventually be made.

I determined from the literature and from the round zero and round one responses that a variety of orientations of international education existed in the minds of experts in the field. To make meaning of this medley of orientations, 1 developed four conceptual perspectives that clustered similar orientations into one of four holistic views about international education. Each of these four conceptual models describes a different perspective on international education and is defined and described in the next chapter.

The first round of the Delphi survey had yielded the first three questions for round two. These three questions were made up of (1) lists of resource people, (2) functions for these resource people, and (3) program goals (called "agenda 
items"). Each of the two lists for the first three questions had to be equivalent. To divide each of the lists into two equal parts, a three step process was followed.

First, the original lists were divided into the four perspectives of international education.

Second, after this was done, items from each of the four perspectives were randomly sorted into the two lists; each list had an equal amount of items from each perspective.

Third, each of the two lists from each question was scrambled out of order so that respondents would not be able to recognize the four perspectives which were to be analyzed within each list. The purpose of hiding the perspectives was to decrease experimenter contamination and the potential for respondents falling into a response set.

Each of the two new lists for each question was then treated equally, and the respondent task became to pick priority items from each list. These measures should have served to increase reliability and replicability. Thus, in the first question for round two, respondents were asked to prioritize a total of 10 items, 5 from each list of 20. In the second question, respondents were asked to prioritize a total of 8 items, 4 from each list of 13. In the third question, respondents were asked to prioritize a total of 8 items, 4 from lists of 15 or 16 . Hence, each item had approximately a one in four chance of being selected.

In analyzing the responses for the first three item categories, the items were ultimately all to be put back into single lists and divided up into the four clusters for analysis so that consensus could be determined both for individual items and for the general perspectives represented by the clusters.

Data for the final two items were simpler to organize since they were shorter and needed no dividing. Although all 29 respondents had responded to round one, Question 4 (philosophy of international education), there was much in 
common among responses, and I was able to collapse all 29 responses into 10 philosophies. In most cases, two or more responses were merged so that the actual wording of any single respondent was not used. From this list of ten items, respondents were asked to pick three priority items.

Question 5 surveyed the needs and pressures which competed for the attentions of the experts as they pursued an internationalist agenda. This question ended up with 17 items after some collapsing of round one responses. I used Likert-type scales here since perceived pressure on the individual was deemed an attitude which could conveniently yield interval data without making the survey too cumbersome to fill out.

Thus, five categories were created for rounds two and three, which included a wide variety of resource people, functions for resource people, programs and agendas, philosophies, and competing needs and pressures, all of which the respondents claimed would be valuable to their leadership efforts as they worked for fundamental, needed change in internationalizing the schools.

To sursmarize the process of creating the round two instrument, round one responses were integrated into the round two instrument. This was done essentially in three ways. First, the expository answers given to round one open ended questions were converted into groups of closed form items, each group representing one of the categories of questioning. Second, as a part of this conversion process, the number of categories was collapsed from nine to five. Third, the directions to each of the categories were altered to suit the closed form, and instructions to each category were revised to achieve more precision in the round two responses. Conceptually, these revisions in the survey instructions mostly involved reinforcing that the purpose of the research was to study global education and not multiethnic education. 
Prior to mailing round two, participants who had not been contacted by phone since round zero were called and informed that round two was coming in the mail. Respondents who had been phoned during round one were not phoned again, since this may have seemed officious. On April 28, 1988, the round two package was mailed to the 29 respondents. This round two package included a letter of transmittal and the seven page survey instrument. Also included in this mailing were a stamped, pre-addressed return envelope and another theme pen. Letters of transmittal were based on a form letter but customized to comment on specific communications made between the researcher and some of the respondents. References were made to the comments of individual respondents on the phone or in the open form responses to the round one survey. In these letters 1 raised the possibility of naming the respondents in a future publication, and I expressed my continuing appreciation for their participation. On the survey instrument, the five new sections of questions and their associated closed form items were each followed by open form questions designed to enable respondents to clarify their responses or concerns.

The round two return deadline was May 17, 1988. On May 17 and May 18, follow-up telephone calls and letters (see Appendix E) were conveyed to encourage those respondents whose surveys had not been received to complete the survey and to thank them for their participation. In some cases messages were left with the respondents' personal secretaries. Round two was completed by May 28. One participant wrote that she had not realized at the time she agreed to participate how consuming the Delphi process would be of her time and she respectfully withdrew. The 28 other experts, or $96 \%$ of the respondents who had returned round one, completed round two. 


\section{Round Three Delphi Process}

Since the categories and the lists of items were formed, analysis of round two led to no real changes in the content of the round three instrument. Respondents had only to select priority items on éach check list towards the development of consensus.

Upon receiving completed round two surveys, the Delphi researcher can easily quantify the responses made and insert these figures into the survey for the next round. This is done by listing the percentage of respondents selecting each item in the prior round. The priorities of the participants from round two are identifiable as those items in each category which have been selected by a high percentage of participants. In this way the qualitative information provided by round one is transformed into quantitative survey data. With the inclusion of this summary information, respondents can see which items were deemed most salient by their peers.

Following these procedures, a summary of the round two responses was integrated into round three (see Appendix D). Comments which were made by each respondent during round two were inserted in the round three instrument so that they could be shared by all. This sharing of information is what makes the Delphi technique effective for the formation of a consensus.

The round three Delphi instrument was the longest since all the data gathered from rounds one and two were summarized and integrated into the round three survey. Integration was achieved in four ways. First, responses to the open ended questions which concluded the survey in the first two rounds were presented; the responses to these questions, which evaluated the survey overall, were relocated to the beginning of the third round survey. This relocation 
enabled respondents, as they began the round three survey, to get some idea of the general reaction of their peers to this research.

Second, all open ended comments made in response to each of the five questions in the survey were included. These comments were placed before each of the questions rather than after them (as they had been presented in the second round instrument) so that the ideas and perspectives of the participants could be shared before they made their decisions on the closed form items.

Third, and perhaps most important, the percentage of respondents in the second round who had selected an item was inserted before each closed form item.

A fourth addition to round three was the elimination of all items on which it was clear that a consensus would not be reached. These items were not removed from the survey instrument altogether, but rather eliminated by crossing over them with strikethrough marks (e.g., "I). This procedure enabled respondents not only to benefit from the insights of other experts regarding which items were valuable, but also to see those items which were not valued. Items which had been selected by less than $20 \%$ of the respondents in round two were stricken through. Erroneously, in the survey section on functions of international resource people, I struck through four items which were selected by exactly $20 \%$ of the respondents, however, this could not have had a significant effect on the findings or conclusions of the study. Two of these four were cultural leadership items which, in the end, received the highest percentage of selections by respondents.

Although including these data added to the amount of reading required of the survey, I hoped that sharing the insights and experiences of the experts would enhance their decision making processes in the third round. After all, the ultimate purpose of the survey was to synthesize ideas. Following each of the five 
questions in the third round instrument, respondents were again provided with open ended questions which encouraged them to clarify their item selections wherever useful.

Often Delphi instruments for a new round are accompanied by a separate instrument which has been filled in with composite responses (feedback) of earlier rounds. Such companion surveys are meant to serve as guides to respondents, to be read simultaneously with the completion of the blank instrument for a new round. There are greater advantages to locating the composite responses from the previous round right on the blank instrument for the new round, provided that these additions do not make the resulting blank survey form unmanageably long. Using this latter technique makes earlier responses more accessible and more clearly integrated into the decision making process during the actual completion of the the new round. This technique was used since I felt it was a more efficient way for respondents to consider the feedback information. Although the round three form had to be lengthened to 12 pages in order to integrate round two feedback, respondents did not have to follow two instruments (a blank and a composite) at once. Including the feedback directly on the new instrument virtually guaranteed that respondents would see the percentage of responses which had been given to each item in the previous round, especially since these percentages were placed directly next to the blank spaces provided for making third round selections.

Prior to the mailing of round three, I telephoned all round one participants who had not been contacted during the previous round to personally thank them for their participation thus far and to inform them that the third round of the survey was coming in the mail. Again, in some cases messages were left with personal secretaries when participants were not available. The round three package included a letter of transmittal, the 12 page closed form survey 
instrument, a stamped, pre-addressed return envelope, another pen and the Demographic Survey Summary (see Appendix G).

At the suggestion of two of the participants, the round three instrument queried whether each respondent wished to have his/her name and position included in the demographic summary to be distributed at the completion of the surveying.

Round three was mailed to 28 respondents on June 1, 1988 with a requested return date of June 20,1988 . On June 20, follow-up phone calls were made to respondents who had not met the deadline. I left messages for respondents who could not be reached personally and I then sent follow-up letters to them (see Appendix E). All respondents returned the round three survey, for a $100 \%$ return rate. One survey, however, came in five weeks late and was not included in the round three Delphi analysis. Thus, all calculations made in the round three analysis are based upon a sample population of 27 rather than 28. The data provided by this one respondent was left in the rounds one and two analyses, since it had been fed back and used by respondents.

On July 21,1988 , four and one-half months after the first mailing, the five page, final round three Delphi Survey Summary was mailed to the 28 respondents who had completed round three (see Appendix F), along with a message of appreciation (see Appendix E).

\section{Data Analysis}

A bank of valuable, exemplary leadership opportunities and strategies for the development of international resources had emerged from the review of the literature. With the Delphi survey, this researcher was questioning, however, whether the experts in the survey were aware of and using these resources. What 
was their purpose in using them? Which of these resources were most useful to the experts? What problems were they running into in trying to develop these resources? Did the actions of any of these experts describe leadership? These question were the foundation of the data analysis. The data analysis was responsive, and did not follow a wholly preconceived formula. Nevertheless, it conformed to the general conventions of the Delphi technique.

Through the rounds, no effort was made to indicate to the respondents the conceptual groupings of items which I had begun to form out of the responses to the first round; all items were listed in random order in the second round. All responses were deemed useful and they all contributed to the round two item pool. As stated, however, some responses which were decidedly equivalent were collapsed.

As detailed earlier, responses to each question were fed back to and evaluated by respondents in the second and third rounds. Wherever a majority of responses had fallen on an item, consensus was declared. Consensus could be declared for several items in each of the questions. On the other hand, since there were approximately four times as many items as there were choices for the respondents, there was a possibility that no consensus would be reached on any item.

Based upon the consensus items, the researcher built a composite profile of the most valuable opportunities for developing international resources in the local community. As a part of the profile, the responses were also analyzed to see if they corresponded to the leadership behaviors covered in the review of the literature.

It quickly became evident, though, that one composite profile was not sufficient. Although all survey participants were experts in internationalizing schools, the notion had begun to emerge as early as the nominating process that 
these experts were of several distinct types. Global education is not a unified field. These types were analyzed in the chapters four and five. The experts were divided up into four groups, each with different perspectives on international education. These perspectives were named: (1) instruction and curriculum development, (2) multicultural education, (3) economic security, and (4) cultural leadership. Based upon the consensus items and the literature, four contrasting profiles were built based upon the types of response patterns.

After this, in response to the need for synthesis of all perspectives in the field, the key analysis dealt with identifying which one of the perspectives, if any, encompassed all of them. This synthesis was hypothesized to be described by the fourth perspective, cultural leadership.

\section{Weaknesses in the Technique}

There are any number of ways to build consensus, and it is possible that any number of factors could have influenced the consensuses reached herein. Factors which may have contributed to the shaping of consensus may have included (1) the addition of another survey round, (2) the addition of items which additional literature review may have indicated could have been in the item pool, but were left out because they were not listed by any of the respondents, (3) instances of imprecision and distortion which always occur when placing social phenomenon into categories, and (4) the process of finding true experts in the field. Even if a completely valid consensus were reached, it would not be possible to confidently generalize findings from Southern California sites to the entire United States population. At best, it might be said that the findings were not necessarily generalizable to educators nationwide, but that they might be useful. 
Whatever the expertise or representativeness of the respondents, the internal validity of the survey, or the validity of responses to the survey, we can never know the future and so we can never be sure of obtaining true information (Linstone, 1978). As Helmer stated, "In the absence of a time machine, true experimentation about the future is a logical impossibility" (1983, p. 121).

The Delphi technique presents us with unknowns. The degree of anonymity, the degree of open or closed form questioning, the degree of homogeneity of the panel, and the optimal panel size are all variables, and there is not much that can be done in a single study to measure their impact upon the results.

Researchers encounter particular problems in trying to measure social perceptions. Using the Delphi technique to measure societal elements is "less determinate than [measuring] the future of technological progress" (Helmer, 1983, p. 256). As Uhl noted about social research, "there is no way to check the plausibility of expert's responses" (1983, p. 86). For example, we can determine respondents' advocacy of thinking globally and acting locally during the course of the survey, but we can't really know how much real change their actual actions have brought or will bring. Nominations of experts in the field during round zero gave some indication of the real world effectiveness of the respondents in this survey, but the validity of these nominations is not established. Obviously, some nominees who talked like experts may not prove to be experts after the test of time. If the nominations did not lead to the identification of true experts, the data could be viewed as the inbred reflections of a closed circle of specialists. This study was small in population and confined to distinct geographical boundaries; the human interactive element added by the nominating process made the study more responsive and context-laden than quantitative research normally would 
be. Thus, even following the recipe closely, attempts at replicating this study could generate other (albeit useful) data.

The premise of this survey is another possible weakness. In forming a sample, I used local experts, but I asked them, for the purposes of the study, to imagine themselves in a simulated group meeting of community members from various international constituencies. These experts were then asked what initiatives they could best hope to make in such a meeting, based upon their experiences. Next, to test the value of this experience, the experts were asked if such initiatives would help create a more shared, international culture in their actual school communities. This was the basic approach of the research. But perhaps the questions the experts answered in the Town Meeting were not the same questions they would have faced in actuality, Relations among identity groups and their representatives are embedded into the school (and any organization) in microcosm. So even if there is little doubt that the community initiatives described by the experts in the survey are true and that the respondents were all prominent and respected experts, the degree to which the initiatives have permeated or would permeate the social context of any particular school community is still not known. All we can test is how far reaching the experts think their own initiatives are. Thus, the Delphi survey is no more accurate than the intuitions of experts participating in this survey. Perhaps intuitions can tell us about tomorrow's thoughts and actions but, still, they may have little to say about tomorrow's intuitions.

There is a related weakness in the obtrusiveness of the research design. Once a survey is complete, the experts of course find themselves in their own groups without the intellectual latitude provided by a simulation. After a simulated experience, the participant is transported back to his/her daily routine with its own set of expectations. We can't measure the true relevance of a 
simulation such as this one. Furthermore, any written survey, despite personal letters and phone calls to respondents, is somewhat impersonal and artificial. Characteristics such as persuasiveness, perseverance and charisma, which are often associated with change and leadership, are not measured by this survey.

In an extensive critique, Linstone (1978) noted that the Delphi technique can simplify or manipulate issues. "The Delphi questionnaire assumes a certain cultural background. When faced with new paradigms . . . [we often] do not visualize a future situation in its own holistic pattern" (p. 298-299). This can lead to distortion.

There are other possible weaknesses in this research technique. In relying upon pooled expertise, we also rely upon the care with which the respondents complete the questionnaires. Perhaps some respondents participated out of courtesy rather than commitment. For example, two participants were alumni of the University of San Diego, where the research is being conducted, and they may have had unrepresentative empathy. Most respondents held doctoral degrees; empathy for the doctoral candidate seemed to be a small but identifiable issue, even though it was stressed in round zero that only individuals with a clear commitment in the area being studied were sought as participants. Further, perhaps it is not unreasonable to suspect that not every single respondent tork the necessary time and effo: $i$ to complete all parts of the survey with all his or her powers of insight. The Delphi process is demanding, and the researcher relied upon scant resources to motivate the participants: their commitment, the promise of receiving results, a free pen, some intrinsic value, perhaps. At the same time, there is never a quarantee that any consensus will be reached on any group decision, and the clear priorities which emerged through the rounds are testiments to the concentration and focus of the respondents, both individually and as a unified, expert voice. 
Despite room for imprecision in the Delphi technique, the method must be made to fit the problem, not vice verse, and the Delphi has proven particularly useful when "The problem does not lend itself to precise analytical techniques but can benefit from subjective judgments on a collective basis" (Linstone, 1978, p. 275). 
CHAPTER IV

FINDINGS OF THE STUDY: INTERNATIONAL RESOURCE DEVELOPMENT

The primary purpose of this study has been to discover ways in which school officials demonstrate leadership through the development of local international resources. An effort has been made to discover the emerging communities of interest in contemporary schools and, specifically, to identify the dynamic partnerships which school leaders can create by using local international resources. Identifying dynamic partnerships and emerging communities of interest in the arenas of international educators was the basic goal of the research. Through this process, a synthesis of the traditionally diverse global education values has been conceived.

\section{Demographic Analysis}

The demographic questionnaire was designed to elicit information specific to the respondents and their schools. All respondents completed all the items. All percentages in the demographic analysis have been rounded off to the nearest tenth. The numbers in the tables represent the number of responses to an item out of the possible responses. Normally, there were 28 possible responses, since 28 experts completed all three rounds of the survey. The demographic information received from the one respondent who dropped out of the survey after the first round has been removed from the analysis. The 
Demographic Questionnaire Summary, Appendix G, includes detailed information regarding the results of the demographic questionnaire. This is the document which was mailed to all participants with the round three Delphi instrument. However, this information is broken down into greater detail in the text below.

\section{Panelist Data}

Position Titles

The respondents had a number of titles as indicated in Table 1.

\section{Table 1}

lob Titles of Respondents

\begin{tabular}{ll}
\hline Responses & Job Title \\
\hline Superintendent & 14 \\
Assistant/Deputy/Associate Superintendent & 6 \\
Principal & 2 \\
Director of Educational Partnerships & 2 \\
Industry and Education Partnership Specialist & 1 \\
Community Based Education Facilitator & 1 \\
Communication Coordinator & 1 \\
Administrator on Special Assignment & 1 \\
\end{tabular}

Note. $n=28$. 
The obvious prevalence towards district superintendents reflects the nominating process. This process began at the superintendents' offices, and was used to screen out individuals without considerable community influence.

\section{Years in Job and Years at Current Site}

The panelists had a mean of 9.2 years in their position. They had been at their current sites for an average of 9.8 years.

Age

A breakdown of age categories is shown in Table 2 .

Table 2

Age of Panelists

\begin{tabular}{lc} 
Age Range & Number of Participants \\
\hline $20-30$ & 0 \\
$31-40$ & 1 \\
$41-50$ & 14 \\
$51-60$ & 10 \\
$61-70$ & 3 \\
$70+$ & 0
\end{tabular}

Note: $n=28$; mean $=50.3$ years. 
The fact that most participants $(85.7 \%)$ were from 41 to 60 years of age reflects the sampling process which began at the superintendent level. This was a wholly expected. The level of expertise and influence in the community required of this study indicates that only highly experienced educators would be admitted into the sample population.

\section{Gender}

The.demographic survey revealed that $22(78.6 \%)$ of the respondents were men and $6(21.4 \%)$ were women. All 14 superintendents were male. Six of the 10 assistant or deputy superintendents were male. One half of all nonsuperintendent positions were filled by women. Since there was no gender bias in the nomination process, the difference is explainable by the current power structure existing in Southern California school districts.

\section{Academic Degrees}

The 28 respondents indicated that they had earned a total of 74 academic degrees: $100 \%$ had bachelor's degrees; $92.9 \%$ had master's degrees; and $71.4 \%$ had doctorate degrees. Of the 14 superintendents in the study, all but one (92.9\%) held doctorate degrees. Five of the six assistant superintendents (83.3\%) also held doctorate degrees. Both of the two principals in the study held doctorates. 


\section{Formative experiences}

Respondents were asked to recall specific reasons or formative experiences to explain their interests in internationalism. This question was open ended and some respondents cited more than one reason. Their reasons were collapsed into nine categories. Of the 22 respondents who answered this question, the largest number had generally intellectual reasons, such as their general interests, readings, personal philosophies, and the studies they had undertaken as students. The responses are listed in Table 3.

Table 3

Formative Experiences

Future Group Prevalence

responses

Intellectual reasons (reading/personal philosophy/ academic studies) 10

No experience or no answer given 6

District needs/Local demographics 4

Upbringing 3

Business and community involvement 2

Living overseas 2

Travel

Exchange experiences

Navy

Note. $n=22$.

Travel experiences received only two responses. If the categories of living overseas, exchange experiences and Navy are included along with travel, then it 
can be generalized that 8 of 22 respondents, or $36 \%$, had significant experiences in foreign countries. This percentage was still considerably lower than I had expected among professionals active in community international relations.

\section{Institutional Data}

\section{The Institutions}

Since respondents were guaranteed anonymity, information from items 1 . (a) - your name and 2. - your telephone number - are not reported in this analysis. The Delphi round 3 summary includes names of all respondents who stated that they wished to have their names released (see Appendix F). Of the 28 respondents, 23 expressed this wish.

All 28 respondents were from public institutions. They worked in 27 different school districts; only one school district, San Diego Unified School District, was represented by more than one participant. Of the 27 districts, 2 $(7.4 \%)$ were county offices of education; $17(63.0 \%)$ were unified districts of both elementary and secondary schools; $4(14.8 \%)$ were secondary districts; and 4 $(14.8 \%)$ were elementary districts. The districts, listed in alphabetical order, are as follows: Alhambra City High School District; Basset Unified School District; Bellflower Union School District; Cajon Valley Unified School District; Cardiff School District; Del Mar School District; El Segundo Union School District; Encinitas Unified School District; Garvey School District; Irvine High School; La Mesa-Spring Valley Elementary School District; Long Beach Unified School District; Los Angeles Schools; National School District; Newport Mesa Unified School District; Norwalk-La Mirada School District; Ontario; Montclaire School 
District; Orange County Department of Education; Pomona Unified School District; Poway Unified School District; San Diego City Schools; San Diego County Office of Education; San Ysidro Elementary School District; Santa Ana School District; Santa Monica School District; Torrance Unified School District; Yorbita School (Roland Unified School District).

\section{Student Enrollment}

Most respondents worked at the district level and made their responses accordingly. A few worked at site level and responded to questions on the basis of their site demographics. Only $3.6 \%$ of the respondents reported enrollments of less than 500 students. $14.3 \%$ of the respondents were from districts or schools of between 500 and 2,000 students. $7.1 \%$ were from schools/districts of between 2,000 and 5,000 students. $17.9 \%$ were from schools/districts of between 5,000 and 10,000 students. The majority of respondents, $57.1 \%$, were from schools/districts enrolling more than 10,000 students. Student enrollment data is displayed in Table 4

Table 4

Student Enrollment

\begin{tabular}{lcc}
\hline Enrollment Range & Responses & Percentages \\
\hline 500 or less & 1 & $3.6 \%$ \\
$500-2,000$ & 4 & $14.3 \%$ \\
$2,000-5,000$ & 2 & $7.1 \%$ \\
$5,000-10,000$ & 5 & $17.9 \%$ \\
$10,000+$ & 16 & $57.1 \%$ \\
\hline
\end{tabular}

Note. $n=28 ;$ mode $=$ more than 10,000 students. 


\section{International Make-up in the Schools/Districts, Present and Future}

Respondents were asked to identify the international make-up of their school/districts by listing each specific nation or region of origin in order of prevalence. All respondents reported an influx of immigrants. Seven spaces for listings were provided, although few respondents used all of them.

In analyzing categories of foreign groups, the groups were collapsed extensively. The category of Hispanic was used for groups from Central America and South America. The category of Asian was used for Chinese, Vietnamese, Cambodian, Laotian, Far East Asian, Japanese, Korean, Hong Kongese, and other oriental peoples. The category of Persian/Arabian was used for Arabians, Persians and Parsis. European groups mentioned were Russian, German and and Western European in general. Most of these responses were estimates based upon individual judgements rather than actual school or district figures. This was appropriate and as intended, since the experts' perceptions of their local populations were more important to this research than the actual demographics.

Some groups which were listed by respondents had to be eliminated from the survey analysis since they are not nationalities or foreign groups, but rather ethnic groups. Most notably, 14 respondents, or $50 \%$ of the sample, listed "black" as one of the prevalent international groups in their community. This was a key finding since so many of the respondents, to some degree, considered international education to be a local effort towards integration rather than a global effort. (The differing concepts of internationalism will be analyzed later.)

Other responses were eliminated from the demographic analysis as well. One respondent differentiated between Hispanics U.S.A. and Hispanics Mexican and Central American. This distinction was not used as U.S.A. Hispanics could 
not be considered foreign. Other respondents mentioned groups that did not distinguish nationalities. There were two listings for "limited English proficiency," one for "WASP," one for "Jewish," one for "American Indian" and one for "ethnic." Again, this type of categorization was tangential to the purposes of the survey, and unfortunately the wording of the questions did not succeed in keeping such listings out. For analysis, categories such as U.S.A. Hispanic, black, Jewish and American Indian were all counted in the category, "United States American."

There were other listings put into the United States American category: Caucasian (6), white (5), Western European (2), Anglo (2), and American (2). The directions to the next round of the survey emphasized the importance to the research of isolating nationalities and not ethnic, racial or minority groups. As will be analyzed later, the grey area between minority and national groups may partly be responsible for some of the confusion about the goals and objectives of international education.

The international make-ups cited as the most prevalent in school/district communities and the number of respondents listing them were: United States American (21), Hispanic (6), and Asian (1). Thus, $75.0 \%$ of respondents believed that United States American was the single most prevalent group, with $21.4 \%$ citing Hispanic, and 3.6\% citing Asian. The percentage for Hispanics seems high and could reflect some respondents' misunderstandings in distinguishing between natives and foreign nationals.

This misunderstanding is most understandable in the case of Hispanics. Respondents were asked to treat Hispanics who were already assimilated (defined in the survey as those of the second generation in the United States) as not foreign. Partially due to a variety of legalities involving permanent residence and citizenship, and partially due to the cultural relativity of the meaning of assimilation, it remains unclear whether some Hispanic people are in fact 
assimilated. This is a heated political issue in California and it has created a special class of people. For example, many migrant children move between Mexico and California two or more times each year. (One California school has even agreed upon a common report card with a school in Michoacan, Mexico, allowing students to pick up where they left off with each move ["California schools meet," Edcal, 1988]).

United States American, Asian and Hispanic were by far the most prevalent community groups. Twenty-seven, or $96.4 \%$ of the 28 respondents, listed groups in the category of United States American in the top two prevalent groups, with $82.4 \%$ listing Asian in the top two, and $67.8 \%$ listing Hispanic in the top two prevalent groups.

The breakdown of the top seven prevalent groups is listed in Table 5. There were considerably more than 28 responses to this question since respondents were able to list anywhere between zero and seven community groups. The popular conception is that the prevalent Southern Californian foreign group is Hispanic, and so the finding that the experts surveyed believed Asian to be the more prevalent group was surprising at first. Note, however, that there are considerably more Asian nationalities represented than Hispanic, and so some respondents listed several Asian groups and only one listing for Hispanic. Presumably, this was because Asian groups, such as Japanese and Southeast Asian, are perceived to have less ethnic communality than do the Hispanic groups. The range of Asian values integrating into Southern California school communities may be wider than that of Hispanic, but it is not necessarily more intense.

$I$ asked the respondents to project basic changes in the demographic make-up of their schools/districts by the year 2000 . Of the 28 respondents, 26 responded to this item. Four respondents $(14.3 \%)$ answered that they expected 
no change in population make-up. I expected that these responses would represent small districts, suburban districts or upper middle class districts, whereas

Table 5

International Make-up of Schools/Districts

\begin{tabular}{lcc}
\hline Group & Responses & Percentages \\
\hline U.S. American & 27 & 96.4 \\
Asian & 23 & 82.1 \\
Hispanic & 19 & 67.9 \\
Filipino & 6 & 21.4 \\
No change & 4 & 14.3 \\
Arabian/Persian & 3 & 10.7 \\
Pacific Islander & 2 & 7.1 \\
Other - African, Russian, & & 10.7 \\
\multicolumn{1}{c}{ Western European } & 4 & \\
\hline
\end{tabular}

Note. $n=28$; Total Responses $=88$

I expected urban district respondents to report that there would be greater demographic changes. Inner city schools are popularly thought to experience the most demographic change. However, these expectations were not borne out and no clear pattern of responses to indicate the future demographics of schools with a prevalence of Asian or Hispanic school populations was identifiable. Respondents indicated that the largest influx of foreign groups would be from 
Latin America and Asia. Three respondents indicated that they believed that there would not only be an influx of Hispanics, but that Hispanics would become the majority group in their schools/districts. Two respondents indicated this same belief in regard to Asians. Complete findings are in Table 6.

Table 6

Future Influx of International Groups

\begin{tabular}{lcc}
\hline Future Group Influx & Responses & Percentages \\
\hline Influx of Hispanics & 13 & 46.4 \\
Influx of Asians & 11 & 39.3 \\
Few changes or no changes & 6 & 21.4 \\
Influx of Filipinos & 2 & 7.1 \\
\hline
\end{tabular}

Note. $n=28$.

One demographic question was added to the cover page of the second round Delphi instrument. This question asked for an estimated percentage of community members whose parents had a regional origin other than that of the United States. The question was meant to help respondents clarify their understandings of the differences between foreigners and nationals. The 24 answers showed an average of $32.3 \%$ of foreign parents. These answers ranged between $5 \%$ and $75 \%$. Note that these figures may not reflect the actual 
demographics of the average sample site since responses from small and large districts were weighted equally.

\section{Typical Respondent Profile}

From the data presented above, a composite profile of the average panelist in this study was developed. This typical respondent is described below.

The typical respondent was a $\mathbf{5 0}$ year old, male, superintendent with a doctoral degree who has been at his job for about nine years and has been in his district for about ten years (although he most often came into the district at his current job level). The respondent is at the top of his organization; he is an achiever. The subject of international linkages in the community is relevant to his personal goals as well as his professional goals. He attributes his interest in international education more than anything else to personal reasons such as readings and studies, or to his personal philosophy. There is a low to moderate chance that he has either lived or vacationed abroad, been on a scholarly exchange, or travelled with the Navy.

He manages a combined elementary and secondary district providing educational services for more than 10,000 pupils. His district is predominantly white, but has both Asian and Hispanic minority populations which are strong and becoming stronger. About one third of the community population originates from countries other than the United States. Typically, the school community's foreign population comes from Latin America or Asia. Although community minorities will continue to grow through the turn of the next century, the typical respondent predicted that white United States citizens would still be the largest group in his district by the year 2000 . 
For the purposes of this research, the typical respondent is considered an expert in developing international resources in the school community, and the term expert is used throughout this work in referring to the respondents.

\section{Delphi Analysis}

During round zero, the nominating process leading to the selection of the sample population, a few respondents asserted that they were unaware of clear patterns of local international resource development in their communities, although they were familiar with various specific initiatives. It was commonly stated that there was no specific policy emphasis on foreign groups, a statement which reflected espoused policy but, evidently, not the policy in practice. Through the Delphi process of focusing on this issue, clear patterns of schoolcommunity interaction emerged that took the research far from round zero.

The Delphi survey was structured as a simulated "Town Meeting." Each respondent was asked to imagine that he/she had been made chairperson for a Town Meeting of prominent local community members who represented international organizations or who had distinctive international skills and experiences. The purpose of the meeting was to assess school needs and to plan strategies for change so that schools would be better prepared for the next century. This was intended to simulate a leadership task. At the meeting, respondents were asked to focus specifically on internationalism in their local communities and to consider how international initiatives could put the school in a position of communitywide leadership. The assumptions stated to the participants were that international resource development would be necessary for community leadership and that change was a constant educational goal. 
Leadership was defined in each round as "the ability to bring real, constructive change and to unite coalitions in new understandings."

Each round of the Delphi survey simulated a separate Town Meeting. Thus, there were three meetings. The Delphi instrument used for round two was a composite of round one responses, so that it also served as a round one survey summary (see Appendix C). Likewise, the round three instrument integrated a summary of the round two survey (see Appendix D). Integration of newly emerged information, called feedback, was used to move the respondents towards a consensus of opinion.

After three rounds of Delphi surveying, consensus was reached on each of five areas of inquiry which, together, provided answers to the research questions. Consensus required that a majority of respondents agreed to a statement. Stability of responses, less than $15 \%$ change in response rate from one round to the next, was also considered where applicable. If an item had greater than a $50 \%$ response rate in both rounds two and three, the $15 \%$ rule was not necessary. Where two or more consensus items received the same percentage of responses in round three, the item which had a higher percentage in round two was listed first in the tables showing consensus items. Although tables which analyze and summarize the responses of each round of surveying are provided in the text, the reader can find more detailed information concerning. each item in the three Delphi summaries in the Appendices $C, D$ and $F$. These three summaries are the documents which were sent to respondents after each round.

\section{$\underline{\text { Round One Results }}$}

Respondents' willingness to go through this round, and all the rounds, and their interest in sharing information indicate that this is a valued area about which 
they wanted to learn more. The very high response rate attests to this same interest, as well as to the face validity of the survey instruments and the effectiveness of the sample selection process. The fact that a high percentage of selected top level administrators from across Southern California were willing to devote a total of over an hour and a half each to filling out the three survey instruments, and that all superintendents and deputy superintendents who completed the first round of surveying completed the second and third rounds, are indicators that international education in the community is a priority issue for them and, presumably, for their districts.

Round one respondents answered open form questions in eight areas of inquiry. Responses were to be turned into separate closed form questions to be used in the next two rounds, each measuring one area of inquiry. The eight round one questions represented various aspects of the research questions and were: (1) international resource people and their functions in the school community, (2) program development goals, (3) needs for thinking globally and acting locally, (4) specific programs which address the need for thinking globally and acting locally, (5) competing administrative goals, (6) competing community goals, (7) future resource people, and (8) future program development goals.

Most of the data generated in round one has been listed, categorized and analyzed in the rounds two and three data analyses (as discussed later; also see Appendices $($ and D), and in the Delphi Survey Summary which followed round three (see Appendix F). As is common in exploratory research, some restructuring of the survey was required before the research could proceed from round to round. Most of the restructuring occurred after round one. Restructuring after round one enabled unnecessary questions and redundant responses to be either eliminated or collapsed into other questions and responses. 
Very little data were analyzed following round one, since the main purpose of this round was to develop banks of items which would be put into categories. Still, much was learned through the process of shaping the round two instrument out of the round one data, and this process is described below. Also, a second purpose was met in round one, that is, to begin grouping the items into distinct clusters, each representing a different perspective of international education in the community. The groups were not clearly formed at this stage, as readers will discover; yet general groups of items for each of the questions did begin to take shape.

\section{International Resource People in the Community}

Before sending the original round one survey, a list had been compiled from the literature on specific jobs and functions of individuals who were most effective in serving the schools as international resources. The decision was made not to include this list of international resources and resource people in the first round survey, but rather to leave this question open ended in the first round so that participants could generate such a list without researcher bias.

In the first open ended question, respondents generated a list of international resource people including, in general, state, county and district educational/curricular specialists, local business contacts, local organization and foundation contacts, parents and board members of the school district, prominent local individuals, and university contacts. The specific resource people cited were listed on the round two survey form, turning the open form question into a closed form one, from which respondents could select their priorities. The complete list with specific job functions, as well as responses for the other 
question categories are presented in the Delphi analyses for rounds two and three, below, and were not deeply analyzed at this stage.

Interestingly, the list generated in round one for use in round two by the survey respondents included virtually every example of international resource person that had originally been generated in the literature review, plus a few additional examples. This concurrence was a convincing one in validating the expertise and credibility of the respondents. Likewise, the items generated for other questions in round one concurred with many of the findings from the literature.

\section{Agenda for the Town Meeting}

Question 2 in round one dealt with generating an agenda for the Town Meeting. Collectively, the respondents produced lists of issues which they felt needed consideration in order to make the best use of the international resources available in their communities, and they are listed below. Added to the lists are programs cited in response to question 4 , a question which was found to be redundant and was eliminated after this round.

Responses to this question (and those merged from question 4 responses) could be categorized into (1) curricular items, (2) local multicultural items, (3) business and technology related items, and (4) global items. Examples of items are listed by category. More examples were actually generated than are presented here, since redundant items were eliminated.

1. Curricular items cited were:

Embedding international and multiethnic elements into core curriculum. International issues in the economics classes.

Regional studies classes. 
Social studies, literature, and science curriculum.

District involvement in AFS Program.

Magnet mathematics and science program for minority students to compete in engineering careers.

Marine science units on ocean ecology.

English as a second language and other courses for immigrant students.

Anthropology courses.

Curricular emphasis on cooperative learning.

2. Local multicultural items listed by respondents were:

A drop-out prevention program which deals with many immigrant students.

Homework help centers for immigrant students.

High school careers program including Pacific Rim careers.

3. Business and technology related items listed were:

Corporate sponsorship and funding for global education activities.

Vocational electronics lab supplied by local electronics plant.

A magnet program with a high school center for international commerce. International business internships for teachers.

4. Global items listed were:

A "Celebration of America" week to recognize the contributions of many nationalities and cultures to the microcosm at the school.

Foreign study tours for teachers and students.

A seminar in Mexico for special education teachers to strengthen Spanish fluency.

A student committee on exchanging intercultural views.

An after school program with local foreign senior citizens to deal with cultural relativity. 
Of course, these categories are not mutually exclusive. For example, a magnet high school program in commerce might fall into the business or the curriculum categories.

Practically all of the programs documented in the literature were listed by the experts, plus more. As in the first question and all round one questions, the items generated here were listed as choices for the new, closed form question to be used in round two.

\section{The Needs and Goals for Developing International Resources}

Round one, question 3, asked for a response to the statement, "Why do we need this [Town] meeting? I question how it can lead to long term, fundamental change in the school goals, and I question whether it even should!" Respondents were asked to state their case here, reflecting their philosophies and their views of the fundamental purposes behind developing international resources. Aside from their use in the development of item banks, the responses to this question were instrumental in reshaping the survey instruments for use in the following two rounds, and so they are detailed below.

All respondents reacted favorably to the statement and almost all came to the defense of the Town Meeting. Their responses could generally be grouped according to whether they addressed curricular needs, multicultural needs, economic needs, political needs or global and cultural needs. These statements are enlightening, and at least a sample of them warrant printing.

The comment, "We need to address the perceived needs of our increasingly transient and pluralistic population," points to multicultural needs, as does the statement, "The community we serve is obviously vastly different from the community of even ten years ago." The statement, "We are in a state of rapid 
change in California. One fourth of the world's immigrants settle in California. We must all adjust and plan together ..." also points to multicultural needs.

Only one respondent cited needs directly related to economics, referring to "recent research from the business community emphasizing the need for school reform."

One respondent commented that "Schools can achieve their goals ... when all pupils have equal access to quality programs and when a climate of mutual support is developed." Although the mention of equal access falls under the rubric of multicultural needs, it also implies the economic needs of the school community. Also, the mention of mutual support focuses the statement on political needs.

A few other comments integrated several types of needs. "We plan to take a proactive stance in the face of not only a changing curriculum but a changing world." "Schools need to prepare students to participate in this world culture." These statements focus on curricular needs as well as global and cultural needs.

Four of the comments $(14.8 \%)$ did not risk controversy, but instead focused on procedural concerns. For example, a superintendent noted, "The school goals are being reviewed and your ideas are welcome." An assistant superintendent wrote, "I believe that the board member would be hard pressed to challenge in this way. I would probably remain quiet and allow others to react."

Other procedural comments tackled the potential controversy head on, seeming more directive than one might expect outside a simulation. For example, one superintendent stated that his response to the comment would be: "The majority of the board has already approached the concept. Thanks for sharing your concerns, but the project is critically important to our community." 
Clearly, the statement used in this question was useful in prompting participants to begin to form a consensus. This conclusion is supported by the overall strength of the responses generated in support of the statement. One conclusion drawn from the answers to this question was that multicultural needs seemed to be the prevalent type of needs as respondents addressed the issue of international resource development in their communities. However, responses to this question led to a more basic finding. It began to appear at this point in the survey analysis that respondents really were addressing some very different agendas and operating with some very different philosophies in working for what they called international education. This same, fundamental problem, that is, the diffusion of goals in the field of international education, was identified in the literature.

\section{Philosophy of International Education}

As stated, the object of round one was to generate an item bank for each question. Once items were generated, some items from different round one questions could be either eliminated or collapsed into a single category. The first instance of collapsing occurred with regard to round one, question 4, which asked for responses to the statement, "If you can, list two or more programs at your school which reflect the philosophy that 'Education is one of the basic factors in international relations, quite as important as diplomacy, commerce and military power in its implications for war and peace'."

The respondents supported the quotation strongly and most felt that it expressed their philosophies. Only one respondent would not support it, stating, "I'd assume that I would not take sides or support a specific point of view." Otherwise, the answers provided an array of community international programs 
which could be inspirational to educators looking for model initiatives. The philosophical statement used for this question was added to the list of representative philosophies to be used for the remainder of the Delphi survey. This list is presented in the analyses of the next round.

There was considerable overlap in the responses to this question and some other questions in the survey instrument. Second round questioning here would have unnecessarily taxed the efforts of respondents in an already lengthy survey. Specifically, the responses to the above question were very similar to responses given regarding the functions of international resource people and the agenda items (salient issues for developing international linkages). Thus, these responses were merged with the other round one responses and need no further reviewing here.

\section{Competing Needs and Goals}

Since round one information was gathered with open form questions, it was highly unlikely that a consensus would be reached in one round. In one instance, however, a consensus was declared in the first round, and this enabled the survey to be shortened. A very strong agreement was reached on the question of competing administrative goals, that is, internal organizational goals which compete for the time and resources of school officials as they pursue an internationalist agenda. The agreement was so clear that, despite the stability of responses requirement, further surveying on this question was obviously not necessary. Respondents listed mostly items related to budgeting, paper work and bureaucratic demands, and competing curricular and instructional demands. Some expected social problems were listed, such as drugs, discipline, absenteeism, and sex-related problems. Although the question of competing 
administrative goals was taken out of the Delphi process, the findings are treated as a part of question 5, competing needs, in the round three Delphi analysis.

In responding to a related question, external pressures and conflicts, respondents developed a variety of items. Listings included parent organizations, state mandates, taxpayers' and homeowners' associations, teachers organizations, LULAC groups, immigrant groups, chambers of commerce and other building and industry groups, school boards, and others. Respondents felt that these groups had their own agendas which could work to counter the school's efforts towards building international networks in the communities. Since these were competing goals, outside the goals for international education, no effort was made to place them in international education categories. No useful patterns were located among these listings at this stage, and so analysis was put off until the next round, during which respondents could begin identifying their priorities.

\section{Agenda 2000}

The final question on the round one survey asked respondents to list items which they believed would be on the agenda of the Town Meeting if it were held in the year 2000. The responses to this question are listed below have been placed into four clusters, some unavoidably overlapping.

1. The first list generally involved curriculum and instruction topics for the 2000 s.

Providing students with technological knowledge and global experience Foreign study and preparing students to live abroad

New thinking styles

New structures for schools and new learning environments

Second languages for elementary students 


\section{Computer education}

Parents as jointly responsible educators

Harnessing science and technology to the humanities

2. Another group of responses addressed community topics.

The multicultural, multilingual, multi-economic nature of our community Contributions of immigrants of the 1980 s

3. A third category of responses addressed national topics.

A national school district

Outer space teaching

4. Other responses could be categorized as global topics.

Health and environmental issues of the 21 st century

Management of conflict; attainment of peace

The cooperative world economy and technologies

Developing international understanding between cultures

Creating a worldwide curriculum

Agreeing on standard ethical principles

These four categories used in analyzing this question, curricular issues, community issues, national issues, and global issues were similar to those responses made for other questions and were useful in the analysis which began after the second round. Although the categories used previously were not the same as the final four categories which were used in the final analyses of the Delphi survey, they are similar. The development of the four final categories of international school-community partnerships was evolutionary, and the categories solidified throughout the rounds and as a result of the rounds.

With the round one survey, I had aimed to measure two sets of responses, one regarding present use of international resources in the community and another regarding projections of future uses. However, several factors led to a 
decision to eliminate these aims. First, I determined that by continuing to elicit specific year 2000 information I would add about twenty minutes to the round two survey response time. Additionally, despite the importance of the listings above, many of the responses in round one were vague when it came to making future projections. Others added little or nothing to the list generated for the year 1988. Therefore, the distinction between 1988 and 2000 was eliminated and the categories were collapsed. To accomplish this collapsing, wording was changed for round two so that respondents were asked to address their answers not to 1988 and 2000 conditions separately, but rather to resource development which was "proactive" and "most likely to lead us into the next century." With this change in wording, the survey was shortened by two questions.

Along with the other instances of collapsing, the collapsing of present and future item categories presented in round one brought the final number of survey questions down from eight to five: (1) International resource people, (2) International resource development programs, (3) Agenda items--Salient issues in developing international linkages, (4) Statement of philosophy, and (5) Competing needs and pressures.

\section{Round Two Results}

During round one respondents had successfully generated items which were to serve as closed form responses to each of the five survey questions. In creating the round two instrument, the item banks were arranged into check lists so that respondents could select those items which they felt best answered each question.

Consensus was not a real possibility in round two since respondents did not have the uniform item banks presented to them until this round. Although some 
items were selected by a majority of respondents, no consensus could be declared since stability of response from one round to the next was a requirement for consensus. The most important result of round two, then, was the elimination of items which received a low percentage of responses. These items remained on the round three instrument, but were stricken through (see Appendix D) so that respondents could consider only items on which there was a reasonable chance of their reaching a consensus. All remaining items needed further consideration in round three and, therefore, yielded few conclusive results as yet.

Summary information on items which were selected by a majority of respondents in round two and on items which respondents found less useful is presented in the following text.

\section{International Resource People}

In the first question, international resource people believed to be most capable of giving support to the respondents' leadership efforts, four items were selected by a majority. These items were: a Latin American or Asian member of the school board, a corporate leader/executive of an international corporation or bank, a Latin American or Asian chairperson or parent organizer of an international parent committee or PTA, and the editor of a local Asian or Latin American newspaper. A comment made by one respondent helps understand these priorities: These people are "Well connected, with access to people from several different constituencies." The emphasis on Latin American or Asian individuals is understandable, considering the demographic trends described in the demographic analysis presented earlier. This particular finding is less generalizable than almost all others since it is contingent upon the unique geographical position of Southern California. Most communities nationwide, 
however, either have foreign groups or experience some demographic shift, and so the information generated for this question is liable to be externally valid in the sense that it should be relatively worthwhile or useful; there is always the need for resource development across groups.

The following 14 of the 40 resource people listed on the round two survey instrument were selected by less than $20 \%$ of the respondents, and so they were stricken though on the round three survey instrument:

1. District coordinator, foreign students program

2. Aerospace/telecommunications expert

3. Chief of protocol, county office (receives/assists foreign dignitaries)

4. President, local branch of the American Bar Association

5. Intercultural counsellor

6. President, local branch of the the American Medical Association

7. Government official, trade regulations

8. Law enforcement official of Latin American or Asian heritage

9. Local member, state department of education international studies project

10. Director, foreign exchange organization

11. Chairperson, parent program for migrant students

12. Community activist

13. Member, state foreign student affairs advisory committee

14. University professor or dean, international relations

The items which remained in the survey seemed to have some common threads. As one respondent stated, "They represent a broad cross section of the community that would support international education." This perspective helps explain why the community activist and president of the American Medical Association received the fewest of respondents' selections. The elimination of 
resource people such as the intercultural counselor, the director of a foreign exchange organization, the community activist or the chairperson of a parent program for migrant students might be explained by such respondents' comments as "Not part of local power structure," or "They are too specialized or narrow, therefore have limited viewpoints and limited resources."

Other individuals may not have had the power resources respondents sought. One respondent wrote that he sought "decision makers," and so resource people such as the district coordinator of foreign students program or the intercultural counselor may not have qualified.

Some of the individuals in the stricken-through list do fit respondents' characterizations of resource people they seek, that is, those who are "resourceful" and "can marshall resources." Still a clearer common denominator of those resource people who were more popular seemed to be their closeness to elementary and secondary education. School officials may not have had much access to such resource people as chief of protocol at the county office or government official of trade regulations. Such people have power and resources which are fairly remote from schools. As one respondent characterized the best resource people, they are "active people in school and/or community with experience in minority culture."

\section{International Resource Development Programs}

Five of the 28 functions of international resource people were selected by a majority of respondents. These are the functions the resource people provide towards developing programs which can assist school officials make the kinds of changes that will be necessary in preparing for the next century. They were:

1. Help prepare students for international citizenship 
2. Serve on the school board with clear understanding of community expectations

3. Lead the school-business partnership program at a large multinational corporation which provides the school with useful resources

4. Coordinate school efforts in obtaining global education resources and consult on international trends for curriculum updates

5. Inform school leaders of future trends and global issues: global interdependence, geopolitics, health, poverty, etc.

The selections of all of these functions except perhaps the first could be explained by the comment of one respondent, who stated he was looking for "Effective communication to appropriate decision groups." The latter three selections can be explained by the comment of another respondent who was seeking "People who can ... bring resources to schools."

Seven, or one-fourth, of the 28 functions for international resource people which were listed in the round two survey were stricken through and thus eliminated from the Delphi process. These items were:

1. Plan educational strategies for foreign students

2. Work directly with students to motivate and orient them towards global business needs

3. Help prepare students for international business

4. Work with the school's leadership for pluralist legislative action beyond the community arena (issues which transcend local politics)

5. Contact and negotiate with a wide variety of foreign countries and companies which can provide capital and human resources

6. Help provide telecommunications links/data bases with schools overseas

7. Provide frequent speakers, audio-visuals 
It is especially difficult to generalize why these seven functions for international resource people were viewed as less valuable than some of the others. The range of percentages for the items selected in response to this question was considerably smaller than the range for the first question; that is, the answers were more spread out, indicating that respondents may have had a harder time deciding among these items. Some very similar items received different percentages of the total selections. For example, helping to prepare students for international citizenship was one of the most popular functions selected, while motivating students towards global business needs received one of the lowest percentages. The former seems to be a more all encompassing function. As one respondent commented, "Some very specific efforts might misdirect the overall emphasis or intent."

Serving on the school board with a clear understanding of community expectations and coordinating school efforts in obtaining global education resources both received a high percentage of selection by respondents, while providing frequent speakers and audiovisuals, providing telecommunication links with overseas schools were seldom selected. One respondent explained that he sought resource people who could "start with what is most functionally salient," and all of the selected items seem functional. Perhaps service on the school board was viewed as more salient since it is more likely to bring basic changes. In general, however, patterns among items which were not selected are difficult to discern and so, before the third round responses were in, summary information was hard to find.

As done with all round two responses, the item selections made in this question were tallied and inserted onto the round three instrument for all respondents to see. 
Agenda Items--Salient Issues in Developing International Linkages

Respondents were asked to create agenda items for the Town Meeting. These items represented the respondents' perceptions of the most salient issues that would have to be addressed in the course of developing international linkages in the community. As stated, consensus was not reached on any items in round two, holding to the standard of stability of responses. Nevertheless, two items, education's role in addressing global problems (e.g., communications barriers, ecology, food, survival) and teaching conflict resolution and cooperative decision making each each selected by a majority of respondents as issues which are most salient in preparing schools for the next century. Although the question asked respondents to consider issues of importance in their local communities, what these two items have in common is that they transcend local community issues; they are global issues which appear in the community in microcosm. Such findings are useful in the drive towards an integrated theory of international education which could have a more universal meaning and more broadly acceptable values.

Ten of the 32 agenda items on the round two survey instrument were stricken through for round three, and most of the stricken through items were not so global in nature. The first eight of these eliminated items were:

1. How well have the schools met instructional needs over the past 20 years?

2. Alternative methods of schooling

3. Appropriate use of school facilities; dealing with changing enrollment patterns

4. How to generate political support in the community 
5. International resources available in the community to augment school financing

6. What are schools across the country doing in this area?

7. The place of international and non-European social studies in the curriculum

8. Demographic developments and immigrant contributions in the United States: their impacts on our educational programming

One respondent's comment seemed to sum up the difference between the most salient and the least salient items in his statement that the greatest educational need was "Learning how to live in a global society, understand one another, and work collaboratively." Another respondent explained the prevalence of broad and global agenda items in stating, "No one agenda item can operate successfully without interrelating with broad goals."

The ninth and tenth agenda items which were eliminated from this question in the round three instrument were "Comparison of United States education system with leading foreign systems" and "Teacher and student foreign exchanges and study tours." One respondent's statement that "Those items selected are outgrowths of the most salient" might explain the lack of interest in these two items. For example, foreign exchange is an outgrowth of several of the items which were selected by more respondents, such as "Strategies for promoting awareness of interdependence of people and nations over time" and "Preparing students to live abroad and work in the international economy."

\section{Statement of Philosophy}

Ten statements of philosophy were generated in round one, and two of these statements were selected by a majority of respondents in round two. These 
were: "Education is one of the basic factors in international relations, quite as important as diplomacy, commerce and military power in its implications for war and peace" and "We need to address the perceived needs of (and our common goals with) an increasingly transient and pluralistic population which is vastly different from the community of a few years ago." Interestingly, the first statement conveys a global approach to education which is applicable to the local community, and the second conveys an approach which is strictly oriented to the local community.

Three statements were eliminated from further consideration due to the low percentages of responses they received. These were:

1. Schools can achieve their goals ... when all pupils have equal access to quality programs.

2. We need to take a proactive stance in the face of not just a changing curriculum but a changing world.

3. We need to be adapting the school to changing socio-economic demands.

One respondent commented that "All of the philosophies are good." The respondents provided very little commentary on these statements of philosophies, however, and so it is difficult to find a pattern among the three items which might explain why they were not often selected. On the other hand, the two items which received a majority of responses do seem to be more encompassing and more clearly targeted.

\section{Competing Needs and Pressures}

The final question in the second Town Meeting asked respondents to rate the outside interest groups which vie for control over schools goals and the 
process of change. These groups would or do press agendas counter to the specific internationalist agenda developed earlier in the survey. Rating was done on Likert-type scales. Four groups, the board of trustees or board of education, parent groups, state legislature or government, and dominant or upper middle class, vocal majority groups were rated by respondents as causing the most pressure against leadership efforts in international resource development in the community. The board of education is a logical response, since it reflects a traditional struggle between boards and top level school officials. Parent groups are another traditional source of pressure on school officials. These two are liable to be cited as pressure groups no matter what the agenda is.

Regarding the pressure caused by dominant or upper middle class, vocal majority groups, some respondents pointed out that the pressure they caused was growing especially fast now that this group's status as a majority was slipping. One respondent even confided that he had just been fired by a school board made up mostly of the individuals from traditionally dominant ethnicities; his school population shifted rapidly, so that the white population was no longer the dominant group, yet the board rejected this respondent's every effort to institute internationalist programs tailored to the new community demographics.

The growing demands of state government are well documented, particular in California, and result from shifting funding patterns and the school accountability movement.

Two groups were given particularly low ratings, indicating that, according to the perceptions of the respondents, they cause little or practically no pressure to the change efforts of school officials. These two groups were organizations of recent immigrants and liberal political organizations (ACLU, NAACP, etc.). The finding that recent groups of immigrants are felt to cause little pressure is 
understandable, since the school officials in this survey expressed an interest in serving these groups.

The percentage of each number on the scales, 1 through 5, selected by respondents for each item on this question was calculated. The two highest percentages for each item were inserted into the round three survey instrument for the respondents to consider.

\section{Round Three Results: Data Analysis Through the Town Meetings}

While round two provided an opportunity to understand low priority items which were to be stricken through, round three analysis was mostly concerned with consensus items. A complete listing of all responses to round three, the consensus reaching round, is included in Appendix F, the Delphi Survey Summary. Item numbers are left in the tables presented in the text for an easier reference to the appendices.

The five areas of inquiry (item categories) finalized in round two and measured by the Delphi survey were:

1. International resource people,

2. International resource development programs,

3. Agenda items--Salient issues in developing international linkages,

4. Statement of philosophy, and

5. Competing needs and demands.

Although round three provided space for further clarification of items and questions, ṇo resporident used these spaces. A consensus was reached for a variety of items on each area of inquiry. 
International Resource People: Consensus Items

The resource people selected by the experts are presented in Table 7 in order of the strength of consensus. The percentage of respondents who selected each of these items in the final round follows each item. The respondents reached a consensus on seven items. A particularly strong consensus was reached on the utility of resource people from school site councils and local businesses.

\section{Table 7}

International Resource People: Consensus Items

\begin{tabular}{lll}
\hline Item \# & Delphi Item & Percentage \\
\hline
\end{tabular}

7 Corporate leader/executive of an international corporation or bank

12 President, the school district's Multiethnic Advisory Council

18 Latin American or Asian chairperson/parent organizer, international parent committee or PTA

34 Adopt-a-school contact person (e.g., community relations director) at a multinational corporation

22 Teacher (social studies, literature, science, art), foreign born with a global perspective

9 President, a citywide international community committee

3 Latin American or Asian member of school board 51.9

Note. $n=28$. 
Approaching the 21 st century, the experts will be looking primarily to community members from corporations and multiethnic groups for support in their own efforts to develop internationalism in the school community. Additionally, in Southern California the Hispanic and Asian communities will be tapped to provide resource people both in the school and in the surrounding school community. This is understandable, considering the projected, continuing influx of these two groups in Southern California, as nationwide.

Three of the items on which respondents reached a consensus, the adopta-school contact person, the foreign born teacher with a global perspective and the president of a citywide international community committee, had not achieved a majority response in the second round, receiving $48 \%, 44 \%$ and $48 \%$ of the respondents' approval, respectively. The other four items on which respondents reached a consensus were selected by the majority of respondents in the second round and remained in the majority in the final round.

Some comments made by respondents following this item category help explain their choices. Respondents were and will be looking for a balanced perspective from "a good cross section of the community," as one superintendent phrased it, to move their efforts forward in international education. Useful resource "people are "big picture" people, as one respondent called them; resource people with narrow agendas from individual interest groups are avoided except in their efforts to connect a variety of constituencies.

Consensus on certain items in no way indicates that resource people upon whom. a consensus was not reached, such as those items eliminated in round two, could not be useful to efforts to make better use of international resources in the community, but only that they were not viewed as the most useful. 
International Resource Development Programs: Consensus Items

Question 2 in rounds two and three tested the functions provided by international resource people as they develop programs with the school. Respondents reached a consensus on five items in this question. As shown in Table 8, the first four of these items were particularly valued, that is, they received

Table 8

The Functions of International Resource People: Consensus Items

Item Number

Delphi Item

Percentage

24 Coordinate school efforts in obtaining global education resources and consult on international trends for curriculum updates

$4 \quad$ Help prepare students for international citizenship

25 Inform school leaders of future trends and global issues: global interdependence, geopolitics, health, poverty, etc. $\quad 77.8$

20 Lead the school-business partnership program at a large multinational corporation which provides the school with useful resources

16 Provide a clear vision of minority employment needs/ perspectives and assist the school in developing appropriate programs

Note. $n=28$. 
responses from over $70 \%$ of the respondents. These four choices demonstrate that resource people who can bring resources into the school, both for the classroom and for school officials, will be highly sought after. Respondents' comments reflected that the role played by community resource people should be to communicate broadly and across groups. They need to articulate a "more inclusive perspective," which is concrete in that it is clearly "functionally salient," as one superintendent put it. These comments strongly suggest that what the experts are looking for is communicators, people who are influential and can rally community support for the school and its resource needs. Three of the five items indicate that they are also looking for expert advice on global trends.

All of the consensus items received a majority of responses by the second round except for the last item, which received $44 \%$ of the responses in round two. Interestingly, "Serve on the school board with a clear understanding of community expectations" received a majority of responses in round two but dropped off to $34.6 \%$ in the third round. This item did not describe a program which could have a broad influence or prompt strong school-community communication, as the consensus items did. Also, this particular item described an interaction between two community groups and did not really have as clear an impact upon student program development as did the consensus items. This is not to say that instructional programming was the main priority of the experts. It was not. The respondents did, however, seem to pick items which integrated a multiplicity of internal and external organizational goals, and also had a filter down effect upon curriculum development and the planning of student programs. 
Agenda Items--Salient Issues in Developing International Linkages: Consensus ltems

For question 3, respondents developed a list of prevalent issues which they believed must be addressed in order for school leaders to effectively develop international linkages. Respondent comments were very broad on this question. More than in the first two questions, they addressed the needs for international competence and for developing conflict resolution skills and global perspectives in curriculum. Values seemed to be the real heart of the issue. Generally, responses dealt with the need to develop a more global set of values: "The whole issue of cultural diversity versus U.S. 'traditional values' will continue to be of major importance," stated one respondent.

Respondents reached a clear consensus on six items. This was a remarkable list, spanning from small, instructional issues to community, national and global values. The list was a strong one: about 20 percentage points separated the least priority consensus item from the nonconsensus item receiving the highest percentage of responses. The six items are listed in order of priority in Table 9. Five of the items, (1) staff development, hiring and teacher training practices, (2) teaching conflict resolution and cooperative decision making, (3) skills, knowledge and creativity required by a futures oriented business community, (4) international resources available in the community to promote students' global awareness, and (5) education's role in addressing global problems (e.g., communication barriers, ecology, food, survival), were closely related to instruction and curriculum development. Commented one respondent, "These items give a good source of baseline data and academic/economic emphases with respect to curricular change." Another exemplary comment was, "No one agenda item can operate successfully without interrelating with broad goals." This 
Table 9

Agenda items--Salient Issues in Developing International Linkages: Consensus Items

\begin{tabular}{lll}
\hline Item Number & Delphi Item & Percentage \\
\hline
\end{tabular}

10 Staff development, hiring and teacher training practices

31 Strategies for promoting awareness of interdependence of people and nations over time

11 Education's role in addressing global problems (e.g., communications barriers, ecology, food, survival)

17 Teaching conflict resolution and cooperative decision making

3 Skills, knowledge and creativity required by a futures oriented business community

13 International resources available in the community to promote students' global awareness

Note. $n=28$.

could explain why so many of the consensus items call for a merging of business and community educational goals. This helps demonstrate that, according to the respondents, however related or distant resource people and their functions normally are from school activities, their collaborations with the school ultimately lead to changes in the classroom.

Although the needs for business collaboration and resource development figured into the agenda as they did in questions 1 and 2, the consensus items are 
quite different in focus than those identified in the first two categories. The prevalent agenda, as set by school experts, would emphasize both the process of classroom teaching and the broad communication of a global perspective in the community and beyond. These are more idealistic concerns than those expressed in the responses to questions 1 and 2 . One can surmise that given the opportunity to set the agenda themselves, rather than call up the agendas of community leaders, the experts would focus upon educational and philosophical issues.

The responses to this question demonstrated a difference in the outlooks of school experts and their perceptions of the outlooks of community leaders. This variance would represent a potential or actual conflict if school experts are harboring agendas which they believe community resource people would not choose to address. This conflict will be analyzed later.

Two of the lowest rated agenda items in the third round were "using the school sites as community/neighborhood centers" and "technologically enhanced, global learning systems, communication with foreign sister cities/schools." This might at first seem to demonstrate a low concern on the part of school experts towards taking practical steps to break down barriers between the school and its external environment and to promote interorganizational communication; such a conclusion cannot be drawn, however, since other items upon which the respondents reached a consensus do not point in this direction, and since they had not been stricken through in round two. Thus, the logical conclusion is that, whatever measure of utility these two particular items had, other items in the list had more or were seen as more encompassing or more fundamental. Additionally, respondents may have believed that high technology was not financially feasible and, hence, the more important job was to locate and cultivate partnerships which could ultimately provide such resources. 


\section{Statement of Philosophy: Consensus Items}

Question 4 tested the philosophy of the respondents on international education in the community. This question was placed late in the survey intentionally. It was hoped that this question, following seven pages of check lists on preferred international resource use, would find respondents with a heightened sense of their own philosophical orientations. In other words, after making so many selections in the earlier parts of the survey, respondents should have begun to focus on some principles which would help them separate what they did value from what they didn't.

Respondents had the opportunity to select three of ten philosophies which had been developed in the first round, and all respondents took this opportunity. They reached a very strong consensus $\mathbf{( 9 2 . 6 \%}$ of respondents) on the philosophy that "Education is one of the basic factors in international relations, quite as important as diplomacy, commerce and military power in its implications for war and peace." Interestingly, this item was the only statement not generated by the respondents' actual words; rather, it was taken from the literature since it expressed the first round views of many of the respondents.

Other philosophies were either direct quotes or statements made up of two or more very similar responses that were combined. The second priority philosophy received a majority of selections during the second round, and by the third round it was selected by $\mathbf{8 1 . 5 \%}$ of the respondents for a consensus. This statement was, "We need to address the perceived needs of (and our common goals with) an increasingly transient and pluralistic population which is vastly different from the community of a few years ago."

The two statements are quite different from one another, reflecting respondents' efforts to identify a balanced perspective. The first statement 
addresses national needs and, although it is practical from the standpoint of the federal government, it is rather idealistic in the context of the local community. The second statement addresses local needs for a multicultural perspective and is the most practical of the three. The third priority statement addresses global needs and is the most idealistic of the three in nature; this statement read, "Schools need to prepare students to participate in a world culture." This item gained a consensus (59.3\% of respondents) in the third round, although it was selected by slightly less than $50 \%$ of the respondents in round two.

Looking at the statements, one could generalize that respondents favored broad goals dealing either with global trends or local demographic trends.

\section{Competing Needs and Pressures: Consensus Items}

There were two components to this question. The first was internal: What demands upon administrative time would the internationalist agenda have to compete with? The second was external: What outside pressures or agendas would weigh most heavily upon internationalist programs and initiatives?

The first component, competing internal demands, received responses by all respondents except the one respondent who was not an administrator. One respondent commented, "There are too many other demands and pressures upon the school, and upon my (administrative) time(!) to worry about getting more interest groups involved." Although this comment had more intensity than most, its theme was representative of many comments made. Respondents were pressured for time and by interest groups.

Respondents' statements about internal pressures were assessed after the first round. They are included here rather than in the first round analysis so that they may be considered along with the other findings of the completed Delphi 
survey. The items did not represent resource development opportunities and were only ancillary to the survey. Since this question was not directly related to the development of international resources in the community, and also because the patterns they showed were so immediately clear, it was not necessary or useful to attempt to build a consensus on them. This was not a Delphi item. No research was conducted on the relationships between administrative pressure and the philosophical orientations or program goals of administrators.

A compilation of the responses that were made in round one are located in Table 10. Similar but not like responses have been collapsed for this listing. A number of the pressures listed by respondents, such as "mandated state and district priorities," could equally be considered external pressures; the distinction was not always clear. The plan was to have the 29 respondents who completed the round one survey develop the listing of pressures on their time. Since one respondent was eliminated from round three, his responses were taken out of the data; and, since one respondent was not an administrator and couldn't respond to the question, there were a total of 27 respondents. The top three priorities, listed in bold face type, were selected by a majority of the 27 respondents.

The three priorities exceed all others by at least 19 percentage points. As the table shows, the responses to this question were less than startling and are simple to analyze. They conform to time worn problems: time and money.

Current high profile political issues which cost valuable administrative time are represented in the responses. Examples are state mandates and demands from special interest groups. Well known current social issues such as drug abuse, special education and child care also found places on this listing.

The second component of this research question dealt with finding external pressures which compete with community resource development. 
Respondents' perceptions of external pressures were measured on Likert-type scales. In rounds zero and one, a small handful of administrators stated that they

Table 10

Which Pressures Compete Most for Administrative Time: Priority Items?

Too many meetings, too much work to do-- limited time, paperwork, etc.

Overcrowded curriculum (competing curricular programs such as music, special education, GATE, basic skills education, goals of academic excellence)

Mandated state and district priorities

Problems with drugs, attendance, discipline, poor test scores, sex, etc. $\quad 30$

Parent organization or school site council demands $\quad 15$

Motivating community and parent interest/support $\quad 15$

Extra programs such as child care, athletics, health and special services 15

$\begin{array}{ll}\text { Supervision of instruction } & 11\end{array}$

Lack of staff interest/support and needs for staff training 11

Administrative demands from community special interest groups

and immigrant families

Too many disparate groups, mandating too much student ability grouping

Teachers do not have time for more activities 4

Possible problems with the teachers union 4

Lack of need/the feeling that these concerns are already addressed enough

Implementation

Note. $n=27$. 
saw no outside pressures upon their school goal setting and that forcing them to pick five or ten of the strongest pressures would not have been useful. These comments proved neither prophetic nor representative, and the respondents developed a substantial bank of external pressures which weighed against their internationalist leadership efforts.

Some competing needs and pressures may not have been viewed as such if they were perceived as positive or complementary forces. For example, given two respondents who held very different conceptions of international education, what might be a goal for one could be a competing, though complementary force for the other. What was measured, then, was the amount of negative pressure. Pressure was rated on a "1" to " 5 " scale, "1" being lowest pressure and "5" being highest. Three items received considerably higher pressure ratings than all others, and they are listed in bold face type in Table 11.

To measure the responses to the Likert-type scales used for this item category, the pressure rating given in the third round for each item was averaged to the nearest hundredth. As was the case with earlier consensus items, all responses were shaped through the three rounds of surveying. The final round pressure ratings are listed in descending rank in Table 11. In this way, every item reached a priority of opinion, some for very low pressure, and others for more moderate or high pressures.

As Table 11 shows, the three highest competing external pressures felt by the respondents are all political in nature. Two of these pressures, those being caused by dominant or upper middle class groups and conservative political organizations, are felt mostly in the local community and are not particularly present in the state or national arenas. Another finding was that government mandates, which received considerable attention as an internal pressure, rated as 
Table 11

Competing External Pressures: Priority Items

Item Number

Delphi Item

Meana

14 Dominant or upper middle class, vocal majority groups

3.96

9 State legislature and government

3.80

11 Conservative political organizations (John Birch, Moral

Majority, etc.)

3 Problem oriented groups (AIDS Society,drug awareness

group, etc.)

2 Parent groups

1 Board of Education

3.35

5 School site council/Advisory committees

3.19

8 Homeowner groups/Taxpayers Associations

3.00

13 Ethnic and religious groups

17 Individual parents or community members

10 Government social service agencies (Health Department, Law Enforcement, Child Services)

7 Chamber of Commerce or industry

15 Councils on education

16 Individual teachers (not a group)

6 Building industry

12 Liberal political organizations (ACLU, NAACP, etc.)

$4 \quad$ Recent immigrants

Note. $n=28$.

$\mathrm{a}_{1}=$ lowest; 5 = highest.

the second highest external pressure. Still other political pressures come from problem oriented groups and homeowner and taxpayer groups. Thus the greatest pressures generally come from interest groups. One superintendent 
stated, "Often decisions made are driven by political agendas which may not reflect the most urgent needs of students. These agendas are driven by groups that want to influence how things are done." Of course, there are other formidable sources of external pressure, but to find interest groups so freely peppering the list is no surprise.

Moderate pressure, respondents wrote, came from those directly involved with the educational system, such as parents and school site councils. One can surmise that these pressures are strong, but more liable to be seen as complementary.

Whether pressures was viewed positively or negatively, since research in leadership behaviors demonstrates that leaders are motivated by pressure and called to action by conflict, was significant. For example, respondents indicated that pressures from immigrants was low. This would indicate that their own agendas for resource development in the community conflicted little with the agendas of immigrants. Yet it is clear from the demographics that respondents felt considerable pressure as a result of changing community demographics. An explanation for this might be that respondents felt any conflicts with immigrant groups were generative, and that these conflicts brought constructive issues to the surface. Perhaps these respondents are attempting to demonstrate leadership in minority group issues by capitalizing on positive pressure; or, perhaps they were too busy managing conflict and satisficing what they believed were manageable demands to attempt real leadership. Or perhaps another explanation is that the minority groups haven't learned the system yet, haven't matured in their political skills yet, and haven't taken on American political and social values yet but still hold to the values from the old country which may not encourage participation and involvement. 
While they seemed concerned with minority groups, respondents felt that traditionally dominant groups brought a high level of pressure against their efforts at change. This would be negative pressure. As in all politics, the stakes are determined by where one sits. Initiatives which could help immigrants might tax the traditional majorities. Reading the demographics, it is understandable why the experts would be concerned with standing by the Hispanic and Asian minorities; their minority status is diminishing and the schools must be central to their hopes of building a shared future with their communities.

Examples of other pressures which were rated as low are councils on education and liberal political organizations.

Curricular pressures were not often listed by respondents, no doubt because they are not external concerns. Nor were global or cultural concerns listed by respondents, presumably since the point of this question was to survey whatever pressures compete with these very same concerns.

\section{Importance of the Town Meeting}

In the third round, a final question was added to the survey which asked participants about the importance of this research. The question read, "Interview: You are leaving this final meeting and the local press has taken a big interest in your work. They ask you for a quotable quote about the importance of this work. If you wish, you may use this opportunity to say something that honestly reflects your goals and perspectives."

This open form question served at least three functions. First, it was intended to generate useful quotes for the survey summary and to provide useful perspectives which could be used in the qualitative analysis. The quote was obviously one-sided, however, and its other functions were more important. 
Secondly, the question provided the experts with an opportunity to think about the value of their participation and perhaps to anchor some of the discoveries which they had made in the process of their participation. Thirdly, it was intended to provide a meaningful closure experience for survey participants, each of whom had invested a good deal of his/her time to the survey and filled in a total of 27 pages of survey forms. It enabled respondents to have a final say and to synthesize their beliefs and feelings.

It was perhaps significant that the third round took place during the time of school closing for most participants, making it particularly demanding of their time and efforts. Eight of the 27 or $29.6 \%$ of the participants chose to respond to this closing item. Some of their quotes are enlightening.

- "If we don't hang together, we will certainly all hang separately... !"

- "The world of tomorrow is today! We must join together to have a workable plan for the future in our ever shrinking world."

- "International cooperation is a social imperative. Preparing students for global existence must be top priority for all of us. We must recognize diversity as a socially enriching factor in our lives."

- "Schools need to prepare students to compete in an ever increasing international marketplace and to contribute to world peace and understanding in the 21 st century."

- "This meeting represents the beginning of an effort to assist all students to be aware of the international culture of America."

- "The year 2000 is very close, we all need to be thinking about our community changes and how we can make things better. This is a good beginning, just making us think."

- "Our goal is to live and work as one." 
- "The children's song, 'It's a small world' is true today and we must prepare our children to live in a global world both economically and culturally. It is in the best interest of the U.S. and the world."

Much like the responses to earlier questions, these responses are categorizable into four perspectives generally dealing with curriculum development, equal opportunity in the community, United States competence in the international marketplace, and international culture.

\section{Analysis of the Town Meeting Format}

Aside from content input, some respondents commented on the format of the Town Meeting and their general impressions of the meeting. I asked for such comments in the final two questions of the instruments used in all three rounds. In response, one respondent recommended "that this process be done in a full day community conference." Others emphasized that time at the meetings would have to be devoted to discussion of the purpose of the meetings or of procedural matters. These comments, though often insightful, were not a part of the consensus reaching process, but they were fed back to respondents for general interest and for the promotion of the overall meaning of the survey. Most respondents either responded "no" or "none" to the final two questions or left them blank. In response to the question, "Do you have anything you wish to add or explain about any of your responses to this survey?" respondents answered as follows.

- "Often decisions made are driven by political agendas which may not reflect the most urgent needs of students.

- "The more affluent and well educated people use the system to obtain their needs." 
- "A recent school board election has transformed the district's direction so that there is much pressure on all aspects of working with non 'American' peoples."

- "I would do my best to make the internationalist agenda the 'official' agenda."

- "Very creative approach."

- "The year 2000 is not that far away."

- "Interesting to say the least."

- "Right on target!! I'm excited about what you will share with us from this study."

- "I like the way you presented your ideas."

- "Interesting project! Good luck."

- "Now that we've done this, what are the implications for my personal behavior and for the behavior of the other actors in schools? Would this town meeting really lead to substantive change?"

- "Very interesting study."

- "My responses are influenced by my current assignment and the constant influx of new students. Schools must be able to adjust to serve changing needs."

- "I have just visited the [international school] and have been offered the job of Director. I am retiring from [my current] position."

Through the rounds, the respondents were thorough. In the first round of surveying all respondents answered all items, with the exception of one respondent who did not answer the items in the last item category. In the second round of surveying, all respondents answered all questions. In the third round, one respondent stated that the survey was confusing in its directions (although he answered all questions correctly) and he requested another survey if useful. Otherwise, all evaluative responses were highly supportive of the survey, both for 
its format and content. In round three, four respondents did not complete all items; three of these four selected only half of the required items in questions 1 , 2 , and 3, and one selected too few items in two different question categories. To the request that they identify confusing or difficult items, respondents wrote:

- "It would be wonderful to have all of these people in our community but we do not."

- "Many people involved in global education have not studied or traveled extensively and this bothers me!"

- "[The first round survey is] not very consistent with priorities in our district. This would be a poor strategy for me to pursue."

- "I'm with these [minority] people--without help (people) and money. Don't ask us to do more!"

- "I suggest you add your phone number so you can be contacted quickly if need be."

- "I felt that some of the directions on this [third] survey were unclear-If I did not respond in the manner desired, please send another survey." Overall, the responses were clear and concise, and evidence of Helmer's criticisms of the Delphi technique as described in Chapter 3, Review of the Literature, that it sometimes produced literary outpourings and that respondents may not be motivated due to the anonymity of the survey, were nowhere to be found in this Delphi research. 
CHAPTER V

ANALYSIS AND SYNTHESIS OF THE FINDINGS

Second Cut: Toward a Categorized Approach

\section{Four Models of Global Education}

Many of the findings made in the first level of analysis of the results were expected. For example, it was no surprise to find that the respondents were seeking resource people from corporations who could bring resources into the schools. Not only is this a well known trend, but it was discussed with many of the respondents in round zero. A school official could hardly be nominated or accepted into almost any survey pertaining to school-community relations if he/she were not already aware of such trends. The truth is, many of the goals and philosophies identified in the first level of analysis could be described as demand characteristics resulting from the participants' pre-conceived understandings of the research. What was needed was some way to understand why some respondents selected certain types of items, and others selected others.

More insight was needed in understanding not only the preferences of the experts, but the background assumptions which guided them toward those preferences. What tacit rules were they following? What lenses were they looking through?

Initially, as researchers often do, I planned to use some of the demographic information to help answer such questions. However, analysis of individual surveys 
showed that the relevant demographic information on the sites and the respondents' background experiences in international education were not significantly associated with their responses to the Delphi survey.

The need for further analysis does not imply that the consensuses reached by the respondents are not externally valid: All were based upon specific work which was actually taking place in the field of international resource development in the respondents' community or in communities of which they had direct knowledge. In round one, respondents gave specific examples of this work. These examples could be valuable to practitioners and theorists. Yet, listings of resources, goals, philosophies, and competing interests were not enough to get to the underlying patterns of development in the field being studied. Therefore, after the preliminary analysis, a second level of analysis was made in an effort to ascertain the prevalent perspectives of the experts.

The literature and the survey responses made it clear that international education was a confused field, in need of integration. For example, experts rely upon different resource people for very different reasons, all in the name of international education. The result is that educators sometimes use the same language to refer to very different things. Likewise, in the literature, international education is defined in a wide variety of ways, some mutually exclusive. In fact, many analysts and practitioners work without a conceptual model and proceed exclusively and single-mindedly. Indeed, there were few rules to follow in setting out towards a categorized approach of analysis.

However, through the rounds, responses to questions about developing international resources in the community had mostly been categorizable. Checking through the categories and conceptual clusters which I had formed in the first and second level analyses of each question, it became clear that there were commonalities between the categories made of responses to all questions 
on the survey. Using these commonalities, a second level analysis was designed. All items in the survey dealing with international resource development were found to fall into four conceptual clusters. Four models were created to represent these conceptual clusters. These models reflected the literature that had been reviewed, generally in the areas of international education, community education, multicultural education and leadership, as well as the fresh information provided by the experts. Each model describes one of four prevalent perspectives or orientations of international education.

The objective of the creation of these models was to isolate whatever connections, background assumptions and clashing opinions lay behind the selection of different types of items by the experts. The focus of the second level of analysis was not on prevalence of individual items, but on the patterns which the items formed. Did they fall into the models in meaningful ways? Were there any prevalent models?

Question by question, I placed the response totals for each item into one of the four models. The total percentages of items selected in each of the four models for each question was tallied. This meant that consensus could be determined on the general perspectives underlying the responses of the experts to each question. Thus, an effort was made to find the underlying consensus in each of five areas of inquiry with regard to four models of international education. Consensus was declared wherever a majority of items selected by respondents in each survey question fell into a single model.

The four models were further refined from the first round responses, and they continued to take shape throughout the rounds of the survey as more responses came in, more related literature came into focus, and more efforts were made to differentiate between items from different perspectives. The gradual building of the models is a good example of the convergence of opinion 
that gradually develops through the rounds of a Delphi study. The four models are: (I) global curriculum development, (II) multicultural education, (III) education for national security, and (IV) cultural leadership. These models, although useful for analysis, were not revealed to the respondents during the Delphi rounds so as not to introduce researcher contamination.

Of course, there are risks in creating conceptual models. All are reductionist. None are mutually exclusive. In spite of these formidable problems, theoretical bases and concrete examples can be described which enable readers to distinguish fairly easily between the various approaches to the complex field of international education. It might even be said that many people use general models--see with distinct perspectives--so they may as well be aware of them. Thus, despite the very difficult problem of distinguishing between model perspectives with absolute clarity, the creation of models can be useful.

It should be emphasized that the four perspectives, per se, are not normally addressed in the literature as they are here, that there may be many ways of dividing up differing approaches to community leadership in international education, and that the four models were survey results and certainly not survey assumptions. The patterns continually evolved. To finalize these four perspectives before the start of the survey and to write them into the survey instrument would have been to write researcher bias into the survey by forcing respondents into orientations which were really a priori perspectives.

The four models are defined and detailed below. Each is characterized by a variety of descriptors, including (1) its goals, (2) its actors (proponents or implementers), (3) its historical perspective, (4) its dominant metaphor or symbol, (5) its arena (periphery of impact), (6) its stakeholders, and (7) its strengths and weaknesses. 


\section{Model 1: Global Curriculum Development}

Goals. Model I encompasses all efforts to promote international education through curriculum development. Curriculum development is often accompanied by staff development, which is sometimes a primary objective towards the goal.

Actors. Proponents work to add international perspectives or studies such as Third World studies or conflict resolution to the curriculum. Although they treat the school as representative of an international system, their perspective is for the most part trapped within a closed system where change can come only from the inside. It is an internal systems model. Thus, experts may care deeply about global perspectives and problems, but their programs hardly reach beyond the school doors.

Aside from teachers and curriculum writers, educational materials publishers and university schools of education and international relations are also actively involved in promoting global perspectives in education.

Historical Perspective. Two separate histories combined for the realization of this model: the early 1900s, when the myth of politics-free education was formed, and the 1970s, when global perspectives began to be integrated into curricula across the United States.

Metaphor. Since Model $\mathrm{I}$ is an outcome of the tradition that educational change is the sole province of professional educators, and that educational change best occurs from inside the school, the little red schoolhouse is an appropriate metaphor here.

Arena. As the metaphor emphasizes, the internal organization is the domain of Model I. As in most fields, the insiders are the experts. Often the experts look outside the organization and many of the changes they wish to make 
are prompted by the perception of changing external social conditions. Based upon these expert perceptions, changes can be designed and implemented inhouse.

Stakeholders. The primary stakeholders are students, as well as teachers looking to diversify their classroom experiences. District level curriculum writers also have a stake. These three groups are treated as the key resources available for school development.

Strengths and Weaknesses. At best, global curriculum development is a rationalistic plan stated as this: The problem is that students need to be prepared for a global culture, and so the school has the responsibility to integrate global perspectives into the curriculum. It is a popular model since preparing studenis is what schools do. As a result of global curriculum development, students and teachers may eventually cause important changes outside the school. Further, Model I can be an appropriate and effective parallel to international education initiatives of a larger scope.

At worst, it an elitist plan designed for and by academics, with no fundamental link to community needs; thus, it risks falling prey to the temporary philosophies of curriculum writers who are good at scope and sequence, but aloof.

Defenders of this model would claim that today's schools have a variety of mechanisms to avoid tunnel vision in curriculum development. Boards form textbook committees, and various councils are formed from community members. While some of these tactics work, the fact remains that much of what goes on in the classroom by-passes mechanisms for external input and evaluation.

Integrating global perspectives into the curriculum will produce short or, at most, medium term change in the school system and little or no direct, 
identifiable change in larger systems. Cultural transmission is a fundamental goal for all schools. Model I educators pass along the culture--according to them.

\section{Model Il: Multicultural Education}

Goals. The multicultural education movement involves programs which help schools adapt to changing ethnic populations. The purpose of multicultural education is generally to provide equal access to public educational resources. Programs such as bilingual instruction, busing, equal opportunity in hiring, civics curriculum development and the formation of multiethnic site councils embody common multicultural education objectives.

Often educators who attempt to pursue international education goals look first to their own communities. American communities are changing rapidly. Adapting the school so that it meets the needs of an increasingly diverse constituency is the goal of multicultural education.

Actors. Proponents of this orientation include local political and ethnic coalitions. It also includes administrators who are either pressured by such constituencies to press for integration or recognize this community need and press for greater representation of minority groups in the schools. Multicultural educators normally make contacts with resource people for a variety of reasons, including felt political presence, potential to make demands, perceived power in the community, and government mandates.

Federal and state policy makers and the court justices, guided by the First Amendment, are key actors in this movement as well.

Historical Perspective. Model II development accelerated during the years of the Johnson presidency. These were the early years of integration and busing, 
where non-Caucasian groups began for the first time in American history to gain political power and representation.

Model II is a structural and organizational process model of international education; multicultural educators have historically aimed their global initiatives at making system adjustments to accommodate growing needs in the surrounding community which normally result from changing demographics. Often these changes have impacted school finance, such as after the historic Serrano vs. Priest decision in California. These initiatives have generated local change.

This model also emerges from a political perspective; initiatives are often responsive to outside pressures, mandates, coalitions, etc., and are generally short or medium term. Adaptations in the organization may have an impact on the surrounding culture, but this impact will be tangential to the fundamental mission of multicultural education--adapting to changing demographics; and adapting is not the same as impacting. Thus, the real reason for multicultural education is coping with the changing, demanding United States plurality. District boundaries are watched carefully. Faced with an influx of immigrants, multicultural educators have preferred to respond with bilingual education programs before any thought has been given to instituting global perspectives across the curriculum, working with intercultural organizations, or creating global linkages.

Today, some Model II educators view multicultural education as an entirely different field than international education, since they are concerned with problems and promises which exist only in their districts. At the same time, this model is commonly called international education, and it is a field with which international education shares numerous goals. Model II planning, however, does not focus on globally shared objectives and values; nor is it designed to operate in a global system. 
Metaphor. The Supreme Court decision, Brown vs Board of Education, provided the dominant metaphor for multicultural education. This case spurred busing, gerrymandering of school districts across the nation, and a new concern with the pluralistic nature of the United States. The melting pot is another useful metaphor for multicultural education. This metaphor, used in the traditional way, does not represent a true integration of values, but rather the disintegration of values of new groups as they melt into the vast pot of more traditional, United States values.

Arena. The prevalent minorities in the community, the state, or the courts determine the periphery of influence of multicultural education activities, all of which take place inside the school district. School officials charged with implementing these determinations have little to do outside the district. Thus, it is a system open to the the community, but mostly closed beyond this.

Stakeholders. Often the stakeholders appear to be outside groups, such as ethnic groups and minorities. The school district organization and all of its employees must comply with Model II external demands in order to survive, and so they are stakeholders too. Elected political officers whose constituencies are gerrymandered also have a stake. In any case, the stakeholders live or work within the community boundaries.

Strengths and Weaknesses. The multicultural education movement has had a powerful influence on United States education. Multicultural initiatives are often successful in addressing the challenges of international education: Eventually they can raise intercultural awareness, foster intercultural harmony, usher more universal educational goals into the school community, and involve local international businesses and cultural organizations in efforts to develop resources. Because of such eventualities, multicultural education is often confused with international or global education. 
But it is not. It may be idealistic in its stated philosophy, but it has a reactive and very practical orientation in practice. Because it is limited to local communities, for example, multicultural educators care about Mexicans and Vietnamese who are living in their community, but they need not care about those cultures in general. They care about Japanese because the Japanese neighborhood is growing; the perception that our children will need to be prepared to negotiate with Japanese in the future is not what really moves them. While Model I emphasizes global values and not community values, Model II emphasizes community values and not global values. Any overlapping is incidental.

Multicultural educators may have a commitment to international education, and their conception of the arena goes beyond the school gates, but not beyond the physical boundaries of the local district.

\section{Model 111: Education for Economic Security}

Goals. Education for economic security is the model representing efforts to promote international competence in United States schools and to spread positive information about the United States, globally. Education is viewed as a national strength, much in the same way military power, diplomacy and commerce are. As an objective, the federal government, particularly in the 1980s, has attempted to transfer some of the federal responsibility for education to international corporations, defense contractors and other businesses. Educational objectives towards this goal include foreign language acquisition, scientific and technological training, economic education, and other training aimed at enabiing the United States citizenry to compete in the global 
marketplace; these goals are fueled by the drive for national power and resource acquisition. While these may be universal values, they are not shared values.

This perspective reflects an economic determinist conception of cultural development. World peace or cooperative solving of perceived world problems such as health and population are sometimes subordinate and ancillary goals; they are more often espoused goals than goals in action. For example, it has commonly been the policy of the United States federal government that the preservation of international peace be a function of a national defense strong enough to deter aggression. In this light, training future weapons researchers falls under the rubric of education for world peace.

Actors. Model III embodies the perspective of the United States federal government, the United States international business community and, to a lesser degree, research universities. Foreign language educators and foreign language education professional associations are active in the Model III arena as well.

This perspective also has a few followers in the local arena. Local educators who have adopted this perspective hold quite a different perspective than proponents of the first two perspectives. Economic security educators in the community are generally pragmatists who seek out opportunities for school funding. They may implement some global curriculum development, but they do this only if it is an outcome of their search for funding. Like multicultural educators, they respond to immediate or projected needs or pressures, in their case, financial pressures or enticements. Yet, Model III educators are more speculative and proactive than multicultural educators, who often act in response to short term demographic change, if not court order. In the community, wellconnected and influential community members are sought by local educators with this perspective. Such a perspective contrasts with that of local educators with a multicultural perspective, who clearly seek those resource people who 
represent a cross section of community foreign and ethnic groups. In fact, the same resource people (such as a multinational corporation executive) might conceivably be sought after by proponents of both multicultural and economic security educators, although for different reasons (i.e., political group pressure for the former, resource acquisition for the latter).

Model III educators also may be the corporate leaders themselves, looking to craft a positive community image; or they may be looking to gain tax breaks or funding from the government through the promotion of business training for minorities. Such funding also became available to universities and research centers during the 1980 s and it accelerated in the late 1980 s.

Historical Perspective. Woodrow Wilson initiated efforts to promote international security through education, although these efforts were not successful in his own lifetime. Since the post-World War II days, the United States federal policy has treated education as an instrument of international strength. The Cold War made it startlingly clear that national intelligence was a key element in the race for global power. There was a pronounced break in federal progress in this area generally during the 1960s, while the United States turned its attentions to Model II and the nation's changing population. The differences between Models II and III are clearer in the federal policy arena than in the typical local policy arena.

The Reagan White House emphasized new federal funding schemes in order to dissociate itself from local politics of education, as well as to transfer the responsibility for United States educational effectiveness to the business community, where it felt it the stakes lay.

Metaphor. Reaganomics has provided a key metaphor for those serving to carve out such initiatives. But really, this model was built in the 1960s. The Soviet challenge to the United States in the space race raised the profiles of 
education and technology as sources of global power and influence more than ever before. Perhaps the most accurate symbol for Model III is the Sputnik.

Arena. The purpose of education, according to Model III educators, is the economic and overall national security of the United States. Global democracy is their lesser goal. Their buzz word is international competence. Most of the goals of international educators of other perspectives, they feel, will be automatic outcomes of our success in business, from locally to worldwide.

Although economic security is an international effort, the periphery of this perspective is the national boundaries; the goal is United States security, and global security is seen as an outcome of this. The global perspective inherent in Model III is opportunistic. For example, economic security educators care less about Ethiopian droughts than Saudi Arabian oil. Thus, the model encompasses both the federal government's international education initiatives and the increasingly popular concept of the school-business partnership. What the two have in common is this underlying belief: The world's economy is globally interconnected, but not really its culture.

An economic security perspective differs greatly from the first two perspectives in its periphery of influence. Unlike the schoolwide or communitywide systems described in the first two frameworks, economic security oriented educational systems may reach far across the globe in attempting to spread United States influence. The model operates as the United States participates in the United Nations and the World Bank. There is a still greater contrast. At the risk of overstating the case, those of an economic security perspective view the United States populace as a single actor, therefore, with values which are essentially flat and homogeneous; those of the first two perspectives see the United States population as richly textured and more pluralistic. 
Stakeholders. Educational funding patterns began to change dramatically in the 1980s as a result of the growth of this perspective, and so international education gained some new stakeholders. Examples of these stakeholders are local multinational corporations looking for trainees, federal level education officials concerned with the ability of the United States to compete, university deans looking for research contracts with corporations or the Department of Defense, and politicians seeking to broaden their support bases.

Because of the periphery of its potential impact, education for economic security can be viewed as based more upon global needs than multicultural education can. But because self-interest is the driving force in this perspective, advocates are sometimes guided by less universal values and more limited moral parameters than are the Model I and Model II actors. For this reason, employers of foreign community members have an economic security frame of reference rather than a multiethnic frame of reference. They seek minority representation and international understanding, but their motivation is profit.

Strengths and Weaknesses. Indeed, the economic security movement advances many of the basic goals of international education. It involves programs which heighten awareness of global interdependence and impart skills and competencies which will enable students to eventually function in foreign and international settings. It may serve as an instrument of international understanding. Among international educators, those of the economic security perspective may have a more practical objective than global curriculum developers, who practice internal system change; but they do not have a farther reaching vision.

Generally, the influence of the education for economic security perspective is local, national and global, but it embodies more limited ideals than earlier perspectives do. Proponents of Model III may operate in global systems, 
but the stakeholders are all American. This fact limits their efforts. Economic security values are not global values, but nationalistic values; hence, although education for economic security is widely treated as the basis of international education, it hardly espouses universal values and is far from many other conceptions of international education. At a time when most international educators are trying to say that the values of the San Diego businessman cannot betray those of the farmer in a choking Brazilian rain forest, education for economic security seems short sighted and selfish. Global curriculum development and multicultural education are not liable to foster global values in a global arena; but neither is education for economic security.

\section{Model IV: Cultural Leadership}

Goals. A new vision for international education is cultural leadership. Leadership was defined in Chapter I as the achievement of a synthesis of diverse values. A working definition based on this and used for the Delphi survey called leadership the ability to bring real, constructive change and to unite coalitions in new understandings. Cultural leadership involves mobilizing resources across groups, across organizations, and across cultures so that they become united. Cultural leadership requires developing an ecological image of international affairs, wherein no part of the global environment, cultural or ecological, is independent. At the same time, cultural leaders do not devalue the distinct qualities of each individual culture and ethnicity; yet their coexisting vision of a global culture transcends and transforms the values and conflicts of specific groups. Therefore, cultural leadership means not just the empowerment of individual cultures, but the creation of new, more broadly shared culture. If their 
visions and actions are motivational enough, leaders cause a synthesis of diverse, cultural values and, in this way, they are cultural leaders.

Actors. Model IV actors are idealistic, far sighted, and proactive. Immediate or medium term community pressures and economic needs are valued less than longer term, broader educational goals which will build a foundation for future generations. Since their value systems are broadly integrative, encompassing economic, political, academic, ethnic and other values, their orientation is called cultural. Since they are able to bring real, constructive change and to unite coalitions in new understandings, they are leaders.

Cultural leaders believe that attention to the larger needs will inherently answer the smaller ones. Therefore, cultural leaders in the school treat the school, the community and the nation as subsystems of a global system. For example, they are less concerned with multiethnic relations than with international competence, as the first is viewed as a subset of the second. They are wholly concerned with curricular change, multiethnic harmony and the economic security of their home country, but they act as though a global perspective cultivates and instills all of these. They favor curricular change, but they believe that real change in the curriculum will be the outcome of growth in the network of shared values; they seek external organizational linkages and trust that these will lead to appropriate internal organizational changes. The latter will inherently foster the former, as broad values filter into the organization. They believe the school can have an impact not only on the community but, as a part of our state, national and international systems, a global impact. The resources they rely on are part of global networks which clearly extend beyond school district, state and national boundaries. 
Model IV actors are able to locate global resources in virtually every local community. Their initiatives are attempts to connect the school to global trends, systems and values, and they trust that curricular and inside organizational structures will naturally align themselves with this overarching orientation. Perhaps their toughest work is holding to broad principles in the face of the multiplicity of smaller and more immediate demands commonly thrust upon them. Without a powerful, action oriented vision, the demands of budgeting and the constraints of time will consume their efforts.

Past experiences seem to move cultural leaders to exert influences which transcend the more limited purposes of others who have competing interests. They have a clear sense of ecology; they view world problems as shared across the globe, believe that these problems will increasingly impact all humanity, and base their actions accordingly. Such individuals are rare, although their objectives are not uncommonly espoused.

Historical Perspective. This new paradigm has its roots in all three earlier histories. Instead of trying to separate international curriculum development, local educational politics and social issues of an international nature, and international security issues, this model unites them with their common goals. The model emphasizes that local educators can have an impact in all arenas and that, as the saying goes, "it's a small world." The notion that local actors could participate in global systems on an everyday basis emerged powerfully out of the World Future Society's First Global Conference on the Future, in 1980, which called the 1980s the decade for thinking globally and acting locally. Research on leadership begun in the late 1970s confirmed the value of this concept by demonstrating the relationship between leadership and the creation of internalexternal linkages between systems. 
Metaphor. Think globally, act locally is a prevailing metaphor for this model. It's a small world is another useful metaphor. These global network metaphors call for transnational values which are beyond the values normally associated with security policy or foreign policy.

Arena. The periphery of Model IV efforts is the world. It is in this sense that cultural leaders are idealistic, and they generally know they are idealistic. Yet global systems are operating in individual nations, communities and schools.

Stakeholders. Model IV stakeholders are everyone--they are citizens of the world. Thus, educators with this perspective seek universal, moral program goals that synthesize diverse values as broadly as possible, and connect the internal and external systems of curriculum, organization, community, state and world, across cultures.

Strengths and Weaknesses. This is by far the most difficult perspective to practice, mostly because it requires holding on to long term goals for which few groups have the patience or funding. Nevertheless, a loose coalition of cultural leaders are beginning to demonstrate that if they can integrate the objectives from the first three types of international education that are closest to universal, then their goals may evolve into a slate which can gain broad support. The search for common, workable objectives is all that keeps this perspective from being leaden down with idealism.

\section{Summary: Descriptors of the Four Models}

The four models of international education each consist of conceptual clusters which are normally interwoven and matched to the situation, since each international education program has its own set of objectives. However, an orientation towards one of the models is commonly underlying the overall goals 
Model I

Instruction and

curriculum development

Goals:

Actors:

Teachers, curriculum writers

\section{Historical \\ Perspective/ \\ Percipitating \\ Events:}

Historical automomy of educators; 1970 s global perspectives in curriculum movement

Metaphor:

Little red schoolhouse; Myth of politics-free education

Arena:

The school (internal organization)

Stakeholders:

Students, teachers, curriculum developers and publishers

People isolated from the

Orientation: outside environment
School districts, minorities and ethnic groups

ict, state and Seducation officials; minorities and ethnic groups

The 1960s civil rights movement

\section{Brown vs. Board of Education; legislated morality; the melting pot}

The local community

\section{Model III}

Economic security

International

competence and

economic security

Federal government

multinational

businesses, foreign

language advocates

Post-World War II era

The American Defense

Education Act; United

States Information ACt

Sputnik; Rise of

Japanese competition

Interorganizational groups and partnerships, federal government

Multinational businesses, federal govern ment contractors and

People at the mercy of the environment

People as masters of the environment grant recipients

\section{Model IV}

Cultural leadership

Promotion of universal

principles

Leaders

1980s futurist movement;

Woodrow Wilson's internatonal initiatives

Think globally, act locally
World, including school, business, academic,

community, state, nation, and international arenas

Everyone

People as a part of and in harmony with the environment

Figure 1. The four models of international education based upon perceptions of local practitioners. 
of international educators, consciously or unconsciously. As educators become more aware of their background assumptions, the perspectives become more distinct.

All four models of international education have much in common. But, as outlined in Figure 1, there are constants in each model which makes it distinct from the others and able to serve the cause in its own ways.

\section{Consensus on Perspectives}

The four perspectives are to some degree developmental in that each is larger in scope than those before it. For example, curriculum development can be considered a small part of an initiative to promote national security through education. For another example, based upon my review of the literature and research, I believe that the last perspective, cultural leadership, provides a synthesis of all conceptualizations of international education. It is global because it transcends school, community and national goals.

As introduced in the previous chapter, the second level analysis was done in three steps. First, each of the five survey questions were examined. All the items from each question were grouped into one of the four models. In this way, answers to each question were distributed into four lists, representing the four models. Second, the total percentage of items selected by respondents from each model was calculated for each question. Third, these percentages were examined to determine if respondents had reached a consensus or at least had expressed a clear prevalence on one of the four models. Prevalence could be analyzed in two ways for each question: First, by comparing the number of percentage points of all items selected from each of the four models and, second, 
by comparing the number of consensus items which respondents selected from each of the models.

Wherever $50 \%$ or more of all consensus items from any one question fell into any one of the four models of international education, a consensus was declared reached on that question. Likewise, whenever $50 \%$ or more of all percentage points from any one question fell into any one of the models, a consensus was declared on that model. When a consensus could not be obtained for any question, attention was given to the model with the most item selections. Since the four perspectives were not revealed to respondents and international education was never defined in the survey, I hoped that this technique would enable me to discover the real, often underlying or subconscious goals and objectives these experts held for international education, as well as some of their background assumptions about the field.

Clustering the responses and the numbers of consensus items into models served another function. Since some items are more similar than others, one item of one perspective could conceivably have received more selections than either of two rather similar items representing another perspective, but less than the two combined. In this situation, the former would have appeared as a higher priority than either of the two latter when in fact the latter perspective was more highly valued. Similarly, respondents could reach a consensus on a single item from one model and yet select most items from another model, none of which gained a consensus of responses. In this case, the model with no consensus items could in fact be a higher priority. 


\section{International Resource People: Priority Perspectives}

By the third round of the survey, priority resource people had been generated by the experts. Tables 12 through 15 list the items from survey question 1 as they are divided into their models. Each table concludes with the total percentage of votes received by that model as a whole. All resource people who had received less than $20 \%$ of the vote in the second round were eliminated from the round three survey item pool--only round three item selections were considered. Note that the total should be $1,000 \%$, or one hundred percent for each of five item selections per group, with two groups of items. The total percentage is, however, slightly less than 1,000 since some respondents selected less than the required amount of items. Consensus items and total percentages going to each model are listed in bold face type.

There are consensus items in all four models, indicating that a wide variety of resource people are sought out by the experts. Since there were a total of 896 percentage points, no single model received a majority.

Model II resource people were the priority. Consensus had been obtained regarding seven resource people and three of these were Model II types. Model II resource people also received $43 \%$ of the total (896) percentage points possible, reflecting a prevalence but not a consensus.

Perhaps due to the dramatic population shifts that Southern California is undergoing and will be undergoing as it approaches the next century, the experts were (and anticipate being) especially sensitive to Model II. On the other hand, responidents from smaller and more ethnically homogeneous schools did not appear to differ significantly in their responses from respondents in more heterogeneous, urban districts. The survey did not include a random sampling of Southern California sites, however, and so generalizations are hard to make. 
Another possible explanation for the apparent preference for Model II resource people is that even respondents whose schools were not experiencing much demographic change are well aware of state and national demographic trends. Since respondents were asked to base their answers on their own experiences and also the experiences of others who were working to develop international resources, they may have felt that the trends in their own schools were only a small part of the picture.

Table 12

International Resource People: Global Curriculum Development Perspective

Delphi Item

Percentage

Social studies, literature, science and art teachers, foreign born with a global perspective

The district's staff specialist or consultant, international curriculum development

Local businessman of foreign heritage who effectively speaks to students on values and life skills

Director, global perspectives in $\mathrm{K}-12$ education project at local university 
Table 13

International Resource People: Multicultural Education Perspective

Delphi Item

Percentage

President, the school district's multiethnic advisory council

81.5

Latin American or Asian chairperson/parent organizer, international parent committee or PTA

77.8

Latin American or Asian member of school board

Editor of a local Asian or Latin American newspaper

44.4

Chairman, the community's Asian, Latin American or multinational civic organization

Demographic specialist

A key minority employer

Chairman, Asian or Latin American businessmen's association

Director of international relations at the county school district level

President, industrial or Urban League, board of realtors, or homeowners' group

A translator who works with the schools

Pastor or leader of a religious organization 


\section{Table 14}

International Resource People: Education for Economic Security Perspective

Corporate leader/executive of an international corporation or bank

Adopt-a-school contact person, e.g., community relations director at a multinational corporation

Executive, international division of Chamber of Commerce or

Pacific Trade Center

Total

200.0

Table 15

International Resource People: Cultural Leadership Perspective

President, a citywide international community committee

Former foreign exchange student or teacher, now prominent community member

Director, community resource center an educational foundation

Noted futurist or think tank international education expert

Director of international relations at a local university

Communications specialist or producer, local branch of international radio/tv station 
Economic security oriented resource people received $22 \%$ of all selections and two consensus items. The relatively low showing reflects the fact that Model III is particularly prevalent among state and federal educational officials concerned with, in general, wide scale, national economic expansion. At the same time, two of the economic security items, both of which deal with school partnership, each received very high individual percentages. It is possible that this perspective, given continued support from state and federal governments and multinational corporations, will continue to diversify; more items could appear under the Model III rubric in just a few years.

As with Model III, $22 \%$ of the total points possible fell into the cultural leadership model. One consensus item fell into this model. Thus, the experts believed that Model IV community members were and would continue to be the capable of giving support to the leadership efforts of the respondents and their peers, but not nearly to the extent that Model II community members were. This finding probably does not attest to weaknesses of the utility of this model, but rather to the prevalence of the influence Model II community members. In any community, international educators will not have as large a bank of global education resource people to draw upon as they do of Model II actors.

Model I resource people, generally members or adjuncts of the school organization who can contribute to the curriculum development and instructional processes, received the lowest percentage of all selections and one consensus item. This indicates that the experts are more concerned with interorganizational affairs than internal organizational affairs. While it is easily understandable why respondents would have favored Model II and Model IV resource people, it was a little surprising that Model I resource people weren't seen as very useful. While it would seem that curriculum development would be a concern of all school officials, perhaps the respondents, when working in their 
own communities do not find a great many resource people who can contribute to the process of instruction. Or, perhaps curricular and instructional resources are viewed as best managed in-house. Often curriculum and instruction are viewed by school officials as politically charged issues. A third explanation could be that, if respondents have Model IV perspectives, they may view Model I program development as a secondary initiative, subsequent to farther reaching program developments.

International Resource Development Programs: Priority Perspectives

Question 2 asked respondents to cite the program developments being made by resource people. As done with question 1 responses, question 2 items were re-sorted into the four models. Tables 16 through 19 display the distribution of items according to the models, and list the percentages of respondents' selections of items and models. Respondents were given four selections in each of two groups of international resource development programs for a maximum total of 800 percentage points; however, the actual total is less than 800 since three respondents did not select all four items in each group.

Consensus was obtained for a total of five programs and three of them were in the cultural leadership model. Of the available 715 percentage points, the most (45\%) fell into Model IV; however, it did not receive a majority. Cultural leadership and multicultural education were the top two priorities, in that order, which was opposite the order that they turned up in question 1. Together these two perspectives gathered 544.3 percentage points, or $76 \%$ of all selections.

There was one Model III program upon which respondents reached a consensus. The consensus seems to confirm the obvious, that experts were and will be looking for resource sharing opportunities with multinational corporations. 
Table 16

International Resource Development Programs: Global Curriculum

Development Perspective

Delphi Item

Percentage

Teach classes with a global perspective

Advocate programs for students with special needs

Provide perspective and inspiration re: educational needs at the university level

Total

Table 17

International Resource Development Programs: Multicultural Education

Perspective

Delphi Item

Percentage

Provide a clear vision of minority employment needs/perspectives and assist the school in developing appropriate programs

Provide inservice training/consultation to parents, staff, community

Contact and influence with many segments of district's foreign

community--effective community organizer

Serve on the school board with clear understanding of community expectations

Inform school leaders of cultural and demographic changes locally

Direct a community foundation dedicated to supporting the school

Assist schools with immigrants' problems (e.g., citizenship, language)

Lead politically powerful community ethnic groups 
Table 18

International Resource Development Programs: Education for Economic Security Perspective

Delphi Item

Percentage

Lead the school-business partnership program at a large multinational corporation which provides the school with useful resources 77.8 Inform school leaders of cultural and demographic changes nationally 48.1 Total 125.9

Table 19

International Resource Development Programs: Cultural Leadership Perspective

Delphi Item

Percentage

Coordinate school efforts in obtaining global education resources and consult on international trends for curriculum updates

81.5

Help prepare students for international citizenship

81.5

Inform school leaders of future trends and global issues: global interdependence, geopolitics, health, poverty, etc.

Provide schools access to distinguished foreign citizens and immigrants

Provide student and teacher opportunities such as internships, foreign exchanges, speakers for meetings

Provide publicity aimed at bringing foreign fiscal and human resources into the schools

Total

318.5 
Model III received 125.9 of the 715 possible percentage points, or $17.6 \%$ of all responses to this question.

The respondents gave a low priority to Model I programs. With 44.4 of the total 715 percentage points (6\% of all responses), Model I resource people received considerably less attention than those of other perspectives, as they did in the first question.

\section{Agenda Items--Salient Issues in Developing International Linkages: Priority}

\section{Perspectives}

In question 3 respondents were asked to develop an agenda which focused upon the goal of developing international linkages. Since respondents were allowed four picks in each of two separate listings of agendas, the highest possible total of percentage points for any model was 800 . In all, respondents selected three less items than requested, and so the total percentage points came out to 781 .

Again, no single model contained a majority of item selections. What was surprising, though, was the change in priorities from the first two questions. Curriculum development was rated as the top priority model for an agenda and also received three of the five consensus items, a majority. The priority agenda items are presented in Tables 20 through 23.

The second most valued perspective was cultural leadership, which received the second highest percentage and two consensus items.

Thus, although multicultural education and cultural leadership rated highest in all the earlier questions, there was a dramatic rise in this question in selections of the global curriculum perspective. Despite having more items than 
Table 20

Agenda Items: Global Curriculum Development Perspective

Delphi Item

Percentage

Staff development, hiring and teacher training practices

Teaching conflict resolution and cooperative decision making

International resources available in the community to promote students' global awareness

Developing a more international school culture/climate

Goals and objectives for an international studies program

Table 21

Agenda Items: Multicultural Education Perspective

Maintaining cultural values and diversity despite increasing immigration and integration

Positive steps for ethnic harmony and conflict management in the school community

Parer.tal education and social services for newcomers

Equality of educational opportunity. How are foreign students doing academically?

Demographic developments in the area: Their impacts on educational programming

Developing bilingual and limited English proficiency programs

Using the school sites as community/neighborhood centers 
Table 22

Agenda Items: Education for Economic Security Perspective

Delphi Item

percentage

Skills, knowledge and creativity required by a futures oriented business community

Preparing students to live abroad and work in the international economy 14.8

Partnerships with higher education and business

Total

Table 23

Agenda Items: Cultural Leadership Perspective

Delphi Item

percentage

Strategies for promoting awareness of interdependence of people and nations over time

Education's role in addressing global problems (e.g., communications barriers, ecology, food, survival)

81.5

The role of the school in cultivating a pluralist, international United States society

What are the real district priorities and how appropriate are they?

Perceived needs/understandings for an internationalist local community

Technologically enhanced, global learning systems, communication with foreign sister cities/schools

Total 
any other perspective, multicultural education rated only third in overall percentage of items selected.

One of the the highest percentages of any item in the survey was for staff development. Presumably, given the small measure of concern for curriculum displayed in the earlier areas, the experts believe that the way to develop international curriculum is to hire the best teachers, who may in turn tend to Model I matters. The curricular item gaining the second strongest consensus of opinions in this area was teaching conflict resolution and cooperative decision making. Comments of the experts reflected that this area was of particular value to them as administrators. These experts deal with a broad collection of constituencies and their personal interests in the areas of conflict and cooperation may have projected into their curriculum goals.

Another explanation is possible for the rise in respondent selections in Model I in this question. The first two questions involved tapping resources in the community. Perhaps educators cannot find enough Model I resources in their communities and wish this problem would be addressed more in the future. This would make Model I items figure high on their agendas. Still another explanation is that respondents may have tried to develop a broad slate at the Town Meeting and were aware that some of those in attendance would be especially interested in curriculum and instruction. A final explanation for the rise in Model I selections might be simply that school officials feel more pressure for student achievement than for other areas--few job descriptions hold them responsible for global development.

Model III gained less support in this question category than elsewhere in the survey. The best explanation for this is that ideal Model III programs are embodied by Model IV. An enlightening comment on school-business partnerships came from one of the respondents: "I would like to see the 
partnerships go both ways; with schools providing a marketing test group or some other kinds of support for businesses." This comment implies that, although the experts seek school-community partnerships, some of them may be interested in developing these partnerships more in line with Model IV which accentuates the creation of shared culture. Likewise, it emphasizes a relationship mutuality more characteristic of the longer term, more futuristic programs reflecting the Model IV perspective.

\section{Philosophy of International Education: Priority Perspectives}

In question 4 respondents were asked to focus on the purpose of the Town Meeting. This enabled them to express their philosophies on community based international education. Since respondents were allowed three selections for this question, the total percentage possible was $300 \%$. Two fewer selections than allowed were made and so the total percentage of all items selected was $292.6 \%$. The distribution of items into the four models is shown on Table 24,25 and 26.

Among the ten round one items, three were eliminated in round two and seven were left to choose from. The seven items fell into three of the four models. There were no items pertaining to global curriculum development since no responses were made during round one which fell into this category. The economic security perspective, which received far fewer responses than the remaining two orientations developed in the first round, was represented by one item in this item pool. Multicultural education and cultural leadership were the two areas where the most items were generated in round one and they were given three items each from which respondents could pick. In an effort to force 
Table 24

Statement of Philosophy: Multicultural Education Perspective

Delphi Item

Percentage

We need to address the perceived needs of (and our common goals with) an increasingly transient and pluralistic population which is vastly different from the community of a few years ago.

81.5

We are in a state of rapid change in California. One fourth of the world's immigrants settle in California. We must all adjust and plan together.

We need to develop a climate of mutual support in the community, so that common goals can be found.

Table 25

Statement of Philosophy: Education for Economic Security Perspective

Education has a mandate to keep the United States competitive in the international marketplace. 
Table 26

Statement of Philosophy: Cultural Leadership Perspective

Delphi Item

Percentage

Education is one of the basic factors in international relations, quite as important as diplomacy, commerce and military power in its implications for war and peace.

Schools need to prepare students to participate in a world culture.

Schools need to find ways to enable our next generation to contribute to world peace and understanding.

Total

163.0

participants to narrow their focus, only three priority item selections were allowed. So that respondents weren't forced to select statements representing philosophical orientations other than their own, they were instructed to pick one, two, or three statements.

In this case, unlike in earlier question categories, a clear majority of selections that were made fell into one model, the cultural leadership model. Two of the three consensus items also fell into the cultural leadership model, thus an overall consensus was obtained on the statement of philosophy consensus items. This was especially significant since it was the only instance of a consensus of items developed for one model. Considering all ten items, Model IV received $55.7 \%$ of the possible respondent selections. 
The clear second place model was multicultural education. Finding common goals for a changing, diverse population was the theme of all three of the items in this model.

Model III received one selection. This item was probably viewed as important to those respondents who were particularly interested in schoolbusiness partnerships. Another consensus item, "Education is one of the basic factors in international relations, quite as important as diplomacy, commerce and military power in its implications for war and peace" was closely related to Model III since it involves players from this arena; however, it was placed in Model IV because the goal inherent in this philosophy, generally, global peace, is more global and morally more sophisticated than Model III goals. It calls for a transformation of present policy relying on power to a policy relying on education as equally important as power; or, perhaps in this model education can be viewed as an alternative form of power.

This question differed from all others on the survey in a fundamental way. It asked respondents to express their own philosophy. It was a more personal question than the others and the experts responded by mixing what was doable with what was dreamable. It seems logical that where individuals believe they can express their own views of the issues, free of social and political pressures, the level of idealism and futurism increases. Some school officials would react negatively to such a question out of the belief that public office is not a personal or political pulpit. My own opinion is that the respondents were willing to devote serious attention to expressing their own ideals in an autonomous fashion and that willingness demonstrates integrity, commitment, vision and at least some capacity for leadership on their parts. This is especially true since the consensus was reached in Model IV, a model which reflects nothing of self-interest for the respondents, their schools, or their individual communities. 
Respondents were asked to answer all questions in terms of what was already occurring and expected to continue occurring as they prepared schools for the next century. But preparing for the next century may have proven to be something of an intangible, esoteric task. This survey question gave them an opportunity to be more idealistic. Creating an agenda for a simulation provides creative latitude which may have contributed to the high percentage of items selected in Model IV, since Model IV is the most global and futuristic perspective. Respondents, its seems, would apply these philosophies if only they could, and no one knows if they will.

\section{A Third Cut: Toward an Integrative Model}

Throughout the second cut data analysis, the division of data into four models served the purpose of isolating various perspectives on international education. However, the goal of the research could not be simply to categorize the different perspectives of the field. A categorized approach was useful largely as an objective towards a larger goal, which was the development of an integrative model. The need for this goal was a key finding made in the review of the literature and was verified through the Delphi process. Thus, a fundamental goal of the research, beyond clarifying the differing perspectives, would have to be to synthesize the four models so that a transcendent vision of international education needs could be identified and addressed clearly by all players in all arenas. In this way, the research and analysis followed a path of inductive reasoning as follows: Gather the items (generally, round one), divide the items into conceptual clusters (generally, rounds two and three), and form a synthesis out of the diverse concepts (generally, the Delphi summary). 
The need for this process made the research formative, shifting elements often found in the research design to the process of data analysis. In the final analysis, I have sought to identify a single perspective from the data, and to try to analyze how realistic such a synthesis is. In other words, the third level of analysis considers the question: Is a new synthesis of internationalism in the school community forming?

Table 27 provides a look at the combined response totals for the first four questions. The total selections made throughout the survey from each model is displayed. In the table, Model I is global curriculum development, Model II is multicultural education, Model III is education for national economic security and Model IV is the cultural leadership perspective. Reading the table, the total number of percentage points for the first four Delphi items are expressed as "points." The percentage of all points falling into each model throughout the final survey is expressed as "\% of points." The fourth column of the table records total number of consensus items which fell into each model. The fifth column of the table records the percentage of total consensus items which fell into each model. Model IV is in bold print since it received the highest ratings.

Table 27 reveals the proximity of percentages of total points received by each model (column three) to corresponding percentages of consensus items received by each model (column five). This finding implies that consensus items were representative of all items in their respective models. In other words, there is some indication that the items were well suited to their models, and that the prevalence of items was indeed related to the models in which they were assigned. This further implies that the respondents were indeed applying guiding principles to their selections and that, therefore, a categorized approach was meritous. 
Table 27

Comparison of the Four Models of International Resource Development

\begin{tabular}{ccccc}
\hline Model & Points & \% of points & consensus items & \% consensus items \\
\hline I & 444.4 & 16.6 & 4 & 19.0 \\
II & 892.2 & 33.2 & 5 & 23.8 \\
III & 437.0 & 16.3 & 4 & 19.0 \\
IV & 911.0 & 33.9 & $\mathbf{8}$ & 38.0 \\
TOTALS & $2,684.6$ & 100.0 & 21 & 100.0 \\
\hline
\end{tabular}

There was one exception to the proximity of point percentages to consensus percentages. This was in the case of Model II, which received considerably more percentage points than percentage of consensus items. This might reflect a reluctant preoccupation with Model II concerns. Throughout the survey, more items fell into Model II than any other model. Experts are highly aware of these concerns, and they frequently site them as salient issues in their communities. At the same time, the results of the Delphi survey indicate that Model II concerns, however myriad, are not as important to international educators as Model IV concerns.

Cultural leadership is the leading perspective among the experts, although no consensus was obtained on a single perspective when a total of all item selections on all questions was considered. Realistically, there are two prevalent components to the perspective of today's expert in international education. The first is a globally oriented, cultural leadership perspective. The second is a practical and more locally oriented, multicultural education perspective which is 
tailored to constituents and the changing and demanding demographic realities confronted in the community. These two perspectives are blended together to suit the degree of discretion from situation to situation. Greater discretion at the hands of the experts means greater idealism in their perspective.

Cultural leadership was not a title that was given lightly. To label a model "leadership," it had to stand up to a great many expectations and implications, some of which will come out only once the analysis is complete. Yet, the cultural leadership model is the only one which works in all arenas and transcends group differences, and therefore, even if it cannot yet be called a leadership model, it is clearly the only model available to experts in the pursuit of leadership.

\section{Delphi Summary: Composite Profile}

Based upon three levels of analysis, it was possible to produce a composite profile of international resource development in the local community. The profile reflects the perspectives of 27 experts in Southern California as they plan for the next century. Particular attention in this profile is given to areas where the composite matches Model IV. In this way, the profile specially deliberates over the worth and applicability of Model IV in today's world.

Multiculturally oriented local resource people will be most commonly sought and promoted by the experts. One might surmise that, from where the experts sit, these resource people would be seen as representing pressure groups; yet, nothing could be farther from the truth. No minority or foreign group rated high as a source of external pressure which would hinder initiatives in international education. In fact, the category of "recent immigrants" rated lower than any other items on the scale of competing external pressures (1.77 on a scale of 5) and "ethnic and religious groups" rated low to moderate (2.85 out of 5). The 
conclusion is that, if multicultural groups were seen as a pressure, then it is a positive pressure, one that schools will wish to use generatively as they seek leadership opportunities in international resource development.

The resources are and will be available to serve schools in a variety of specific ways. The 1960 s are long past, but systems for integration continue to be negotiated. District advisory councils, parent committees and multiethnic school board members will all be priority contacts for experts in their efforts to lead.

Corporate representation will also be key in such leadership efforts. The experts will be looking to corporate executives and liaisons who can assist in structuring partnerships. Aside from resource people who can work directly inside the schools, the experts will occasionally be looking to citywide organizations which can link the school with broader constituencies.

A wide variety of specific resource people and programs are identifiable and should be useful to the experts. At the same time, the experts stress that it is not just specific resources or people who are needed. Rather, a diversity of contacts, balanced and representative of the community, are needed. As an assistant superintendent commented about his priority resource people, "they each represent a different community within the larger community."

Despite its top priositization for the purposes of resource acquisition, multicultural education planning is not, however, viewed as the most important international education need in the local community. Experts are aware that to be in the lead in working with resource people they will have to provide not only systemwide or communitywide educational leadership, but cultural leadership. This means that they will be unable to merely respond to community needs for internationalism or to wait for issues to manifest themselves; moreover, they must take an active role in seeking out key resource people so that schools can be on the cutting edge of community and broader change. 
In working with the schools, resource people will serve a variety of prominent functions. Foremost, they will need to be able to locate global education resources and make them available to the schools so that students can be prepared for the impending needs for international citizenship. Aside from the pressing needs for resources, school leaders will also need information. World health, population, geopolitics and poverty will all seem closer to the doorstep of United States schools as global networks tighten. Still closer to home, businesses will also be valuable in providing a clear vision of minority employment needs providing schools with the appropriate perspective as they develop proactive programs.

Working with these valuable resource people, the leaders among experts will be developing their dialogs with the community in a number of areas, and new agendas will emerge. These new agendas will embrace a broad spectrum of needs, primarily those of multicultural education, cultural leadership and global perspectives curriculum development. Educators will be developing leadership roles in addressing global problems. Long term strategies will need to be conceived and built so that schools can promote awareness of the interdependence of people and nations over time. These strategies will have to answer not only to the community, where demographics will continue to change, but inside the classroom and through global linkages.

The agenda will, of course, reach into the classroom. There, conflict resolution, cooperative decision making and futurism will have to be integrated into the curriculum in order to adequately prepare the citizenry for the coming century. The leaders will facilitate this curriculum development by refocusing their hiring and staff development practices in concert with the growing needs for a global perspective. This refocusing has already begun. 
Given the opportunity to set the agenda themselves, rather than call up the agendas of those they consider to be the community leaders, the experts believe they would be able to focus more upon philosophical issues and universal principles. There are a variety of ways to explain this variance of perspectives. It could be explained that the experts would like to develop a more global agenda but are hindered by the demands for a more multicultural one. This would be logical given the changing state of demographics in many districts. Yet, when the experts are asked about what causes the greatest conflicts in the carrying out of their agendas, they do not often cite ethnic and multicultural community groups.

A more viable explanation for the variance in perspective that exists between the concrete plans and the philosophies of the experts could be that they don't believe that a more global perspective would be conflictual, but just that the people in the community have not come to understand such an agenda very well, at least not yet. Indeed, the experts themselves are not committed to a cultural leadership agenda, even if they believe that it sounds better than others. They do believe that the agenda will become more global in time, though. Perhaps it is not uncommon for perspectives to grow idealistic as people peer further into the future.

Here in 1989, there is no consensus on Model IV; but there is a preference for it. Today's leading educational philosophies transcend traditional philosophies. The leaders in international education will be seeking to meet communitywide needs in ways that prepare students for a global culture more than a community culture or even a national culture. School leaders will be forming linkages with integrated, broad based, community groups and with leading internationalist organizations. They will be collaborators and linkers. They will work with resource organizations and resource people who can integrate their missions with the school mission. This outside work will supersede 
the work that educational leaders personally do inside the school. The arena of school leaders is opening up; the numbers and types of actors to be found in this arena is diversifying, as are the uses for the school physical plant.

As they plan for the next century, experts will be guided by their belief that "education is one of the basic factors in international relations, quite as important as diplomacy, commerce and military power in its implications for war and peace." In relating their philosophies to war and peace, the experts could be foreshadowing a long term trend, that is, the application of a broad, moral imperative to leadership efforts. This imperative addresses not only curricular and national security needs, but community and worldwide needs. For example, a long term trend in the federal government has been towards increasingly treating education as a vehicle for developing the nation's global competitiveness. But the federal government's initiatives will not be of primary concern to the experts; and, in continuing the policies of the Reagan presidency, the federal government under Bush continues towards the goal of turning over responsibility for international competitiveness training to business and school communities, anyway.

Moreover, the trend will be towards citizen diplomacy, where educators will communicate through networks which parallel those of government diplomats. Exchange organizations, cultural organizations at home and abroad, and multinational businesses are increasingly becoming adjunct school organizations. Their leaders will work in closer association with educational leaders, facilitating linkages from local to global. Also implied by the priorities of the experts is that school leaders, as new diplomats, will foremost be communicators. They will be working largely outside the school organization. Phone bills will grow. Perhaps teleconferencing or related technologies will 
become essential. These are the trends, although not by much; the experts expressed clear priorities, but not a clear consensus.

Perhaps it is needless to say that there have been and will be a wide variety of conflictual pressures which the experts confront as they walk down the hallways of their schools harboring such planetary agendas. Competition for the time and attentions of administrators could be stiff and the obstacles could obscure many goals.

Internally, budgeting is the most prominent of these obstacles. Ironically, the experts believe that a fundamental advantage of their work in internationalizing the school is that it will provide new resources. So why the concern with budgeting? Perhaps the clearer conflict is that seeking new, internationalist agendas will certainly not simplify life for administrators. They view the curriculum as already overcrowded and their efforts seem constrained by too many meetings and too much paperwork. Much of their time seems more mandated than discretionary, and when burdened with day to day management demands, the experts tend to spend less time in pursuit of their longer term goals. Where is the time for leadership?

At the same time, the search for more universal educational values could synthesize scattered efforts and the broadening array of potential resources. This synthesis could be the nexus of future efforts to implement innovative educational programming. Synthesis streamlines: standard time and money burdens could be eased. The promise of international leadership in the community will have to rest on the restructuring of internationally salient priorities, not in a reprioritization of old, sometimes mythical values. When theorizing, the experts are willing to make these kinds of tough choices and, through their plans and philosophies, they indicate that they would like to do the same in their communities. 
Considerable external pressure will also weigh on the goal of international leadership in the community. Despite a good deal of talk about increasing site level autonomy, the experts devalue such rhetoric. The fact is, they state, that government mandates will continue to take away much of the control local leaders might claim for their own.

The most basic pressure, however, is conservatism. The first and third greatest negative pressures cited by the experts were "dominant or upper middle, class, vocal majority groups" and "conservative political organizations (John Birch, Moral Majority, etc)." This finding would seem to confirm the continuing relevance of the politics of education myth, wherein traditionally dominant community groups unrelentlessly attempt to maintain the status quo. Of course, myths change through time. The difference between the traditional form of the myth and its form in the late 1980 s is that school officials no longer view themselves as a part of the old guard. The in-game is falling apart, but slowly. The fact that the traditional majority groups still work to keep new groups out of the political apparatus appears to be self-defeating, turning once prevalent groups into isolated, political interest groups. Ironically, the experts, who historically represented that traditional majority, today view recent immigrants as their very least threat-a dramatic evolution of perspective.

Local foreign groups are genuinely viewed as resources which benefit the school community. But there is a hitch; in the experts' view, this democratic, global perspective is not shared by the majority of their constituents. "Freedom," said Will Rogers, "is the right to kick about it," and evidently this is a freedom to which traditional majorities have become all too accustomed. Not so among foreign groups. From the standpoint of the experts, such groups are passive in their efforts to get the educational system to develop a more international or multicultural set of values. While the old guard campaigns to preserve more 
traditional, homogeneous values, foreign community groups don't seem to kick. This could explain the experts' feelings, identified in a Model II consensus item, that their own agendas differ considerably from the agendas of their local constituencies. Experts don't see this as a problem, and devote much of their attentions to integrating diverse minorities into the school communities.

This is a problem though, since, if a universal perspective is to be found and applied, it must reach beyond the local community and tap the broadest of values. This problem may serve to isolate school officials interested in changing values. One superintendent stated: "I'm with these people--without help (people) and money." There is lonely exasperation beneath these lines. Who are "these people?" This superintendent, who was himself from the traditional (white, middle class) majority, had attempted to adapt the school to a changing community ethnicity. In doing this, he had apparently grown isolated from his own group, including the board, while never quite gaining the power resources or leadership to reach the minority. Wherever localized values and pressures preoccupy the arena, real change is impossible, and this is the red flag for leadership.

The fourth most prevalent pressure facing local international education practitioners is "problem oriented groups (AIDS society, drug awareness group, etc.)." Although the examples of problems listed by the experts are very contemporary, this finding is hardly new; it indicates an historical problem often cited in the literature, that is, the public perception that the school should be accountable for practically any social ill. These are the problems which the public has grown accustomed to reading about. They become newspape: features almost daily, and so their prominent placing in this survey comes as no surprise. The only surprise is that these sources of pressure and conflict were rated as second in priority behind traditionally dominant groups. Perhaps this is because, 
almost mythically, it has been these very groups which are most likely to blame the schools for such problems.

The fifth and sixth priority pressures cited by the experts, respectively, "parent groups" and "board of trustees/board of education," are also very traditional pressures. One respondent described a superintendent he knew who found himself resentfully resigning his position due to his school board's staunch refusal to support his proposals for "working with non 'American' peoples."

The need for restructuring of priorities is most evident considering the conflicting perceptions of and goals for international education. Although cultural leadership, the most prevalent perspective of the experts, represents a global view, multicultural education also figures prominently in the work of the experts. These two perspectives share some goals, but conflict in others. Concern for community demographics may not help in the development of more global values or international competency. For this reason, the experts as a group still fall short of fully espousing and practicing the synthesis required of cultural leadership.

A striking example of this limitation is that when asked for examples of foreign groups in the community, the experts often cited groups of United States citizens--ethnic groups, such as blacks and Jews. Warned a director of community partnerships in a large urban and suburban district, "State and local government officials must, by the year 2000 , be representative of all ethnic groups and effectively represent an international, one world point of view." The point is, when ethic groups are called "foreign," they are in a sense being referred to as unAmerican and alien. Foreigners and United States ethnic groups alike are the outsiders in the school community. The problem with this viewpoint is that the United States is not being damaged or compromised or burdened by ethnic groups--the United States is ethnic groups--but still, some are "us" and others are 
"them." Leaders will need to find global values locally, while they "avoid local politics," as one superintendent phrased it.

The federal government has had a similar, us-them stance. Federal goals for international education have been structured into win-lose initiatives where United States profit takes priority over global development and far sighted, ecological planning. To embrace the future in a truly interconnected world would be to develop values broader than those found in a single community or a single nation. Educational experts are better at stating this philosophy than at doing it. This could be considered the most fundamental conflict uncovered by this research. It seems the balance between diversity and unity will always be delicate, as will the balance between practice and ideals.

Research in leadership has demonstrated that unifying these sometimes contradictory values will require a transcendent vision to start. Such a synthesis may be in its early stages. For example, a San Diego County communications coordinator pointed out three examples of programs which he felt would best shape fundamental educational goals for the next century. These are: "(1) summer study tours for students parents and teachers [which could offer] high school credit for students, staff development credit for teachers, and continuing education credit for parents, (2) utilization of technology in the electronic bulletin board via computers with sister cities/schools in foreign countries, and (3) impact of growing third world populations and its implication for education and international studies programs." Although these three programs were included on this respondent's wish list, they all exist in various locations today, and this is evidence of Model IV in action.

Programs are not leadership, but taken as a part of a pattern, such programs can be felt as a groundswelling. If we can assume that, although the cultural leadership model has only very recently become more prevalent among 
the experts than the other three models, then an important trend can be discerned from this research. It is possible that movements in global curriculum development, multicultural education, and education for economic security have been the forerunners which have been leading to a more global perspective. In this research, the experts envisioned an increasingly interconnected, global society on its way. There is no consensus of opinions on this, only a prevalence. So while many experts will continue to espouse smaller scale values, it is possible that a larger vision is coming together.

One superintendent stated, "Our goal is to live and work as one;" but this is a cautionary tale: If experts are to be leaders, visions must be turned into widespread action. There is little surprise in the finding that new actions will encounter traditional, countervailing pressures against change. Structuring, articulating and promoting new agendas in ways which arouse traditional constituencies and enable them to transcend their old concerns is a fundamental leadership challenge. A second fundamental challenge is balancing what is ideal with what is possible. As the experts were addressing goals for international education, they seemed to keep these challenges in mind. One said, "We must join together to have a workable plan for the future in our ever shrinking world." 


\title{
CHAPTER VI
}

\section{SUMMARY AND RECOMMENDATIONS}

\author{
Summary of the Study
}

\section{Background Issues}

Culture acts as an autonomic nervous system for education, embedding unknowns and deep assumptions about its own meanings; and while curriculum committees and school boards tinker with the educational body's conscious responses to its surroundings, it is that innate, taken for granted culture, like the turning of the planets, which guides the process firmly along its course. Educators have joined in a search to find out what makes this autonomic nervous system perform, and there are a flurry of new findings. In these findings are promises that educational planners may have a hand in shaping functions which have traditionally been outside of their spheres of influence.

In addition to their traditional role of transmitting knowledge and values, educational systems are charged with a new range of aspirations and needs. A wide variety of economic, political, social and cultural developments whose roots lie outside the educational system are are impacting the arena, challenging the leadership of educators. Organizational theorists Lorence and Lorsch advocated "activities [which] seek to move the organization towards degrees of boundary permeability and relationship mutuality with respect to both internal and external 
environments that are appropriate to the challenges facing the organization" $(1967$, p. 20). Alderfer and Brown stated,

Schools share with businesses the dilemmas of managing tensions. To some extent, such tensions may well be a function of the external environment. . . . Inevitably, compulsory universal education leads to microscopic replication of the tensions of the larger society in its schools, even though gerrymandered school districts can produce relatively homogeneous schools. Race, socioeconomic class, religion, generation, and other wellsprings of social conflict are often represented in classrooms in potentially explosive forms. $(1975$, p. 23)

There are new roles for educational leaders. Among the most salient of these roles is international cultural relations. Through international cultural relations, "institutions and peoples form an understanding of one another across frontiers" (Mitchell, 1986, p. xiv). School leaders have been summoned into this arena as the global interconnectedness of United States communities has grown; for while official relations between cultures do not often directly touch the lives of most people, cultural relations do. As Senator Fulbright wrote a generation ago, "The shape of the world a generation from now will be influenced far more by how well we communicate the values of our society to others than by our military or diplomatic superiority" (Mitchell, p. 2). MacLeish echoed the same view: "Foreign offices are no longer offices to speak for one people to another; the people can speak now for themselves" (Mitchell, p. 2). If these views represent our future, it is essentiai that schools and educators engage in and teach the language of intercultural relations. Cultural leadership prompts the convergence of conflicting, conventional barriers that separate peoples. International and community educational leaders in today's public schools agree with near unanimity on one idea: "Education is in reality one of the basic factors in 
international relations, quite as important as diplomacy and military power in its implications for war and peace" (Mitchell, 1986, p. 190). For this reason, educational leaders of today are beginning to view themselves as cultural leaders.

\section{Objectives of the Study}

The ultimate goal of Think Globally, Act Locally: A Delphi Study of Leadership in the Local Community Through the Development of International Resources has been to identify the leadership potential inherent in the development of international resources found within the school community. With this research, strategies used in developing this potential have been sought and have emerged. The objectives of this search have been:

1. To characterize what experts in international resouce development do and what leaders could do, both in the schools and in the local community;

2. To identify far sighted program developments and dynamic schoolcommunity partnerships;

3. To identify practical and philosophical goals for fusing international perspectives, universal cultural values, federal values and local educational values; and

4. To identify competing demands and pressures.

In creating educational systems for now and the future, educational leaders today must align the schools with a widening body of cultural organizations. Finding new resources and establishing relationship mutuality are essential for proactive educational development. They are equally essential for avoiding isolation from community and national values which educational systems are charged with passing along. But in seeking an educational system for the common good, the passing along of local and national priorities is no longer 
enough. Avoiding more universal, global values also means isolation. Educators are naturally concerned about this threat. In organizations, as with individuals, isolation brings the surrendering of automony and the forfeiture of leadership.

Uniting diverse groups with broad values; shaping culture; ending isolationism; turning conflict into generativity and symbiosis: these are challenges about which leaders strategize. The globalization of local and national cultures touches every school, and so one of the greatest challenges for educators is in promoting global educational values.

There has been no dearth of research on how culture shapes the educational mission. Many studies are available on globalization of the curriculum taking place inside the schools. Many more focus on federal initiatives, university initiatives and business initiatives. But it is only the local educator, in the local arena, who can provide leadership in the districts and communities across the United States.

Working with their communities, many educators today believe that they can lead. Opportunities are often found untapped only because no one has thought of them or because no one has realized, as many of the experts in this research have, that the work of district and county educators does fit into broader plans. These are the plans of cultural leaders and this research has attempted to isolate them.

\section{Methodology}

With this study, I have sought to generate a collective vision of international educational leadership in the local community. The Delphi technique was chosen because it can engage experts in an anonymous debate regarding social trends and because it it has been shown to stimulate generative, 
far-sighted dialog on an emerging area. A more quantitative methodology would have demanded a larger sample, inhibiting the opportunity for interactive dialog. A more qualitative methodology would have limited the sample size and, thus, the breadth and generalizability of the collective vision generated.

The survey was designed and piloted during the fall and winter of 1987-88.

The research was confined to Southern California in order to facilitate communications between the researcher and the respondents during the rounds of the Delphi survey and in order to confine the research to an arena in which internationalism could easily be discerned. Since neither future predictions nor attitudes towards social trends are verifiable, at least in the short run, a random sample was not attainable; however, a stringent sample nominating process was designed to admit only experts into the sample population. In creating the sample, private schools and district and county public schools throughout Southern California were randomly selected. Superintendents and school directors were contacted for nominations of individuals who were considered experts, and these individuals were interviewed over the telephone. In the end, 27 district and county sites, all public, made up the core of the sample. In addition to the very high return rate, the sampling process turned out to be efficacious in that it resulted in responses which complemented findings in the literature.

The Delphi process may be considered a process that limits the sample since it is fairly time consuming. On the other hand, it can add a measure of reliability, since completion of all the rounds requires persistence and, hence, dedication to the area of inquiry on the part of the respondents. Only respondents well suited to the task would normally be willing or expected to comply with all of its demands. For example, one respondent wrote in response to his receipt of the Delphi Survey Summary: "The results are exciting as well as 
interesting. 1 . . believe it will have a profound effect upon future learning programs." Virtually all respondent comments on the survey's form and content were positive. Delphi surveys also have a demonstrable external validity. Following the rounds of a Delphi survey, the predictions of expert sample groups have been shown to be significantly more accurate than the average or modal estimates of individual experts.

For this Delphi study respondents completed three rounds of survey instruments between March and June of 1988. Surveys normally took about 45 minutes each to complete. There was a return rate of $58 \%$ for the first round survey. This first round mailing included 50 potential respondents, some of whom had not agreed to do more than consider the survey. Once the first round sample of 29 respondents had agreed to the study, there was hardly any respondent attrition: 28 of the round one respondents completed round two $(96.6 \%$ return rate); and 28 respondents completed round three (100\% return rate), although one respondent's third round response was too late to be included in the Delphi summary.

A Demographic Survey was designed for the creation of a profile of respondents and their institutions. The demographic survey was sent with the round one Delphi survey. Although the experts turned out to be primarily white, middle aged, male school district superintendents, their offices were anything but the bastions of traditional majority groups, as is clear from what follows.

The final Delphi survey resulted in descriptive statistics which detailed the process of the development of international resources in the local community. 


\section{$\underline{\text { Results }}$}

Research seldom has explored what educators are doing in their own communities in order to develop global resources and values. Experts in the field of local use of international education resources are far easier to locate in universities, foundations, and professional associations, which are less bound to the political demands of constituencies. The specific, single issue interest groups located within local communities demand so much of the time and energies of school officials that global leadership initiatives are risky and often excessively demanding. A global interest group in a local community would be a rare thing. Historically, leadership which is far-sighted enough to plan for such broad values has been equally rare. This makes the search for leaders in the field difficult.

There are no real criteria for expertise in the field of international resource development in the community. I have gone to considerable lengths in this research to demonstrate that this is a field which has been fragmented and interpretive. Limiting the sample to those whose specific job descriptions matched the goals of the research would have eliminated practitioners from all but a very few large districts. As a result, it could have been concluded that there are very few experts. A second, more workable conclusion was that the experts are those, first, with an interest and intellectual background in the field and, second, in professional positions which provide them with enough influence to contribute to the cross-cultural changes that are being called for in the literature. The term expert was used in this latter sense. Such individuals exist in many districts, although they may not think of themselves as international education experts. Their rare expertise was tapped for this study.

Who are the experts? They have no common title. They have all worked with international groups in their communities, although some have not had 
extensive opportunities to do so. Additionally, all the experts are aware of peers who have had extensive opportunities to work internationally, and they keep informed of this work. In some schools they are superintendents or assistant superintendents. In other local and county district offices and school sites they hold such titles as director of educational partnerships, industry and education partnership specialist, community based education facilitator, or communication coordinator. There are certain to be more of such titles in the future.

The experts appear to be guided by one or more of four paradigms of international education, each emphasizing different concerns. These are: Model I, curriculum and instruction concerns; Model II, community multicultural education concerns; Model III, national economic security concerns; and Model IV, more universal, globally shared concerns. Not all experts are guided by Model IV. In fact, in this research, no effort was made to divide the experts according to these models. The conclusions of this study and the models constructed are based upon combined responses.

Although the experts come from all perspectives, they agree with some essential background assumptions of this study. First, they feel powerful demographic shifts are underway in the United States, if not in their own districts. Second, they all believe that change is a fundamental, constant educational goal. Third, even those who emphasize Model I responses (oriented to the internal organization) believe they could make a difference in their outlying communities; they do not believe that school officials must confine themselves to internal organizational change initiatives. They can be leaders of broader movements.

The findings of the Delphi study established that the experts are interested in functional salience, not just talk. In stimulating global educational values, philosophy is not enough. They have expounded upon a wide variety of specific 
plans being made as United States schools prepare for the coming century. These plans are the heart of the findings of this research.

Perhaps naturally, members of growing foreign groups are becoming motivated to serve as resource people for school internationalist experts. Corporate liaisons and media representatives concerned with international issues will also seen as key resource people as the next century approaches. Such people will be of singular use when they are well connected, in positions of influence and with access to resources. Experts will seek a cross section of individuals. Their advice is to stay away from groups which are less well connected and which interpret issues in terms of their special interests.

The experts identified many avenues to take in order to provide the school with resources. Businesses have a mutual interest with the schools in preparing students for international competence. Telecommunication and computer firms are examples often cited. Experts believe business representatives and ethnic group representatives will be valuable not only in providing capital resources, but as members of site councils and advisory boards. Some resources can be used directly for symbolic or educational purposes. For example, one responded had put together a "Celebration of America Week" to recognize the contributions of many nationalities and cultures to the microcosm of the the school.

The experts agree that communication, the ability to work collaboratively, and cooperative decision making are the skills of the future. Community international educators see themselves much like diplomats: Broad goals from diverse groups will need to be interrelated and educational technology, an increasingly powerful resource which can be brokered for influence, may help with this objective. The experts are a new breed of hometown diplomats who say that they need expert advisors who can track far reaching trends in such areas as global business, employment, geopolitics, health and curriculum and provide 
them with "baseline data." Preparation will also need to be given to teachers and in-house curriculum planners who will need the skills required of the global classroom.

Over the course of this research, one thing became immediately clear. Regardless of what philosophy actors hold, it is essential that they have some clear philosophy to pursue and which is communicated by their actions. In order to meet the needs of broad constituencies, philosophies will have to be in evidence out front and they must be clearly targeted. They will have to be action oriented. Philosophies such as "the school must adapt to changing socio-economic conditions" are weak because they point in no direction.

The ability to communicate across groups will be increasingly important as minority groups gain strength and vie more intensely for community power. In these conditions, it will be essential to remember that the traditional bastions of power such as middle class Caucasians may feel amplified threats to their prominence and power. These groups appear to be especially sensitive to reverse discrimination. They will ask, "What's in it for us?" and so programs and philosophies must reach them equally.

Time, money, competing political agendas, government mandates and contentious individuals always accompany long term change initiatives and the experts are aware that they will somehow need to overcome these complications in order to be effective in this arena.

Taken individually, the plans of any one expert do not add up to global leadership. However, taken as a whole, a clearer picture emerges of the promise of thinking globally and acting locally. What is not clear is whether this research, which was based upon a simulation, has been more effective in testing the need for leadership or the existence of leadership in action; the former is certainly a more generalizable finding. The resources and opportunities some educators are 
pursuing lay all over the community, often poised and ready, but still largely untapped at the school-community interface. A clear consensus of the Model IV orientation on the part of the experts would be required to tap these resources in ways which will bring about lasting change. Today, Model IV is the most commonly espoused of the four models, but there is no consensus.

\section{Conclusions: Getting to Model IV}

As useful as summary listings of experts and resources in local international education might be, understanding of the field goes deeper. Findings expressed here are based upon a synthesis of responses of the experts. As discussed, through the rounds of the Delphi survey, several models were discovered which guided the actions and thoughts of practitioners. Model IV transcends all the models. Thinking globally while acting locally, any model can be transformed into Model IV, and applying Model IV, global developments can be achieved locally.

\section{Developments in Curriculum and Instruction}

Developing curriculum, instructional technology and staff in order to foster a global perspective can have a valued impact on the school organization. This is what Model $I$ is about.

A bias for traditional curricula, reflecting values of a world according to traditional, Western European, majority groups of the United States, is no longer acceptable to today's experts. "We have no choice in 1988 but to introduce our students to the whole world, even if history or social studies may appear at times to become more a smorgasbord than a train of events and people pulled by one engine" (Wilson, 1988, p. 4). Likewise, "foreign languages are critical for 
involvement with business, politics, and even recreation in a shrinking world. . . . Children between the ages of 7-10 may be at a critical stage for the development of cultural pluralism" and at age 10 children are reported to have a maximum degree of openness to people perceived as dissimilar to themselves (Pesola \& Curtain, 1988, pp. 3, 6).

Many university international educators recognize this. However, university and local educational officials alike agree that preparing students for international competence must begin well before the freshman year in college. While an understanding of the global economy could be cultivated at college, skills like communication, cooperative decision making and foreign language should be studied earlier. Experts advocate meaningful cultural experiences across the curriculum and point out specific programs which are being used for integrating international or multiethnic elements into virtually every subject area.

Knitting global perspectives across the curriculum can result in inspired, far reaching programs and experts believe that they give youths valuable, essential skills towards international competence; but most of the experts also recognize curriculum developments as isolated efforts which do not amount to cultural leadership. Cetron characterized this shortcoming as the difference between myth and reality.

Myth: Education should remain, for the most part, the sole province of teachers, since they are best equipped to decide what to teach and how to teach it.

Reality: Studies indicate that the most effective schools are those in which school administrators and teachers ... a actively involve the community in setting goals, implementing programs, and evaluating results. . . . It means that community members ... are actually in the school every day. Schools 
of the future will be built upon these relationships. (Cetron, 1988, pp. 1011)

Thus, Model I leaves many unanswered questions. Where do global values come from and who decides what they are? Is global education really an in-game among teachers seeking professional growth? Why should communities support them--what's in it for them? How can curricular developments gain long term backing?

Today, universities, consultants, businesses, nonprofit organizations, government bodies and cultural and international organizations all need to have a hand in curriculum and staff development so that curriculum developments reflect a broader culture. If the outside, international community is not involved, then it's not global education. Educational planning and processes do not start with curriculum development; they come closer to ending with it.

This conclusion can lead to new ways of pursuing a global approach to curriculum and instruction. Such initiatives must be developed in concert with diverse resources available in the school community. University educational research centers, foundations, corporate consultants on curriculum and multiethnic site councils, for example, all have much to contribute in the refinement of curricuium and the preparation of teachers. Curriculum resources and a wide variety of student participatory experiences abound in the global community surrounding most schools. These resources can help insure that the classroom is more representative of the global community and less representative of a few individuals on the school staff who, no matter how sincere their aims for global education, cannot possibly see through as wide and representative a scope on their own as they could if the process was done collaboratively.

New organizational linkages also serve the school organization as a whole and not only the classrooms of a few motivated individuals. Schools have a 
culture of their own, which can reflect shared or conflictual and isolated visions. Global linkages in the community cut across cultural lines, making the school more truly a microcosm of its enveloping communities of interest.

\section{Thinking Locally}

When searching for cultural universals, the local community today can be a confusing place. Take the typical California community, for example. Twenty five percent of the students are non-English speaking. "Two thirds of the world's immigrants today come to the United States. In contrast to previous decades, $80 \%$ are not from European countries but from Asia, the Caribbean or Latin America." ("Affirmative Action Focus," 1988, p. 1). Before 1960, stated Peck, "there was at least some communality--shared religious values overarched Catholic-Protestant differences and even Judeo-Christian differences. Where previously a fundamental common ground flourished, the rule today is pluralism beyond the imaginations of the founding fathers" ("Schools Find It," 1988, p. 1). Stated one school official who was surveyed:

Our district is in a population transition. The students entering our schools come from homes where English is not spoken and many of their parents are illiterate in their own native language. A sizeable number of our new arrivals also come from disturbed areas. A high percentage of our English language residents speak an alternative dialect of English. Our programs must address this reality.

No wonder there is a shortage of school personnel "able to bridge the cultural gaps and reach immigrant families" ("Schools Find It," 1988, p. 1).

The fundamental conflict of school leaders today is not inside the school gates. There is a gap in values, a perceptual gap, which lies between local, Model 
II values and global, Model IV values. School officials are well versed in the changing demographics, and while these figure highly in their planning efforts as in their philosophies, they confuse the school's role in multiethnic integration, which is needed in their home communities, with the need for global perspectives in education. They seldom make a conscious distinction between these two needs. Multicultural value changes occurring in communities are bound to be lead to reactive, short-sighted changes in the local educational system until educators plan for broader, national and international value changes which surround the system. This is the shortcoming of the Model II perspective.

The guidelines published by the Los Angeles School District for multicultural education serve as a typical example of efforts to address the need to unite diverse forces in school communities.

The program should be cross-cultural in nature instead of being structured upon separate and distinct racial or ethnic groups. Programs that deal separately with blacks, Chicanos, Asians, Native Americans, and other groups have some value, but an effort should be made to show similarities and differences among such groups and among individuals within groups. (Los Angeles City School District, n.d., p. 1)

An international culture may be emerging, but there are conflicting and countervailing social forces. Thus, regardless of some progressive guidelines, school officials end up spending most of their planning time attempting to address the concerns of specific groups with specific problems. They have come to see homework help centers, drop-out prevention programs, and bilingual education instruction as international education. As admirable as these programs are, they end up serving very specific groups which are seen as outside current cultural norms, and they do little to cultivate values which will serve every group. Moreover, their unspoken goal is to homogenize the minority cultures. 
On the surface, the Los Angeles statement seems to advocate a global perspective based upon universal values. But why, it could be asked, does it say that one program has "some value," while "an effort should be made" in another, conflicting type of program. The Los Angeles statement tries to say two things at once and so it ends up meaning little. This ambiguity was a major problem through the 1980s and is a key challenge for the 2000s.

Despite the emerging global philosophy espoused among experts, schools are not very far in practice. Superintendents and local practitioners still commonly speak of international education as a matter of integrating incoming minority groups.

Over the next two decades, the Hispanic population--a complex and arbitrary aggregation of Americans whose lineage is Spanish, Cuban, Puerto Rican, Mexican, South or Central American--may carve deeper changes into the landscape of ... education than any other minority group. (Odin, 1987, p. 2)

Many educators assume that these changes will require adjustments in the present systems. Others read such quotes as mandates for the restructuring of current systems. The former sees the community changing, while the latter sees the world changing. International education is a homonym.

There are reasons for this, of course. The reasons reflect another type of gap, an intellectual gap, between theory and practice. Local practitioners are in the service of school boards and local interest groups who demand an education tailored to specific, immediate community needs. Theorists often view educational conditions through a long term, more global, futuristic frame of reference. Many local practitioners approach international education more reactively, in response to short term needs for English as a foreign language instruction, foreign language instruction, and sometimes adult school in the areas 
of vocational training and English language. The theorists aim at strengthening the interconnectedness of the world. The local practitioners aim at civics education for responsible citizenship within the community and the national polity. In the extreme, the theorists view the local practitioners as working class, Civil War patriots and the local practitioners view the theorists as do nothing, United Nations eggheads.

Despite theoretical breakthroughs in understanding global education needs, teachers continue to address global curriculum, district administrators continue to address multicultural education and state and federal governments continue to address international competitiveness. In a concerted effort, there would be a more common aim.

Concerns for minority groups are not the only distracting influences towards attaining a global perspective. While there are social and intellectual challenges in managing the population transitions of United States communities, traditional school constituencies are making the challenge still greater. It is widely reported that "the declining [traditional] middle class" is the group which school leaders find pressures them most ("Schools Find It," 1988, p. 1). "Political patronage, union pressure and cronyism" are widely viewed as degenerating and isolating factors characteristic of many United States schools ("When Schools Become Jungles," 1988, p. 70). The survey confirmed this view (see Tables 10 and 11). Often such interest groups consist of a shrinking majority of white groups trying to preserve their dominant status. This preservationism is occurring in the cities and the suburbs alike.

It may come as surprise that the influence of minority groups is not felt primarily in the inner city where such groups have traditionally made their homes and challenged dominant values. The white populations in inner cities have diminished greatly over the past thirty years, and whites today comprise just three 
percent of the nation's central city school population. It is possible that they will become too much of a minority to be prominently felt. Meanwhile, there is a corresponding, more recent demographic change taking place in the suburbs, creating new challenges for outlying school districts, both small and large. Most Model II holdouts live in the suburbs ("Study Shows," 1988).

Varying perspectives and models of behavior have made the global education field rife with paradox. Many handshakes have been made between members of two organizations who genuinely believe they have reached an agreement, when in fact they do not agree at all. Hands shake, smiles exchange, in unwitting agreement to diametrically opposed belief systems. Internationalist programs have been set up, funding provided, and even philosophies carved based upon incongruity. As is clear from the Los Angeles statement above, one person can read one thing in the statement, a second person can read another.

In the Delphi survey, the grouping Latin American may be symptomatic of the continuing unfamiliarity of United States citizens with these countries. It is very seldom that one hears a United States American refer to a French person or an English person as a "European" anymore. If they have become a significant part of the United States population, are Latin Americans still just allies, or must they be seen as cousins, or family, as Europeans are?

Stated an assistant superintendent, "The whole issue of cultural diversity versus United States 'traditional' values will continue to be of major importance." No set of universal values can be achieved as long as this issue remains unresolved. One superintendent described the school as a microcosm of both the community and the world. Yet later in the same survey he stated that "The students we are planning for are now in our system," reflecting less than a world view. If the system is rapidly transforming demographically, why base future plans on today's figures? 
Those educators who stand out as leaders are planning for more than just their current student bodies. Cultural leaders plan broad system and social changes.

In their search for global values, some well intentioned school officials may fail by treating the goals of prevalent ethnic groups as automatically representative of global values. This may be a conditioned response to the onerous perception of powerful outsiders gathering at the community doors. It seems likely that some school officials will always define their roles by community needs and expectations rather than by broader values, but, then, not all school officials will be leaders. Intergroup communications, conflict resolution, knowledge of cultural relativity and ecological balance are all global values which can be pursued in microcosm. As one superintendent stated, "community necessitates that all sub groups must interact and focus on common values." An assistant superintendent stated that "We need to seek community out of the diversity."

Of course, not all practitioners adhere to one perspective or another regarding internationalism; starting with Model II, a more global, integrated perspective can be sought. A consensus on this emerging perspective is still not at hand, even among many experts. The result has been a conflict which digs so deeply into the world views and background assumptions of most people that it has seldom been acknowledged. For while many educators view an organization such as the Chicano Federation as a powerful outside interest group attempting to exert force upon the school, a majority of top level, district and county educators view such groups as valuable resources whose cooperation is the key to, even the foundation of, leadership efforts.

An assistant superintendent for a small urban district explained that one of the greatest demands towards developing international education was that there were "too many disparate groups and needs to effectively group students." This notion of "disparate groups" conveys the basic limitation of the multicultural 
perspective. The assistant superintendent blamed the existence of groups for problems in the system. Disparate groups are a weakness from his perspective. Stated Boyer, "'Bilingualism' has become a code word for confrontation. Pedagogical considerations have been overshadowed by political concerns. Many whites see bilingual education as a push to divide the nation culturally and linguistically. For Hispanics, such opinions are seen as insensitive and prejudicial challenges to their own rich language and traditions" (Boyer, 1984,.p. 63). Given a cultural leadership perspective, this same diversity would be viewed as a generative force.

Futures-thinking school administrators will seek opportunities for developing new coalitions. Analysis of the Delphi results, as well as a review of the literature, shows that moving Model II into Model IV will call for global educators to establish interrelationships with civic leaders, media, nonprofit service providers, helping professionals and international benefactors. The Legal Aid Society, the Rotary Club and the Civic Art League are all potential resources. Key local Immigration and Naturalization Services (INS) figures, local university foreign service officers, and nonprofit educational organization leaders will be, too.

Foreign students now spend three billion dollars a year at United States colleges, and far more in and around their college towns (Groennings, 1988, p. 2); this development is turning universities into key centers of local international resources. Libraries, museums and other community resource groups seeking international connections will either collaborate with the school, or press demands upon it. By taking initiatives in the formation and direction of community committees and structuring cooperative arrangements, school administrators should be on the leading edge of planned community changes which meet the needs of a broadening array of interests. The make-up of school governance will change as schools increasingly become the centers of community 
activities. Needs for new sources of funding will contribute to this development. A wide variety of community resource sharing developments, such as job and technology sharing, will place new constituencies into school governance.

None of this is to deny the intense needs for multinational education in response to changing demographics. But this limited view distorts the bigger picture. "Help me. I'm all alone with these people," the school superintendent in the Delphi study cried. For those who no longer choose to stay alone, the resources are available.

\section{Views From the Corporate Boardroom and Capitol Hill}

Globalization of the economy has divided the needs and interests of the federal government, the local community and its businesses, and local the school. Can the four find common goals and visions in international education?

The prevalent, Model III paradigm of United States international education was developed in the post-World War II years when (1) the United States was the clear economic and technological world leader, (2) the United States population was far more homogeneous, (3) United States educational institutions were the envy of the world, (4) foreigners involved in United States higher education were often dignitaries who would assume leadership positions in their home countries, and (5) it was generally assumed that almost any American contact with a foreign person promoted global understanding.

In this paradigm, foreign interchange in the United States has been designed to bring unilateral gains for the nation. "Until recently, the conduct of international relations was essentially a matter of secrecy and subterfuge, and the humanistic concerns of communication were most often reserved for the citizenry at home," wrote Condon and Yousef (1987, p. vii). United States persons 
largely value independence, and the value of interdependence is traditionally less prevalent (Condon \& Yousef). This is reflected in federal policy. Independent initiatives in international education have gained federal support to the extent that they have been seen as profitable or for their utility in spreading United States influence abroad.

Through the 1970s and much of the 1980s, the perceived loss of economic and technological power and influence worldwide threatened the independence of many United States organizations and groups. This threat was likened to a national disaster. Much of the accountability fell into the educational arena. It stressed many United States institutions and brought upon them a sense of loss of control (Baum, 1988). The need to retain control resulted in a competitive posture by the United States federal government, and educators were made to feel acutely responsible for upholding Model III, that is, for breeding competitiveness. The National Commission on Excellence in Education stated: "Our once unchallenged preeminence in commerce, industry, science and technological innovation is being challenged by competition throughout the world" (1983, p. 2). Competitiveness it is a common and effective motivator; in the case of United States international educational policy making, it seemed to be used in an effort to regain global economic dominance. The paradox is that in order to enjoy financial independence in today's United States, the federal government must function internationally and interdependently. This new set of global conditions has brought continued stress upon the more parochial, Model III paradigm of international education.

By the late 1980s, notions of domination were being replaced by those of "keeping up." An influential report released in 1987 by the Study Commission of Global Education, urging schools to "keep up with a changing world," was praised 
by Secretary of State George Schultz ("Schools Urged," 1987, p. 4). But in the back of Schultz's mind, no doubt, were recommendations he made elsewhere:

- About half the decline in our gross national product in 1982 came from deterioration in our international accounts, particularly our experts to developing countries.

- Our exports to Latin American countries declined by $22 \%$ as these nations became less able to repay their American debts.

- Without the decline in our exports, our GNP would actually have risen by $22 \%$ in the last half of the year. Instead, it fell fractionally. ("Global Awareness," 1985, p.2)

By emphasizing competitiveness, the Model III, national economic security paradigm of education has guided the federal government along its path. For example, $64 \%$ of the total federal obligations for research and development in education were allotted to the Defense Department in 1987 (Thiers, 1988, p. 4; "Federal Funds," 1988, p. 13). But the very new, dismal set of conditions, as pointed out by Schultz, has made Model III approaches seem increasingly obsolete.

Therefore, the federal government began considering other financial steps to encourage education for international competitiveness in the international arena. Despite regular requests from the Office of Management and Budget to eliminate most of the federal programs dealing with international awareness, Congress actually increased funding for foreign languages, exchanges, and intelligence. At the request of Congress, the Department of Education was asked to examine the concept of a national endowment for international education (Edwards, p. 40). The proposed Alliance for Education Act would authorize $\$ 30$ million per year (for three years) to create alliances among business, industry, schools, institutions of higher education, state agencies, and the like. (Müller, 
1988, p. 7). The Education for Economic Security Act received a major increase in funding in 198. This Act has prompted corporate sponsorship of education. Federal spending for education has declined in the past decade; during this period, schools were expected to cooperate increasingly with the private sector ("Federal Funds," 1988). Reliance on the school-business partnership concept has provided a justification for cuts in funding, but it also reflects a changing focus of United States policy. Underlying federal acts during the mid-1980s was the acceptance of the loss of control over the global marketplace and the genesis of a new strategy for regaining global economic leadership. The new strategy, still being conceptualized, is characterized by partnership, cooperative efforts, and win-win global transactions, not domination and independence.

Congressional committees and corporate boards are keeping a close watch on global trends, but in the meantime the view from the board of education or superintendent's office is often clouded by local concerns. School officials actively seek out exchanges with businesses, and all the while they see little connection between their own goals and national goals. There exists the perception of distance between local and federal goals.

Despite the perception, there is evidence that local views are beginning to merge with the view from Washington. Federal international education programs today are targeted at students of select foreign languages, business students, school-business partnerships and science and technology programs (Müller, 1988). These opportunities will filter down to the public schools, creating a new set of opportunities for local educators seeking funds. Local experts are anything but inspired by federal goals for international competitiveness; yet where do they target their internationalist programs? They listed: students of foreign languages, business and economics students, school-business partnerships and science and technology students. 
The interrelationships of local educators are fanning out. In the future, those with an interest in local development of international education will not only deal more with the INS and the United States Information Agency (USIA). They may deal with members of Congress, Justice Department personnel, the Social Security Administration and other federal agencies in order to establish a broad base of support. National associations will play similar roles. The National Association for Foreign Student Affairs, which has begun to move into the elementary and secondary school arena and attracted federal grants in doing so, may have information and influence which will assist local educators.

As they merge with United States international interests, the interests of local educators are also merging with those of businesses, from local to multinational. In an effort to gain tax advantages, public relations opportunities, as well as effective training and recruitment practices which may provide them with a competitive edge in the future, businesses are expected to become key partners with schools in the drive to educate United States students for international competence.

World information flow, global and agricultural weather patterns, global adjudication of disputes, international trade conditions, Third World trade (where the United States does about as much trade as with Western Europe and Japan, combined), foreign aid, global health, and human rights conditions will all help determine the success of international businesses and create new concerns shared by businesses, the federal government, and local schools. Local communities are becoming more sensitive to global conditions. Hamilton (1986) cited exemplary headlines from hometown newspapers across the United States:

- World Unrest Hits Home for Local Industry, from The (Aurora, Illinois) Beacon-News,

- Texas Town Feels Tug of Foreign Affairs, from The Dallas Morning News, 
- Area Churches Generous in Third World Donations, from The Hattiesburg (Mississippi) American,

- Local Entrepreneurs Tap into Global Territory: Mission of Marketing, The (Everett, Washington) Herald .. (pp. xi-xii)

Just as the United States may continue to lose more control over global trade without the support of its educational systems, the United States educational systems may lose control over local funding without the support business programs. Businesses have historically played a very small role in precollegiate education. Like schools, they too were critical observers of the federal shifts in education funding which took place during the Reagan years. Suddenly, a good deal of responsibility for the training for international competence fell upon their shoulders. For their part, they sometimes didn't know how to approach this new situation, and considerable tax advantages were certainly forsaken. Gradually, they have begun to find targets. Their targets come as no surprise: students of foreign languages, business and economics students, schoolbusiness partnerships, and science and technology students.

In an effort to implement education for economic security, government officials, diplomats and international dignitaries, corporate leaders from banks, technology executives, industrialists, import/exporters and others have started becoming key contact people for local educators, challenging their creativity and leadership abilities. Foundation support for schools is available in foreign firms wishing to tighten their foothold on United States markets and in cultural organizations wishing to gain prominence. Business internships, foreign exchange programs for students and teachers (often run by private organizations under contract by schools) are not only among the most fruitful programs offered by schools, but their longer term impact will be the embedding of internationalism into school goals and core curricula. 
As the future world becomes more technologically complex and regionally interdependent, educational institutions will have to adapt. Such movements will fuel the drive for more sophisticated educational technology which is compatible with increasingly global educational networks. Electronic information sharing, multilingual desk top publishing, computer assisted learning, laser disc technology, electronic interaction with schools throughout the world are examples given by the experts of the coming educational technology which is appropriate for the global age and compatible with school-corporate sharing.

As inspiring as technological visions are, the school officials surveyed were not highly concerned with costly technologies, and very few saw technology as having more than a small place on their own local educational agendas as the twenty first century approaches. Values is the issue, not technology. The experts are communicators and partnership agents, not technologists. At the same time, educational planners foresee relying increasingly upon technological and futurist experts and consultants. A consensus of school leaders from this research indicates that such contacts will be needed to inform them of future trends and global issues such as interdependence, international communications, geopolitics, world health, and poverty.

Not always, perhaps not even often, will contact making amount to leading, but when the stakes get high, when conflict is being aroused, or when critical support is needed, well established, shared resources and relationship mutuality will provide the networks of power or influence required of leadership.

As the next century approaches, economic security, communications technology, and far reaching partnerships will characterize local, business and federal plans for international education. Schools, businesses and government are developing a global perspective which is driving Model III into Model IV, but 
much leadership will be required in continuing to focus the actors from all three arenas on common sights.

\section{Coming Together of Concerns}

Although the very different perspectives of international competitiveness and international cooperation have remained almost totally confused, a few beginnings have been made leading towards "a marriage of concerns for world awareness and democratic commitment" (Pickus, 1987, p. 27). In October, 1987, the month this research began, the Alliance for Education in Global and International Studies was chartered. It was begun in response to the need for integration of concerns. Targeting elementary and secondary schools for its work, the Alliance stated:

We recognize that promoting a sense of responsibility that crosses ideological, cultural, and national boundaries is a complex and controversial undertaking. For some, a sense of world responsibility seems to require abandonment of a commitment to one's own nation. For others, a commitment to one's own nation precludes the pursuit of world responsibilities. We affirm the wisdom--indeed the necessity--of a commitment to both one's own nation and the world. We seek a world in which people of other nations make the same commitment. Because our society encourages free and open criticism of particular governmental policies while maintaining a fundamental loyalty to our common political community, we see no contradiction in such joint commitments. (Alliance for Education in Global and International Studies, p. 1)

This statement addresses one of the most fundamental areas for conflict to be resolved in achieving a new global paradigm in the United States. A global 
village just doesn't sit well with many people. But the new paradigm doesn't have to describe a global village; it can be a global federation where each culture uses different approaches and distinct strengths, all to achieve more universal cooperation.

The search for overarching goals might result in the creation and strengthening of international friendships between individuals and nations, the development of new markets for United States products, the promotion of development education, the enhancement of international training of United States students, and the use of foreign technical experts to bolster the development of technology in the United States and abroad.

The Think Globally, Act Locally theme illustrates a merging of different orientations of international education, fired by the search for more universal values. In declaring the 1990s "The Global Education Decade," the Forum for International Education stated this aim:

The Decade will bring together organizations, institutions, associations, and individuals who recognize the growing interdependence in all aspects of international relationships and appreciate its impact here at home as well as abroad; who are dedicated to educating Americans from all walks of life on the need for international involvement and for understanding that we are at the same time citizens fo the U.S. and the world; and who are committed to working for policies and programs encouraging democratic government and economic development throughout the world. (Kniep, 1988, p. 3)

In the search for synthesis of global values in education, the blending of cultural, idealistic and financial concerns, such as in the above statement, is required. Sputnik was not enough of a blend because it was fueled strictly on competition. Toyota, now a joint United States-Japanese venture, could become a more useful 
symbol of global values since it fans United States fires for competition and cooperation at once. In the educational arena, national and state funding have been restructured so that local leaders know that goals for international competitiveness must be achieved not just through mathematics and science, but through international studies, foreign languages and cultural exchange as well. The local race for funding is underway. Local leaders know that they must depend not solely upon government sources, but also on corporate and private sources. These local leaders are beginning to navigate in many of the same waters as diplomats and university leaders.

In an interdependent world with rapidly changing populations, any multicultural education from a leadership perspective must encompass global educational goals. Local leaders who would be leaders in international education would not be content in allowing international education to refer only to various types of educational and cultural relations among nations while allowing multicultural education to apply only to local initiatives.

The stature of the experts surveyed in this research is telling; most of them are not strictly specialists in international education, but top level school officials responsible for the overall shaping of the educational mission. They agree with a strong consensus that the top three agenda items for schools as they plan for the next century are: (1) developing educational programs oriented towards cooperative decision making, (2) strategies for promoting awareness of interdependence of people and nations over time, and (3) education's role in addressing global problems (e.g., communications barriers, ecology, food, survival). These are optimistic findings since these goals are not only appropriate for multiethnic integration efforts in the local community. They transcend them, and they reflect a global perspective which could steer educational systems towards universal values. 
While in traditional communities the school is viewed as the purveyor of basic skills and static values, in progressive ones it is viewed equally for its role in cultural transformation. The cultural leadership paradigm encompasses these two views: the role of the cultural leader is to develop an educational system which can both refine and transmit cultural values both within groups and across them.

\section{Recommendations for Global Educators}

The American Forum asserted:

Now is the time for global educators across disciplines and at all levels of the educational system to meet with state and local government officials, business and labor leaders, federal agency personnel, and representatives from other international interest groups:

- to address the need for educational change that will reflect a global perspective;

- to construct mechanisms which will support such long-term change, and

- to affirm the 1990s as the Decade for Global Education (Global Perspectives in Education, 1988, p. 1).

This research indicates that while educators support such challenges in cultural leadership, they find narrower, less meaningful concerns dominating much of their time. Model IV calls for a restructuring of priorities; cultural leadership transcends prevalent, narrower perspectives. Although local educational systems, governments and international corporations do not always feel the same motivations to respond to global conditions, there will have to be a convergence of values in the future. The challenges they face will all be the same. Martin has written that the fundamental problem is, "How to Save the Forests of the World" (Martin, 1988, p. 37). Placement of Martin's essay in an 
educational journal gives it metaphorical meaning, but this is not poetry; many school children have never seen a forest, but their future survival depends upon it. Few school classes will have the chance to travel to distant jungles, yet they have shared futures. Education, business, and government, with their traditional purviews of awareness, finance and regulation, respectively, all have a common goal in "saving the forests." None can do much without the efforts of the others. Global problems will lead to economic and social disruption without a common effort (MacDonald, 1988; Mintzer, 1988). Changing global ecological conditions could choke the world the way the oil embargo choked the United States in the 1970s. This time Westerners will be in line with Iranians, Africans and Soviets. Without devaluing the cultural distinctiveness that gives each group strength, they will need to think in terms of common goals.

Day to day localized concerns, mostly time and money, customarily distract all but truly leading organizations from long range and socially far reaching initiatives. As global problems lay themselves upon local doorsteps, planning from the top must increasingly filter downwards. The smaller the world gets, the more far sighted the visions of leaders will need to be and the more universal will be the values they inspire.

Given the needs for international competence in business, corporate sponsorship is recognized as a promising area for resource development in international education. This is a new area, and it comes with risks. Driven by the profit motive and subsequent public relations needs, not all corporate sponsors have truly positive goals. "Major public relations firms have increasingly designed programs targeting classrooms to further the special interest of their clients through free lesson plans--complete with training manuals, media materials, handouts and expert speakers" ("Information Assault," 1988, p. 1). Many are offered directly to vulnerable local teachers, bypassing the educational planners. 
Opportunism is obviously not a global value. Corporate sponsorship is a relatively new floodgate for educational planners, and it should be opened cautiously. There may even be times coming when industrially caused damages to the ecosystem pit educators and corporations against one another.

Aside from corporations, community organizations and foundations, futurist consultants, and communications specialists offering technologically enhanced, global learning systems are resources which can be tapped. The latter two of these are not yet widely utilized.

In an information age, the fundamental skill will be communication. Resource opportunities will be wasted without the nurturing of close linkages which allow cultures to share changes and develop mutual traditions--not just international, but interpersonal.

Intercultural communication has a long way to go before its becomes a democratic process. Leaders will not allow institutions to speak for them. They will need to touch people personally in order to change them. Traditionally, United States individuals relate quite simply with individuals from other English speaking countries. They can mimic a British accent and it is funny. But they cannot joke about Mexican water, as President Carter demonstrated when his attempt to do this turned into an international insult. They cannot mimic a Japanese accent. Interculturally shared assumptions are not always predictable. More intimacy will have to be developed. As the circle of resources and contacts spreads out for tomorrow's school official, communication skills will be at a premium. Skills and techniques in cross-cultural communication will be essential. Comparative communication styles, values systems and thought patterns will be emphasized in developing effective day to day interpersonal communications.

In conclusion, educational expertise guiding us into the 21 st century, if it is to be leadership, will be characterized by pluralistic, consensual and personal 
interrelationships across cultures and institutions. A fundamental change in thought is in order, so that "it's a small world" is not just cocktail party talk where everyone knows interrelationships exist, but not for them.

Global education is moving out of the purple and becoming politically and socially credible. A small anecdote might help illustrate this. In response to a Delphi round two question, 22 of the 28 respondents immediately agreed to release their names as survey participants. After the conclusion of all the surveying, I received a call from a participant and he told me that, although he had indicated earlier that his name should not be released, after reading the survey summary he had changed his mind. Would I please include his name? We discussed the public perception of global education, and he reflected how it has often been viewed as naive and idealistically soft. "I was surprised to see how many people I know who were in the survey. After I saw from the results how many others have been thinking what l've been thinking, trying to do so many of the same things as I have, I began to admit more openly that these are valid goals and not just talk" (personal communication, August 5, 1988). Global perspectives in education is sometimes branded as soft, esoteric shadow talk, and this must stop. In the 1960s and 1970s, to most school officials, many educators heard global perspectives as the voice of a subculture. Approaching 2000, the problems and promises of a global culture will be addressed across cultures and specifically integrated into the goal statements of leading schools and districts.

\section{Recommendations for Further Research}

Helpful would be follow-up research to see if any respondents structured any community meetings such as the research simulated. Similarly, since one purpose of the Delphi technique is the facilitation of change, the respondents 
could well be surveyed in a follow-up survey after a significant amount of time in order to see if their attitudes and behaviors in the area of research have changed more than the norm. Another study might survey board members of the organizations involved in the Delphi survey to see if a global paradigm is acceptable to them. A study of corporations involved in funding and participating in global education could also be very useful. Still another study could survey the traditional majority groups in some of the sample sites, since these groups were perceived as a major impediment to change.

The study dealt only lightly with computer enhanced technology, satellite education and new communications styles, which could impact international education in the coming years. A follow-up study might well focus on this particular dimension of international education.

It was surprising and regrettable that no private schools were culled into the sample through the nominating process. Surprising, because an educational philosophy of such prominent concern to top level public school officials appeared to be one to which private educators have remained aloof; regrettable in the implication that private educational organizations are islands, removed from a cultural mission any broader than the interests of paying clients. The nominating process was not designed to yield a statistically representative sample, though, and this concern warrants further research. Perhaps in the future, attracting global clients and patrons from multinational organizations will become a fiscal responsibility of private educational leaders. An useful follow-up study might be to run these survey results by priate educators and get their reaction.

Do global trends actually seem abstract and remote to local educators? What global events have an impact upon local educators, and how? What is the nature of global trends which educational planners have used? As important as global trends are for the long run, they often seem to lack salience here, today. 
Yet some do have a direct impact and produce resulting actions. Identification and analysis of salient, global events and trends could be revealing and could make an instructional follow-up study.

A number of prominent, specific organizations have a large impact on international education in the United States. NAFSA is moving into the elementary and secondary education arena, and its influence upon the direction of local community international education could be measured in a follow-up study. The Fulbright Academic Exchange Program represents the largest federal expenditure on international cultural exchange, and a study of its funding patterns could be useful in ascertaining the federal priorities in international education. Specialized study of cultural and academic exchange organizations, as well as the structure of school-business partnerships, could also supplement this study.

A final area for further study might be the area of foreign interrelationships of local educators. Most of the activities identified in this study concerned internationalism within the local community. A global leadership study could focus specifically upon the linkages local educators are forming with overseas organizations.

Model IV and the Process of Change

Researchers may never be able to ascertain exactly who is an expert in school-community relations of an international nature, yet this was the continuing need throughout this research. To be an expert, one needs a guide to action. One needs to be a diagnostician who uses theories and models which guide his/her decisions. The model determines what questions the expert asks, what data he/she considers, what goals are valued, and what actions he/she ultimately takes. When a subordinate or a researcher asks, "What is the plan?" experts may 
or may not have one, but they are most certainly aware of the plans that are out there. All to often, as Bolman and Deal (1984) pointed out, people do what they do because of wants, needs, beliefs, attitudes, feelings, and abilities of which they are little aware. This is all to say, that if there is a prevalent model of international education--if Model IV is operating today in any significant way--we should do well to continue to clarify its goals and objectives. And if Model IV is not operating, then something else is needed.

The creation and existence of a unified field of international education is certain to be subject to criticism. "Must I use the same approach to every situation?" one might understandably ask. Federal level educational officials certainly have very different needs than those on the local level. Site level managers have specific functions to fulfil if they are to operate the school on Monday. As the United States population changes, a multicultural perspective is necessary. Curricular change is a must if any school is to keep up with immediate and medium term educational needs and attempt to offer a state of the art curriculum. Integration of the above perspectives is a problem for most practitioners in all three respective arenas.

But the greater problem comes when practitioners become inflexible, locked into job slots and reactive decision making. An integrated model is not a model for site level educators to use every day. It is a model for change, and the constant need for change was a background assumption of this work. No respondent took exception to this assumption when it was described during the research. At the same time, leaders know their limits. You can't always have it all. Starting with Models I, II, or III, one can grow into Model IV just as an independent individual may progressively become self-actualized in the larger society. 
When faced with new challenges, inflexibility is a loser. The challenge of change is for leaders. Leadership, if it is to be responsive to the tensions produced when conditions are stagnant and growing stale, if it is to offer a new way out of old conflicts, if it is to negotiate emerging values and form new goals, will need a flexible, integrative model upon which everyone in the arena can agree. Today's population in the United States is sophisticated. The citizenry recognizes the old symbols, overtly or tacitly. They can feel these symbols when the little red schoolhouse keeps new values out. They perceive that Brown vs. Board of Education is a decision that should be taken for granted by now, and not debated over any longer. They have long accepted the challenge of Sputnik and expect that if the nation still does not have this challenge well in hand, then it never will. The changes we face when we look to the twenty first century are new, and the old models are cumbersome and wasteful. For a small world, getting smaller, an integrated model of international education is the only relevant one. Only a transcendent, artistic, and cutting edge vision can pare our perspective down to what is essential. Cultural leadership is not required to conduct all programs in internationalism; only to bring change. 


\section{References}

AACD helps revise risk report. (1987, November 26). Guidepost pp. 1, 10.

ACSA expands communications to school leaders. (1988, March 6). Sacramento, CA. Edcal, pp. 1-2.

Advisory Council on International Education. (1986). International education: Cornerstone of competition. Washington, DC: Southern Governors' Association.

Affirmative action focus of committee meeting. $(1988$, May 23). Edcal p. 1.

Alderfer, C. P. \& Brown, L. D. (1975). Learning from changing: Organizational diagnosis and development. Beverly Hills, CA: Sage.

Alderfer, C. P. (1984). Problems of changing white males' behavior and beliefs concerning race relations. In P. S. Goodman (Ed.), Change in organizations (pp. 122-165). San Francisco, CA: Jossey-Bass.

Alger, C. F. (1980a, April). Enhancing the efficacy of citizen participation in world affairs. Proceedings of the Symposium on Citizenship and Education in Modern Society. (Available from the Mershon Center, Ohio State University, Columbus, $\mathrm{OH}$.)

Alger, C. F. (1980b, spring-summer) Columbus-in-the-world: An Ohio city looks at international connections. New Ways, pp. 4-8.

Alger, C. F. (1982). Creating a more equitable world by making our cities lifelong learning communities for participation in the world. Proceedings of the 2nd YOKE Symposium, 9 190-198.

Alger, C. F. (1987). The world relations of cities closing the gap between social science paradigms and everyday human experience. Paper presented at the 1987 annual meeting of the American Political Science Association, Chicago.

Alliance for Education in Global and International Studies. (1987, October). A Statement of Goals and Values. Washington, DC: World Without War.

Althen, G. (1988). American ways. Yarmouth, ME: Intercultural Press. 
Amara, R. (1978). Probing the future. In J. Fowles (Ed.), Handbook of futures research (pp. 411). Westport, CN: Greenwood.

Amara, R. (1980). Thinking globally, acting locally. In F. Feather (Ed.), Through the '80s: Thinking globally, acting locally (pp. 38-41). Washington, DC: World Future Society.

Anderson, L. (1979). Schooling and citizenship in a global age: An exploration of the meaning and significance of global education. Bloomington, IN: Social Studies Development Center.

Annual Report (1987). Constitutional Rights Foundation. Los Angeles: CA.

Argyris, C. (1984). How learning and reasoning processes affect organizational change. In P. S. Goodman (Ed.), Change in organizations (pp. 47-86). San Francisco, CA: Jossey-Bass.

Arrien, A. (1988, April 22). Symbols and myths of life transitions. Paper presented at the Association for Transpersonal Psychology Seminar, Fullerton, CA.

ASCA program seeks to heighten awareness of cultural diversity. (1987, November 26). Guidepost, p. 12.

Assembly rejects bill requiring school AIDS-prevention film. (1987, July 17). The San Diego Union, p. 2.

Basic facts about the United Nations. (1977). New York: United Nations Office of Publications.

Baum, A. (1987, April). Disasters, natural and otherwise. Psychology Today, pp. $57-60$.

Bell, T. (1984, September). [untitled], Northeast Conference on the Teaching of Foreign Languages Newsletter, p. 64.

Bellah, R. N., Madsen, R, Sullivan, W.M., Swidler, A., \& Tipton, J. M. (1985). Habits of the heart. Berkeley, CA: University of California Press.

Benne, K. D. (1985). Moral dilemmas of managers. In W. G. Bennis, K. D. Benne, \& R. Chin (Eds.), The planning of change (4th ed.) (pp. 471-479). New York: Holt, Rinehart and Winston.

Bennis, W., \& Nanus, B. (1985). Leaders: The strategies for taking charge. New York: Harper and Row.

Billingsley, G. (1984, summer). Delphi technique aids curriculum planning. Lournalism Educator, pp. 7-14. 
Bolman, L. G., \& Deal, T. E. (1984). Modern approaches to understanding and managing organizations. San Francisco, CA: Jossey-Bass.

Book and library programs (1985). United States Advisory Commission on Public Diplomacy, 1985 Report. Washington, DC: United States Information Agency, p. 39.

Borg, W. R., \& Gall, M. D. (1983). Educational research: An introduction. New York: Longman.

Bowman, J., Kierstead, F. D., \& Dede, C. J. (1980). Education in the eighties: An appraisal. In F. Feather (Ed.), Through the '80s: Thinking globally, acting locally (pp. 320-338). Washington, DC: World Future Society.

Boyd, W. L. (1976). The public, the professionals, and educational policy making: Who governs? Teachers College Record. $77,540$.

Boyer, E. L. (1983). High school: A report on secondary education in America. New York: Harper \& Row.

Boyer, E. L. (1984, November). The test of growing student diversity. The New York Times Education Fall Survey, p. 63.

Brigs, Jr., V. M. (1984). Immigration policy and the American labor force. Baltimore MD: Johns Hopkins University.

Brockhoff, K. (1975). The performance of forecasting groups in computer dialog and face-to-face discussion. In H. A. Linstone \& M. Turoff (Eds.), Delphi method: Techniques and applications (pp. 291-321). Reading, MA: Addison-Wesley.

Brooks, A. (1984, November). A round-trip ticket to improve teaching. New York Times Education Fall Survey, pp. 14-16.

Buchen, I. H. (November-December, 1987). Faculty for the future. The Futurist, p. 22-25.

Buchman, M. (1988, April). Spanish 101--For administrators. Thrust pp. 36-37.

Bureau of Public Affairs. (1985, February). 1984 Human Rights Report (Special Report No. 121). Washington, DC: U. S. Government Printing Office.

Burns, J. M. (1978). Leadership. New York: Harper \& Row.

Busher, M. (1987, Novermber 6). Castor pushes for global education. Boca Raton News, p. 2 B.

Business Japan. (1983). National Institute for Educational Research Journal, 28 , 40-42. 
Business-school partnership signed. (1988, April 18). Edcal, p. 1.

California schools meet the challenges. (1988, July 4). Edcal, p. 1.

California State Department of Education (1985). Model curriculum standards, grade nine thorough twelve. Sacramento, CA: Author.

Campbell, R. R. (1959). The folklore of local school control. School Review, 67 , 1), 1-16.

Carnegie Forum on Education and the Economy. A nation prepared: Teachers for the 21st Century. Washington, DC: Carnegie Foundation, 1986.

Cetron, M. J. (1969). Technological forecasting: A practical approach. New York: Gordon and Breeach.

Cetron, M. J. (1985). Schools of the future: How American businesses and education can cooperate to save our schools. New York: McGraw-Hill.

Cetron, M. J., Soriano, B., \& Gayle, M. (1985, August). Forecasting American education. The Futurist, pp. 18-25.

Children's fund. (1982). UNICEF News, p. 14.

Cleveland, H. (1980, May/June). A passion for paradox. Global Perspectives, pp. 7-10.

Cleveland, H. (1982). People lead their leaders in an information society. In H. F. Didsbury, Jr. (Ed.), Communications and the future: Prospects, promises, and problems (pp. 167-173). Bethesda, MD: World Future Society.

Cleveland, H. (1986, Summer). The future of international governance: Managing a Madisonian world. Futures Research Quarterly p. 6-13.

Cleveland, H. (1988, May). The revolution in education for a global age. Access, pp. $1,8$.

Cleveland, $H$. (3988, May-June). The future of international governance. The Futurist, pp. 9-12.

Cline, R.S. (1981). The CIA under Reagan, Bush and Casey. Washington, DC: Acropolis.

Collins, H. T. (1986-87). School principal survey. In J. Torney-Purta (Ed.) Evaluating global education: Sample instruments for assessing programs (pp. 496). New York: Global Perspectives in Education. 
Condon, L. (1980, May/June). Issues for the coming year: A point of view. Global Perspectives Newsletter, pp. 1-2, 15-16.

Cornish, E. (1977). The study of the future. Washington, DC: World Future Society.

Cranston, A. (1987, Winter). Senator Alan Cranston reports to California.

Cubberly, E. P. (1914). The public school administrator. Boston, MA: Houghton Mifflon.

Cyphert, F. R., \& Gant, W. L. (1970) The Delphi technique: A tool for collecting opinions in teacher education. Phi Delta Kappan 21, 417-425.

D'Amour, L. J., \& Rittenberg, S. (1980). Shaping urban futures through public participation. In F. Feather (Ed.), Through the '80s: Thinking globally, acting locally (pp. 408-419). Washington, DC: World Future Society.

Davies, D., \& Zerchykov, R. (1978). Citizen participation in education: Annotated bibliography. Boston, MA: Institute for Responsive Education and Human Resources Development Division of Optimum Computer Systems, Inc., pp. 74-91, 257-267.

Deal, T. E., \& Kennedy, A. (1982). Corporate cultures. Reading, MA: AddisonWesley.

Delbecq, A. L., Van de Ven, A. H., \& Gustavson, D. H. (1975) Group techniques for program planning: A guide to nominal and group Delphi processes. Glenview, IL: Scott Foresman.

Draper, J. B. (1987-88, Winter). News from Washington. FL:SNEWS, p. 3.

Edelman, M. (1971). Politics as symbolic action. Chicago: Markham.

Edwards, J. D. (1987, September). Foreign language education for international economic competitivenes: Recent initiatives. Northeast Conference on the Teaching of Foreign Languages Newsletter, p. 40-43.

Edwards, J. D. (1988, January). Foreign language education for international economic competitiveness: Recent initiatives. Northeast Conference on the Teaching of Foreign Languages Newsletter, pp. 40-43.

Eisner, E. W. (1979). The Educational Imagination. New York: Macmillan.

Eliot, T. S. (1948). Notes towards the definition of culture. London: Falser.

Federal funds for education research show sharp decline in past decade. , (1988, July 7). Guidepost, p. 13. 
Finn, C. E., \& Doyle, D. T. (1985, January 6). As states take charge cf schools: A new plan. The New York Times Education Survey, p. 1.

Fiske, E. B. (1984, December 2). States gain wider influence on school policy. The New York Times, p. 1.

Fowles, H. A. (Ed.). (1978). Handbook of futures research. Westport, CN: Greenwood.

Gardner, J. W. (1965). The anti-leadership vaccine. Annual Report of the Carnegie Corporation. New York: Carnegie Corporation.

Gilman, R., \& Theobald, R. (1985). Strategies for Cultural Change. Context: A Quarterly of Humane Sustainable Culture, 9, 1-64.

Global Awareness. (1985, Spring/Summer). Newsletter. Minneapolis, MN: Global Education Center, College of Education, University of Minnesota, p. 2.

Global awareness. (1985, Spring/Summer). Newsletter of the Global Awareness Program of Florida International University, p. 2.

Global Perspectives in Education (1988). Education and international competence. New York: Author.

Global privatization. (1987, November-December). The Futurist, p. 39.

Goodman, D. (1987, September). Playboy interview: John Scully. Playboy pp. 51-66.

Goodman, P. S., \& Kurke, L. B. (1984). Studies of change in organizations: A status report. In P. S. Goodman (Ed.), Change in organizations (pp. 1-46). San Francisco, CA: Jossey-Bass.

Gorham, A. L., (Ed.). (1986, November). Access, pp. 1-3.

Governor's Citizens' Committee on Education. (1973, March). Improving Education in Florida: A Report. Tallahasse, FL: Florida State Legislature.

Governor's Study Commission on Structure and Governance of Education. (1975, May). Final Report of the Governor's Commission on Education. Annapolis, MD: Author.

Grabow, S., \& Heskin, A. (1985). Foundations for a radical concept of planning. In W. G. Bennis, K. D. Benne, \& R. Chin (Eds.), The planning of change (4th ed.) (pp. 259-269). New York: Holt, Rinehart and Winston. 
Grauer, S. R. (1983, November 19). Mind/brain research--Frontiers in education. Paper presented at the annual meeting of the European Council of International Schools, Rome, Italy.

Grauer, S. R. (1986). Beyond the curriculum: Creating the conditions for learning. (Report No. TM 860 125). Del Mar, CA: Center for International Education. (ERIC Document Reproduction Service No. 266 181)

Grauer, S. R. (1987). United States federal policy on international education: An historical analysis. San Diego, CA: Center for International Education.

Groennings, S. (1988, October/November). The empires of the mind: The global economy and higher educators' agenda. Access, pp. 2-4.

Grove, C. (1982). Improving intercultural education through the orientation of sojourners. The International Schools Journal, 4, 13-26.

Guba, E. G., \& Lincoln, Y. S. (1985). Effective evaluation. San Francisco, CA: Jossey-Bass.

Haas, J. D. (1986, Summer). Educational futures: Six scenarios. Futures Research Quarterly, pp. 15-30.

Hamachek, D. E. (1971). Encounters with the self. New York: Holt, Rinehart and Winston.

Hamilton, J. M. (1986). Main street America and the Third World. Washington, DC: Seven Locks.

Hansen, J. C. (1988, September). Edward Kellog Strong, Jr.: First author of the Strong Interest Inventory. Lournal of Counseling and Development, pp. 916.

Heath, A.E., Neimeyer, G. J., \& Pedersen, P. B. (1988, September). The future of cross-cultural counseling: A Delphi poll. Lournal of Counseling and Development, pp. 27-30.

Heckinger, F. (1983). Classrooms at war. Hollywood, CA: Center for Cassette Studies.

Helmer, O. (1978). The research tasks before us. In J. Fowles (Ed.), Handbook of futures research (pp. 763-778). Westport, CN: Greenwood.

Helmer, O. (1983). Looking forward: A guide to futures research. Beverly Hills, CA: Sage.

Henderson, $H$. (1980). Identifying the planetary coalition for a just new world order. In F. Feather (Ed.), Through the '80s: Thinking globally, acting locally (pp. 52-57). Washington, DC: World Future Society. 
Hill, J. (1987, September 28). Curriculum key to educational reform. EdCal. p. 1.

Hoopes, D., Ed. (1984). Global guide to international education. New York, NY: Facts on File.

House of Representatives, (1984, May 13). American defense education act (Report 98-754). Washington, DC: United States Congress.

Hudgins, A. C. (1979). Law and education: Contemporary issues and court decisions. Richmond, VA: Michie.

Husen, T., \& Postlethwaite, T. N. (Eds.). (1985). The international encyclopedia of education, Vols. 2, 5. Oxford, England: Pergamon.

Information assault. (1988, Summer). Issue Traces, pp. 1-2.

International Education Act, U. S. C. Title $20 § 1119$ et seq. (1980a).

International Education Act, U. S. C. Title 20 §§ 3141-3144, 3190 et seq. (1980b).

International studies organizations forming alliance. (1987, November). Access. p. 3.

Johns, J., \& Morphet, J. (1973). The economics and financing of education. Englewood Cliffs, NJ: Prentice-Hall.

Jones, W. (1988, May 16). Soviets stage a bold 'Vanya.' The San Diego Union. p. C1.

Jones, W. (1988, May 16). Soviets stage a bold "Vanya." San Diego Union, p. C1.

Kirkwood, T. F. (Ed.). (Fall 1985). First annual awards presented. Global awareness. (Miami, FL: Global Awareness Program of Florida International University), p. 6.

Kluckhorn, F., \& Strodtbeck, F. L. (1961). Variations in Value Orientations. Evanston, IL: Row, Peterson.

Kniep, W. M. (1988, May). The 1990s: The global education decade. Access, $p$. 3.

La Morte, M. W. (1982). School law. Englewood Cliffs, NJ: Prentice-Hall. 
Lamy, S. (1986/87). Conflict evaluation questionnaire. In. J. Torney-Purta (Ed.) Evaluating global education: Sample instruments for assessing programs (pp. 439). New York: Global Perspectives in Education.

Lamy, S. L. (1987). The contemporary international system: A world in transition. In W. Kneip (Ed.), Next steps in global education: A handbook for curricuium development (p. 37). New York: Global Perspectives in Education.

Linstone, H. A. (1977). Introduction. In H. A. Linstone, \& W. H. C. Simmonds (Eds.), Futures research: New directions (p. 29-32). Reading, MA: Addison-Wesley.

Linstone, H. A. (1978). The Delphi technique. In J. Fowles (Ed.), Handbook of futures research (pp. 273-300). Westport, CN: Greenwood.

Linstone, H. A., \& Turoff, M. (Eds.) (1975). The Delphi method: Techniques and applications. Reading, MA: Addison-Wesley.

Linstone, H. A., \& Turoff, M. (Eds.). (1977). Futures research: Techniques and applications. Reading, MA: Addison-Wesley.

Lorence, P. R. \& Lorsch, J. W. (1967). Organizations and environment. Boston, MA: Division of Research, Graduate School of Business Administration, Harvard University.

Los Angels City School District (n.d.). Multicultural Education. Los Angeles: author.

Loye, D. (1978). The knowable future. New York: John Wiley \& Sons. p. 46.

MacDonald, G. J. (1988, Spring). Scientific basis for the greenhouse effect. Lournal of Policy Analysis and Management, pp. 425-444.

Malia, J. R., \& Shea, E. C., Eds. (1979). Multiculturalism and education: A select bibliography. Toronto, Canada: Ontario Institute for Studies in Education.

Marshall, C. (1985). Appropriate criteria of trustworthiness and goodness for qualitative research in educational organizations. Quality and Quantity, 19 , 353-73.

Martin, C. (1988, Spring). How to save the forests of the world. International Schools lournal, pp. 37-42.

Martino, J. P. (1978). Technological forecasting. In J. Fowles (Ed.), Handbook of futures research (pp. 369-396). Westport, CN: Greenwood.

Martino, J. P. (1985, March). Looking ahead with confidence (Special report). IEEE Spectrum, pp. 76-81. 
Massachusetts State Board of Education. (1974, October). Effectiveness, Efficiency and Equal Opportunity in the Public Schools of Massachusetts. Boston MA: Massachusetts Advisory Council on Education.

McKiddy, G. E. (1986/87, Winter). Global education, new directions. International Quarterly, pp. 3-4.

Miles, I. (1978). The ideologies of futurists. In R. B. Fowles (Ed.), Handbook of futures research (pp. 67-97). Westport, CN: Greenwood Press.

Miles, M. B., \& Huberman, M. A. (1984, May). Drawing valid meaning from qualitative data: toward a shared craft. Educational Researcher.

Mintzer, I. (1988, Spring). Living in a warmer world: Challenges for policy analysis and management. Lournal of Policy Analysis and Management, pp. 445459.

Mitchell, J. M. (1986). International cultural relations. London: Allen \& Unwin.

Mitropoulos, M., \& Psomopoulos, P. (1985). Communications with and without technology (pp. 320-421). Futures Survey Annual 1985, Bethesda, MD: World Future Society.

Motamedi, K. K. (1985). Adaptability and copability: A study of social systems, their environment, and survival. In W. G. Bennis, K. D. Benne \& R. Chin (Eds.), The planning of change (4th ed.) (pp. 186-194). New York: Holt, Rinehart and Winston.

Murray, J. V. (1968). The development and test of a concept and methodology for long-range forecasting (Doctoral dissertation, University of Colorado, 1967). Dissertation Abstracts International, 29, 358A.

Müller, K. E. (1988, June) Federal legislative update. Access, pp. 7-8.

NAASP develops exchange program. (1988, January 18). Edcal, p. 1.

Nation's governors endorse global view. (1987, November). Access, p. 2.

National Advisory Board on International Education Programs. (1983, December). Critical needs in international education: Recommendations for action (Publication No. 421054 4221). Washington, DC: Author.

National Commission on Excellence in Education. (1983) A nation at risk: The imperitive for educational reform (Publication No. 065-000-00177-2). Washington, DC: United States Government Printing Office.

NEH releases report on the humanities in the nation's schools. (1988, January). Access, p. 3. 
New York State. (1972). Report of the New York State Commission on the Quality, Cost and Financing of Elementary and Secondary Education, vol. 3. New York, NY: New York State Commission on the Quality, Cost and Financing of Elementary and Secondary Education.

News and notices. (1987, September-October). Access, pp. 11-13.

Odin, P. (1988). Hispanics help shape the educational landscape. Black Issues in Higher Education, $4,2$.

Oriven, G. (1984). The global yellow pages. New York: Global Perspectives in Education.

Outstanding recomendations. (1987, December 14). Edcal, p. 2.

Peck stresses community consciousness. (1987, May 28). Guidepost, pp. 1, 3.

Peck, M. S. (1987). The different drum. New York: Simon \& Schuster.

Pesola, C. A., \& Curtain, H. H. (1988, June). Elementary school foreign languages: Perspectives, practices and promises. Access, p. 3-6.

Pickus, R. (1987). Teaching the young. American Purpose, 1, 25-27.

Pirsig, R. M. (1974). Zen and the art of motorcycle maintenance. New York: Bantam.

Ponterotto, J. G., \& Benesch, K. F. (1988, January). An organizational framework for understanding the role of culture in counseling. Lournal of Counseling and Development, p. 237.

President's International Youth Exchange Initiative. (1984). Washington, DC: United States Information Agency.

Prigogine, I, \& Stengers, P. (1984). Order out of chaos: Man's new dialogue with nature. NY: Bantam Books.

Read, H. B., \& Louhran, E. L., (Eds.). (1984). Beyond schools: Education for economic, social and personal development. Amhurst, MA: University of Massachusetts, School of Education.

Record enrollment of foreign students in U.S. (1988, January). Access, p. 4.

Remy, R. (1985, Spring/Summer). What is global education? Newsletter. Minneapolis, MN: Global Education Center, College of Education, University of Minnesota, p. 2.

Response by Paul Gagnon. (1988, March-April). Access, p. 11. 
Rhoades, K. (1987, February). Danforth funds future schools project. Communicator p. 2.

Riles, W. (1978, April 4). M/C reference \#135. Sacramento, CA: State of California Department of Education, p. A.

Riles, W. C. (1970). The Urban Education Task Force Report: Final report of the Task Force on Urban Education to the Department of Health, Education, and Welfare. New York: Praeger.

Rosenbaum, J. (1983). Preparing college students for future careers in nonbroadcast private telecommunications: A report on a national Delphi survey of professional video communicators. Dallas, TX: International Television Association.

Rosenbusch, M. H., \& Ames, I. O. (Eds.). (1987, Fall). NAESP resolution supports FLES. FLESNEWS, p. 5.

Rost, J. C. (1981). Education myth and public policymaking. Urban Education, 15(4), 419-434.

Rost, J. C. (1981, August). The political model: A synthesis form the literature. Paper presented at the National Conference of Professors of Educational Administration, Seattle, WA.

Rost, J. C. (1985, November). Shaping the school culture of educational excellence: The nature of transforming leadership. Paper presented at the California Principal's Conference, Anaheim, CA.

Rost, J. C. (1986). Politics of education myth. Unpublished paper. San Diego: University of San Diego, Graduate School of Education.

Rost, J. C. (1987, November) The politics of instructional leadership. Paper presented at the California Principals Conference, Anaheim, CA.

Scanlon, D. G. (1960). International education: A documentary history. New York: Teachers College.

Scanlon, D. G. (Ed.). (1960). The elements of fundamental education. International education: A documentary history. New York: Teachers College. pp. 178-182.

Schattschneider, E. W. (1960). The semisovereign people. New York: Holt, Rinehart, Winston.

Scheid, P. (1984, February). Message to all readers of the ISA Bulletin from the chairman of ISA. ISA Bulletin, pp. 3-4. 
Schein, E. (1985a). Organizational culture and leadership: A dynamic view. San Francisco, CA: Jossey-Bass.

Schein, E. (1985b). Process consultation. In W. G. Bennis, K. D. Benne, \& R. Chin (Eds.), The planning of change (4th ed.) (pp. 283-286). New York: Holt, Rinehart and Winston.

Schine, J. G., \& Harrington, D. (1982). Youth participation for early adolescents: Learning and serving in the community. Bloomington, IA: Phi Delta Kappa Education Foundation.

Schoen, D. A. (1985). Conversational planning. In W.G. Bennis, K. D. Benne \& R. Chin (Eds.), The planning of change (4th ed.) (pp. 247-253). New York: Holt, Rinehart and Winston.

Schools urged to give students global perspective. (1987, October 27). Guidepost, p. 4.

Schools urged to give students global perspective. (1987, October 29). Guidepost, p. 4.

Scott-Blair, M. (1985, April 15). Education issues stir brisk debate. San Diego Union p. B1.

Shane H. G. and Weaver, R. A. (1978). Futures in education. In J. Fowles (Ed.), Handbook of futures research (pp. 711-712). Westport, CN: Greenwood.

Small, M. G. (1980). Toward a systematic education. In F. Feather (Ed.), Through the '80s: Thinking globally, acting locally (pp. 344-350). Washington, DC: World Future Society.

Smith, A. F. (1988, May). The state of global education. Access, pp. 9-12.

Smith, K. K. (1984). Philosophical problems in thinking about organizational change. In P. S. Goodman (Eds.), Change in organizations (pp. 316-376). San Francisco, CA: Jossey-Bass.

Smith, V. (1986-87). Assessing current needs. In J. Torney-Purta (Ed.), Evaluating global education: Sample instruments for assessing programs (pp. 21-33). New York: Global Perspectives in Education.

State delegations begin to form. (1987, September-October). Access. p. 1.

Stephenson, C. M. (1980) The international relations of a metropolitan area: San Diego in the world/The world in San Diego. (Doctoral Dissertation, The Ohio State University, 1981). Dissertation Abstracts International, 42, 4829A-4930A. 
Stewart, M. (1984). The age of interdependence: Economic policy in a shrinking world. Cambridge, MA: MIT Press.

Study Commission on Global Education. (1987, May/June). Report. San Diego: International Studies Education Project of San Diego.

Study shows little progress on desegregation. (1988, August 1). Edcal, p. 1.

Sussman, J. (1973). A nation prepared: Teachers for the 21st century. Washington, DC: Carnegie Forum on Education and the Economy.

Teachers buy TV ads to appeal for school funds. (1987, September). Edcal. p. 1.

Thiers, N. (1988, May 26). AACD joins education groups' protest of Bennett's record. Guidepost p. 4.

Thompson, M. (1983, October). Private foundations and public education. California lournal, pp. 394-395.

Tiedeman, D. A. (1985). Media services in higher education: A delphi study for the 1990s. Unpublished doctoral dissertation, University of San Diego, San Diego.

Toffler, A. (1980). The third wave. New York: Bantam.

Torney-Purta, J. (Ed.) (1986-87). Evaluating global education: Sample instruments for assessing programs. New York: Global Perspectives in Education.

Uhl, N. P. (1983). Using the Delphi technique in institutional planning. In N. P. Uhl (Ed.) New directions for institutional research (pp. 81-93). San Francisco, CA: Jossey-Bass.

United States Advisory Commission on Public Diplomacy (1985). Report. Washington, DC: United States Information Agency.

United States Department of Education. (1985a, March). Application for Grants Under the Secretary's Discretionary Program for Mathmatics, Science, Computer Learning and Critical Foreign Languages. (CFDA Publication No. 84.168F). Washington, DC: United States Government Printing Office.

United States Department of Education. (1985b, September). Application for Grants Under Title VI of the Higher Eduction Act of 1965, As Amended. (CFDA Publication No. 84.017). Washington, DC: United States Government Printing Office.

United States Government Manual, 1984/85. (1984). Washington, DC: United States Government Printing Office. 
United States Information and Educational Exchange Act of 1948, U. S. C., Title $22 \S 1431-1456$.

United States Mutual Educational and Cultural Exchange Act of 1961, U. S. C. Title 22 § 2451-2458.

United States Senate Committee on Labor and Human Resources (1980, May 15). Senate Report 96-733, International Education Programs.

Washington, DC: United States Government Printing Office.

United States Senate Committee on Labor and Human Resources (1986). Senate Report 99-597. Washington, DC: United States Government Printing Office.

USCA General Index. (1984). Washington, DC: United States Government Printing Office.

Walter, S., \& Choate, P. (1984). Thinking strategically: A primer for public leaders. Washington DC: Council of State Planning Agencies.

Warner, B. (1987, November/December). The high school academy: A collaboration that worked. Thrust, pp. 31-33.

Waterlow, C. (1980). The community of the future. In F. Feather (Ed.), Through the '80s: Thinking globally, acting locally (pp. 150-157). Washington, DC: World Future Society.

Weick, K. E. (1984). Management of organizational change among loosely coupled elements. In P. S. Goodman (Ed.), Change in organizations (pp. 375-408). San Francisco, CA: Jossey-Bass.

Wesley Apker. (1984, September 28). Edcal, p. 1.

What parents, school board members, school administrators and teachers can do (1987). Want to internationalize your school? New York, NY: National Council on Foreign Language and International Studies, p. 1.

What we want from our schools. (1985, May). The Progressive. 49, 9-10.

When schools become jungles. (1988, June 6). Time, p. 70.

Wiles,'D. K., Wiles, J., \& Bondi, J. (1981). Practical politics for school administrators. Boston, MA: Allyn and Bacon.

Williams, W. (1988, May 22). Clarke's "global village" here now. Satellite TV Week. p. 1.

Wilson, A. (1988, February). Book review. Access, p. 4. 
Wilson, A. (1988, February). Book review: What do our 17-year olds know? Access, p. 4.

Winfield, F. E. (1986). Connecting curriculum to the real world. Momentum 1759.

Woyach, R. B., \& Love, J. (1983). Citizenship and world affairs: The impact of a community-based approach to global education. Educational Research Quarterly $\underline{8}(1), 36-47$.

Wurr, J. (1986/87, Winter). Community service makes a difference. International Quarterly, p. 26.

Wynne, E. A. (1985, December/1986, January). Transmitting moral values. Educational Leadership p. 4-6.

Zusman, R. (1974). Parent involvement in Title I programs. Integrated Education, 12(5), 19-20. 


\section{Appendix A \\ DEMOGRAPHIC QUESTIONNAIRE}

\section{Think Globally, Act Locally: \\ A Delphi Study of the Educational Leadership through the Development of International Resources in the Local Community by Stuart R. Grauer}

A. Personal Background. Your responses to the following items are requested for the development of an overall profile of the respondents and institutions participating in this Delphi study. Your specific responses will be kept anonymous in the development of this general profile.

1. (a) YOUR NAME:

(b) YOUR INSTITUTION/DISTRICT:

(c) Check one: PUBLIC , or PRIVATE

(d) YOUR JOB TITLE (specify):

(e) Years in your job

(f) Years at your current site

2. YOUR TELEPHONE NUMBER:

3. (a) YOUR AGE (check one): $20-30$ ; $31-40$ ; 41-50

$51-60$ ; $61-70$ $; 70+$

(b) YOUR GENDER: male ; female

4. ACADEMIC DEGREE(S) you have earned (check all that apply and indicate major or specialization, and school):

DEGREE MANOR SCHOOL (a) Bachelor's

(b) Master's

(c) Doctoral 
5. STUDENT ENROLLMENT AT YOUR SCHOOUDISTRICT--list the number of students in the area you are responsible for in your job (full time equivalent):
(a) 500 or less
(b) $500-2,000$
(c) $2,000-5,000$
(d) $5,000-10,000$
(e) more than 10,000

6. Identify the international make-up of your school/district by listing each specific nation or region of origin in order of prevalence. If you are not sure, please give an educated guess. List up to six.

most prevalent group

next largest

7. Can you project any basic changes in this listing by the year 2000 ? If so, describe.

8. If you can recall any specific reasons or formative experiences to explain your interests in international relations, please cite them briefly and in order of importance.

When complete, please return this questionnaire to:

\author{
Stuart R. Grauer \\ Director \\ Center for International Education \\ 1509 Forest Way \\ Del Mar, CA 92014
}


Appendix B

Round One: Letter of Transmittal and Delphi Instrument

Stuart R. Grauer

Center for International Education

1509 Forest Way

Del Mar, CA 92014

April 6, 1988

Dear : [sample]

Welcome. You, along with 52 superintendents, deputy superintendents and top level school officials from southern California have been carefully screened to participate in this Delphi survey of educational leaders. As I discussed with you on the telephone, this is a study of emerging resources in the school community. The specific objective is to assist educators in identifying ways in which international interests and groups in their communities can be most effectively linked to schools.

Some of the adaptations schools make are more subtle than others, but what is important in this survey is your personal expertise, sensitivity and intuition as leaders. Your participation in this survey, which is the outcome of four years of research at the University of San Diego, can be crucial in helping to open up new channels for partnership.

This Delphi study consists of three rounds of surveys, each of which may take thirty minutes to complete. The second and third rounds will each include summary feedback from the previous round. The feedback is provided as a means by which the Delphi respondents may reconsider their original responses and to allow an opportunity to change those responses so that a meaningful consensus can be obtained. This may be a unique opportunity for you to enter into an anonymous dialog with leaders in the area of international resource development in the local community. There is also a brief demographic survey which will be distributed with the first round only; this will be used to develop an overall profile of the respondents and their institutions.

The results of this study will be presented in three ways: one, a dissertation to be published by University Microfilms; two, journal articles reporting various aspects of the study; and, three, a proposal to present findings at a professional conference. Additionally, I would be glad to forward findings to your organization and to make the survey instrument available to you for your own uses. 
The demographic survey and the first round of the Delphi survey are enclosed. A stamped and addressed envelope is enclosed for your use in returning the instruments. From my sample selection process I know that you are particularly active in your school community, with little time for additional paperwork. At the same time, this active role is what makes your contributions to the research especially valuable. You are among a uniquely talented and experienced group. With your assistance, a great many opportunities for future leadership can emerge over the next 10-20 years. I thank you whole-heartedly for your participation.

Please mail your responses to this first round no later than April 20, 1988 to allow sufficient time for summarization prior to the mailing of the second round. I would welcome any comments that you may have concerning any aspect of principal selection not covered in the instrument. Your responses will be held in strictest confidence unless prior authorization is granted. You may reach me at (619) 755-9319 (home/answering machine) or (619) 756-0500 (work) if you have any questions or concerns.

Thank you.

Sincerely yours,

\author{
Stuart Grauer \\ Doctoral Candidate \\ University of San Diego
}




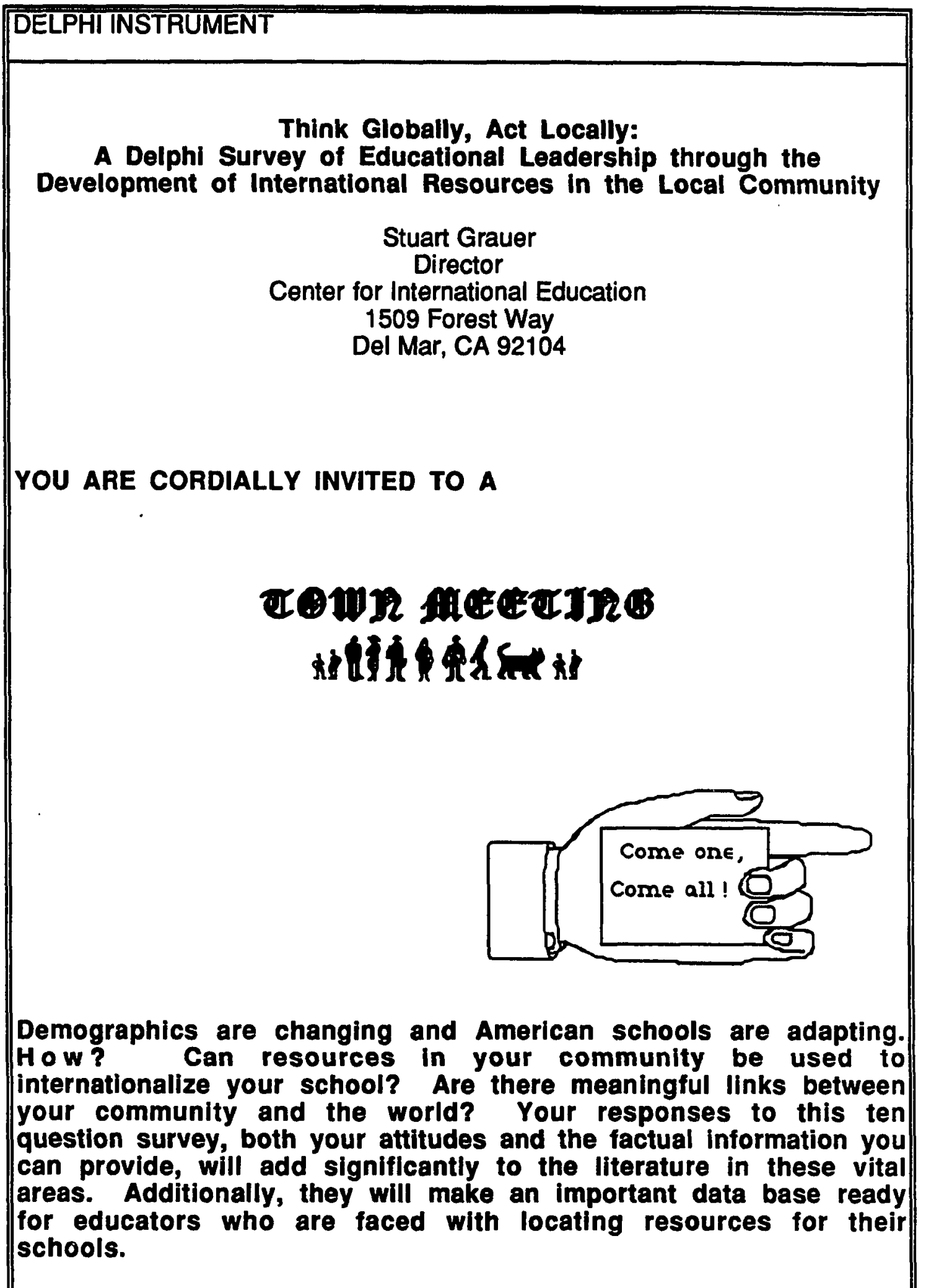


A. THE TOWN MEETING. The purpose of this survey is to test whether the school could generate community leadership by drawing upon international resources in the local community. The survey makes the assumption that change is a constant school goal.

Imagine you were made chairperson for a "Town Meeting" with prominent local community members from international organizations or with international skills and experiences. The purpose of the meeting is to assess current school needs and to plan a school which would be most prepared for the next century. At this meeting you want to get the special input of these international constituencies in your local community and to consider ways they could be involved in shaping the broad mission of the school. Such people should be qualified to serve on school boards, school-community advisory committees, parent involvement projects, curriculum teams or similar organizations involved with the shaping of school values and goals.

Note that the next round of this Delphi survey will provide you with a composite of respondents' listings and ask you to rate the value of each.

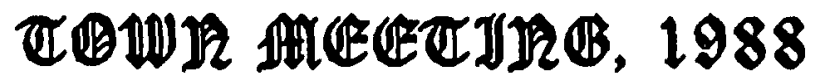

1. Who should attend? List community members whose support has most helped the school in its efforts to show community leadership (e.g., people who have heiped in planning, made resources available, or created change).

You need not use their actual names. What is important here is their stature, their job, the resources they have available, or their roles in the community which have made them capable of leadership.

International Resource Person: (Example) Chairman of the local Vietnamese Refugees Committee.

Value to the school: (Example) Represents a growing constituency in the community; he has access to school volunteers and has interested a local airline branch in school-business partnership. He has challenged the school board to support the curriculum project of a group of Vietnamese scholars from the local university. 


\begin{tabular}{|l|}
\hline a. International Resource Person: \\
\hline Value to the school: \\
\hline b. International Resource Person: \\
\hline Value to the school: \\
\hline C. International Resource Person: \\
\hline Value to the school: \\
\hline
\end{tabular}

2. AGENDA. List three items which you would place on the agenda for this community meeting. In general, items may reflect either practical program development or philosophical goals. Remember: this meeting is a chance to strengthen the school as well as your own leadership. (You may refer to programs currently in use.)

a.

continued 
b.

c.

3. Early in the town meeting a school board member stands up and asks:

"Why do we need this meeting? I question how it can lead to long term, fundamental change in the school goals, and I question whether it even should!"

The room goes stubbornly silent. As chairperson, what would you say?

4. A local university exchange student now raises his hand and states this:

"Education is one of the basic factors in international relations, quite as important as diplomacy, commerce and military power in its implications for war and peace."

Could you support his abstract point with any concrete examples of programs at your school which have gained your support and which embrace a similar philosophy?

5. Interruption: A local school administrator has come to this meeting even though she does not represent an international group. Suddenly you notice her in the back corner of the room and she looks unsettled. She stands up and says:

"There are too many other demands and pressures upon the school, and upon my time(!) to worry about getting more interest groups involved."

What administrative demands do you anticipate she would mention that compete most directly with tonight's goal of internationalizing the school? List three.

a.

b. 
c.

6. A teacher who also is a member of a populous and well established local ethnic group makes this comment:

Outside interest groups and politicians already have too much influence in the schools. Teachers are the experts, but we're no longer free to teach. We must be careful at meetings like this not to give outsiders even more power over the schools. to?

What powerful groups in your community might the teacher be referring

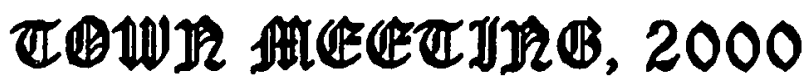

7. Imagine that a similar meeting were held in the year 2000. Again, you are Chairperson. Forecast the international resource people you believe will be most valuable in working with the school to plan important changes in the year 2000. You need not know these people. What is important here is your ability to consider the trends in your community so that you can hypothesize.

a. International Resource Person (2000):

Value to the school:

b. International Resource Person (2000):

Value to the school: 
8. AGENDA, 2000. It is the year 2000. What three items would you place on the agenda of this meeting to help shape fundamental educational goals for the new century? This is your wish list. Are there philosophical goals you'd want discussed? Specific programs you'd wish to develop? Forecast two or three agenda items.

a.

b.

c.

9. Do you have anything you wish to add or explain about any of your responses to this survey?

10. If some item in this survey has been particularly confusing or difficult to answer, please note the page and item number and describe why it was particularly confusing or difficult.?

\section{Uhank you for participating in the Town Atexting. at}

If you have questions, call (619) 755-9319.

This concludes the Delphi survey. Please proceed to the demographic survey, next page. The demographic survey is a one time only survey which will be used to gather background information on respondents. 
Appendix C

Round Two: Letter of Transmittal and Delphi Instrument

\author{
Stuart R. Grauer \\ Center for International Education \\ 1509 Forest Way \\ Del Mar, CA 92014
}

April 28, 1988

Dear [Sample]:

Welcome to the second of three rounds of this Delphi survey on leadership initiatives for community international education. I am truly impressed by the credentials of the 29 panelists. There is an average of over eight years experience in current jobs and collectively the group has a total of 245 years of experience in current job categories. 83 percent have doctoral degrees. I will provide you with complete demographic information along with the survey results shortly after the conclusion of round three, in about six weeks. But at least as impressive as the expertise of the respondents has been the quality of responses which came out of the first round. The patterns which are developing are enlightening in many ways, and encouraging to say the least. The crucial task now is to find areas for consensus.

Since this study is depending upon a small sample of experts, your continuing participation is vital. Enclosed, please find the second round of the survey. In order for the survey to continue as scheduled, could you please return it by Tuesday, May 17.

I want to thank you again for your willingness to participate in this study, for your efforts, and for your patience and responsiveness which are making this research possible. Your responses in particular conveyed that you are an expert among top experts: please stay in the survey.

Thank you.

Sincerely yours,

\author{
Stuart Grauer \\ Doctoral Candidate \\ University of San Diego
}


Think Globally, Act Locally:

A Delphi Survey of Educational Leadership through the Development of International Resources in the Local Community

\author{
Stuart Grauer \\ Director \\ Center for International Education \\ 1509 Forest Way \\ Del Mar, CA 92104
}

WELCOME TO THE SECOND

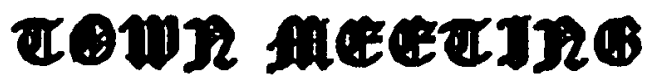

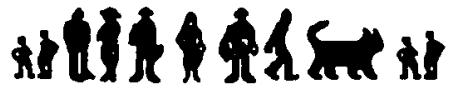

YOUR NAME:

Estimated \% of parents in your district who have

a region of origin other than the United States

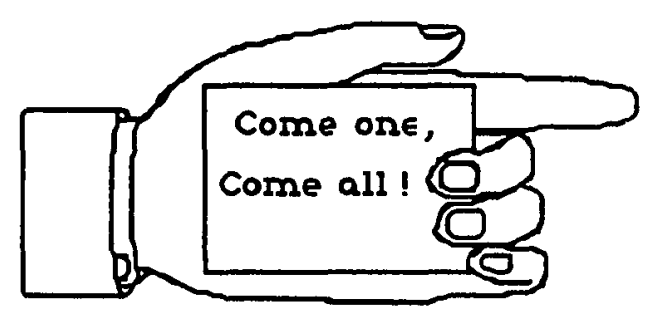

Demographics are changing and American schools are adapting. How? Can resources in your community be used to internationalize your school? Are there meaningful links between your community and the world? Your responses to this survey, both your attitudes and the factual information you can provide, will add significantly to the literature in these vital areas. Additionally, they will make an important data base ready for educators who are faced with locating resources for their schools. 
THE TOWN MEETING. The purpose of this survey is to test whether the school could generate community leadership by drawing upon international resources in the local community. The survey makes the assumption that change is a constant school goal.

As in the first round of surveying, you have been made chairperson for a "Town Meeting" with prominent local community members from international organizations or with international skills and experiences. The purpose of the meeting is to assess school needs and to plan a school which would be most prepared for the next century. At this meeting you want to focus on internationalism in your local community and to consider ways to shape the broad mission of the school.

Note that the next and final round of this Delphi survey will provide you with a composite of respondents' priorities and ask you to rate them.

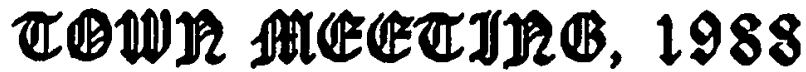

I. Who should attend? The following community members attended the first Town Meeting. They were cited as most capable of giving support to your efforts at leadership. Leadership as used here indicates the ability to bring real, constructive change and to unite coalitions in new understandings.

You now wish to form a subcommittee of those who are the most effective change agents and could lend the most support to your leadership efforts community-wide. Who do you pick? For this item you have ten picks, five from each group.

Note: These are examples only, and should be generalized to actual people you can think of who are being (or can be) utilized by school leaders in any school community. Assume that the people below are all local community members of sensitivity, diplomacy and influence.

\section{Pick 5}

1. A translator who works with the schools

2. District coordinator, foreign students program

3. Latin American or Asian member of school board

4. — Aerospace/telecommunications expert

5. Chief of Protocol, county office (receives/assists foreign dignitaries)

6. Coordinator of student and teacher foreign exchange programs

7. Corporate leader/executive of an international corporation or bank

8. Demographic specialist

9. — President, a citywide International Community Committee

10. President, local branch of the American Bar Association

11. Intercultural counsellor

12. President, the school district's Multiethnic Advisory Council

13. Director of International Relations at the county school district level

14. Director, Community Resource Center (an educational foundation)

15._ President, local branch of the America Medical Association more 
16. Former foreign exchange student or teacher, now prominent community member

17. Government official, trade regulations

18. Latin American or Asian Chairman/parent organizer, international parent committee or PTA

19 Law enforcement official of Latin American or Asian heritage

20. Local member, State Dept. of Education international studies project

\section{Pick 5 more}

21. The district's staff specialist or consultant, internat'l curriculum development

22. Teacher (soc. stud., lit., science, art), foreign born with a global perspective

23. Chairman, Asian or Latin American businessmen's association

24. Chairman, the community's Asian, Latin American or multinational civic organization

25. Director of international relations at a local university

26. Director, foreign exchange organization

27. Editor of a local Asian or Latin American newspaper

28. ___ Executive, International Division of Chamber of Commerce or Pacific Trade Center

29. Pastor or leader of a religious organization

30. President, Industrial or Urban League, Board of Realtors, or homeowners' group

31.___ Director, global perspectives in K-12 education project at local university

32. Local businessman (of foreign heritage) who effectively speaks to students on values and life skills

33. A key minority employer

34.___ Adopt-a-school contact person (e.g., community relations director) at a multinational corporation

35. _ Chairperson, parent program for migrant students

36. Communications specialist or producer, local branch of international radio/tv station

37.___ Community activist

38. - Member, State foreign student affairs advisory committee

39. N Noted futurist or think tank international education expert

40._ University professor or dean, international relations or econ. specialist

41.___ Other (describe):

42. How would you characterize the resource people you selected? 
43. Please comment on what causes you the most reservations about potential resource people whom you did not select:

II. Functions of International Resource People. The following list represents roles played by international resource people whom you invited to the first Town Meeting. What are the most valuable functions of these resource people? What roles do they play which are most valuable in making changes that are necessary as we prepare for the next century.

Indicate whatever action you believe is actually occurring in schools today (not necessarily your own) and is also proactive, that is, leading us into the future. As in the last question, check the most valuable items. You have 4 picks per group.

Note: These are examples only, and may be generalized to comparable situations. Remember, the goal is fundamental change.

The function of this internationalist resource person is to. ..

\section{Pick 4}

1.

2.

plan educational strategies for foreign students

1.

3.

4.

5

6.

-

7.

8.

9.

10.

12.

13. business needs help prepare students for international business help prepare students for international citizenship nationally foreign exchanges, speakers for meetings university level immigrants teach classes with a global perspective lead politically powerful community ethnic groups work directly with students to motivate and orient them towards global inform school leaders of cultural and demographic changes locally inform school leaders of cultural and demographic changes provide student and teacher opportunities such as internships, provide inservice training/consultation to parents, staff, community provide perspective and inspiration, re: educational needs at the provide schools access to distinguished foreign citizens and serve on the school board with clear understanding of community expectations

\section{Pick 4 more}

14. work with the school's leadership for pluralist legislative action beyond the community arena (issues which transcend local politics)

15. advocate programs for students with special needs 
16.

provide a clear vision of minority employment needs/perspectives and assists the school in developing appropriate programs

17. contact and negotiate with a wide variety of foreign countries and companies which can provide capital and human resources

18. direct a local community foundation dedicated to supporting the school

19. help provide telecommunications links/data bases with schools overseas

20. lead the school-business partnership program at a large multinational corporation which provides the school with useful resources

21. assist the school on immigrants' problems (e.g., citizenship, language)

22. provide frequent guest speakers and audio/visuals for school events

23. contact and influence with many segments of district's foreign

24. community--effective community organizer. and consult on international trends for curriculum updates
25. inform school leaders of future trends and global issues: global interdependence, geopolitics, health, poverty, etc. coordinate school efforts in obtaining global education resources

26. provide publicity aimed at bringing foreign fiscal and human resources into the schools

27. other (state briefly):

28. Can you characterize those roles you selected which you believe will be especially valuable to education in the next century?

29. If you think it could add clarity to your choices, try to characterize the roles you did not select:

over, please 
III. Agenda. The following items were generated in the first Town Meeting as issues needing attention in the community. Now, as chairperson, you must limit the agenda so that it focuses on only the most salient issues. After all, unless we identify where the real international needs lie, how can lead the way to them? Again, the goal is fundamental and ne 3 ded change specifically towards internationalism.

For this poll, you again have a number of votes to cast on the most salient items for inclusion, in this case only 4.

\section{The top priority Agenda items are...}

\section{Pick 4}

1.

Equality of educational opportunity. How are foreign students doing academically?

2. How well have the schools met instructional needs over the past 20 years?

3. Skills, knowledge and creativity required by a futures oriented business community

4. Alternative methods of schooling

5. Appropriate use of school facilities; dealing with changing enrollment patterns

6.

7.

8.

9.

Comparison of US education system with leading foreign systems
How to generate political support in the community Partnerships with higher education and business

economy

10.

11. Staff development, hiring and teacher training practices

12. Education's role in addressing global problems (e.g. communications barriers, ecology, food, survival) International resources available in the community to augment school financing

13. International resources available in the community to promote students' global awareness

14. Parental education and social services for newcomers

15.__ What are the real district priorities and how appropriate are they?

\section{Pick 4 more}

16.

17.

18.

19.

20.

21.

22.
Goals and objectives for an international studies program Teaching conflict resolution and cooperative decision making Demographic developments in the area: their impacts on educational programming Teacher and student foreign exchanges and study tours Technologically enhanced, global learning systems, communication with foreign sister cities/schools

The role of the school in cultivating a pluralist, international United States society

What are schools across the country doing in this area? 
23. Developing bilingual and limited English proficiency programs

24. _ The place of international and non-European social studies in the curriculum

25. Demographic developments and immigrant contributions in the United States: their impacts on our educational programming

26. D__ Developing a more international school culture/climate

27. _ Perceived needs/understandings for an internationalist local community

28. Positive steps for ethnic harmony and conflict management in the school community

29. Maintaining cultural values and diversity despite increasing immigration and integration

30. Using the school sites as community/neighborhood centers

31.__ Strategies for promoting awareness of interdependence of people and nations over time.

32. Other (state):

34. Characterize those agenda items which you feel will be most salient in the next century.

35. Do you have any comments on the reservations you have for agendas you did not select?

IV. The following responses are round one responses to the question "Why do we need this meeting" (the Town Meeting)? They represent distinct philosophles. As Chairperson, you know that they are too diverse and need focusing, and so you take a poll. Usually, as Chairperson, you keep your philosophy to yourself. Now, with your vote, you have a chance to express it. Vote for items that you truly believe would support efforts for fundamental and needed change which will lead us into the next century.

For this poll, you have up to three votes to reflect your belief system.

Statement of philosophy on international education

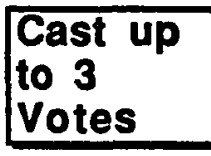

1. W_ We are in a state of rapid change in California. One fourth of the world's immigrants settle in California. We must all adjust and plan together." 
2. "Education has a mandate to keep the United States competitive in the international marketplace."

3. "Schools need to prepare students to participate in a world culture."

4. access to quality programs."

5. ___ "Education is one of the basic factors in international relations, quite as important as diplomacy, commerce and military power in its implications for war and peace."

6. WE "We need to take a proactive stance in the face of not just a changing curriculum but a changing world."

7. W_ We need to develop a climate of mutual support in the community, so that common goals can be found."

8. contribute to world peace and understanding."

9. W_ We need to be adapting the school to changing socio-economic demands."

10. W We need to address the perceived needs of (and our common goals with) an increasingly transient and pluralistic population which is vastly different from the community of a few years ago."

11. If your three votes haven't given a clear picture of your philosophy, can you add a clarifying statement? 
v. Interest Groups. The final question in the first Town Meeting asked you to cite the outside interest groups which vie for control over the school goals and the process of change. In your perception, these groups would or do press agendas counter to the specific internationalist agenda you developed earlier in the survey. They are restated below.

Generalize these categories to your own experiences and the experiences of others in positions similar to your own that your have knowledge of.

Circle one number on each 5 point scale: "1" is the least pressure on your efforts at educational leadership and " 5 " is the greatest pressure on your efforts at educational leadership:

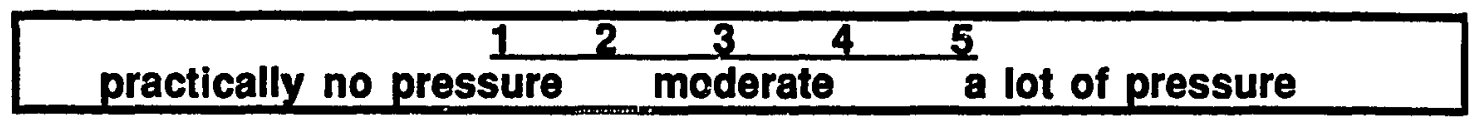

\section{How much does/would the goals of each compete with the} internationalist agenda?

1. Board of Trustees/Board of Education

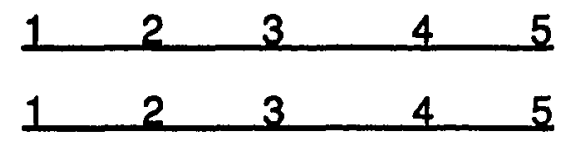

2. parent groups

3. problem oriented groups (AIDS

Society,drug awareness group, etc.)

4. recent immigrants

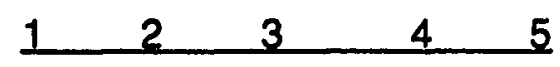

5. school site council/ advisory committees

$\begin{array}{lllll}1 & 2 & 3 & 4 & 5\end{array}$

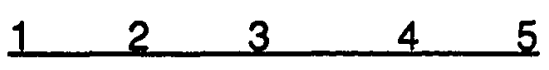

6. building industry

$\begin{array}{lllll}1 & 2 & 3 & 4 & 5\end{array}$

7. Chamber of Commerce or industry

$\begin{array}{lllll}1 & 2 & 3 & 4 & 5\end{array}$

8. homeowner groups/Taxpayers Assoc.

9. state legislature/government

\begin{tabular}{lllll}
1 & 2 & 3 & 4 & 5 \\
1 & 2 & 3 & 4 & 5 \\
\hline
\end{tabular}

10. government social service agencies (Health Dept., Law Enforc, Child Serv.)

11. conservative political organizations (John Birch, Moral Majority, etc.)

$\begin{array}{lllll}1 & 2 & 3 & 4 & 5\end{array}$

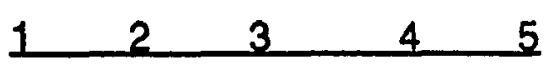

12. liberal political organizations

$$
\text { (ACLU, NAACP, etc.) }
$$

13. ethnic and religious groups

14. dominant or upper middle class, vocal groups (traditional majorities)

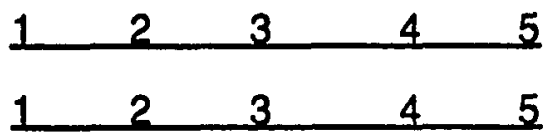

$\begin{array}{llll}1 \quad 2 & 3 & 4 & 5\end{array}$ 
15. councils on education

16. individual teachers (not a group)

17. individual parents or community members

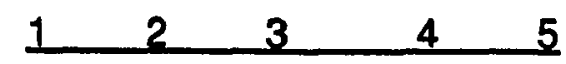

$\begin{array}{lllll}1 & 2 & 3 & 4 & 5\end{array}$

$\begin{array}{lllll}1 & 2 & 3 & 4 & 5\end{array}$

VI. Do you have anything you wish to add or explain about any of your responses to this survey?

VII. If some item in this survey has been particularly confusing or difficult to answer, please note the page and item number and describe why it was particularly confusing or difficult.?

\section{Uhattk you for participating in the Town ftexting. witife the}

When complete, please return this survey to:

Stuart R. Grauer, Director

Center for International Education

1509 Forest Way

Del Mar, CA 92014

(619) $755-9319$ 
Appendix D

Round Three: Letter of Transmittal and Delphi Instrument

\author{
Stuart R. Grauer \\ Center for International Education \\ 1509 Forest Way \\ Del Mar, CA 92014
}

June 1, 1988

Dear [sample]:

Welcome to the third and final round of this Delphi survey on leadership initiatives for community international education. The responses and interest expressed in the first two rounds indicates that the information being generated is highly salient to leading educators throughout Southern California. The crucial task, introduced in the second round, is to find areas for consensus.

Since this study is depending upon a small sample of experts, your continuing participation is vital. Enclosed, please find the third round of the survey. In order for the survey to continue as scheduled, could you please return it by Iune 20. Also enclosed is the "Demographic Survey Summary." A number of you have expressed an interest in knowing more about other leaders in the field who are contributing to this research.

The special addition to this round is the inclusion of participant responses to the first two rounds. Inserted before each item in the survey you will find the percentage of respondents in the last survey round who selected that item. Additionally, you will find a listing of all open ended comments made in response to each category of items in the survey. These comments are placed before the short form items so that your ideas and perspectives can be shared before you make your selections. Although these insertions add to the amount of reading the survey requires, it is hoped that the insights and experiences of other experts will make your considerations easier.

Generation of consensus in this field is especially important since, as the literature indicates, the pressing needs in both international education and leadership today are the needs to synthesize diverse goals and to find more universal principals to guide program developments. This is our task. Delphi surveys such as this have been highly effective in generating clear consensus towards a clearer view of the future. This is the reason for multiple rounds.

As you complete this survey, please bear in mind that the goal is not simply integrating foreign or ethnic groups in your community, but using international resources to create global linkages and further internationalist goals through educational leadership. 
I want to thank you again for your willingness to participate in this study, for your efforts, and for your patience and responsiveness which have made this research possible. The input that has already gone into this survey is extraordinary: aside from the hundreds of hours of research that went into constructing and piloting this survey, the survey now represents approximately 30 concentrated hours of effort by you, some of the top experts on international education in Southern California and, in some cases, in the nation. The responses of the group that you are in have already validated a good deal of research reflected in the literature and they stand to add to this literature considerably.

Shortly after the conclusion of this round you will receive a "Delphi Summary" which conveys the findings of this research. I hope you will find this useful in your future endeavors. I am highly aware of the rather consuming involvement which this survey has required of you and I hope that you will feel free to call upon me if I can be of service to you in some way.

Thank you.

Sincerely yours,

Stuart Grauer

(619) $756-0500(w)$

(619) $755-9319(\mathrm{~h})$ 


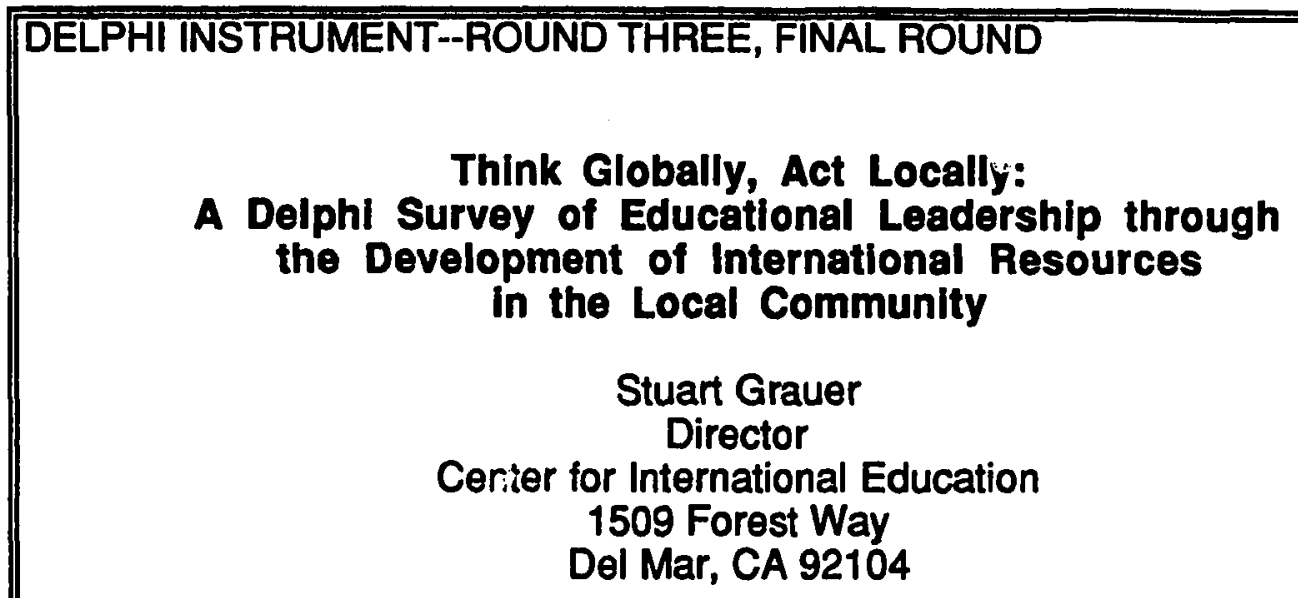

Think Globally, Act Locally:

A Delphi Survey of Educational Leadership through the Development of International Resources in the Local Community

Stuart Grauer

Director

Ceriter for International Education

1509 Forest Way

Del Mar, CA 92104

WELCOME TO THE FINAL

\section{TOWR meETRB

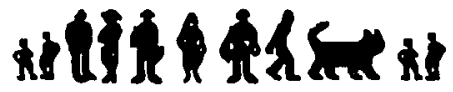

YOUR NAME:

Do you wish to allow your name to be

released as a participant in this survey? yes ; no

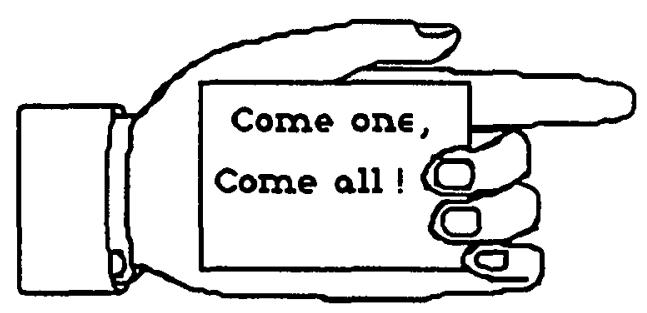

Demographics are changing and American schools are adapting. How? Can resources in your community be used to internationalize your school? Are there meaningful links between your community and the world? Your responses to this survey, both your attitudes and the factual information you can provide, will add significantly to the literature in these vital areas. Additionally, they will make an important data base ready for educators who are faced with locating resources for their schools. 
THE TOWN MEETING. The purpose of this survey is to test whether the school could generate community leadership by drawing upon international resources in the local community. The survey makes the assumption that change is a constant school goal.

As you recall, you have been made chairperson for a "Town Meeting" with prominent local community members from international organizations or with international skills and experiences. The purpose of the meeting is to assess school needs and to plan a school which would be most prepared for the next century. At this meeting you want to focus on internationalism in your local community and to create in the school which puts the school in a postion of community wide leadership.

Note that this round of the Delphi survey provides you with a composite of respondents' priorities. These priorities are expressed both as percentages of responses received by each item and as listings of comments made by respondents to open form questions. They will be used to determine consensus on each item. You may consider these percentages and comments when rating each item. Items which were rated with very low frequency are marked with strikethroughs and are considered out of the survey.

\section{Respondents' comments about the first two rounds of surveying:}

- Do you have anything you wish to add or explain about any of your responses to this survey?

a. "Often decisions made are driven by political agendas which may not reflect the most urgent needs of students."

b. "The more affluent well educated use the system to obtain their needs."

c. A recent school board election has transformed the district's direction so that there is much pressure on all aspects of working with non "American" peoples.

d. "I would do my best to make the internationalist agenda the "official" agenda."

e. "Very creative approach."

f. "The year 2000 is not that far away."

g. "Interesting to say the least."

h. "Right on target!! I'm excited about what you will share with us from this study."

- If some item in this survey has been particularly confusing or difficult to answer, please note the page and item number and describe why it was particularly confusing or difficult.?

a. It would be wonderful to have all of these people in our community but we do not.

b. "Many people involved in global education have not studied or traveled extensively and this bothers me!"

c. "The survey is] not very consistent with priorities in our district."

d. "A town meeting would be a poor strategy for me to pursue ...[at first]."

e. "I'm with these people--without help (people) and money. Don't ask us to do more!"

the Town Meeting convenes»s> 


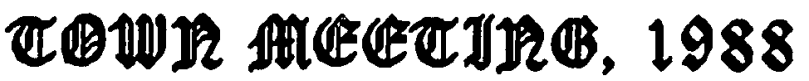

I. Who should atterid? The following community members attended the first two Town Meetings. They were cited as most capable of giving support to your efforts at leadership. Leadership as used here indicates the ability to bring real, constructive change and to unite coalitions in $\mathrm{new}$ understandings.

You wish to form a subcommittee of those who are the most effective change agents and could lend the most support to your leadership efforts community-wide. Who do you pick? For this item you have ten picks, five from each group. The items follow a listing of comments made in the first round.

Note: These are examples only, and should be generalized to actual people you can think of who are being (or can be) utilized by school leaders in any school community. Assume that the people below are all local community members of sensitivity, diplomacy and influence.

- How would you characterize the resource people you selected (below)? RESPONDENTS'COMMENTS FROM ROUND 2 (some are condensed and represent more than one respondent comment):
a. "Resourceful"
b. They represent a broad cross section of the community that would support international edication.
c. They represent various publics and may bring a global perspective.
d. "Diverse, knowledgeable, aggressive, realistic."
e. "Interested in improving learning, open minded, 'big picture' people."
d. "Decision makers"
e. "Active people in school and/or community with experience in minority culture."
f. "Change agents with balance and access to media"
g. Broad knowledge and experience.
h. "Well connected ...access to people from several different constituencies."
i. "Leaders with a history of getting things accomplished."
j. "Caring, bright, visionary"
k. "Cross section of community, business/industry, education and decision makers."
l. "Balanced perspective."
$\mathrm{m}$. "Broad sphere of influence ...can branch out."
n. "Broad, international perspective."
o. "Serve as 'advisors' to many groups."
p. "Can marshall resources."

- Comments on what caused you the most reservations about potential resource people whom you did not select (below):

RESPONDENTS' COMMENTS:

a. "Personal agendas"

b. They are too specialized or narrow, therefore have limited viewpoints and limited resources.

c. Similar viewpoints, too limited to provide needed diversity/need for a "representative group"

d. They have hidden or limited agendas.

e. "Need power people from school, business and government who can effect and implement change."

$f$. Not a good cross section of the community.

g. Prevents having an objective group. 

h. "Too far left or right."
i. "Need for media personnel ...to provide communication/information to community."
j. "College/county/state people too removed from reality!"
k. "I would not have limited to five."
m. "Have concems against the imperative for a global perspective."
n. "i didn't have any reservations about any one."
o. "Not part of local power structure."

\section{Pick 5}

2. $(10 \%)$

3. $(68 \%)$

4. $(12 \%)$

5. $(4 \%)$
1. $(20 \%)$

A translator who works with the schools

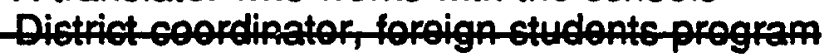
Latin American or Asian member of school board Aorospacotolocommications-oxpent

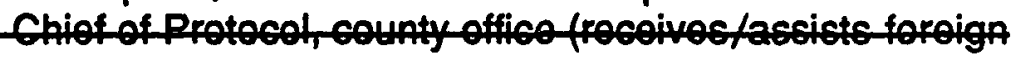
dignitariot

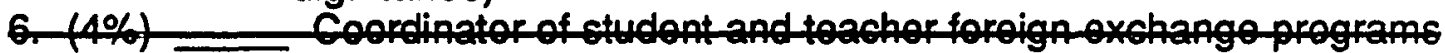
7. $(68 \%)$ Corporate leader/executive of an international corporation or bank

8. $(20 \%)$

9. $(48 \%)$ Demographic specialist

$10 .(0 \%)$ $11 .(16 \%)$ 12. $(76 \%)$

13. $(24 \%)$ President, a citywide International Community Committee

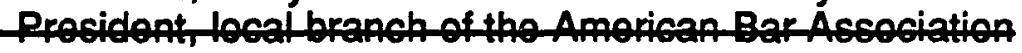

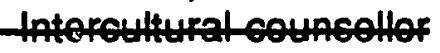
President, the school district's Multiethnic Advisory Council Director of International Relations at the county school district level

14. (20\%)___ Director, Community Resource Center (an educational foundation)

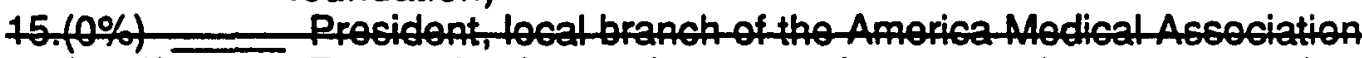 16.(44\%)__ Former foreign exchange student or teacher, now prominent community member

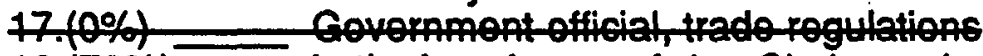
18. $(72 \%)$ Latin American or Asian Chairman/parent organizer, international parent committee or PTA

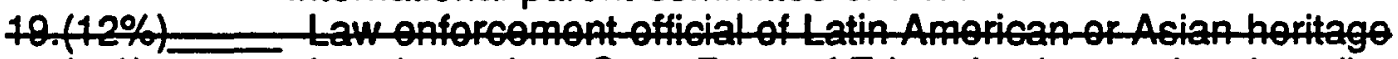 20. $(8 \%)=$ Localmor, Stato Dopt of Education in national tudios projostos

Pick 5 more

21. $(36 \%)$ The district's staff specialist or consultant, internat'l curriculum development

22. (44\%)__ Teacher (soc. stud., lit., science, art), foreign born with a global perspective

23. (20\%)___ Chairman, Asian or Latin American businessmen's association

24. $(36 \%)$ Chairman, the community's Asian, Latin American or multinational civic organization

25. $(36 \%) \_$Director of international relations at a local university

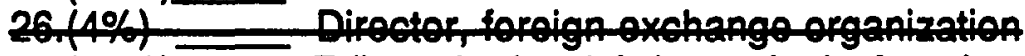

27. $(56 \%)$ Editor of a local Asian or Latin American newspaper mores> 


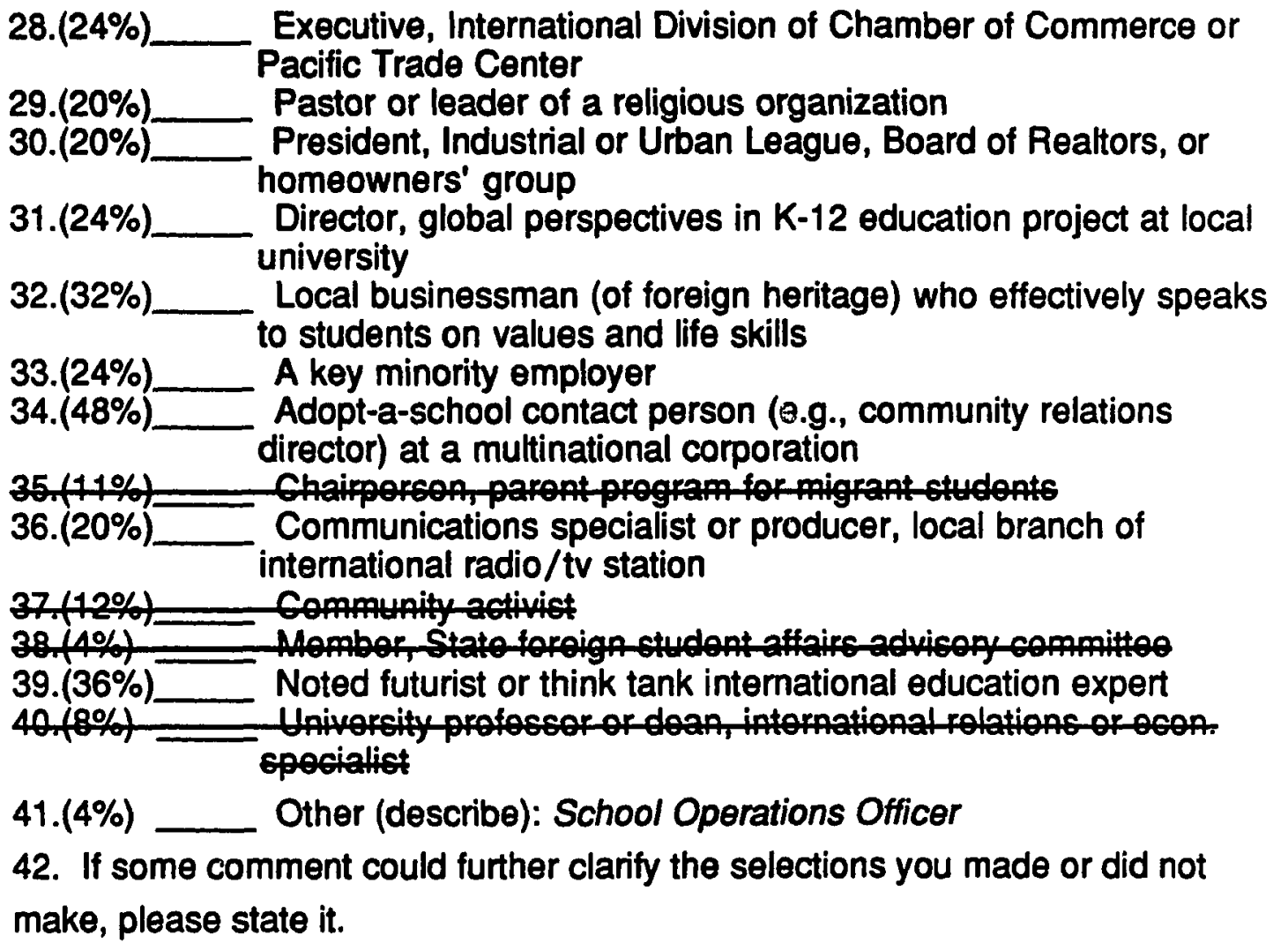

II. Functions of International Resource People. The following list represents roles played by international resource people whom you invited to the second Town Meeting. What are the most valuable functions of these resource people? What roles do they play which are most valuable in making changes that are necessary as we prepare for the next century.

Indicate whatever action you believe is actually occurring in schools today (not necessarily your own) and is also proactive, that is, leading us into the future. As in the last question, check the most valuable items. You have 4 picks per group.

Again, comments and percentages from the first round precede the items.

Note: These are examples only, and may be generalized to comparable situations. Remember, the goal is fundamental change.

- Comments about roles you selected which you believe will be especially valuable to education in the next century:

RESPONDENTS'COMMENTS FROM ROUND 2 (some are condensed and represent more than one respondent comment):
a. "Futurists/visionary"
b. "The main role should be to provide legitimate global perspective ...and have a track record."
c. "Proactive ...need to inform school leaders of demographic changes locally and statewide." 
d. "Able to give diverse opinions on changes ahead ...futuristic and realistic (economic)."

e. "People who can speak to students today and bring resources to schools."

f. "Effective communication ...to appropriate decision group(s)."

g. "Pluralism."

$h$. "I would hope that by the next century, we will be able to get beyond the 'special interests/special needs' view of intemationalism and into a more inclusive perspective. We need to seek community out of the diversity."

i. "Understanding the interdependence of the various cultures in order for us to enjoy the good life and still love our freedom."

j. "Organize and operationalize community awareness to a global perspective."

k. "Support all beyond minority link (e.g., foreign students, all kids)."

I. "Creative strategies."

m. "I would like to see partnership programs go both ways; with schools providing a marketing test group or some other kinds of support for businesses."

$n$. "all aimed at helping students/community gain a global perspective and a better understanding of human/national interdependence."

o. "The roles vary from informing/clarifying broad international education trends (micro) to addressing our community's specific (micro) problems."

p. "Building a cadre of knowledgeable leaders who will work for global at all opportunities; start with What is most functionally salient?

q. "The curriculum will be influenced by the needs of the international business world."

- Characterization of the roles you did not select:

RESPONDENTS'COMMENTS:

a. "I would not select people who could not make students aware of international interdependence."

b. "Some very specific efforts might misdirect the overall emphasis or intent."

c. "Ones which accentuate fragmentation rather than community."

d. "Some are limited in their ability to be visionary."

The function of this internationalist resource person is to...

\section{Pick 4}

1. $(20 \%)$ - plan oducational tratogio for foroign-sudonts

$2 .(16 \%)=$ work diroctly with studonts to motivato and oriont hom towards globat businose-noods

3. $(20 \%)$ _ holp proparo-studonte for intornationatbusinoss

4. $(56 \%)$ help prepare students for international citizenship

$5 .(44 \%) \_$inform school leaders of cultural and demographic changes locally

6. (44\%)___ inform school leaders of cultural and demographic changes

7. $(36 \%)$ nationally

7. $(36 \%)$ ___ provide student and teacher opportunities such as internships, foreign exchanges, speakers for meetings

8. $(32 \%)$ ___ provide inservice training/consultation to parents, staff, community

9. $(36 \%)$ ___ provide perspective and inspiration, re: educational needs at the university level

$10 .(40 \%) \ldots$ _ _ provide schools access to distinguished foreign citizens and immigrants

$11 .(48 \%) \ldots$ teach classes with a global perspective 


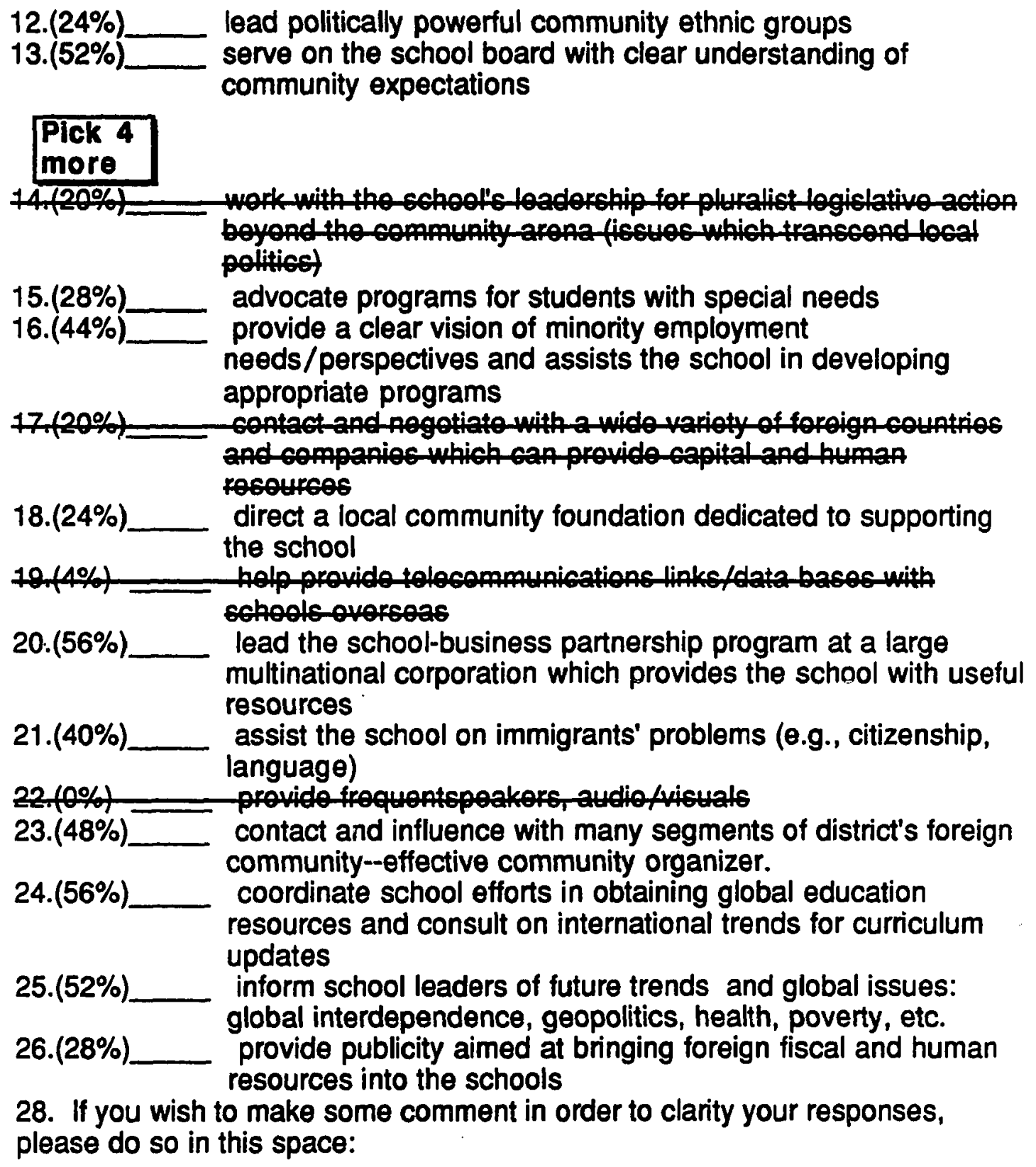

28. If you wish to make some comment in order to clarity your responses, please do so in this space:

III. Agenda. The following items were generated in the first Town Meeting as issues needing attention in the community. As chairperson, you must limit the agenda so that it focuses on only the most salient issues. After all, unless we identify where the real international needs lie, how can lead the way to them? Again, the goal is fundamental and needed change specifically towards developing international linkages.

Again, comments and percentages from the first round precede the items. 
For this poll, you again have a number of votes to cast on the most salient items for inclusion, in this case only 4.

- Agenda items most salient in the next century: RESPONDENTS' COMMENTS FROM ROUND 2 (some are condensed and represent more than one respondent comment):

a. "Interdependence and change."

b. Sensitizing the educational community (students, teachers, parents, etc.) to global interdependence, international affairs and the changing international marketplace.

c. "Meaningiul staff development to meet the needs of all students."

d. "These items give a good source of baseline date and academic/economic emphases with respect to curricular change."

e. "Knowledge and skills students will need to relate to a world economy and cultural diversity and understanding."

1. "Emphasis upon international business expansion."

g. "The whole issue of cultural diversity versus U.S. "traditional values" will continue to be of major importance."

h. "Conflict resolution a real need."

i. Learning how to live in a global society, understand one another, and work collaboratively.

j. "The need to respect the rights of others and the cultural similarities to enhance understanding of acceptance."

k. No one agenda item can operate successfully without interrelating with broad goals.

I. Those which transcend national thinking.

- Reservations about agendas not selected:

RESPONDENTS' COMMENTS:

a. "All have some value."

b. "The 'International State' will be most difficult for many to accept."

c. "Real life may not restrict the agendal"

d. "Emotionalism of the specific item could distract from the overall goal."

e. Those items not selected are outgrowths of the most salient.

f. "It is almost impossible to teach values. The world is a melting pot spilling over in all directions. The needs of the future must be taught today to prepare students for a smaller world."

The top priority Agenda items are ...

\section{Plck 4}

1. $(33 \%)$

Equality of educational opportunity. How are foreign students doing academically?

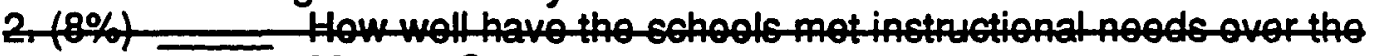
past 20yoafs?

3. $(52 \%)$ Skills, knowledge and creativity required by a futures oriented business community

4. $18 \%$ ) Alternativo mothode-of schooling

5. $(4 \%)=$ Appropiato $=0$ of school facilitios; dealingwith onfollment patteras

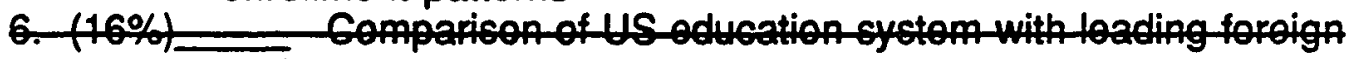
oyotom

7. $(8 \%)$ How to genorato politicateuppot in tho community

8. $(20 \%)$ Partnerships with higher education and business 
9. (24\%)__ Preparing students to live abroad and work in the international economy

10. $(48 \%)$ ___ Staff development, hiring and teacher training practices

11. $(68 \%)$ Education's role in addressing global problems (e.g., communications barriers, ecology, food, survival)

12. (8\%) Intornational rocourcocavailablo in tho community to augmont seheolffinaneing

13. (44\%)___ International resources available in the community to promote students' global awareness

14. $(36 \%) \quad$ Parental education and social services for newcomers

15. $(33 \%)$ they? ?hat are the real district priorities and how appropriate are

Pick 4

more

16. $(28 \%)$

17. $(56 \%)$

Goals and objectives for an international studies program

18. $(28 \%)$

Teaching conflict resolution and cooperative decision making

Demographic developments in the area: their impacts on

educational programming

10. $(4 \%)$ Toachor and-studont foroign-oxchanges-and-study toufs

20. $(20 \%)$ Technologically enhanced, global learning systems, communication with foreign sister cities/schools

21. (28\%)_ The role of the school in cultivating a pluralist, international United States society

22. $(4 \%)$ What afo-schools-across tho county doing in this aroa?

23. $(28 \%)$ Developing bilingual and limited English proficiency programs

24. (8\%) tho-gurficulum

25. $(12 \%)$ _ Demographio dovolopmonts and immigranteontributions in tho- Initod States; thoir impacte-on-ufoduational programming

26. $(33 \%)$ ____ Developing a more international school culture/climate

27. $(20 \%) \_$_ Perceived needs/understandings for an internationalist local community

28. $(28 \%) \_$Positive steps for ethnic harmony and conflict management in the school community

29. $(36 \%)$ Maintaining cultural values and diversity despite increasing immigration and integration

30. (20\%)__ Using the school sites as community/neighborhood centers

$31 .(48 \%) \_$Strategies for promoting awareness of interdependence of people and nations over time.

32. $(0 \%)$ Other (state):

33. If you wish to make some comment which can clarify your responses, please do so in this space: 
IV. The following responses are round two responses to the question "Why do we need this meeting" (the Town Meoting)? They represent distinct philosophles. As Chairperson, you know that they are too diverse and need focusing, and so you take a poll. Usually, as Chairperson, you keep your philosophy to yourself. Now, with your vote, you have a chance to express it. Vote for items that you truly believe would support efforts for fundamental and needed change which will lead us into the next century.

Again, comments and percentages from the first round precede the items.

For this poll, you have up to three votes to reflect your belief system.

$$
\text { Statement of philosophy on international education }
$$

\section{CLARIFYING STATEMENTS FROM ROUND 2:}

a. "The world is changing and we need to work together to benefit all, equally."

b. "All of the philosophies [stated] are good."

c. "Some attention should be given to language acquisition and the need for bilingualtrilingual citizens."

\section{Cast up to 3 \\ Votes}

1. $(36 \%)$ WWe are in a state of rapid change in California. One fourth of the world's immigrants settle in California. We must all cidjust and plan together."

2. (28\%)___ "Education has a mandate to keep the United States competitive in the international marketplace."

3. $(40 \%)$ culture." "Schools need to prepare students to participate in a world

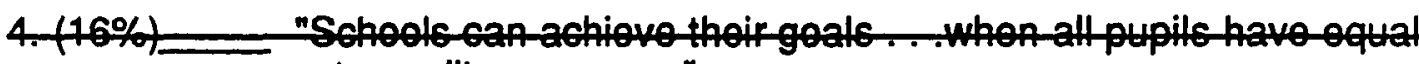
20cose to quatity prome"

5. $(60 \%)$ "Education is one of the basic factors in international relations, quite as important as diplomacy, commerce and military power in its implications for war and peace."

6. $(12 \%)$ "Wo nood to take-2poativo ctanco in tho faco of not jucta changing-ourficulum buta-changing-world"."

7. $(32 \%)$ "We need to develop a climate of mutual support in the community, so that common goals can be found."

8. (24\%) "Schools need to find ways to enable our next generation to contribute to world peace and understanding."

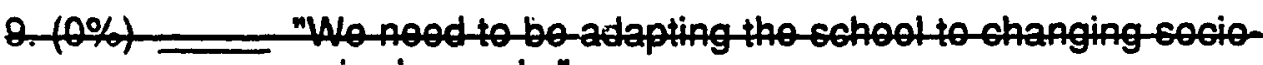
"ander."

10.(52\%)__ "We need to address the perceived needs of (and our common goals with) an increasingly transient and pluralistic population which is vastly different from the community of a few years ago." 
11. If your three votes haven't given a clear picture of your philosophy, can you add a clarifying statement?

V. Interest Groups. The final question in the second Town Meeting asked you to rate the outside interest groups which vie for control over the school goals and the process of change. In your perception, these groups would or do press agendas counter to the specific internationalist agenda you developed in the first two Town Meetings.

Generalize these categories to your own experiences and the experiences of others in positions similar to your own that your have knowledge of.

Circle one number on each 5 point scale: "1" is the least pressure on your efforts at educational leadership and " 5 " is the greatest pressure on your efforts at educational leadership:

Note that, in the interest of reaching consensus, the two most popular selections are listed by their percentages under their corresponding numbers.

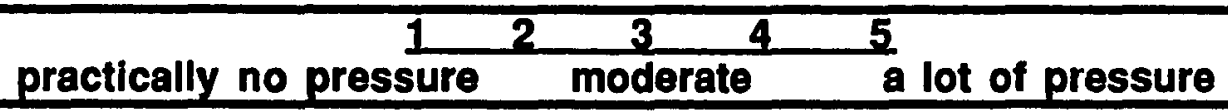

\section{How much does/would the goals of each compete with the} internationalist agenda?

1. Board of Trustees/Board of Education

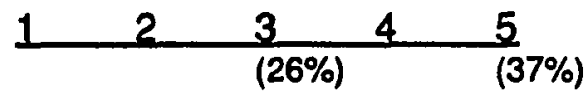

2. parent groups

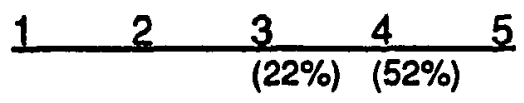

3. problem oriented groups (AIDS

Society, drug awareness group, etc.)

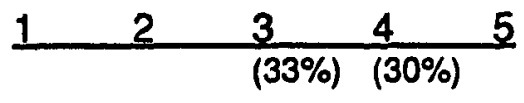

4. recent immigrants

5. school site councill advisory committees

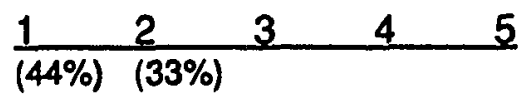

6. building industry

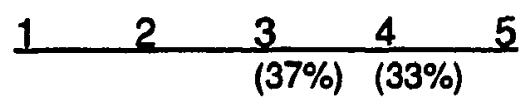

7. Chamber of Commerce or industry

8. homeowner groups/Taxpayers Assoc.
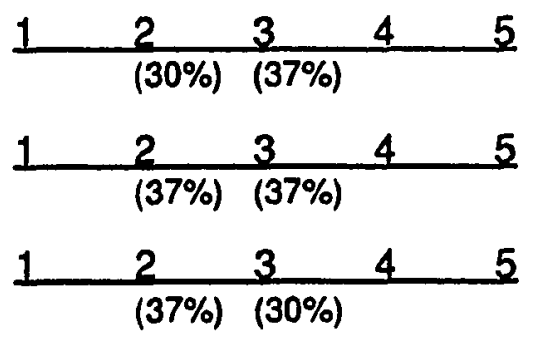
9. state legislature/government

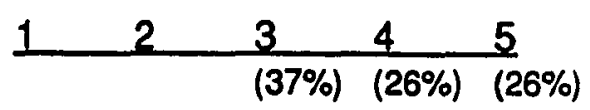

10. government social service agencies

(Health Dept., Law Enforc, Child Serv.)

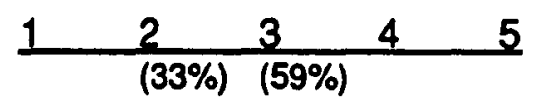

11. conservative political organizations

(John Birch, Moral Majority, etc.)

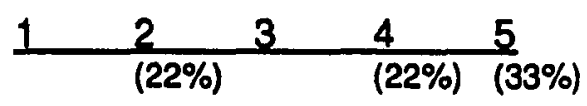

12. liberal political organizations

(ACLU, NAACP, etc.)

$\begin{array}{lllll}1 & 2 & 3 & 4 & 5\end{array}$

13. ethnic and religious groups

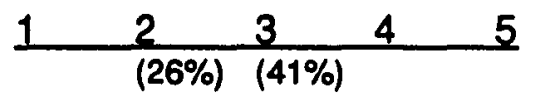

14. dominant or upper middle class, vocal majority groups

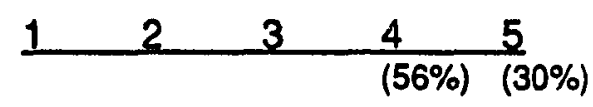

15. councils on education

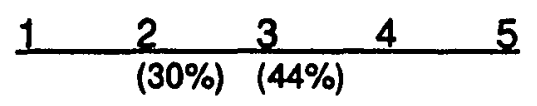

16. individual teachers (not a group)

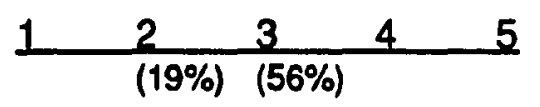

17. individual parents or community members

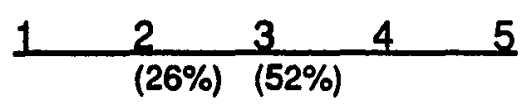

conclusion $\gg>$ 
VI. Do you have anything you wish to add or explain about any of your responses to this survey?

VII. If some item in this survey has been particularly confusing or difficult to answer, please note the page and item number and describe why it was particularly confusing or difficult.?

Interview: you are leaving this final meeting and the local press has taken a big interest in your work. They ask you for a quotable quote about the importance of this work. If you wish, you may use this opportunity to say something that honestly reflects your goals and perspectives.

\section{Uhank you for participating in the Town fteeting.

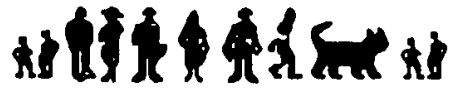

When complete, please return this survey to:

Stuart R. Grauer, Director

Center for International Education

1509 Forest Way

Del Mar, CA 92014 


\title{
Appendix E \\ Reseacher Correspondence
}

Stuart R. Grauer

Center for International Education

1509 Forest Way

Del Mar, CA 92014 tel.(619)755-9319

April 19, 1988

Dear [Sample]:

Just a reminder: round one of the three round Delphi survey, "Think Globally, Act Locally: A Delphi Study of the Leaders," will be analyzed over the course of next week. Many thanks for your willingness to participate. Again, the specific objective of the study is to assist educators in identifying ways in which international interests and groups in their communities can be most effectively linked to schools. Early returns of the surveys have already revealed some remarkable patterns.

The survey has a small sample which includes a distinct group of educational leaders; therefore each survey returned is of particular importance to the area being researched, as well as to the completion of the writing of my dissertation. If your survey has already been sent, you have my wholehearted thanks. If not, won't you please consider sending it along? Hearing from you this week will enable me to include you in the second round, to be mailed in approximately two weeks.

Thank you.

Sincerely yours,

\author{
Stuart Grauer \\ Doctoral Candidate \\ University of San Diego
}


Stuart R. Grauer

Center for International Education

1509 Forest Way

Del Mar, CA 92014 tel.(619)755-9319

May 17,1988

Dear [Sample]:

Just a reminder: round two of the three round Delphi survey, "Think Globally, Act Locally: A Delphi Study of the Leaders," will be analyzed over the course of next week. Many thanks for your willingness to participate. Again, the specific objective of the study is to assist educators in identifying ways in which international interests and groups in their communities can be most effectively linked to schools. Early returns of the second round surveys have revealed some remarkable patterns.

The survey has a small sample which includes a distinct group of educational leaders; therefore each survey returned is of particular importance to the area being researched, as well as to the completion of the writing of my dissertation. If your survey has already been sent, you have my wholehearted thanks. If not, won't you please consider sending it along? Hearing from you this week will enable me to include you in the third and final round, to be mailed in approximately two weeks.

Thank you for making this research possible.

Sincerely yours,

Stuart Grauer

Doctoral Candidate

University of San Diego 
Stuart R. Grauer

Center for International Education

1509 Forest Way

Del Mar, CA 92014 tel.(619)755-9319

June 20,1988

Dear [sample]:

Just a reminder: the third and final Delphi survey, "Think Globally, Act Locally: A Delphi Study of the Leaders," which was sent out on June 1, will be analyzed over the course of next week. This will enable me to complete the analysis of the survey.

I wish to congratulate the Delphi respondents as a group. An extraordinary amount of work has gone into the area of inquiry and we are very close to a long sought after consensus on international education. Since the survey has a small sample, each third round response is critical to the success of the study and the completion of my dissertation. I know that with your academic year closing and possibly with vacation scheduling time may be hard to come by this month. If your survey has already been sent, you have my wholehearted thanks. If not, won't you please consider sending it along? In just a few days I will be able to prepare the final "Delphi Summary." I strongly believe this summary will be useful and interesting to every participant, particularly for the patterns that it reveals.

Please call me at home or at work if you need another survey or you have any questions.

Thank you for making this research possible.

Sincerely yours,

Stuart Grauer

(619) 755-9319 (home)

(619) 756-0500 (work) 
Stuart R. Grauer

Center for International Education

1509 Forest Way

Del Mar, CA 92014

July 21,1988

\section{Dear [Sample]:}

Thank you very much for completing your role as a respondent for my research, Think Globally, Act Locally: Delphi Survey of Educational Leadership through the Development of International Resources in the Local Commmunity. I have enclosed a summary of the Round 3 Delphi instrument as well as an overall summary of the survey. Please note that the Round 3 summary lists those items on which you reached a consensus. You may find that the overall summary will need some further explaining, since I have not familiarized participants with the categories used for analysis of the responses. If you would like to be sent a more in depth analysis, please let me know and I will be happy to send one along. As you may recall, the demographic summary and responses to open ended questions were provided in the round 3 survey.

It seems remarkable that such a diverse group of professionals reached consensus on such an exploratory area and, as a result, you may find that some important directions for education in the next century are contained in these results. What also seems significant is that there was a $100 \%$ response rate; this, as well as the high level of professional responsibility of the respondents (mostly top level superintendents) attests to the value and validity of this research.

I plan to list your institutions in my dissertation and any subsequent publications. Also, almost all of you indicated that your name could be released. The list of these released names is enclosed. If your name is not on it and you would reconsider allowing it to be used, please contact me.

I sincerely hope that your participation in this study will be of some aid to you in your future planning efforts. Please let me know if I can be of service to you or your district in any way. Also, although this work is copyrighted, you should feel free to make use of any of its findings. It has been a privilege working with you all.

Thank you.

Sincerely yours,

Stuart Grauer

(619) $756-0500(W)$

(619) $755-9319(\mathrm{H})$ 
Appendix F

Delphi Survey Summary

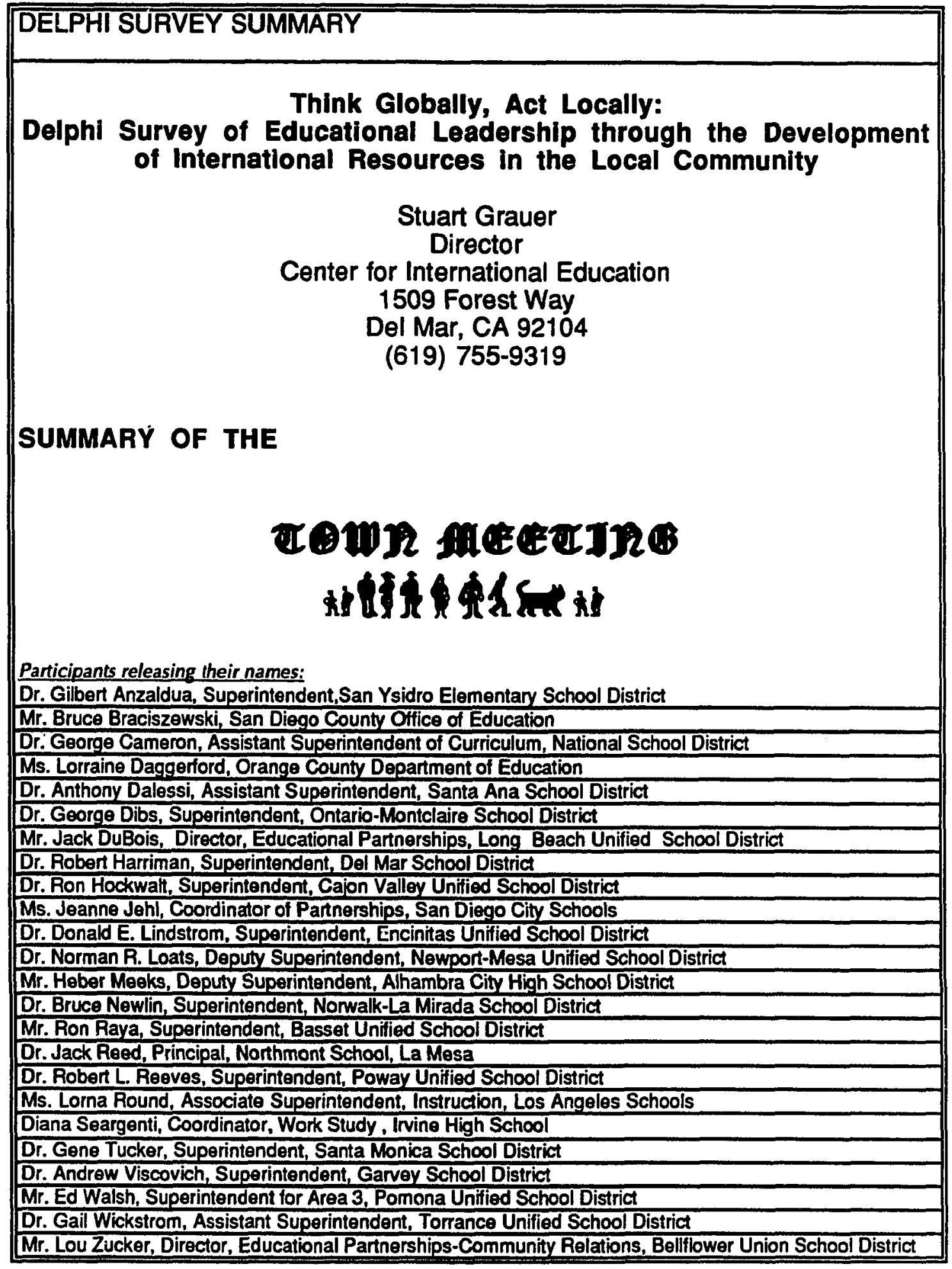




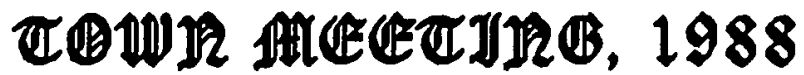

1. Who should attend? The following community members were cited as most capable of giving support to your efforts at leadership. Leadership as used here indicates the ability to bring real, constructlve change and to unite coalitions in new understandings.

Table 1. International Resource People: Priority ltems $(\mathrm{N}=27)$

$\%$ Dethilem

$85.2 \% 7$ Corporate leader/executive of an international corporation or bank

$81.5 \%$ 12. President, the school district's Multiethnic Advisory Council

$77.8 \%$ 8. Latin American or Asian Chairman/parent organizer, international parent committee

$66.7 \%$ 34. Adopt-a-school contact person (e.g., community relations dir.) at a multinat'l corp.

$59.3 \%$ 22. Teacher (soc. stud., lit., science, ant), foreign born with a global perspective

$51.9 \% \quad 9$. President, a city wide International Community Committee

$51.9 \% \quad 3$. Latin American or Asian member of school board

II. Functions of Internatlonal Resource People. The first of the following two lists represents the. programs cited as being used for developing international resources. The second list represents the most valuable functions of community resource people and the roles they play which are most valuable in making changes that are necessary as we prepare for the next century.

Table 2.

Model Programs

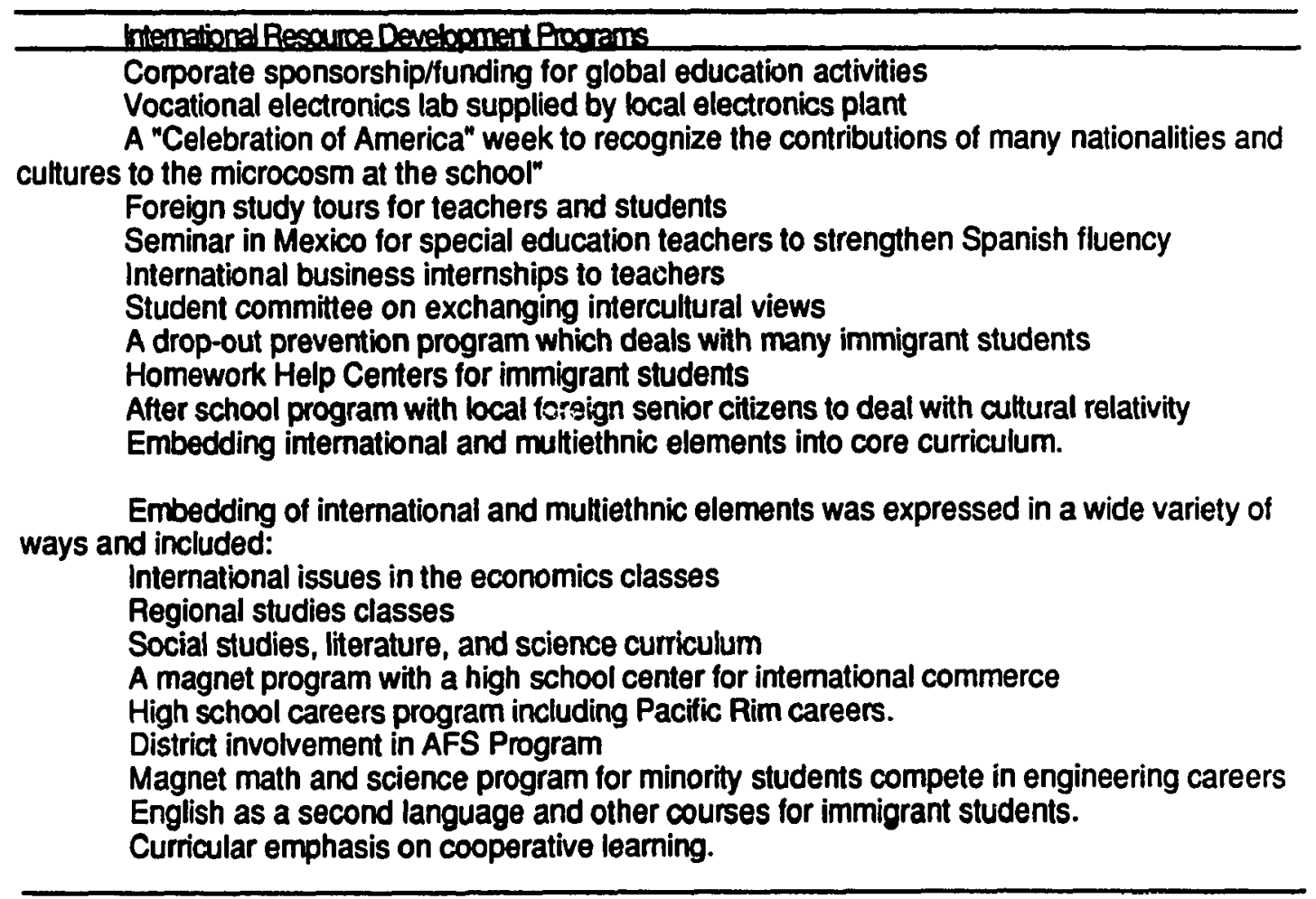


Table 3.

The function of the intemational resource person is to .... Priority ltems $(N=27)$

\begin{tabular}{ll}
\hline$\%$ & Dephilfem \\
\hline $81.5 \%$ & $\begin{array}{l}\text { 24. coordinate school efforts in obtaining global education resources and consult on } \\
\text { international trends for curriculum updates }\end{array}$ \\
$\mathbf{8 1 . 5 \%}$ & $\begin{array}{l}\text { 4. help prepare students for international citizenship } \\
\mathbf{7 7 . 8 \%}\end{array}$ \\
$\begin{array}{l}\text { 25. inform school leaders of future trends and global issues: global } \\
\text { interdependence, }\end{array}$ \\
$\begin{array}{l}\text { geopolitics, health, poverty, etc. } \\
\text { 20. lead the school-business partnership program at a large multinational corporation } \\
\text { which } \\
\text { provides the school with useful resources } \\
\text { 16. provide a clear vision of minority employment needs/perspectives and assist the } \\
\text { school in } \\
\text { developing appropriate programs }\end{array}$
\end{tabular}

III. Agenda. The following items were cited as issues needing attention in the community specifically towards developing International Iinkages.

Table 4.

The Top Priority ltems $(N=27)$

\section{$\% \quad$ Dethilem}

$85.2 \% 10$. staff development, hiring and teacher training practices

$85.2 \% 31$. strategies for promoting awareness of interdependence of people and nations over time

$81.5 \%$ 11. education's role in addressing global problems (e.g., communications barriers, ecology, food, survival)

$74.1 \%$ 17. teaching conflict resolution and cooperative decision making

$70.4 \%$ 3. skills, knowledge and creativity required by a futures oriented business community

$66.7 \%$ 13. international resources available in the community to promote students' global awareness

IV. Philosophy. The following are statements of philosophy which support development of international resources in the local community.

Table 5.

Statement of philosophy on international education: Priority litems (N $=27)$

\section{$\% \quad$ Debhiltem}

92.6\% 5. "Education is one of the basic factors in international relations, quite as important as diplomacy, commerce and military power in in its implications for war and peace."

$81.5 \%$ 10. "We need to address the perceived needs of (and our common goals with) an increasingly transient and pluralistic population which is vastly different from the community of a few years ago."

$59.3 \% 3$. "Schools need to prepare students to participate in a world culture." 
V. Internal and External Pressures. This area rates pressures which vie for control over the formation of school goals and the process of change. The first table lists internal administrative pressures. The second table lists external interests and groups. These groups would or do press agendas counter to the speclfic internationallst agenda developed in the Town Meotings.

Table 6.

Which oressures compete, most for administrative iime?: Priority ltems $(N=29)$

\begin{tabular}{|c|c|}
\hline$\%$ & IntemalAdn'n strative Presure \\
\hline $\begin{array}{l}(61 \%) \\
(48 \%) \\
(48 \%)\end{array}$ & $\begin{array}{l}\text { budgeting constraints } \\
\text { too many meetings, too much work to do--IImited time, paperwork,etc. } \\
\text { overcrowded curriculum (competlng curricular programs such as } \\
\text { music, speclal education, GATE, basic skllis education, goals of } \\
\text { academic excellence) }\end{array}$ \\
\hline $\begin{array}{l}(30 \%) \\
(26 \%) \\
(13 \%) \\
(13 \%) \\
(13 \%) \\
(13 \%) \\
(13 \%) \\
(9 \%) \\
(3 \%) \\
(3 \%) \\
(3 \%) \\
(3 \%) \\
(3 \%)\end{array}$ & $\begin{array}{l}\text { mandated state and district priorities } 9 \\
\text { problems with drugs, attendance, discipline, poor test scores, sex, etc. } \\
\text { supervision of instruction } 4 \\
\text { parent organization or school site council demands } 4 \\
\text { motivating community and parent interest/support } 4 \\
\text { lack of staft interest/support and needs for staff training } \\
\text { extra programs such as child care, athletics, health and special } \\
\text { administrative demands from community special interest groups and immigrant families } \\
\text { too many disparate groups, mandating too much student ability grouping } \\
\text { teachers do not have time for more activities } \\
\text { possible problems with the teachers union } 1 \\
\text { lack of need/the feeling that these concerns are already addressed enough } \\
\text { implementation }\end{array}$ \\
\hline
\end{tabular}

Table 7.

Competing External Pressures: Priority liems $(\mathrm{N}=27$ : range $=1$ - 5)

QUESTION

How much does/would the goals of each compele with the internationalist agenda?

( 1 = lowest; 5 = highest)

mean Dethilem

3.96 14. dominant or upper middie class, vocal majority groups

3.80 9. state legislature/government

3.60 11.conservative political organizations (John Birch, Moral Majority,eic.)

3.423 . problem oriented groups (AIDS Society,dng awareness group, etc.)

3.38 2. parent groups

3.35 1. Board of Trustees/Board of Education

3.19 5. school site council/advisory committees

3.00 8. homeowner groups/Taxpayers Assoc.

2.85 13. ethnic and religious groups

2.77 17. individual parents or community members

2.70 10. government social service agencies (Health Dept., Law Enforc., Child Serv.)

2.50 7. Chamber of Commerce or industry

2.46 15. councils on education

2.35 16. individual teachers (not a group)

$2.30 \quad 6$. building industry

1.96 12. liberal political organizations (ACLU, NAACP, etc.)

1.77 4. recent immigrants 
Ile finfl questlon asked you for a quotable quote about the importance of this work. These are listed below.

Table 13.

Interview: quotable quotes $(N=28)$

\section{STATEMENT}

Interview: You are leaving this final meeting and the local press has taken a big interest in your work. They ask you for a quotable quote about the importance of this work. If you wish, you may use this opportunity to say something that honestly reflects your goals and perspectives.

PANELISTS' COMMENTS

a. "If we don't hang together, we will certainly all hang separately ...!"

b. "The world of tomorrow is today! We must join together to have a workable plan for the future in our ever shrinking world."

c. "International cooperation is a social imperative. Preparing students for global existence must be top priority for all of us. We must recognize diversity as a socially enriching factor in our lives."

d. "Schools need to prepare students to compete in an ever increasing international marketplace and to contribute to world peace and understanding in the 21st century."

e. "This meeting represents the beginning of an effort to assist all students to be aware of the international culture of America."

f. "The year 2000 is very close, we all need to be thinking about our community changes and how we can make things better. This is a good beginning, just making us think."

g. "Our goal is to live and work as one."

$\mathrm{h}$. 'The children's song, 'It's a small world' is true today and we must prepare our children to live in a global world both economically and culturally. It is in the best interest of the U.S. and the world."

\section{Second Cut: Four Perspectives of Global Education}

After the preliminary analysis, a second level of analysis was made in an effort to locate the prevalent perspectives of the experts.

Items from each part of the survey (that is, from each area of inquiry) were analyzed in four conceptual frameworks. The objective of the application of these frameworks was to isolate connections, subtle differences, background assumptions and clashing opinions represented by the selection of different types of items by the experts. The focus was not on individual items, but on the patterns formed by clusters of items. The four frameworks represent distinct and prevalent orientations towards international education today. These theoretical frameworks continued to gel throughout the rounds of the survey. The four perspectives are: global perspectives in curriculum (internal systems), multicultural education, education for national security (politicaleconomic), and cultural leadership. Each Delphi item was placed into one of these categories for the final analysis. The first three perspectives are not viewed as leadership perspectives in that they are relatively short term and limited in scope. The cultural leadership framework represents the synthesis of approaches to international education in that it reflects an open system which applies universal values which are not confined to special interests either inside or outside of the school. It also reflects a leadership posture in that it calls for school leaders 
to be cultural leaders who can raise educational aspirations across their communities and across cultures. Cultural leadership also represents the synthesis called for in the literature. Although no one framework received a consensus of responses, the cultural leadership framework was the clear priority of the respondents. Thus, the study has ended up on an optimistic note.

Table 9 provides a look at the response totals for the four groups, which reflect the above orientations. In the table, perspective $I$ is global perspectives in curriculum, perspective II is multicultural education, perspective III is education for national security and perspective IV is the cultural leadership perspective. Reading the table, the percentage of of all points received by each perspective is expressed as "\% of points." The third column of the table records total number of consensus items received in the first four survey question by each perspective. The fourth column of the table records the percentage of total consensus items reseivec by each perspective.

Table 9

Iotals for Use of Intemational Resources $(N=27)$

\begin{tabular}{c|c|c|c}
\hline Gientation & $\%$ of points & consensus item & \% consensus items \\
\hline$I$ & $13.8 \%$ & 3 & $14.3 \%$ \\
\hline$I$ & $33.9 \%$ & 6 & $28.6 \%$ \\
\hline III & $16.3 \%$ & 4 & $19.0 \%$ \\
\hline IN & $36.0 \%$ & 8 & $38.0 \%$ \\
\hline IOTLLS & $100.0 \%$ & 21 & $100.0 \%$ \\
\hline
\end{tabular}

\section{Uhathk you for participating in the Town fteeting.

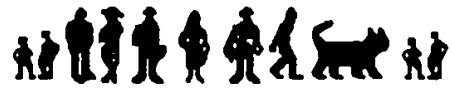

Stuart R. Grauer, Director

Center for International Education

1509 Forest Way

Del Mar, CA 92014 


\section{Appendix G \\ DEMOGRAPHIC QUESTIONNAIRE SUMMARY \\ Think Globally, Act Locally: \\ A Delphi Study of the Educational Leadership through the Development of International Resources in the Local Community by Stuart R. Grauer}

This is the summary of responses from 28 Delphi survey participants who returned the demographic questionnaire. One question pertaining to local demographic conditions was collected in the second round and is inserted as "7b" following question "7."

1. (a) YOUR NAME:

(b) YOUR INSTITUTION/DISTRICTS: Alhambra City High School District; Basset Unified School District; Belffilower Union School District; Cajon Valley Unified School District; Cardiff School District; Del Mar School District; El Segundo Union School District; Encinitas Unified School District; Garvey School District; Irvine High School; La Mesa-Spring Valley Elementary School District; Long Beach Unified School District; Los Angeles Schools; National School District; Newport Mesa Unified School District; Norwalk-La Mirada School District; Ontario; Montclaire School District; Orange County Department of Education; Pomona Unified School District; Poway Unified School District; San Diego City Schools; San Diego County Office of Education; San Ysidro Elementary School District; Santa Ana School District; Santa Monica School District; Torrence Unified School District; Yorbita School Roland Unified School District.

(c) Check one: PUBLIC_28, or PRIVATE 0

(d) YOUR JOB TITLES: Administrator on Special Assignment; Assistant/Deputy IAssociate Superintendent (6); Communication Coordinator (County); Community Based Education Facilitator; Director of Educational Partnerships (2); Industry and Education Partnership Specialist; Principal (2); Superintendent (14)

(e) Years in your job 2,2 vears, average

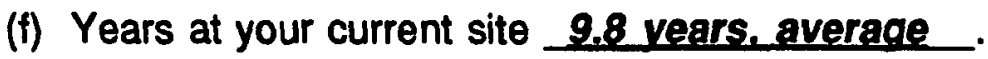

2. YOUR TELEPHONE NUMBER: 1

3. (a) YOUR AGE (check one): $20-30 \_; 31-40 \_1 ; 41-50 \_14$; $51-60 \_10 ; 61-70 \_3 \div ; 0+\ldots$ (average age, 50.3 years)

(b) YOUR GENDER: male 22 ; female 6 .

4. ACADEMIC DEGREE(S) you have earned (check all that apply and indicate major or specialization, and school):

DEGREE MANOR

SCHOOL

(a) Bachelor's _28 (all)

(b) Master's 26

(c) Doctoral 20 
5. STUDENT ENROLLMENT AT YOUR SCHOOLDISTRICT--list the number of students in the area you are responsible for in your job (full time equivalent):
(a) $\mathbf{5 0 0}$ or less
(b) $500-2,000$
(c)
(d) $5,000-10,000 \_5$;
(e) more than 10,000
(c) 2,000 - 5,000_2;

6. Identify the international make-up of your school/district by listing each specific nation or region of origin in order of prevalence. If you are not sure, please give an educated guess. List up to six.

most prevalent group US American (21): Hispanla (6): Asian (1) next largest

$\frac{\text { Aslan (23) }}{\text { Hispanic (19) }}$
Ellipine (6)
Arabian LPersian (3)
Pacifle Islands (2)

7a. Can you project any basic changes in this listing by the year 2000? If so, describe.
Influx of Hispanics (13)
Influx of Asians (11)
Influx of Filipinos (2)
Hispanics will become the majority (3)
Asians will become the majority (2)

Few changes or or changes expected (6)

7b. Estimated \% of parents in your districts who have a region of origin other than the United States

$$
\begin{array}{r}
\text { 'Mean }=33.4 \% \\
\text { Range }=5-75 \%
\end{array}
$$

8. If you can recall any specific reasons or formative experiences to explain your interests in international relations, please cite them briefly and in order of importance.

General interest/reading/personal philosophy/studies (10)

none or no answer (6)

district needs/local demographics (4)

Upbringing (3)

Business and community involvement (2)

Living overseas (2)

Travel (2)

Exchange experiences (2)

Navy (2) 